\title{
Charakterisierung von funktionellen Oberflächenstrukturen des Hepatitis-B-Virus Nukleokapsids
}

\author{
Dissertation \\ zur Erlangung des Doktorgrades \\ der Mathematisch-Naturwissenschaftlichen Fakultäten \\ der Georg-August-Universität zu Göttingen
}

vorgelegt von

Alexander Pairan

aus Kassel

Göttingen 2005 
D7

Referent:

Prof. Dr. W. Liebl

Korreferent:

Prof. Dr. D. Doenecke

Tag der mündlichen Prüfung: $\quad$ 03.11.2005 


\section{INHALTSVERZEICHNIS}

$\begin{array}{lll}\text { AbKÜRZUngen } & \text { VI }\end{array}$

1 EINLEITUNG 1

1.1 Überblick 1

1.2 Verbreitung und Pathogenese der Hepatitis-B-Infektion 2

1.3 Virusstruktur 4

1.4 Hepatitis-B-Virus-Genom und Transkripte 5

1.5 Genprodukte 7

1.6 Infektionszyklus und Virusreplikation 12

1.7 Das Hepatitis-B-Virus Kapsid 16

1.8 Ziel der Arbeit 20

2 MATERIAL 22

$2.1 \quad$ Bakterienstämme 22

$2.2 \quad$ Eukaryotische Zelllinien 22

$2.3 \quad$ Nährmedien 23

2.3.1 Medien zur Anzucht von E. coli 23

2.3.2 Nährmedien und Lösungen zur Kultivierung eukaryotischer Zelllinien 24

$2.4 \quad$ Enzyme und Proteine 25

2.5 Plasmide 26

$2.6 \quad$ Nukleotide 37

$2.7 \quad$ Oligonukleotide 37

2.8 Antikörper 39

2.9 DNA-Längenstandards 40

2.10 Radionuklide 40

2.11 Chemikalien 40

2.12 Lösungen und Puffer 43

$2.13 \quad$ Kommerzielle Kits 46

2.14 Laborgeräte $\quad 47$

$2.15 \quad$ Verbrauchsmaterialien 49 
3.1 Vorbehandlung von Puffern, Lösungen und Materialien 50

3.2 Mikrobiologische Methoden 50

3.2.1 Kultur und Umgang mit Bakterien 50

3.2.1.1 Anzucht von E. coli-Bakterien $\quad 50$

3.2.1.2 Bestimmung der relativen Zelldichte 50

3.2.1.3 Dauerkultur und Stammhaltung 51

3.2.1.4 Herstellung kompetenter E. coli-Bakterien 51

3.2.1.5 Transformation kompetenter E. coli-Bakterien durch Hitzschock 52

3.3 Zellkulturtechniken 52

3.3.1 Kultivierung von eukaryotischen Zellen 52

3.3.2 Einfrieren und Auftauen von eukaryotischen Zellen 53

3.3.3 Zellzahlbestimmung 53

3.3.4 Transfektion von eukaryotischen Zellen 53

3.3.4.1 Transfektion von HuH7-Zellen mit Kalziumphosphatpräzipitation 54

3.3.4.2 Transfektion von HuH7-Zellen mit FuGENE (Roche Diagnostics, Mannheim) 54

3.3.4.3 Transfektion von HEK-293T-Zellen mit Kalziumphosphatpräzipitation 54

3.3.5 Bestimmung von HBeAg und HBsAg 55

3.3.6 Herstellung von Zelllysaten 55

3.3.7 Herstellung von retroviralen Vektoren 56

3.3.8 Transduktion von HuH7-Zellen mit retroviralen Vektoren 57

3.3.9 Vereinzelung und Kultivierung transduzierter HuH7-Zellen 57

3.3.10 Nachweis der Grenzempfindlichkeit von HuH7-Zellen gegenüber

3.3.11 FACS-Analyse 58

3.3.12 Untersuchung nativer Zellen mittels Fluoreszenzmikroskopie 59

$3.4 \quad$ Molekularbiologische Methoden $\quad 59$

3.4.1 DNA-Präparation aus E. coli 59

3.4.1.1 Isolierung von Plasmid-DNA im analytischen Maßstab (alkalische Lyse nach BIRNBOIM \& DOLY, 1979; modifiziert) $\quad 60$

$\begin{array}{ll}\text { 3.4.1.2 Isolierung von Plasmid-DNA im analytischen Maßstab mit dem } & 60 \\ & \text { QIAprep Spin Miniprep Kit (Qiagen, Hilden) }\end{array}$

3.4.1.3 Isolierung von Plasmid-DNA im präparativen Maßstab (alkalische Lyse nach BIRNBOIM \& DOLY, 1979; modifiziert) 
3.4.1.4 Isolierung von Plasmid-DNA im analytischen Maßstab mit dem QIAGEN Plasmid Maxi Kit (Qiagen, Hilden) 62

3.4.2 Reinigung und Konzentrierung von DNA 62

3.4.2.1 Phenol/Chloroform-Extraktion 62

3.4.2.2 Ethanol-Fällung von DNA 63

3.4.2.3 Isopropanol-Fällung von DNA 63

3.4.2.4 Isolierung von DNA aus Agarosegelen 63

3.4.2.5 DNA-Konzentrationsbestimmung in Lösungen 64

3.4.2.6 Agarosegel-Elektrophorese 65

3.4.3 DNA-Sequenzierung 65

3.4.4 DNA-Arbeiten mit Enzymen 66

3.4.4.1 Spaltung von DNA mit Hilfe von Restriktionsendonukleasen 66

3.4.4.2 Ligation von DNA-Fragmenten $\quad 67$

3.4.4.3 Aufpolymerisierung von überhängenden DNA-Enden 67

3.4.4.4 Dephosphorylierung von DNA 68

3.4.4.5 Polymerase-Kettenreaktion (SAIKI et al., 1985) 68

3.4.5 Molekulare Klonierung mit dem PCR Cloning Kit (Qiagen, Hilden) 69

3.4.6 DNA-Nachweismethoden 69

3.4.6.1 Southern-Blot (SOUTHERN, 1975) 69

3.4.6.1.1 DNA-Isolierung und Gelelektrophorese $\quad 70$

3.4.6.1.2 DNA-Transfer auf eine Nylonmembran 70

3.4.6.1.3 Herstellung der mit alkalischer Phosphatase markierten Sonde 70

3.4.6.1.4 Hybridisierung $\quad 71$

3.4.6.1.5 Detektion der Sonde $\quad 71$

3.4.6.1.6 Entwicklung von Röntgenfilmen $\quad 72$

3.4.6.2 Nachweis von HBV-DNA mittels der ,endogenen Polymerase Reaktion’ 72

3.4.6.3 DNA-Isolierung aus angereicherten Nukleokapsiden und Virionen $\quad 73$

3.4.7 Nachweis von HBV-RNA mittels RT-PCR-Technik 74

3.4.8 Arbeiten mit Proteinen 77

3.4.8.1 Immunpräzipitation $\quad 77$

3.4.8.2 Präparation von Nukleokapsiden 77

3.4.8.2.1 Anreicherung durch isopyknische CsCl-Dichtegradienten-Zentrifugation 77

3.4.8.2.2 Anreicherung durch PEG-Fällung 78

3.4.8.3 Western-Blot von Nukleokapsiden unter nativen Bedingungen 79 
4.1 Funktionelle Oberflächen des HBV-Kapsids

4.2 Charakterisierung von oberflächenexponierten AS-Positionen des Coreproteins

4.2.1 Selektion der zu mutierenden AS-Positionen des Coreproteins

4.2.2 Generierung der Coreprotein-Mutanten

4.2.3 Nachweis der Umhüllungskompetenz mittels, endogener Polymerase Reaktion'

4.2.3.1 Untersuchung der Positionen mit umhüllungsdefizientem Phänotyp nach Alanin-Substitution

4.2.3.2 Untersuchung der Positionen mit WT-Phänotyp nach Alanin-Substitution 95

4.2.4 Zusammenfassung der EPR-Ergebnisse der untersuchten AS-Positionen und deren Darstellung im 3D-Modell

4.2.5 Überprüfung der Mutationen an der Position I126 auf transdominant negative Wirkung

4.2.6 Untersuchung der Konzentrationsabhängigkeit der Core-Mutanten für die Ausprägung der Umhüllungsdefizienz

4.2.7 Untersuchung der Kapsidassemblierung-blockierenden Mutanten 106

4.2.7.1 Nachweis assemblierter Nukleokapside mittels nativem Western Blot 107

4.2.7.2 Nachweis von HBV-DNA in zytosolischen Kapsiden mittels Southern Blot

4.2.7.3 Nachweis von pgRNA in zytosolischen Kapsiden mittels RT-PCR 110

4.2.7.4 Nachweis sezernierter Virionen mittels CsCl-Gradienten und nativem Western Blot

4.3 Generierung eines MuLV-Retrovirus-Transduktionssystems für die intergenomische Transkomplementation der I126A Core-Mutation durch das env-Gen

4.3.1 Herstellung des Hüllprotein-exprimierenden HBV-Genoms und Integration in das Retrovirus-Transduktionssystem

4.3.2 Herstellung von HBV Coreprotein-exprimierenden HuH7-Zelllinien

4.3.3 Herstellung von HuH7-Zellen mit konstitutiver Expression von HBV Core- und P-Proteinen

4.3.4 Herstellung von Retroviren mit Hüllprotein-exprimierendem HBV-Genom 
4.3.5 Nachweis der Transduktion von ZK 4 (HuH7-HBVcore ${ }^{\text {WT }}$-pol) und ZK 2 (HuH7-HBVcore ${ }^{\text {I126A }}$-pol) mittels PCR

5 DISKUSSION

5.1 Charakterisierung oberflächenexponierter AS-Positionen des HBV Nukleokapsids

5.1.1 Auswahl der zu phänotypisierenden AS-Positionen

5.1.2 Analyse von umhüllungsrelevanten Aminosäure-Positionen des HBV Nukleokapsids

5.1.3 Untersuchung von Aminosäure-Positionen des HBV Nukleokapsids mit WT Phänotyp nach Alanin-Substitution

5.1.4 Einschränkungen bei der Interpretation der Ergebnisse

5.1.5 Core-Mutanten an Position I126 besitzen keine transdominant negative Wirkung auf die Umhüllungseffizienz

5.2 Etablierung eines HuH7-Zellkultursystems zur funktionellen Transkomplementierung einer Punktmutation im Coregen durch das env-Gen 


\section{ABKÜRZUNGEN}

Die in dieser Arbeit verwendeten Abkürzungen sowie alle physikalischen Größen entsprechen der Konvention der „International Union for Biochemistry“ (LIÉBECQ, 1978). Grundsätzlich werden die international üblichen chemischen Symbole und Abkürzungen der SI-Einheiten (Système International d’Unités) benutzt.

\begin{tabular}{|c|c|}
\hline A & Adenin \\
\hline Abb. & Abbildung \\
\hline Ag & Antigen \\
\hline Ak & Antikörper \\
\hline amp & Ampicillin \\
\hline anti- & Antikörper gegen \\
\hline AP & alkalische Phosphatase \\
\hline APS & Ammoniumpersulfat \\
\hline AS & Aminosäure \\
\hline ATP & Adenosin-5'-triphosphat \\
\hline bidest. & doppelt destilliert \\
\hline b & Basen (engl.: bases) \\
\hline bp & Basenpaare (engl.: base pairs) \\
\hline BSA & Rinderserumalbumin (engl.: bovine serum albumin) \\
\hline $\mathrm{C}$ & Cytosin \\
\hline${ }^{\circ} \mathrm{C}$ & Grad Celsius \\
\hline ca. & circa \\
\hline cCC & ringförmig, kovalent geschlossen (engl.: covalently closed circular) \\
\hline cDNA & $\begin{array}{l}\text { komplementäre Desoxyribonukleinsäure (engl.: complementary } \\
\text { desoxyribonucleic acid) }\end{array}$ \\
\hline $\mathrm{Ci}$ & Curie $\left(1 \mathrm{Ci}=3,7 \times 10^{10}\right.$ Bequerel $)$ \\
\hline $\mathrm{cm}$ & Zentimeter \\
\hline CMV & Cytomegalie-Virus \\
\hline cpm & Zerfälle pro Minute (engl.: counts per minute) \\
\hline $\mathrm{CsCl}$ & Caesiumchlorid \\
\hline СTP & Cytosin-5'-triphosphat \\
\hline $\mathrm{d}$ & Tag (engl.: day) \\
\hline $\mathrm{Da}$ & Dalton \\
\hline dATP & Desoxyadenosin-5'-triphosphat \\
\hline dCTP & Desoxycytidin-5'-triphosphat \\
\hline ddNTP & Didesoxynukleosid-5'triphosphat \\
\hline dGTP & Desoxyguanosin-5'-triphosphat \\
\hline DHBV & Enten-Hepatitis-B-Virus (engl.: duck hepatitis B virus) \\
\hline DMSO & Dimethylsulfoxid \\
\hline DNA & Desoxyribonukleinsäure (engl.: desoxyribonucleic acid) \\
\hline
\end{tabular}




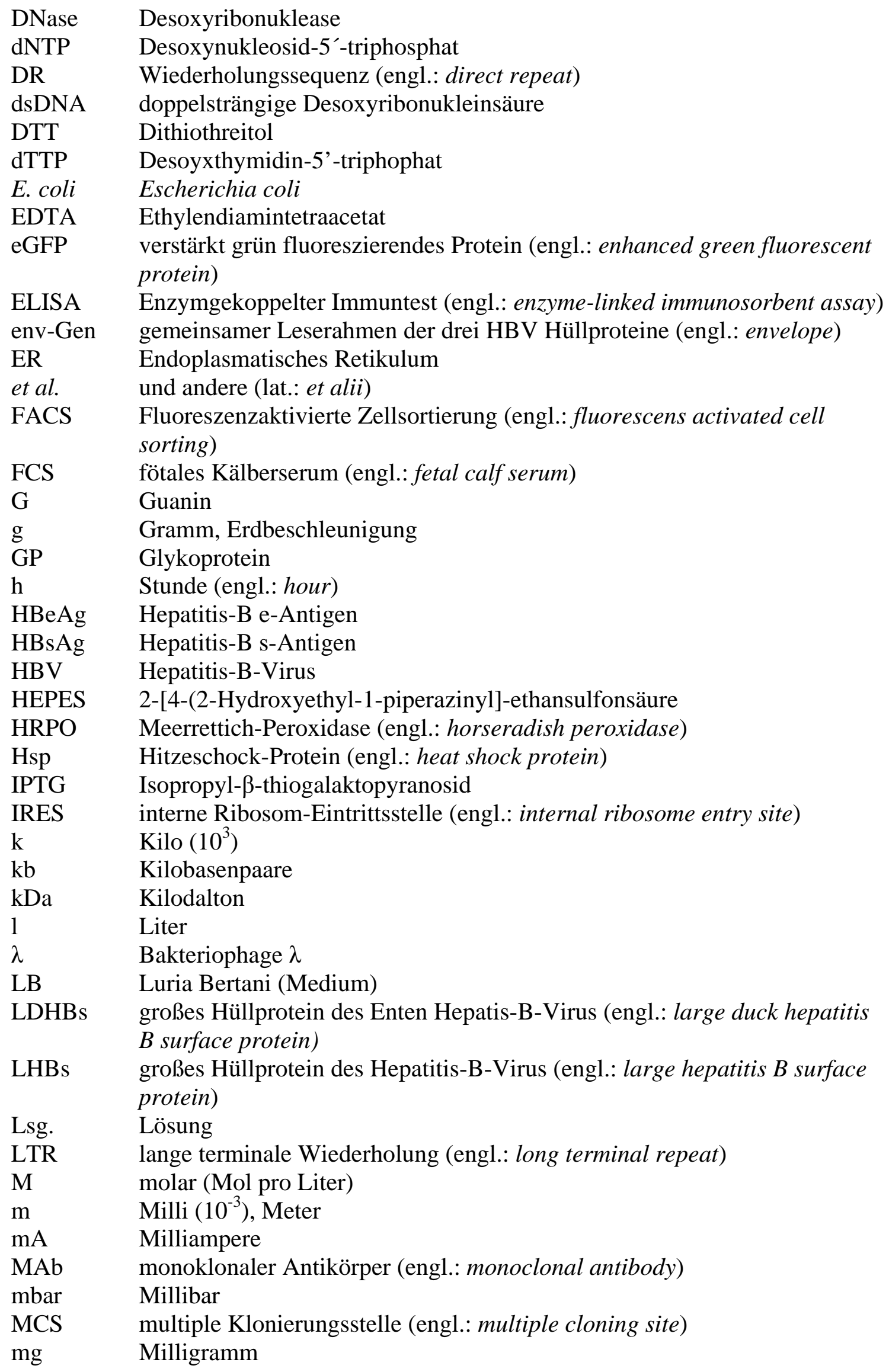




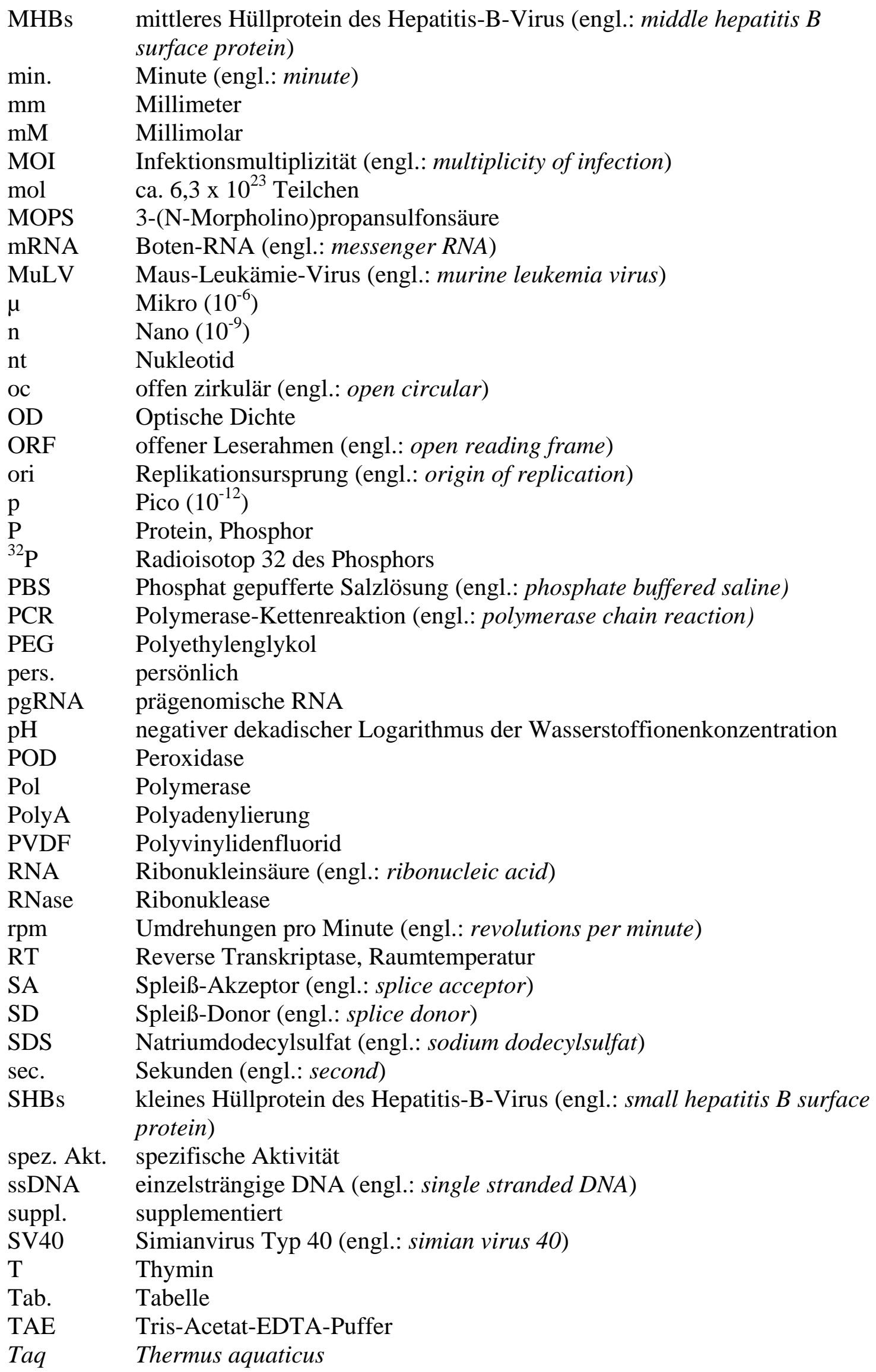




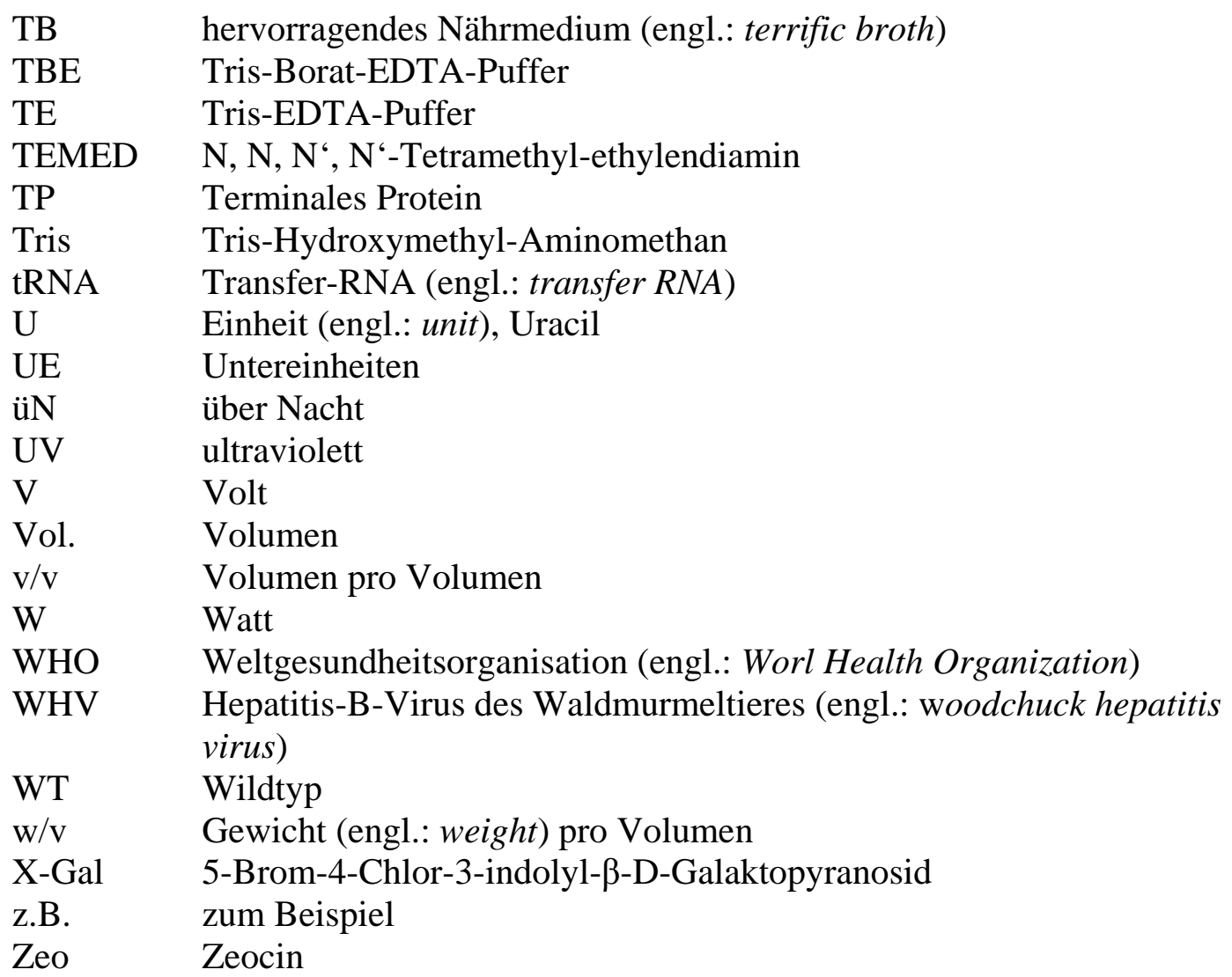

\section{Aminosäuren}

$\begin{array}{llllll}\text { A } & \text { Ala } & \text { Alanin } & \text { M } & \text { Met } & \text { Methionin } \\ \text { C } & \text { Cys } & \text { Cystein } & \text { N } & \text { Asn } & \text { Asparagin } \\ \text { D } & \text { Asp } & \text { Asparaginsäure } & \text { P } & \text { Pro } & \text { Prolin } \\ \text { E } & \text { Glu } & \text { Glutaminsäure } & \text { Q } & \text { Gln } & \text { Glutamin } \\ \text { F } & \text { Phe } & \text { Phenylalanin } & \text { R } & \text { Arg } & \text { Arginin } \\ \text { G } & \text { Gly } & \text { Glycin } & \text { S } & \text { Ser } & \text { Serin } \\ \text { H } & \text { His } & \text { Histidin } & \text { T } & \text { Thr } & \text { Threonin } \\ \text { I } & \text { Ile } & \text { Isoleucin } & \text { V } & \text { Val } & \text { Valin } \\ \text { K } & \text { Lys } & \text { Lysin } & \text { W } & \text { Trp } & \text { Tryptophan } \\ \text { L } & \text { Leu } & \text { Leucin } & \text { Y } & \text { Tyr } & \text { Tyrosin }\end{array}$




\section{EINLEITUNG}

\section{1 Überblick}

Das humane Hepatitis-B-Virus (HBV) ist der Prototyp der Familie Hepadnaviridae (Hepatitis-DNA-Viren). Die Viren dieser Familie zeichnen sich durch ein sehr enges Wirtsspektrum, einen ausgeprägten Lebertropismus (Hepatotropismus; von griech.: hepar) und die Fähigkeit, eine chronisch-persistierende Infektion hervorzurufen, aus. Weiterhin charakteristisch ist ein teilweise doppelsträngiges DNA-Genom, ihre Replikationsstrategie (während des Replikationszyklus wird ein RNA-Intermediat über reverse Transkription in DNA umgeschrieben) (SEEGER \& MASON, 1982), sowie eine Hülle, die dem Virus seine sphärische Form verleiht. Die heute bekannten Hepadnaviren werden zwei Genera zugeordnet: Zum einen den säugetierinfizierenden Orthohepadnavirinae, zum anderen den Avihepadnavirinae, die ausschließlich Vögel infizieren (GuST et al., 1986). Zu den Orthohepadnaviren werden das Hepatitisvirus des Menschen (human hepatitis B virus, HBV; DANE et al., 1970), des Waldmurmeltiers (woodchuck hepatitis virus, WHV; SuMMERS et al., 1978), des Erdhörnchens (ground squirrel hepatitis virus, GSHV; MARION et al., 1980) und des Wollaffens (woolly monkey hepatitis B virus, WMHBV; LANFORD et al., 1998) gezählt. Das Genus der Avihepadnaviren umfasst das Hepatitis-B-Virus der Pekingente (duck hepatitis B virus, DHBV; MAsON et al., 1980) und des Graureihers (heron hepatitis B virus, HHBV; SPRENGEL et al., 1988).

1965 wurde das erste Mal ein bislang unbekanntes Antigen (,Australia Antigen') beobachtet und zunächst mit Leukämie in Verbindung gebracht (BLUMBERG et al., 1965). Drei Jahre später gelang es Prince (PRINCE, 1968), dieses Antigen mit Hepatitis B zu assoziieren. Später stellte sich heraus, dass es sich bei dem ,Australia Antigen’ um subvirale Partikel des HBV handelte, deren Antigenität heute als hepatitis B surface antigen (HBsAg) bezeichnet wird. Diese kommen sowohl in einer sphärischen (Durchmesser etwa $20 \mathrm{~nm}$ ), als auch in einer filamentösen Form (Durchmesser etwa $20 \mathrm{~nm}$, Länge ca. $50 \mathrm{~nm}$ bis $1 \mu \mathrm{m}$ ) vor und enthalten keine Nukleinsäure, wodurch sie 
nicht infektiös sind. Die Partikel bestehen aus einer Lipidmembran und darin eingelagerten Oberflächenproteinen des HBV. Sie werden von der infizierten Zelle in hohem Überschuss relativ zu Viren ins Blut sezerniert. Mit Hilfe von elektronenmikroskopischen Aufnahmen gelang es 1970, das eigentliche Viruspartikel nachzuweisen, das nach seinem Entdecker als Dane-Partikel bezeichnet wurde und eine sphärische Gestalt von ca. $42 \mathrm{~nm}$ Durchmesser besitzt (DANE et al. 1970). Als erkannt wurde, dass Antikörper, die gegen das HBsAg gerichtet sind, neutralisierend auf das Virus wirken, wurden schon 1980 die ersten erfolgreichen Impfstudien mit hochgereinigten HBsAg-Partikeln aus Seren infizierter Patienten durchgeführt (SZMUNEss et al., 1980).

\subsection{Verbreitung und Pathogenese der Hepatitis-B-Infektion}

Schätzungen zufolge sind gegenwärtig weltweit ca. 350 Millionen Menschen chronisch HBV infiziert (PREVISANi \& LAVANCHY, 2002; SEeger \& MASON, 2000; WHO, 2000), so dass dieses Virus zu den wichtigsten menschlichen Pathogenen gehört. Mehr als 2 Milliarden Menschen weltweit haben schon einmal eine Infektion durchgemacht. Dabei gibt es jedoch eine unterschiedliche geographische Verteilung: Während in Südostasien, Zentral- und Südafrika sowie Teilen von Südamerika die Prävalenz der HBV-Infektionen bei 60-90 \% liegt, weisen westliche Industrienationen eine Trägerrate von weniger als zwei Prozent auf (z.B. Deutschland 0,5-0,8 \%) (HollingeR, 1991; PREVISANI \& LAVANCHY, 2002).

Das HBV verursacht sowohl transiente, als auch chronische Infektionen der Leber, die zu verschieden ausgeprägten Leberentzündungen (Hepatitiden) führen können. Die transienten Infektionen können schwerwiegende Erkrankungen verursachen, und ungefähr $1 \%$ enden in einer fatalen, fulminanten Hepatitis, die meist zum Tod führt; ansonsten baut sich nach vollständiger Ausheilung eine Immunität auf. Ca. 5-10 \% der Infektionen entwickeln sich weiter zu persistierenden bzw. chronischen Infektionen, die man in drei Gruppen unterteilen kann: Zum einen den gesunden HBV-Träger, der keinerlei klinische Symptome aufweist, als weiteren den Infizierten mit milder chronischer Hepatitis und geringer Leberveränderung und schließlich den HBV- 
Infizierten mit chronisch aggressiver Hepatitis, die meist progredient bis zum Tod verläuft. Jedes Jahr treten ca. 4 Millionen akute klinische Fälle von HBV auf, und über 25 \% der Träger, 1 Millionen pro Jahr, versterben aufgrund chronischer, aktiver Hepatitis, Zirrhose oder Leberkrebs (Previsani \& LAVANCHY, 2002; Evans \& LONDON, 1998; PARKIN et al., 1999).

In seiner Wirtszelle repliziert sich das Virus sehr effizient und meist persistierend. A priori ist das Virus selbst nicht zytotoxisch, mit Ausnahme einiger zytopathogener Mutanten (LEHNHOFF et al., 1998). In einem transgenen Mausmodell konnte gezeigt werden, dass infizierte Leberzellen vielmehr durch Angriffe zytotoxischer T-Zellen geschädigt werden (CHISARI \& FERRARI, 1995). Virale Antigene werden auf der Oberfläche der Hepatozyten exprimiert, die somit angreifbar werden für eine Immunantwort der zytotoxischen T-Zellen, was letztendlich zum Absterben der betroffenen Leberzellen führt (MORIYAMA et al., 1990). Es wird diskutiert, dass das Virus über viele Jahre chronische Leberschäden verursacht, mit den assoziierten Immunantworten des Wirtes wie Entzündung und Leberregeneration. Letztendlich ist das Risiko, ein Leberkarzinom oder eine Leberzirrhose zu entwickeln, bei chronischen HBV-Trägern 200 mal höher als bei nicht infizierten Personen (BEASLEY et al., 1981).

Die Übertragung erfolgt am effizientesten parenteral über Blut oder Blutprodukte z.B. perinatal während der Geburt oder durch kontaminierte Blutkonserven, wobei schon geringste Mengen ausreichend sein können. HBV ist 100 mal infektiöser als das humane Immundefizienzvirus (HIV). Weniger effizient kann die Ansteckung auch durch andere HBV-haltige Körperflüssigkeiten (z.B. Sperma oder Speichel) erfolgen. Das Blut von HBV-Trägern kann bis zu $10^{11}$ Virionen pro Milliliter enthalten (NASSAL, 1999; RiBEIRO et al., 2002), und diese können bis zu sieben Tage außerhalb eines Organismus überdauern, ohne die Infektiösität vollständig zu verlieren (HoLLINGER, 1991).

Seit 1984 gibt es effiziente Vakzinierungsmöglichkeiten, mit rekombinant hergestelltem HBsAg-Impfstoff aus Hefen (McAleER et al., 1984), durch den sich bei ca. $97 \%$ der Impflinge durch Bildung von Anti-HBs-Antikörpern ein sicherer Infektionsschutz aufbaut. Der Impfstoff ist jedoch sehr teuer und steht vor allem aus diesem Grund nicht für alle betroffenen Gebiete für Massenimpfungen zur Verfügung (WHO, 2000). 
Die Behandlung der chronischen Hepatitis-B Infektionen beschränkt sich auf eine Standardmedikation mit Interferon- $\alpha$ in Kombination mit verschiedenen Nukleosid/Nukleotid-Analoga, die die virale Polymerase inhibieren (z.B. Lamivudin oder Adefovir). Jedoch treten insbesondere bei der Lamivudin-Therapie gehäuft Resistenzen durch Punktmutationen im YMDD-Motiv des katalytischen Zentrums der viralen Reversen Transkriptase (RT) auf, so dass die Wirksamkeit der Medikation genau beobachtet werden muss (LIAW et al., 2000; MELEGARI et al., 1998; KuMAR \& AgraWAL, 2004). Weitere vielversprechende Substanzen wie z.B. Tenofovir werden zur Zeit von der FDA (Food and Drug Administration) auf Zulassung hin überprüft (GANEM \& PRINCE, 2004).

\subsection{Virusstruktur}

Das Hepatitis-B-Virion ist ein komplexes, sphärisches Partikel mit einem Durchmesser von 42 - $45 \mathrm{~nm}$. Im Inneren befindet sich ein ikosaedrisches Nukleokapsid mit einem Durchmesser von ca. 32 bis 36 nm (CROWTHER et al., 1994; BÖTTCHER et al., 1997; WynNe et al., 1999b). Die das Kapsid umfassende Hülle besteht aus einer Lipidmembran zellulären Ursprungs mit den eingelagerten viralen Hüllproteinen SHBs (small hepatitis B virus surface protein), MHBs (middle hepatitis B virus surface protein) und LHBs (large hepatitis B virus surface protein). Während die genaue Zusammensetzung der Virushülle noch nicht genauer definiert wurde, konnten die Komponenten der Membran der subviralen Partikel bestimmt werden. Diese Membran ist reich an Phosphatidylcholin (ca. 60 \% aller Lipide) sowie Cholesterin (ca. 30 \% der Lipide) und unterscheidet sich somit von der Lipidzusammensetzung des zellulären ER (GAVILANES et al., 1982). Der Gesamtgehalt der Lipide ist im Vergleich zum Proteingehalt gering; in subviralen Partikeln liegt das Verhältnis bei 1:4 (SONVEAUX et al., 1995). Dadurch ist die laterale Beweglichkeit der Bestandteile stark eingeschränkt (SАтон et al., 2000).

Das je nach Hepadnaviridae Subtyp 3 - 3,3 kb große, partiell doppelsträngige (pds), zirkuläre DNA-Genom (RoBINSON et al. 1974) befindet sich im Inneren des CorePartikels, ebenso wie eine an das Genom kovalent gebundene virale DNA-Polymerase 
(KAPLAN et al. 1973) und eine Proteinkinase C zellulären Ursprungs (SCHLICHT \& SCHALLER 1989).

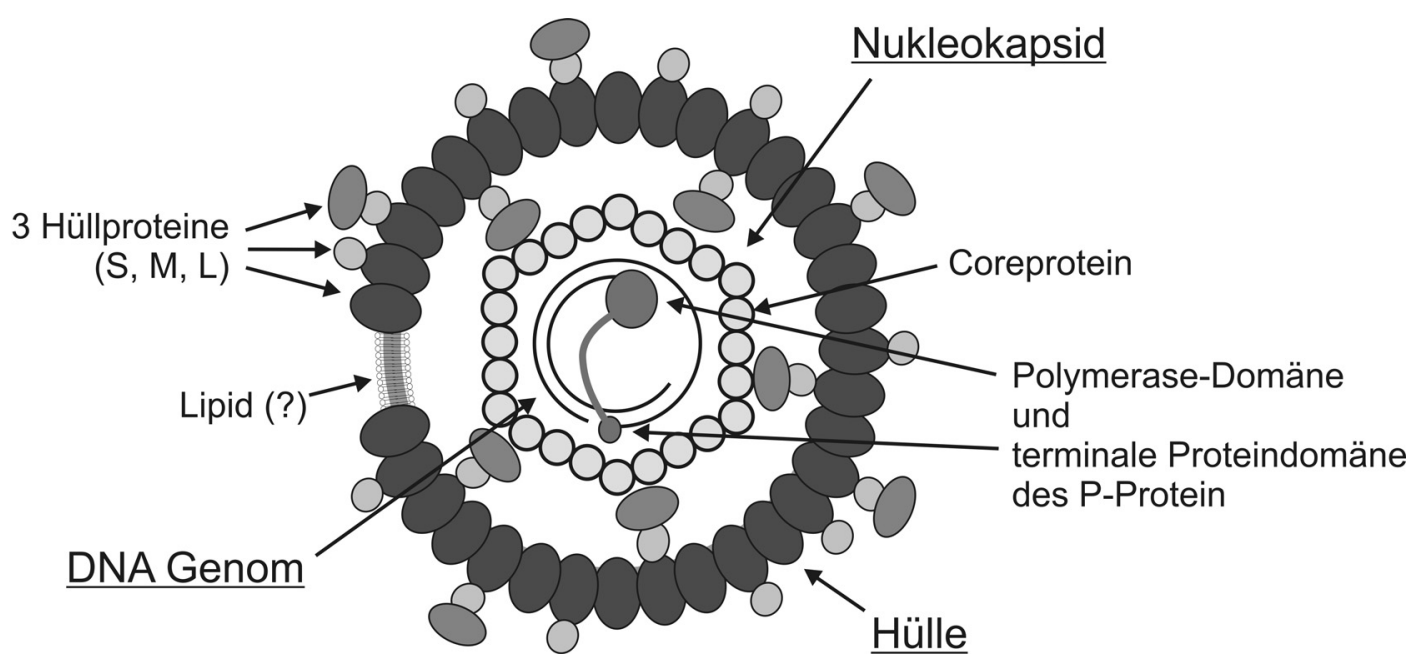

Abb. 1: Schematische Darstellung des Hepatitis-B-Virion.

\subsection{Hepatitis-B-Virus-Genom und Transkripte}

Das Hepatitis-B-Virus hat mit ca. 3,2 kb eines der kleinsten Genome aller DNA-Viren. Die Struktur des Genoms ist zirkulär und partiell doppelsträngig, wobei der kodierende Minus-Strang eine Länge von ca. 3200 Nukleotiden aufweist (TIOLLAIS et al., 1981), vollständig ist und eine kurze terminale Redundanz von 5 bis 8 Nukleotiden (nt) besitzt. Der nichtkodierende, komplementäre (+)-Strang besitzt ein konstantes 5'-, aber variables 3'-Ende, wodurch die Länge dieses Stranges heterogen ausfällt (HRUSKA et al., 1977) und nur ca. 40 - 85 \% des Genoms umfasst (LANDERs et al., 1977). Die Zirkularität des Genoms wird durch die sich überlappenden, kohäsiven 5'-Enden von (+)- und (-)-Strang aufrechterhalten; man spricht von kohäsiver Überlappungsregion (SATtler \& Robinson, 1979). An dem 5'-Ende des (-)-Stranges ist ein virales Protein (terminal protein, TP) kovalent gebunden (GERLICH \& RoBINSON, 1980). Dabei handelt es sich um eine N-terminale Proteindomäne der viralen DNA-Polymerase. Das 5'-Ende des (+)-Stranges besteht aus 18 Ribonukleotiden, die eine bei mRNAs zu findende CapStruktur aufweisen (SEEGER et al., 1986). Beide Strukturen übernehmen Primerfunktionen bei der Replikation (Hu et al., 1997; SEEGER \& Hu, 1997). Weitere für die Replikation des Genoms wichtige Sequenzen befinden sich ebenfalls an den 
jeweiligen 5'-Enden der DNA-Stränge. Dies sind zwei repetitive Sequenzen von $11 \mathrm{nt}$ Länge, die als DR1 und DR2 (direct repeat) bezeichnet werden (SUMMERS et al., 1975; WILL et al., 1987). Während am 3'-Ende des (-)-Stranges DR1 lokalisiert ist, findet man DR2 am 5'-Ende des (+)-Stranges (SEEGER et al., 1986).

Das Genom weist eine hohe Komplexität an genetischer Organisation auf: Alle Nukleotide besitzen eine kodierende Funktion in mindestens einem der vier offenen Leserahmen (open reading frame, ORF), die sich teilweise überlappen (GANEM \& VARMUS, 1987). Der längste ORF (Polymerase-Gen) kodiert für die virale Polymerase, der kürzeste ORF (X-Gen) für das X-Protein, während das PräC/C-Gen für das PräcoreProtein und das Coreprotein kodiert. Der PräS1/PräS2/S-ORF (env-Gen) kodiert für das große Hüllprotein (LHBs), für das mittlere Hüllprotein (MHBs) und für das kleine Hüllprotein (SHBs). Die Steuerung der Transkription erfolgt durch vier Promotoren, zwei Enhancer als cis-Elemente und verschiedene Transkriptionsfaktoren (GANEM, 1996; SCHALLER \& FISCHER, 1991). Es steht jedoch für alle viralen mRNAs nur ein Polyadenylierungssignal ca. 20 Basen vor dem 3’-Ende des (-)-Stranges zur Verfügung.

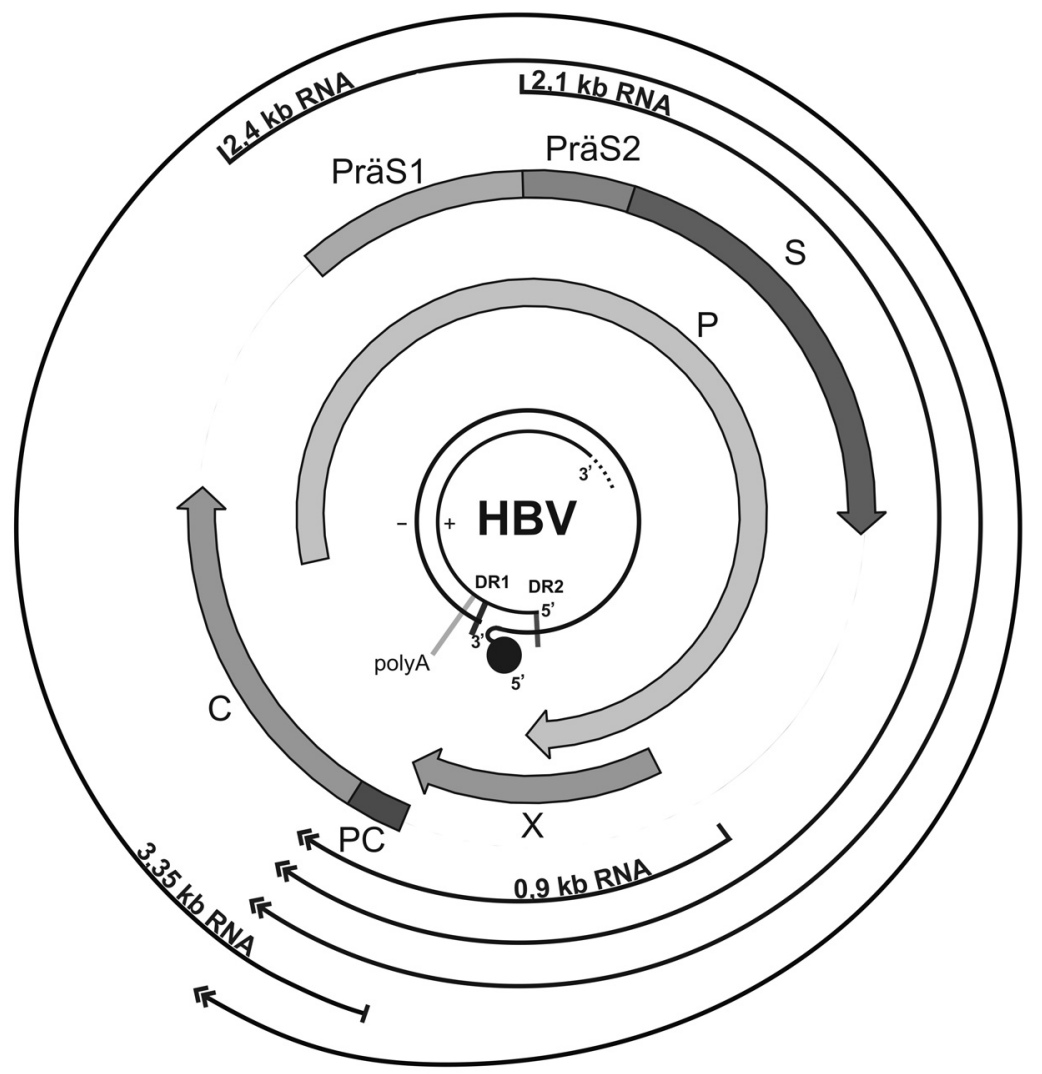

Abb. 2: Schematische Darstellung des HBV-Genoms mit offenen Leserahmen und viralen RNAs. 
PC: Leserahmen des Präcore-Bereichs, C: Leserahmen des Coreproteins, P: Leserahmen der viralen Polymerase, PräS1/PräS2/S: Leserahmen des großen, mittleren und kleinen Hüllproteins, X: Leserahmen des X-Proteins, DR1 und DR2: repetitive Sequenzen (direct repeats), polyA: Polyadenylierungssignal.

Es werden von dem HBV-Genom insgesamt fünf virale mRNA ausgehend von vier Promotoren transkribiert, die alle an einem gemeinsamen Polyadenylierungssignal enden. Ein supergenomisches 3,3 kb Transkript kodiert für das Coreprotein und die Polymerase und dient gleichzeitig als Matrize für die Synthese des HBV-Genoms; sie wird deshalb als prägenomische RNA (pgRNA) bezeichnet (GANEM \& VARMUS, 1987; HuANG \& Summers, 1991; ENDERS et al., 1987). Eine um ca. 30 Nukleotide am 5’Ende verlängerte mRNA enthält zusätzlich das Startkodon für die Synthese des PräcoreProtein. Dieses Transkript dient aber weder als pgRNA, noch werden von ihm das Coreprotein oder die Polymerase synthetisiert (NASSAL et al., 1990). Die Transkription dieser RNAs wird durch Promotoren reguliert, die vor und zwischen den beiden repetitiven Sequenzen DR1 und DR2 lokalisiert sind und vorwiegend leberspezifisch wirken (RALL et al., 1983). Die Transkriptionsaktivität wird in hohem Maße von den beiden gewebespezifischen Enhancern I und II bestimmt (SHAUl et al., 1985; YUH et al., 1992; TREININ \& LAUB, 1987). Das LHBs wird von der 2,4 kb großen mRNA translatiert. Der entsprechende PräS1-Promoter, der hoch leberspezifisch wirkt, liegt ca. 30 nt stromaufwärts der Cap-Stelle (WILL et al., 1987). Das MHBs und das SHBs werden von der 2,1 kb großen mRNA translatiert (SHEU \& LO, 1992). Die Transkription der mRNAs wird vom PräS2/S-Promoter reguliert, der sich vor dem PräS2-Start befindet und nicht leberspezifisch ist (POURCEL et al., 1982). Alle drei Proteine werden kotranslational als Transmembran-Proteine direkt in die ER-Membran inseriert. Die mit 0,9 kb kleinste mRNA dient zur Synthese des X-Proteins.

\subsection{Genprodukte}

Das sphärische Hepatitis-B-Virion besitzt eine äußere Virushülle und im Inneren ein ikosaedrisches Nukleokapsid, auch Core-Partikel genannt.

Das Core-Partikel kommt in zwei Größen vor und besteht je nach Symmetrie aus 90 (Symmetrie: Triangulations-Zahl $[\mathrm{T}]=3$ ) bzw. 120 (Symmetrie: $\mathrm{T}=4$ ) Coreprotein- 
Homodimeren, die sich direkt nach der Synthese der Coreprotein Monomere ausbilden. Das einzelne Coreprotein, das von dem PräC/C-ORF kodiert wird, hat ein Molekulargewicht von 21 kD (WeIMER et al., 1987). Das Nukleokapsid, dessen Schale letztendlich ein Homooligomer ist, beherbergt in seinem Inneren das virale partiell doppelsträngige Genom (RoBINSON et al., 1974) und die kovalent an die Nukleinsäure gebundene virale Polymerase (GERLiCH \& RoBinson, 1980; KAPLAN et al., 1973). Desweiteren wurde auch eine Proteinkinase zellulären Ursprungs nachgewiesen, die für die Phosphorylierung von Serin-Resten des Coreproteins verantwortlich ist (SCHLICHT \& SCHALleR, 1989; KANN et al., 1993; KANN et al., 1997; DAUB et al., 2002), sowie das Hitzeschock-Protein 90 (heat shock protein 90; Hsp90) (Hu et al., 1997) und weitere Faktoren, die für die P-Protein-Aktivität wichtig sind.

Neben dem Coreprotein wird ein zweites Protein, das Präcore-Protein, von dem PräC/CGen kodiert. Dieses Protein bildet die sogenannte Hepatitis-B e Antigenität (HBeAg) aus. Das ,e’ steht für early, da es frühzeitig während einer Infektion als Marker nachweisbar ist. Es ist ein Protein, das für die Replikation des Virus in vitro nicht essentiell ist, wohl aber für die Etablierung einer persistenten Infektion in vivo (TONG et al., 1991; CHEN et al., 1992). Es wird auch angenommen, dass die HBeAg-Expression der Mutter im Embryo eine Immuntoleranz fördert (MiLICH et al., 1990). Weiterhin wird vermutet, dass es die Immunabwehr gegen das verwandte Coreprotein zu einem gewissen Grad abfangen kann (Milich \& LiANG, 2003) und die T-Zell Immunantwort moduliert, indem es den humoralen Th2-Zweig verstärkt und die cytotoxische Antwort abschwächt (MiLich et al., 1999). Das primäre Produkt der Translation (PräHBeAg p25), mit einem Molekulargewicht von $25 \mathrm{kD}$, ist aminoterminal um 29 AS (PräcoreRegion) gegenüber dem Coreprotein verlängert und wird cotranslational in die ERMembran eingeschleust. Die ersten 19 AS dienen dabei als Signalpeptid. Nach der Abspaltung des aminoterminalen Signalpeptids durch eine Signalpeptidase (BRUSS \& GERLICH, 1988; Ou et al., 1986) und des argininreichen Carboxyterminus durch eine Furin-ähnliche Endopeptidase entsteht das reife HBeAg mit einem Molekulargewicht von 17 kD (MessageOT et al., 2003), welches in das Serum sezerniert wird. Obwohl eine große Überlappung der primären Sequenzen des HBeAg und des Coreproteins vorliegt, sind die höheren Strukturen sehr unterschiedlich; zusätzlich kann das HBeAg 
nicht oligomerisieren (NASSAL \& RIEGER, 1993; WASENAUER et al., 1993; BANG et al., 2005).

Das Core-Partikel wird von einer Hülle umfasst, die aus einer Membran mit eingelagerten Hüllproteinen besteht. Die Hüllproteine, die in drei unterschiedlichen Größen vorliegen und verschiedene Gykosylierungsformen aufweisen, sind sogenannte Transmembranproteine, da sie durch Signalsequenzen in der Membran verankert sind.

Das SHBs hat eine Länge von 226 AS und ein Molekulargewicht von 24 kD. Nterminal besitzt es zwei hydrophobe Signalsequenzen mit $\alpha$-helikaler Struktur, durch die es zu einer kotranslationalen Translokation des Proteins in die ER-Membran der Wirtszelle kommt (Abb. 3). Das erste Signalpeptid (I) umspannt die Region von AS 4 bis 28 und wird nicht posttranslational prozessiert (EBLE et al., 1986). Es folgen ca. 50 cytosolisch gelegene Aminosäuren. Die Positionen 80 - 100 stellen das Signalpeptid II dar, das die Proteinkette in der Membran verankert, während die folgenden weitesgehend hydrophilen AS 101 - 168 in das Lumen des ER hineinragen; im reifen Virion zeigt der letztgenannte Bereich letztlich nach Außen und trägt das Hauptepitop. Signal II ist in Abwesenheit von Signal I in der Lage, verkürzte SHBs-Proteine zum ER zu führen und auch den Carboxyterminus korrekt über die Membran hinweg zu orientieren, allerdings sind diese Proteine sekretionsinkompetent. Fehlt jedoch die Signalsequenz II, so sind diese SHBs nicht stabil (BRUSS \& GANEM, 1991a). Weiter in Richtung Carboxyterminus folgen zwei weitere $\alpha$-Helices (168 - 186 Helix III; 189 207 Helix IV), die wahrscheinlich ebenfalls durch die Membran gespannt sind (PRANGE \& STREeCK, 1995; STIRK et al., 1992). Innerhalb der luminalen Sequenz zwischen Signal II und Helix III befinden sich sowohl die $N$-Glykosylierungsstelle, als auch die S-spezifischen Epitope (EBLE et al., 1987). Aufgrund einer fakultativen $N$ Glykosylierungsstelle an Asparagin 146 (EBLE et al., 1987) liegen bis zu 40 \% des SHBs glykosyliert vor. Daher gibt es neben der unglykosylierten Form (P24) auch eine glykosylierte Form (GP27) mit einem Molekulargewicht von 27 kD (PETERson, 1981), die beide die gleiche Membrantopologie aufweisen (Wunderlich \& Bruss, 1996). Kurze Zeit nach der Synthese bilden SHBs über Disulfid-Brücken verbundene Dimere, wobei es keine Präferenz für die Paarung von P24 mit GP27 gibt, wie früher angenommen wurde (BRUSs et al., 1996a). 


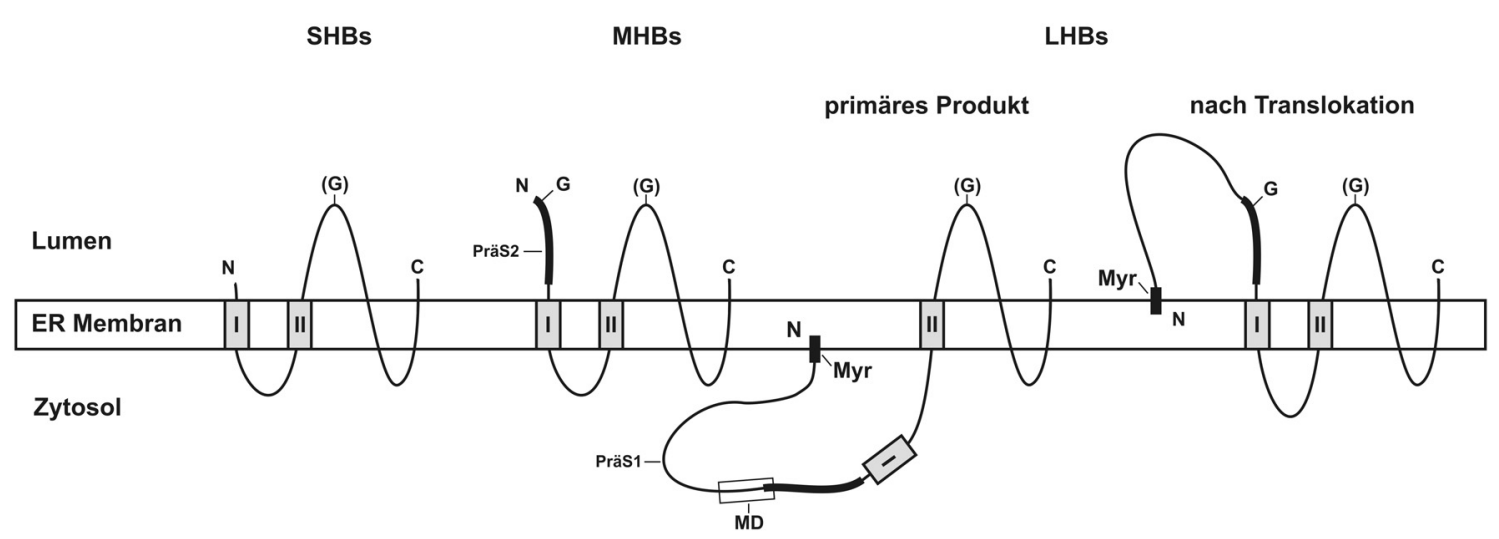

Abb. 3: Schematische Darstellung der drei Hüllproteine in der ER-Membran.

Die Transmembrantopologie der HBV Hüllproteine wird vorwiegend durch die Signalpeptide I und II (graue Boxen) determiniert. G und (G) geben (fakultative) $N$-Glykosylierungsstellen an, während mit Myr die N-terminale Myristylierung von präS1 markiert ist. Die offene Box bestimmt eine Matrix-Domäne (MD) im L-Protein, die für die Interaktion mit dem Nukleokapsid in Frage kommt.

Das MHBs besitzt die gleiche Membrantopologie wie das SHBs, ist aber diesem gegenüber N-terminal um eine hydrophile Sequenz von 55 AS (PräS2-Domäne) verlängert (Abb. 3), da ein alternatives 5'-gelegenes Startkodon für die Translation verwendet wird (STIBBE \& GERLICH, 1982; MACHIDA et al., 1984). Die PräS2-Domäne ist luminal lokalisiert (EBLE et al., 1990). Insgesamt hat das Protein eine Länge von 281 AS und ein Molekulargewicht von 30 kD. Die MHBs-Proteine können sowohl unglykosyliert (P30), als auch ein- (Asn 4; GP33) oder zweifach (Asn 4 und Asn 146 im S-Bereich; GGP36) glykosyliert vorliegen, wobei das GP33 die häufigste Form darstellt (STIBBE \& Gerlich, 1982). Die unglykosylierte Form kommt jedoch nicht in sezernierten Virionen oder subviralen Partikeln vor. Die PräS2-Domäne kann selektiv von der S-Region entfernt werden, da sie empfindlich gegenüber Proteasen ist (HEERmann et al., 1987). Weder für die Morphogenese der Virionen in vitro (BRUSS \& GANEM, 1991b) noch in vivo (FERNHOLz et al., 1991) ist das MHBs essentiell.

Das LHBs hat je nach Subtyp eine Länge von 389 bzw. 400 AS und umfasst neben den PräS2- und S-Domänen (281 AS) eine N-terminale Verlängerung von 108 (Subtyp ay) bzw. 119 AS (Subtyp ad) (VALEnZUela et al., 1980), die sogenannte PräS1-Domäne. Das molekulare Gewicht beträgt $39 \mathrm{kD}$. Auch das große Hüllprotein kann an der $N$ Glykosylierungsstelle im S-Bereich glykosyliert sein, wodurch das Molekulargewicht 
auf $42 \mathrm{kD}$ ansteigt (HEERMANn et al., 1984). Im Gegensatz zum MHBs wird LHBs nicht an Asn4 der PräS2-Region gykosyliert (PRANGe \& STREeCK, 1995; Bruss et al., 1994). An Gly2 ist das LHBs myristiliert, was möglicherweise als Mebrananker dient (PERsing et al. 1987), aber auf die Morphogenese der Virionen selbst keinen Einfluss hat (BRUSS \& GANEM, 1991b); in vivo ist die Myristinsäure für die Infektion wichtig (MACRAe et al., 1991; Bruss et al., 1996b; GRIPON et al., 1995). Die Topologie des LHBs unterscheidet sich von der des SHBs und MHBs (Abb. 3). Der N-terminale Bereich des Proteins (PräS1-Domäne) liegt nach erfolgter Translation zunächst cytosolisch vor, wird jedoch posttranslational bei ca. $50 \%$ der Proteine durch die ERMembran in das Lumen transloziert (BRUss et al., 1994). Dadurch befindet sich später ca. die Hälfte aller PräS1-Domänen auf der Oberfläche des reifen Virions, und diese Domänen treten wahrscheinlich bei der Infektion von Hepatozyten mit dem zellulären Rezeptor in Kontakt (URBAN \& GRIPON, 2002; BRUSS et al., 1996a; GRIPON et al., 2005). Die andere Hälfte der PräS1-Domänen, die auf der zytosolischen Seite verbleiben, sind mit dem Hitzeschock-Protein Hsc70 assoziiert (LAMBERT \& PRANGE, 2003; LÖFfler-MARY et al., 1997; PRANGE et al., 1999) und spielen eine wichtige Rolle bei der Umhüllung der Nukleokapside. Eine von Bruss (BRUSs, 1997) bestimmte Matrix-Domäne (MD) am C-terminalen Ende der PräS1-Region (AS 103 - 124) scheint dabei essentiell zu sein. Der Abstand zwischen der MD und dem Signal II, das in der ER-Membran lokalisiert ist, darf bis auf ca. 26 AS verkürzt werden, ohne dass eine Umhüllung der Kapside blockiert wird (KLUGE et al., 2005).

Die virale Polymerase (P-Protein), die sich innerhalb des Kapsides befindet, hat ein Molekulargewicht von $90 \mathrm{kD}$. Es ist ein multifunktionales Enzym und besitzt vier Domänen. Am N-Terminus ist die terminale Proteindomäne gelegen (TP), die im Nukleokapsid kovalent an das 5'-Ende des Minus-Stranges der viralen DNA gebunden ist. Das TP stellt den Protein-Primer dar, der an der pgRNA die Synthese des DNAMinusstranges initiiert (BArtenschlager \& Schaller, 1988; Bosch et al., 1988). Carboxyterminal schließt sich eine Spacer-Region an, die als „Abstandshalter“ zwischen dem TP und dem carboxyterminalen Bereich dient; dieser unterteilt sich in eine reverse Transkriptase-Domäne (RT) und eine RNaseH-Domäne (FARAUQI et al., 1991). Die RT-Domäne hat sowohl reverse Transkriptase-, als auch als DNA-abhängige 
DNA-Polymerase-Aktivität, während die RNaseH-Domäne die prägenomische RNA während der (-)-Strang Synthese abbaut.

Das X-Protein ( $\mathrm{HBx})$ ist ein regulatorisches Protein mit pleiotrophen Funktionen. Es dient vor allem als Transkriptionsaktivator, zumeist indirekt über Protein-ProteinInteraktionen, wie in vitro gezeigt werden konnte (ROSSNER, 1992; COLGROVE et al., 1989; KeKUle et al., 1993; LeUPIN et al., 2005). Die Funktion oder Bedeutung des HBx für den HBV-Replikationszyklus ist bislang wenig verstanden (HENKLER et al., 1998). Bislang ist nur im WHV Tiermodell bekannt, dass das X-Protein für die Etablierung einer chronischen Infektion benötigt wird. (CHEN et al., 1993; Zoulim et al., 1994). In der Zellkultur scheint die Expression des X-Proteins für die Produktion von Virionen nicht essentiell zu sein (BLum et al., 1992).

\subsection{Infektionszyklus und Virusreplikation}

Auf zellulärer Ebene beginnen Infektionen durch animale Viren mit der Bindung der Viren an Zellen, die geeignet für ihre Vermehrung sind, gefolgt von der Aufnahme, bei umhüllten Viren der Verlust der Hülle und Transport des viralen Genoms zu dem Ort der Replikation. Diese ersten Schritte der Infektion sind bei den Hepadnaviren nicht vollständig aufgeklärt, was vor allem an einer fehlenden HBV-permissiven Zelllinie liegt. Nur primäre humane Hepatozyten (PHH) und primäre Tupaia belangeriHepatozyten können für wenige Tage erfolgreich infiziert werden (GRIPON et al., 1988; KÖCK et al., 2001; GLEBE et al., 2003). Erst 2002 wurde eine infizierbare Leberzelllinie beschrieben (GRIPON et al., 2002), die die Möglichkeit geben könnte, die ersten Schritte der Infektion besser zu untersuchen. Verschiedene zelluläre Proteine wurden als mögliche Rezeptor-Kandidaten beschrieben, jedoch konnte keine Zelllinie nach Expression der Proteine erfolgreich infiziert werden. Mehr Erfolg gab es bei dieser Suche beim Enten-HBV, wo die Carboxypeptidase D (gp180) als zumindest eine Rezeptorkomponente ermittelt werden konnte (BREINER et al., 1998; ENG et al., 1998; UrbAN et al., 1998; ToNG et al., 1999); eine Expression dieses Proteins in sonst nicht permissiven Zellen ermöglichte jedoch keine Infektion. 
Um das HBV in vitro zu untersuchen, bedient man sich daher der Möglichkeit, bestimmte Zelllinien, die aus hepatozellulären Karzinomen hervorgegangen sind (z.B. HepG2 [ADEN et al., 1979] oder HuH7 [NAKABAYASHI et al., 1982]), transient oder stabil mit dem HBV Genom zu transfizieren (Acs et al., 1987; YAGINUMA et al., 1987). Die transfizierten Zellen sezernieren reife infektiöse Virionen.

Der Zelleintritt des Virus erfolgt vermutlich über Endocytose und weiterführend über ein Endosom, aus dem das Kapsid in das Zytosol entlassen wird. Anschließend erfolgt der Transport zum Nukleus durch ein Kernlokalisations-Signal (nuclear localization signal; NLS) am C-Terminus (AS 158 - 168) der Kapsid-Proteine (ECKHARDT et al., 1991; KANN et al., 1999). Untersuchungen mit dem DHBV-Modell zeigen eine Beteiligung der Mikrotubuli an diesem Transport (FUNK et al., 2004), vermutlich über Bindungen des Kapsides mit Transportproteinen (M. KANN, persönl. Mitteilung). Nach Interaktion mit den löslichen zellulären Transport-Rezeptoren Importin $\alpha$ und $\beta$ (KANN et al., 1999) und der daraus folgenden Bildung von cargo-Rezeptor-Komplexen erfolgt die Bindung des Nukleokapsids an den Kernporen-Komplex (nuclear pore complex; NPC) über Sequenzen am $\mathrm{COOH}$-terminalen Bereich des phosphorylierten Coreproteins. Es wurde gezeigt, dass die Kapside intakt in den nukleären Korb (nuclear basket) gelangen und erst dort deassemblieren (PANTÉ \& KANN, 2002), wodurch das Genom in das Karyoplasma gelangen kann. Durch zelluläre Reparaturenzyme wird die Lücke des unvollständigen (+)-Stranges des partiell doppelsträngigen Genoms geschlossen, und es entsteht die für die Replikation nötige kovalent geschlossene zirkuläre DNA (covalently closed circular DNA; cccDNA) (KÖCK \& SCHLICHT, 1993); diese liegt episomal als Nukleosom vor (BocK et al., 1994; NEwBOLD et al., 1995). Die pgRNA sowie die anderen subgenomischen RNAs werden dann im Nukleus der infizierten Hepatozyte durch die zelluläre RNA Polymerase II von der viralen ccc-DNA synthetisiert (KÖCK \& SCHLICHT, 1993; RALL et al., 1983). 


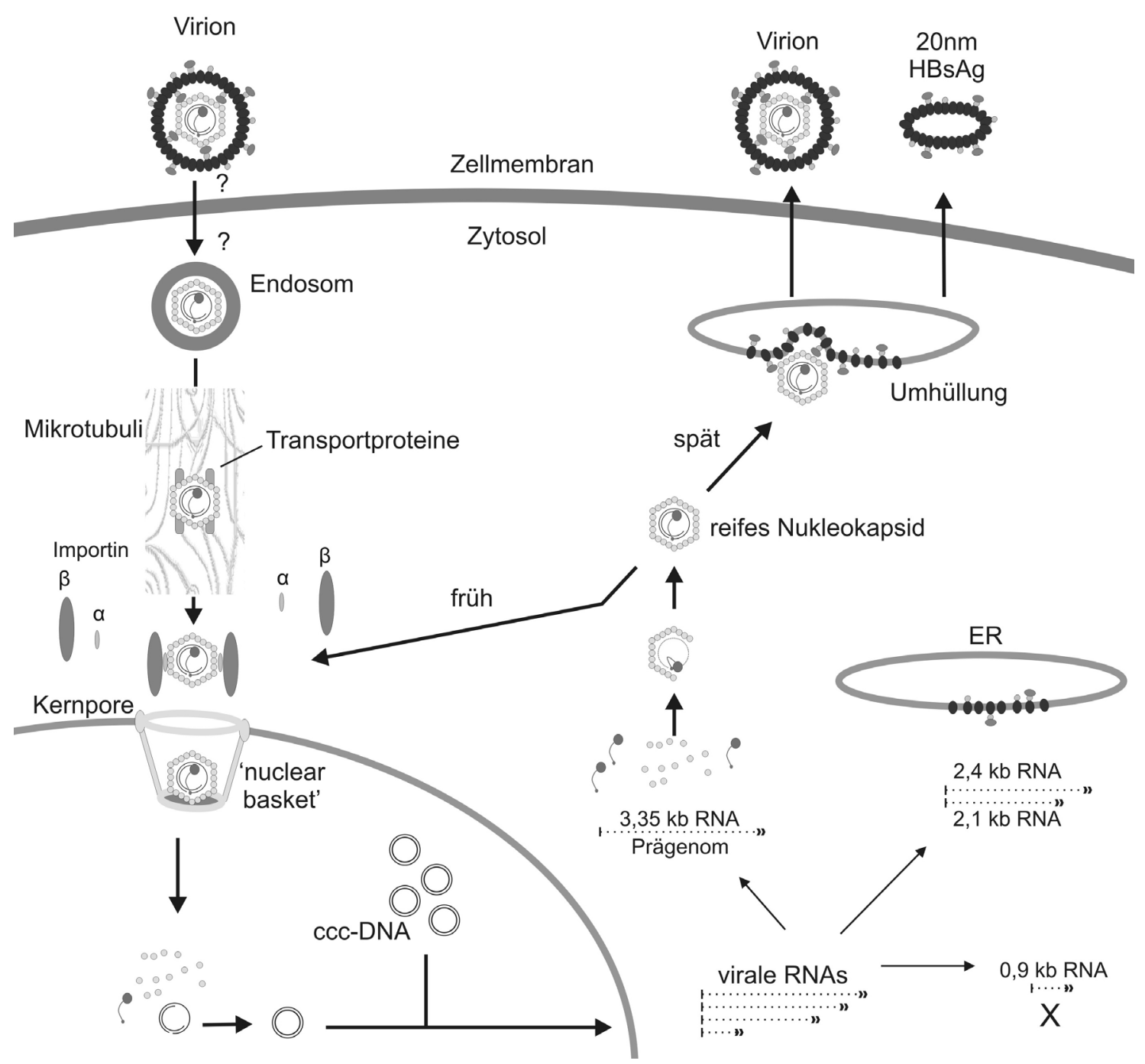

Abb. 4: Schematische Darstellung des HBV-Replikationszyklus (modifiziert nach PONSEL, 2003)

Die entstandenen mRNAs werden in das Zytosol transportiert und für die Translation der viralen Proteine verwendet. Während von den subgenomischen RNAs an der ERMembran die viralen Hüllproteine translatiert und cotranslational in die Membran integriert werden, werden von der pgRNA im Zytosol die Coreproteine und die virale Polymerase synthetisiert. Die virale Polymerase bindet zusammen mit zellulären Faktoren an die sogenannte Epsilon ( $($ ) -Struktur am 5'-Ende der pgRNA (JUNKERNiePMAnN et al., 1990; JeONG et al., 2000). Dieser Polymerase-pgRNA-Komplex wird von Coreprotein-Homodimeren erkannt, die Kapsid-Assemblierung wird initiiert (Bartenschlager \& Schaller, 1992; Pollack \& Ganem, 1994; Hirsch et al., 1990), und es entstehen unreife, RNA-haltige Kapside. Die DNA-Synthese des (-)- 
Stranges und damit die reverse Transkription wird durch protein-priming initiiert, wobei die TP-Domäne als Primer (Tyrosin-Rest 96) an die bulge-Region der $\varepsilon$-Struktur bindet (Summers \& MAson, 1982; Zoulim \& SeEger, 1994; TAVis et al., 1994). Diese Bindung wird durch die Hitzeschock-Proteine Hsp60 (PARK \& JUNG, 2001; PARK et al., 2003) und Hsp90 (Hu \& SEeger, 1996; Hu et al., 1997) stabilisiert. Nach der Synthese von vier Nukleotiden wechselt die wachsende Minus-Strang DNA an eine Position am 3'-Ende der pgRNA (3'-Kopie von DR1), wo die (-)-Strang-Synthese fortgesetzt wird und zeitgleich durch die RNase H-Aktivität die pgRNA abgebaut wird. Ein kurzes Stück von 15 bis 18 Nukleotiden am 5'-Ende der RNA, welches nicht abgebaut wird, dient als ein Primer für die Plus-Strang DNA-Synthese, wofür eine erneute Translokation zum DR2 am 5'-Ende der (-)-Strang DNA nötig ist (STAPRANS et al., 1991). Eine dritte Translokation erfolgt, wenn der Plus-Strang das 5'-Ende des MinusStranges erreicht, um das Molekül zu zirkularisieren und die Elongation des (+)Stranges fortzuführen. Die Aufpolymerisierung des Plus-Stranges des viralen Genoms bricht jedoch nach ca. 1500 bis 2500 Nukleotiden aus bisher nicht genau bekannten Gründen ab. Nach erfolgter reverser Transkription im Inneren der Kapside zur partiell doppelsträngigen DNA spricht man von reifen Kapsiden.

Während der frühen Phase einer Infektion erfolgt ein Transport der reifen Kapside zurück zum Zellkern, wodurch es zu einer Akkumulation von cccDNA kommt, die wiederum als Matrizen für die Synthese viraler mRNA dienen. Untersuchungen am Enten-Modell haben gezeigt, dass ca. 20 bis 50 cccDNA Moleküle im Zellkern vorhanden sein können (TUTTLEMAN et al., 1986). Der Grad des Rücktransports scheint abhängig von der L-Protein-Konzentration zu sein, denn im Enten-Modell zeigte sich ein deutlicher Anstieg nukleärer cccDNA nach Blockierung der Synthese des LDHBs (SuMMERs et al., 1990; LENHOFF \& SuMMERS, 1994). In der späten Phase der Infektion, wenn ausreichend Hüllproteine vorhanden sind, kommt es zur Umhüllung nur der reifen Kapside an einer intrazellulären Membran (GERELSAIKHAN et al., 1996). Propagiert wird hierbei ein direkter Kontakt zwischen den Kapsiden und den in die Membran verankerten viralen Hüllproteinen. Für die Umhüllung selbst sind nur das große und das kleine Hüllprotein notwendig (BRUSS \& GANEM 1991a). Bei Mutationsanalysen zur Ermittlung von Interaktionspartnern wurde eine Region im L-Protein von 22 Aminosäuren (AS 103 - 124) bestimmt (BRUSS, 1997; LE SEYEC et al., 1998; LE SEYEC 
et al., 1999), die nach Mutationen eine Blockierung der Umhüllung reifer Nukleokapside verursacht, jedoch weiterhin die Sekretion von subviralen Partikeln erlaubt. Ein weiterer für Mutationen sensibler Bereich von 12 Aminosäuren (AS 35 - 46) wurde im S-Protein nachgewiesen (LÖFFLER-MARY et al., 2000). Ein akzeptiertes Modell geht davon aus, dass die zytosolisch gelegene N-terminale Schleife des LHBs als Kontaktpartner für eine Protein-Protein-Interaktion mit dem Nukleokapsid in Verbindung tritt, wonach das Kapsid umhüllt wird. Mögliche Bindungspartner auf der Kapsidoberfläche wurden mittels Mutationsanalysen mit zufällig generierten Insertionen und Deletionen innerhalb des Coregens (KosCHEL et al., 1999; KosCHEL et al. 2000) und durch gezielte Alanin-Substitutionen von oberflächenexponierten ASResten bestimmt (Ponsel \& Bruss, 2003). Dabei konnten zwei Deletionen und eine Insertion bzw. elf einzelne Positionen bestimmt werden, die die Verpackung der pgRNA, Kapsidassemblierung und virale DNA Synthese nicht beeinflussen, die Umhüllung jedoch blockieren. Nach der Interaktion von Hüllproteinen und Kapsid erfolgt schließlich an den Membranen intrazellulärer Kompartimente (Post-ER, PräGolgi oder multivesicular bodies) eine vesikuläre Knospung in deren Lumen (PATZER et al., 1986; HUOVILA et al., 1992; FREED, 2002), und über den zellulären Sekretionsweg wird das entstandene reife Virion aus der Zelle transportiert (PATZER et al., 1986; HuOvila et al., 1992; FREED, 2002; VON SCHWEDLER et al., 2003).

\subsection{Das Hepatitis-B-Virus Kapsid}

Das ikosaedrische Nukleokapsid des HBV besteht aus $180(\mathrm{~T}=3)$ oder $240(\mathrm{~T}=4)$ des Coreprotein-Monomeren. Diese haben jeweils eine molekulare Masse von $21 \mathrm{kD}$, bei einer Länge von 185 (Subtyp $a d w$ ) oder 183 Aminosäuren (Subtyp ayw). Das Coreprotein wird in zwei funktionelle Domänen unterteilt: N-terminal befindet sich eine sogenannte Assemblierungsdomäne, die den Bereich von AS 1 bis 144 umfasst, welche vorwiegend hydrophober Natur sind (BIRnBAuM \& NASSAL, 1990; GalliNA et al., 1989). Das kleinste für die Kapsidassemblierung funktionelle Coreprotein reicht von AS 1 bis 140, während C-terminal weiter verkürzte Mutanten unlösliche Aggregate bilden, die keine Kapsidstruktur mehr aufbauen können (WATTS et al., 2002). Im C-terminalen Bereich des Coreproteins befindet sich eine Protamin-ähnliche Domäne (AS 150 - 185). 
Sie weist eine Akkumulation von basischen Resten auf, die in vier Blöcken gruppiert sind. Drei von diesen Blöcken beinhalten ein SPRRR(R)-Motiv, welches nichtsequenzspezifisch Nukleinsäuren binden kann (Petit \& PiLOt, 1985; Hatton et al., 1992); preferentiell aber die mRNA, von der das Protein translatiert wurde (BIRNBAUM \& NASSAL, 1990). Die beiden Domänen werden verbunden über ein Linker-Peptid (AS 141 - 149), welches in Länge und Sequenz gut konserviert ist (BRINGAS, 1997) und Einfluss auf die Assemblierung des Kapsides nimmt: Eine progressive Verkürzung des C-Terminus reduziert die Fraktion von $\mathrm{T}=4$ Kapsiden von 95 \% (Coreprotein AS 1 149) auf ca. $20 \%$ (Coreprotein AS 1 -140) (Zlotnick et al., 1996). Neben der Nukleinsäure-Bindefähigkeit besitzt der C-Terminus fünf potentielle SerinPhosphorylierungsstellen (LIAO \& OU, 1995), von denen S170 für die optimale Verpackung der pgRNA phosphoryliert vorliegen muss (LE POGAM et al., 2005). Diese werden von einer im Kapsid befindlichen Proteinkinase mit Beginn der reversen Transkription phosphoryliert, was die DNA-Bindefähigkeit reduzieren soll (KANN \& GERLICH, 1994). Intrazelluläre Kapside liegen heterogen phosphoryliert vor, während aus Virionen isolierte überwiegend aus unphosphorylierten Coreproteinen bestehen (YU \& SumMERS, 1994a, b). Es wird vermutet, dass im Verlauf einer Infektion der Phosphorylierungszustand der Kapside wieder entscheidend sein könnte: Nur wenn die Coreproteine phosphoryliert sind, würde das Kernlokalisations-Signal des C-terminalen Bereichs nach Außen präsentiert werden, wodurch die Bindung des Kapsides mit den Kernporen-Komplexen (nuclear core complexes; NPC) über den Importin-vermittelten Weg ermöglicht werden würde (KANN et al., 1999).

Die Aufklärung der Struktur des HBV Kapsids wurde durch KryoelektronenMikroskopie von CROWTHER et al., (1994), sowie durch Kristallstrukturdaten von WYNNE et al. (1999a, b) vorangetrieben, während BÖTTCHER et al. (1997) und CONWAY et al. (1997) die Faltung des Coreproteins auf 7,4 respektive $9 \AA$ genau darstellen konnten. Die Struktur des Coreprotein-Monomer wird dominiert von einer langen $\alpha$ helicalen Haarnadelstruktur, die aus den Aminosäure-Resten 50 - 73 (Helix a3) und 79 - 110 (Helix $\alpha 4$ ) besteht. Dabei ist die $\alpha 4$-Helix zwischen den Resten 90 und 92 abgeknickt, so dass der untere Teil ( $\alpha 4 b)$ der Helix von der $\alpha 3$-Helix abgespreizt vorliegt, während der obere Teil ( $\alpha 4 a)$ parallel verläuft. Der N-terminale Bereich (AS 1 -12) nimmt eine irreguläre Struktur ein, gefolgt von einer kurzen Helix ( $\alpha 1$; 
AS 13 -17) und einer längeren Helix $\alpha 2$, die wiederum durch einen Knick nach Aminosäure 37 in die zwei helikalen Strukturen $\alpha 2 a$ (27 - 37) und $\alpha 2 b$ (38-43) unterteilt wird. Insgesamt umwickelt der N-terminale Bereich (AS 1 - 49) die $\alpha$-helikale Haarnadelstruktur fast einmal. Die C-terminale Region besteht aus der Helix $\alpha 5$ (AS 112 - 127), gefolgt von einer Prolin-reichen Schleife (AS 128 -136) und einem ,erweiterten Strang' (ab AS 137) (WynNE et al., 1999b). Ein sehr hydrophober Bereich, der vorwiegend aus den Resten von $\alpha 1$, der Schleife zwischen $\alpha 1$ und $\alpha 2$, $\alpha 4 \mathrm{~b}$ und $\alpha 5$ besteht, könnte eine wichtige Rolle für die Erhaltung der Stabilität des Monomers spielen, zumal die beteiligten Reste in den HBV-Varianten hochkonserviert sind.

Das Kapsomer besteht aus einem kompakt gebauten Coreprotein-Homodimer, das sich aus zwei sich antiparallel gegenüberliegenden Coreprotein-Monomeren zusammensetzt, wodurch eine fast exakte Zweifach-Symmetrie ausgebildet wird. Dabei ergibt sich ein kompaktes 4-Helixbündel, das den charakteristischen Spike auf der Oberfläche der Kapside darstellt. Die Form des Coreprotein-Dimers ähnelt einem auf dem Kopf stehenden ,T', wobei das 4-Helixbündel der vertikalen Linie und die basale Region der horizontalen Linie entspricht. Die helikale Haarnadel-Struktur des Spikes ( $\alpha 3, \alpha 4 a$ und a4b) ist sehr amphipatisch und trägt damit zur Dimerbildung und -stabilität bei. Die zwei Monomere werden durch Cys61 miteinander über eine Disulfidbrücke verbunden, die jedoch für die Dimer- oder Kapsidassemblierung nicht essentiell ist (NASSAL et al., 1992b; ZHENG et al., 1992; ZLOTNICK et al., 1996). Weiterhin hat sich gezeigt, dass sich zwischen zwei Coreprotein-Monomeren, über die AS-Reste Glu64 ${ }_{1}$ und Lys96 2 , sowie Asp78 1 und Glu772, Wasserstoffbrücken ausbilden (Indizes geben die beiden interagierenden Coreproteine an).

Die Assemblierung kann spontan ohne weitere virale Komponenten in vivo und in vitro erfolgen (CERES \& ZLOTNICK, 2002; SEIFER et al., 1993). Diese autarke Bildung konnte auch in verschiedenen Expressionssystemen wie Bakterien (COHEN \& RICHMOND, 1982), Xenopus Oozyten (ZHOU \& STANDRING, 1991) und Insektenzellen (LANFORD \& NotVAlL, 1990) nachgewiesen werden. Im Infektionszyklus des Virus wird die Kapsidassemblierung durch die Bindung der viralen Polymerase an die bulge-Region der $\varepsilon$-Struktur am 5'-Ende der pgRNA initiiert (HIRSCH et al., 1990; BARTENSCHLAGER \& Schaller, 1992; Pollack \& GANEM, 1994). Der Aufbau der Kapside erfolgt durch die Interaktion der Kapsomere über die C-terminalen Domänen des C-Proteins, wobei 
es zur Ausbildung von 5-fach- und 6-fach-Symmetrien kommt. Dabei sind vorwiegend die Aminosäure-Reste der $\alpha 5$-Helix, der Prolin-reichen Schleife (AS 128 - 136) und des ,erweiterten Stranges’ beteiligt. Die Assemblierung des Kapsides ist sowohl von der Konzentration der im Zytosol vorhandenen Coreproteine abhängig, als auch von dem Vorhandensein intakter Membranoberflächen (LINGAPPA et al., 2005). Choi und Kollegen (CHOI et al., 2005) zeigten, dass auch eine erhöhte zytosolische KalziumKonzentration die HBV Kapsidassemblierung fördern kann. Nach der Assemblierung besteht das Kapsid aus einer sphärischen Protein-Hülle, die eine Dicke von $20 \AA$ aufweist. Von dieser Hülle aus ragen die 4-Helix-Bündel als Spikes mit einer Länge von ca. $25 \AA$ und einer Breite von $20 \AA$ in die Höhe. Weiterhin entstehen Kapsidporen, die einen Durchmesser zwischen 12 und $15 \AA$ besitzen; dieser ist groß genug, um Desoxyribonukleotiden Ein- und Austritt zum Kapsidlumen zu gewähren (WYNNE et al., 1999b).
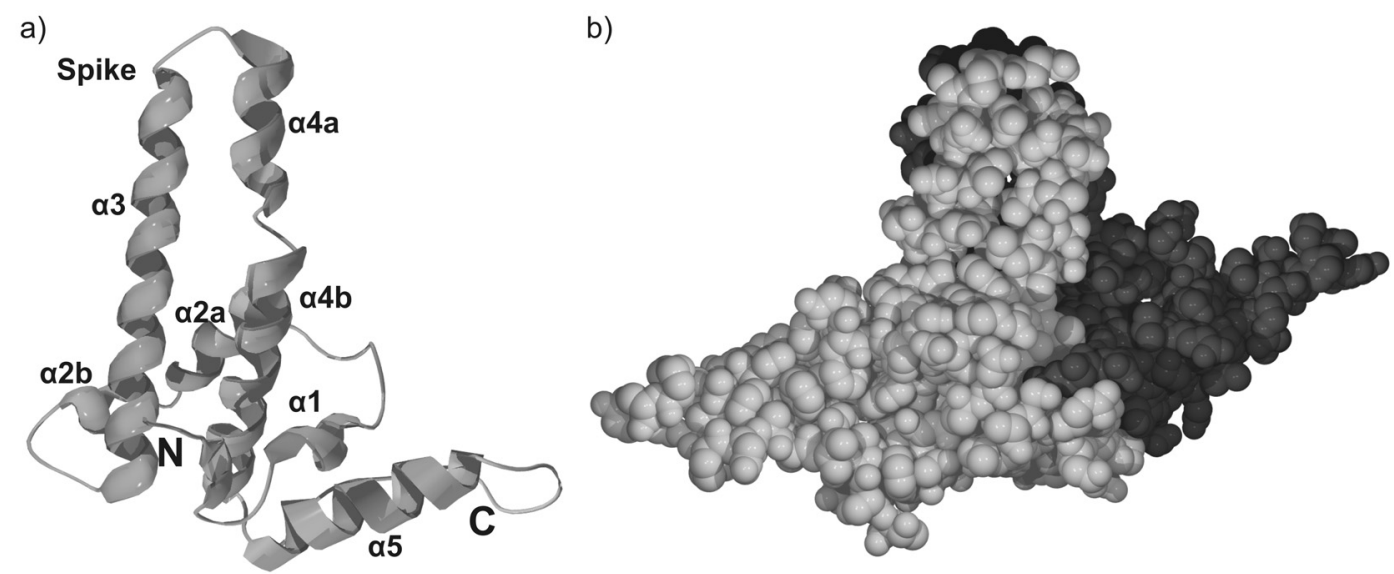

c)

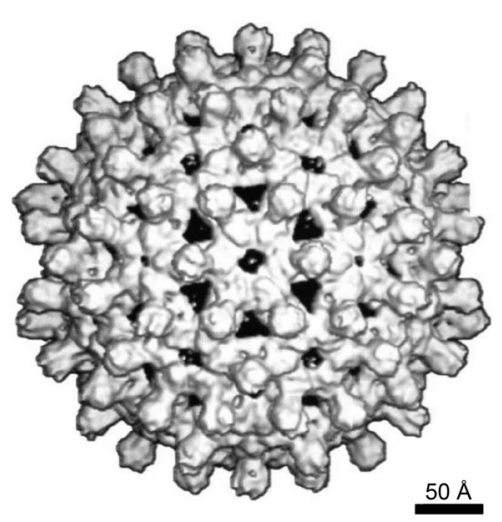

Abb. 5 (vorherige Seite): Darstellung eines a) Coreprotein-Monomers (Faltblattstruktur), b) Coreprotein-Homodimers (Kugelmodell) und c) Nukleokapsids. Teilabbildungen a) und b) 
basieren auf den von Wynne und Kollegen veröffentlichten Kristallstrukturdaten (WYNNE et al., 1999b). Teilabbildung c) ist ein Kryo-Elektronenmikroskopie-Bild eines $\mathrm{T}=4$ Nukleokpasids mit einer Auflösung von $9 \AA$ (CoNWAY et al., 1997, modifiziert).

Das HBV Nukleokapsid besitzt eine besonders immunodominante Region an der Spitze der Spikes (AS 78 -83) (SALFELD et al., 1989; SÄLlbERG et al., 1991), die als konformationelles Hauptepitop des HBcAg eine starke Antikörper-Immunantwort auslösen kann. Diese Region eignet sich auch für Insertion von Fremdsequenzen, sogar von kompletten Proteinendomänen, wie z.B. eGFP, ohne die Assemblierung des Kapsides zu behindern (Kratz et al., 1999). Desweiteren existieren zwei Epitope, die vom assemblierten Kapsid maskiert sind und nur bei dem denaturierten Kapsid oder dem Coreprotein-Homodimer zugänglich sind: HBe1, ein sequentielles Epitop, befindet sich ebenfalls an der Spitze des Spikes, und HBe2, ein konformationelles Epitop, ist um Position P130 lokalisiert (SALFELD et al., 1989). Ebenfalls in diesem Bereich (AS 129 - 132) befindet sich eine Sequenz, die Homologie zur sogenannten L(ate) domain (PPXY) von Retroviren aufweist. Diese hat eine essentielle Rolle bei der Abschnürung des Retrovirus von der Membran (FreED, 2002). Ob das Motiv (PPAY) beim HBV eine solche Rolle spielt ist unklar, da Mutationsanalysen mit Alanin-Substitutionen an diesen Positionen die Bildung von Kapsiden blockierten (PONSEL \& BRUSS, 2003).

\subsection{Ziel der Arbeit}

Das HBV Coreprotein ist ein multifunktionelles, für das Virus essentielles Protein, das nicht nur strukturelle (u.a. Kapsidassemblierung und Verpackung des viralen Genoms), sondern auch funktionelle Aufgaben (u.a. Generierung des Reifungssignals, zytosolischer Transport) besitzt. Desweiteren spielen die Coreproteine eine wichtige Rolle zu Beginn und während des Umhüllungsprozesses: Es wird davon ausgegangen, dass über die Matrix-Domäne (AS 103 - 124) der transmembran gelegenen LHBs ein direkter Kontakt zu der Kapsidoberfläche hergestellt wird (BRUSS, 1997). Die genauen Strukturen und Faktoren, die an dieser Interaktion beteiligt sind, sind bislang jedoch nicht identifizert worden. Es zeigte sich aber, dass elf auf der Oberfläche des Kapsids exponierte AS-Seitenketten nach Substitution zu Alanin einen spezifischen 
Umhüllungsblock generierten, ohne die Kapsidstabilität zu beeinflussen (PONSEL \& BRUSS, 2003).

Das primäre Ziel dieser Arbeit war die Analyse der Variabilität und Funktion von sechs AS-Positionen des Coreproteins, die nach Alanin-Substitution spezifisch die Umhüllung blockierten. Dies sollte durch Substitution dieser Positionen mit weiteren AS-Resten erfolgen, wodurch die Bedeutung und Beteiligung jeder einzelnen der getesteten AS sowohl für den Umhüllungsprozess, als auch für die Kapsidassemblierung untersucht werden würde. Im gleichen Kontext sollten vier AS-Positionen des Coreproteins, die nach dem Alanin-Austausch einen WT Phänotyp zeigten, mehrfach mit weiteren ASResten substituiert werden.

Um weitere Einsichten in die vermutlich direkte Interaktion zwischen dem Nukleokapsid und den Hüllproteinen (LHBs) während der Umhüllung zu bekommen, sollte ein Zellkultursystem auf Basis eines Retrovirus-Transduktionssystem etabliert werden. Mit diesem sollte es zunächst möglich sein, konstitutiv in der Zellkultur exprimiertes WT Core- und P-Protein (Polymerase) mit Hilfe von WT LHBs funktionell zu transkomplementieren. Später sollte das Ziel verfolgt werden, eine ausgesuchte umhüllungsdefiziente Core-Mutante mit zufallsmutagenisierten LHBs funktionell in trans zu komplementieren, so dass reife Virionen sezerniert werden können. Dazu sollte die als möglicher Bindungspartner angesehene Matrix-Domäne im LHBs in ihrer ASSequenz durch zufällige AS-Substitutionen verändert werden. Falls eine Komplementierung möglich ist, wäre dies ein starker Hinweis auf eine direkte Interaktion von Kapsid und Matrix-Domäne des LHBs. 


\section{MATERIAL}

\subsection{Bakterienstämme}

Tab. 1: Verwendete Escherichia coli-Stämme

\begin{tabular}{|c|c|}
\hline Name & Eigenschaften \\
\hline $\begin{array}{l}\text { DH5a } \\
\text { (HANAHAN et al., 1983) }\end{array}$ & 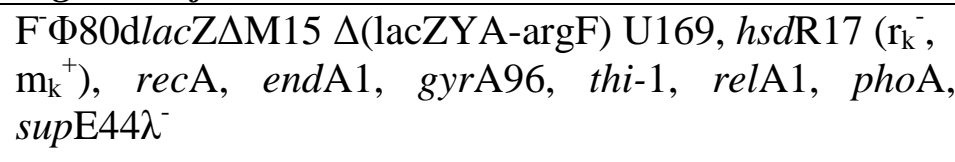 \\
\hline $\begin{array}{l}\text { TOP10F' } \\
\text { (Invitrogen, Karlsruhe) }\end{array}$ & $\begin{array}{l}\mathrm{F}^{\prime}\left\{\text { lac }^{\mathrm{q}}, \operatorname{Tn} 10\left(\text { Tet }^{\mathrm{R}}\right)\right\}, \text { mcrA } \Delta(\text { mrr-hsdRMS-mcrBC }) \\
\text { Ф80lacZ } \mathrm{M} 15, \Delta \text { lacX74, recA1, araD139 } \Delta(\text { ara- } \\
\text { leu)7697, galU, galK, rpsL }\left(\mathrm{Str}^{\mathrm{R}}\right) \text {, endA1, nupG }\end{array}$ \\
\hline
\end{tabular}

\subsection{Eukaryotische Zelllinien}

Tab. 2: Verwendete Zelllinien

\begin{tabular}{|c|c|}
\hline Name & Herkunft / Eigenschaften \\
\hline $\begin{array}{l}\text { HEK-293T } \\
\text { (engl.: human embryonic } \\
\text { kidney-293) } \\
\text { (GRAHAM et al., 1977, KELLY } \\
\text { et al., 1989) }\end{array}$ & $\begin{array}{l}\text { Adhärent wachsende humane embryonale } \\
\text { Nierenepithel-Zelllinie, welche mit dem adenoviralen } \\
\text { E1A Genprodukt (adenovirus type 5) transformiert } \\
\text { wurde. Zusätzlich wird das SV40 large T antigen } \\
\text { exprimiert, welches die episomale Replikation von } \\
\text { Plasmiden erlaubt, die den SV40 origin tragen. HEK- } \\
\text { 293T-Zellen lassen sich transient mit der } \\
\text { Kalziumphosphat-Methode transfizieren. }\end{array}$ \\
\hline $\begin{array}{l}\text { HuH7 } \\
\text { (NAKABAYASHI et al., 1982) }\end{array}$ & $\begin{array}{l}\text { Adhärent wachsende humane Hepatomzelllinie, die } \\
\text { stabil oder transient mit der Kalziumphosphat-Methode } \\
\text { transfizierbar ist. Nach der Transfektion eines } \\
\text { replikationsfähigen HBV-Genoms sezernieren HuH7- } \\
\text { Zellen sowohl Virionen als auch nackte Kapside in den } \\
\text { Zellkulturüberstand. }\end{array}$ \\
\hline $\begin{array}{l}\text { HuH7-HBVcore }^{\text {I126A }} \\
\text { (diese Arbeit) }\end{array}$ & $\begin{array}{l}\text { HuH7-Zellen wurden stabil mit einem Expressions- } \\
\text { vektor für die Core-Mutante I126A transduziert, } \\
\text { wodurch das Protein konstitutiv exprimiert wird. }\end{array}$ \\
\hline
\end{tabular}




\begin{tabular}{l|l}
\hline Name & Herkunft / Eigenschaften \\
\hline $\begin{array}{l}\text { HuH7-HBVcore } \\
\text { (diese Arbeit) }\end{array}$ & $\begin{array}{l}\text { HuH7-Zellen wurden stabil mit einem Expressions- } \\
\text { vektor für das WT-Coreprotein transduziert, wodurch } \\
\text { das Protein konstitutiv exprimiert wird. }\end{array}$ \\
\hline $\begin{array}{l}\text { HuH7-HBVcore } \\
\text { (diese Arbeit) }\end{array}$ & $\begin{array}{l}\text { HuH7-HBVcore }{ }^{\text {I126A }} \text {-Zellen wurden stabil mit einem } \\
\text { Expressionsvektor für das HBV P-Protein transduziert, } \\
\text { wodurch es neben der Core-Mutante I126A konstitutiv } \\
\text { exprimiert wird. }\end{array}$ \\
\hline $\begin{array}{l}\text { HuH7-HBVcore } \\
\text { (diese Arbeit) }\end{array}$ & $\begin{array}{l}\text { HuH7-HBV } \\
\text { Expressionsvektor für das HBV P-Protein transduziert, } \\
\text { wodurch es neben dem Coreprotein konstitutiv } \\
\text { exprimiert wird. }\end{array}$ \\
\hline
\end{tabular}

\subsection{Nährmedien}

\subsubsection{Medien zur Anzucht von E. coli}

Tab. 3: Medien zur Anzucht von Bakterienkulturen

\begin{tabular}{l|rll}
\hline Name & Inhaltsstoffe / Bemerkungen & \\
\hline LB-Medium & 5 & $\mathrm{~g} / \mathrm{l}$ & Hefeextrakt \\
(LURIA BERTANI) & 10 & $\mathrm{~g} / \mathrm{l}$ & Trypton \\
& 10 & $\mathrm{~g} / \mathrm{l}$ & $\mathrm{NaCl}$ \\
\hline SOC-Medium & 20 & $\mathrm{~g} / \mathrm{l}$ & Trypton \\
& 5 & $\mathrm{~g} / \mathrm{l}$ & Hefeextrakt \\
& 10 & $\mathrm{mM}$ & $\mathrm{NaCl}$ \\
& 10 & $\mathrm{mM}$ & $\mathrm{MgCl}_{2}$ \\
& 20 & $\mathrm{mM}$ & $\mathrm{Glukse}$ \\
& 2,5 & $\mathrm{mM}$ & $\mathrm{KCl}$ \\
& 10 & $\mathrm{mM}$ & $\mathrm{MgSO}_{4}$ \\
\hline
\end{tabular}




\begin{tabular}{|c|c|c|c|c|}
\hline Name & Inhaltsstoff & rkung & en & \\
\hline TB-Medium & Lösung A: & 24 & $\mathrm{~g} / \mathrm{l}$ & Hefeextrakt \\
\hline (TERRIFIC BROTH) & & 12 & $\mathrm{~g} / \mathrm{l}$ & Trypton \\
\hline & & 6 & $\mathrm{~g} / \mathrm{l}$ & $\mathrm{NaCl}$ \\
\hline & Lösung B: & 16,4 & $\mathrm{~g} / \mathrm{l}$ & $\mathrm{K}_{2} \mathrm{HPO}_{4} \times 3 \mathrm{H}_{2} \mathrm{O}$ \\
\hline & & 2,3 & $\mathrm{~g} / \mathrm{l}$ & $\mathrm{KH}_{2} \mathrm{PO}_{4}$ \\
\hline & $\begin{array}{l}\text { Nach Autok } \\
\text { Verhältnis } \subseteq\end{array}$ & $\begin{array}{l}\text { werd } \\
\text { gemi }\end{array}$ & $\begin{array}{l}\text { n di } \\
\text { cht. }\end{array}$ & eiden Lösungen im \\
\hline
\end{tabular}

Die Nährmedien wurden vor der Benutzung 20 min. bei $120^{\circ} \mathrm{C}$ autoklaviert. Für die Herstellung von Agarplatten erfolgte vor dem Autoklavieren die Zugabe von 1,5 \% (w/v) Bacto-Agar (Difco, USA). Selektivmedien wurden bei der Anfertigung mit Ampicillin bis zu einer Endkonzentration von 100 mg/l supplimiert. Für den Einsatz von Agarplatten für die Blau/Weiß-Selektion wurden vor Gebrauch $40 \mu \mathrm{l} 40 \mathrm{mg} / \mathrm{ml}$ X-Gal (5-Brom-4-Chlor-3-indolyl- $\beta$-D-Galaktopyranosid; 2.10) und $40 \mu \mathrm{l} 100 \mathrm{mM}$ IPTG (Isopropyl- $\beta$-thiogalaktopyranosid; 2.10) ausplattiert und die Platten ca. $2 \mathrm{~h}$ unter der Sterilbank getrocknet.

\subsubsection{Nährmedien und Lösungen zur Kultivierung eukaryotischer Zelllinien}

Tab. 4: Medien und Lösungen für die eukoryatische Zellkultur

\begin{tabular}{l|l}
\hline Name & Hersteller \\
\hline $\begin{array}{l}\text { Antibiotikum-Antimykotikum, 100x } \\
\text { (Penicillin-Streptomycin-Amphotericin) }\end{array}$ & GIBCO (Invitrogen Corp.), Karlsruhe \\
\hline $\begin{array}{l}\text { Dulbecco’s Modified Eagle Medium } \\
\text { (DMEM) }\end{array}$ & GIBCO (Invitrogen Corp.), Karlsruhe \\
\hline Fötales Kälberserum (FKS) & Biochrom AG, Berlin \\
\hline Geneticin (50 mg/ml) & GIBCO (Invitrogen Corp.), Karlsruhe \\
\hline Trypsin/EDTA-Lösung, 10x & Biochrom AG, Berlin \\
\hline Zeocin (100 mg/ml) & Invitrogen, Karlsruhe \\
\hline
\end{tabular}


DMEM wurde vor Gebrauch mit $10 \%$ (v/v) FKS und $1 \%(\mathrm{v} / \mathrm{v})$ AntibiotikumAntimykotikum supplimiert und bei $4^{\circ} \mathrm{C}$ aufbewahrt. Im Folgenden wird bei der Angabe ,DMEM' stets vom supplimierten Medium ausgegangen. Die Trypsin/EDTALösung wurde vor Gebrauch 1:10 mit $\mathrm{H}_{2} \mathrm{O}_{\text {bidest }}$ verdünnt und ebenfalls bei $4^{\circ} \mathrm{C}$ gelagert. Die Antibiotika (AB) Geneticin und Zeocin wurden nach Angaben der Hersteller bzw. je nach Anwendung dem DMEM zugegeben.

\subsection{Enzyme und Proteine}

Tab. 5: Verwendete Enzyme und Proteine

\begin{tabular}{l|l}
\hline Name & Hersteller \\
\hline DNase I & Roche Diagnostics, Mannheim \\
\hline Klenow-Fragment & MBI Fermentas, St. Leon-Rot \\
\hline PowerScript Long DNA Polymerase & PanBiotech, Aidenbach \\
\hline Proteinase K & Roche Diagnostics, Mannheim \\
\hline Restriktionsendonukleasen & New England Biolabs, Frankfurt a.M. \\
\hline RNase A & Epicentre, USA \\
\hline RNasin Plus RNase Inhibitor & Promega, Mannheim \\
\hline Shrimp Alkaline Phosphatase & MBI Fermentas, St. Leon-Rot \\
\hline T4 DNA-Ligase & MBI Fermentas, St. Leon-Rot \\
\hline Taq DNA-Polymerase & Roche Diagnostics, Mannheim \\
\hline
\end{tabular}

Für fast jedes Enzym oder Protein wurde vom Hersteller ein spezifischer Puffer mitgeliefert, der bei den entsprechenden Versuchen verwendet wurde. Die Zusammensetzung der jeweiligen Puffer ist in den Gebrauchsanweisungen der Hersteller nachzulesen. 


\subsection{Plasmide}

\section{pDrive (QIAGEN, Hilden)}

Der pDrive Klonierungsvektor lag in linearisierter Form vor, besaß an den Enden 5'-UÜberhänge und eignete sich somit für die direkte Ligation von PCR-Produkten mit 3’-A-Überhängen, wie sie beispielsweise von der Taq-Polymerase generiert werden. Die integrierten Fragmente können leicht über die flankierende multiple Klonierungsstelle (multiple cloning site; MCS) in andere Vektoren überführt werden. Eine Selektion erlaubt der Vektor sowohl mit Hilfe der AB Ampicillin und Kanamycin, als auch über Blau/Weiß-Selektion.

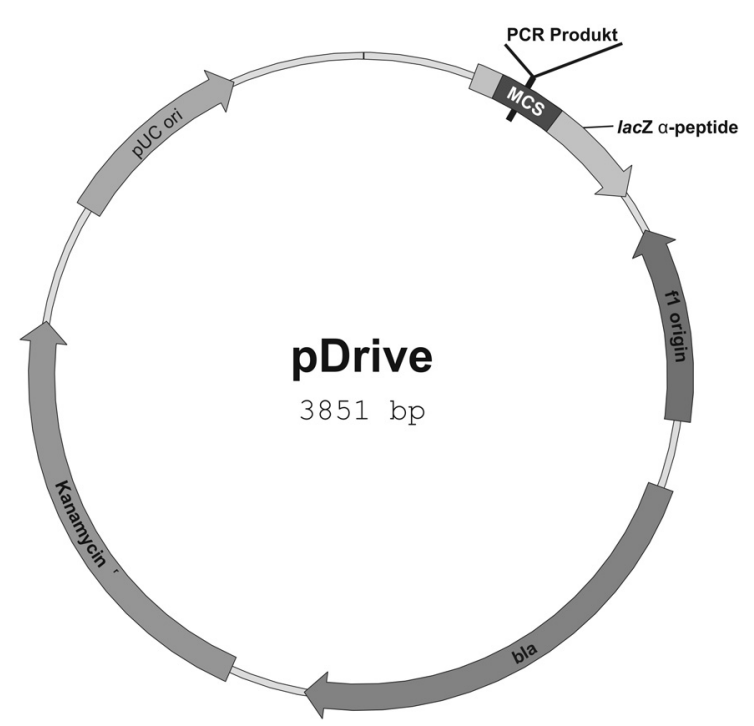

Abb. 6: Graphische Darstellung des Plasmides pDrive (Qiagen, Hilden).

bla: $\beta$-Lactamase (Ampicillinresistenz), Kanamycin ${ }^{\mathrm{r}}$ : Kanamycinresistenz, pUC ori: prokaryotischer Replikationsursprung, lacZ $\alpha$-peptide: $\beta$-Galactosidase, MCS: multiple Klonierungsstelle, PCR-Produkt: Insertionsstelle für PCR-Produkt, f1 origin: Replikationsursprung des f1-Phagens

\section{pDrive-HBVpol (diese Arbeit)}

In den Klonierungsvektor pDrive wurde das HBV Polymerase-Gen über die 3'-AÜberhänge in den linearisiert vorliegenden Vektor einkloniert. Das Gen wurde zuvor mittels PCR aus dem Plasmid pRVHBV1.5 (BRUSs \& GANEM, 1991a) amplifiziert, wobei über die Oligonukleotide (\#424 und \#425) an beiden Enden die 
Restriktionsschnittstelle NruI und eine Kozak-Sequenz (GCC ACC) vor das StartKodon des Polymerase-Gens eingefügt wurde (KozAK, 1986). Durch die flankierenden NruI-Schnittstellen und MCS ist es möglich, das funktionelle Gen in andere Vektoren zu überführen.

\section{pDrive-HBVpol` (diese Arbeit)}

Das Plasmid pDrive-HBVpol- trägt einen Teil des viralen Polymerase-Gens, das mittels PCR-Mutagenese durch einen Basenaustausch an HBV nt 2817 (Polymerase ASPosition 171, TGC [Cys] nach TGA [Stop]) mit einem Stop-Kodon versehen wurde. Dadurch kann nach Insertion dieses Fragments in das HBV-Polymerasegen kein funktionelles Protein mehr exprimiert werden. Das 658 bp große Fragment wurde nach der PCR-Mutagenese über die 3'-A-Überhänge in den linearisierten Vektor pDrive ligiert. Anschließend konnte das Polymerasegen-Fragment über die Restriktionsschnittstellen BspEI und BstEII in genomische HBV Vektoren überführt werden.

\section{pDrive-HBVx- (diese Arbeit)}

In den Klonierungsvektor pDrive-HBVx- wurde ein PCR-Mutagenese-Fragment inseriert, das das X-Gen des HBV trägt. An AS Position 8 im X-Protein wurde durch einen Basenaustausch an HBV nt 1395 das Kodon CAA (Gln) gegen TAA (StopKodon) ausgetauscht, so dass das Gen kein funktionelles Protein exprimieren kann. Das 1817 bp große Fragment wurde nach der Mutagenese-PCR über die 3'-A-Überhänge in den linearisierten Vektor pDrive ligiert. Über die Restriktions-Schnittstellen HpaI und NgoMIV kann das mutationstragende X-Gen in HBV-Vektoren umgesetzt werden.

pEF/Myc-His A (Invitrogen, Karlsruhe)

Das Plasmid pEF1/Myc-His A ist ein 6165 bp großer Vektor, der für die transiente oder stabile Überexpression von rekombinanten Proteinen in eukaryotischen Zellen geeignet ist. Die Gene der Proteine können leicht über die MCS eingesetzt werden. Einfache Detektion und Aufreinigung der Proteine ist durch das in Frame vorhandene myc-Epitop und den C-terminalen Polyhistidin-Anhang gewährleistet. Der humane 
Elongationsfaktor-1 $\alpha$-Promoter reguliert die Expression in einem großen Wirtsspektrum. Als Selektionsmarker in Säugerzellen dient eine Neomycin (Geneticin)Resistenz, während für die Selektion in Prokaryonten ein $\beta$-Laktamase-Gen vorhanden ist.

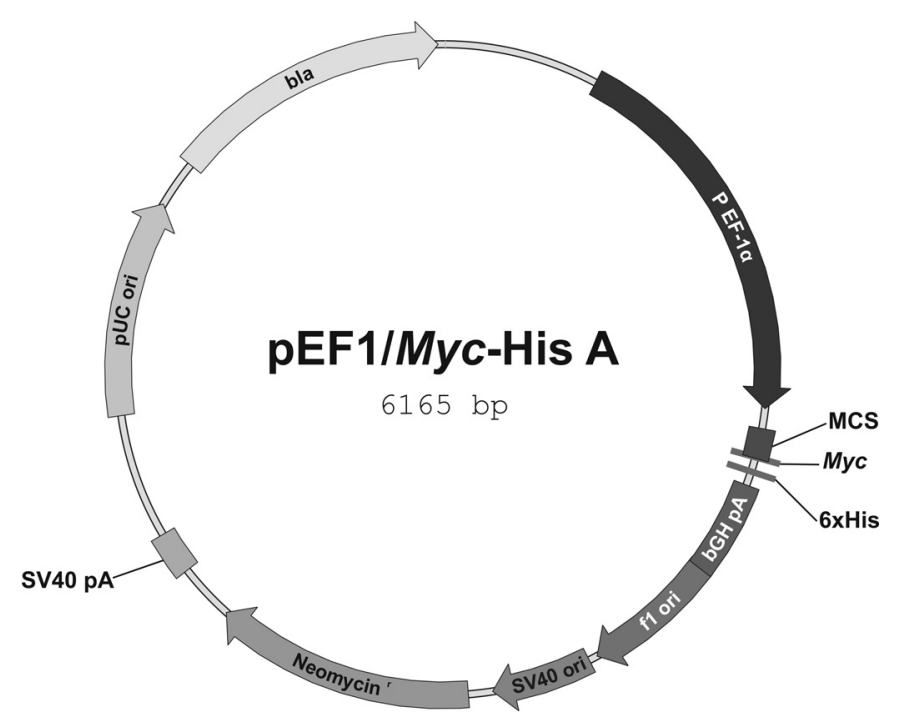

Abb. 7: Graphische Darstellung des Plasmides pEF1/Myc-His A (Invitrogen, Karlsruhe).

PEF-1 $\alpha$ : Promoter des humanen Elongationsfaktor 1 $\alpha$, MCS: multiple Klonierungsstelle, Myc: myc-Epitop, 6xHis: C-terminaler Polyhistidin Anhang, bGH pA: Rinder Wachstumshormon Polyadenylierungssignal (bovine growth hormone polyadenylation signal), f1 ori: Replikationsurspung des f1-Phagens, SV40 ori: SV40 early Promoter und Replikationsursprung, Neomycin ${ }^{\mathrm{r}}$ : Neomycin (Geneticin)-resistenz, SV40 pA: SV40 Polyadenylierungssignal, pUC ori: prokaryotischer Replikationsursprung, bla: $\beta$-Lactamase (Ampicillinresistenz),

pRVHBV1.5 (BRUSS \& GANEM, 1991a)

Eine ca. 1,5-fache Kopie des HBV-Genoms (HBsAg Subtyp adw2; VALENZUELA et al., 1980) wurde über die Restriktionsschnittstellen EcoRV (nt 1041) und BspEI (nt 2327) in den Vektor pBluescript KS(+) (Stratagene, Heidelberg) eingefügt. Das Konstrukt exprimiert und reguliert über die endogenen HBV-Promotoren alle viralen Proteine und das Prägenom. 


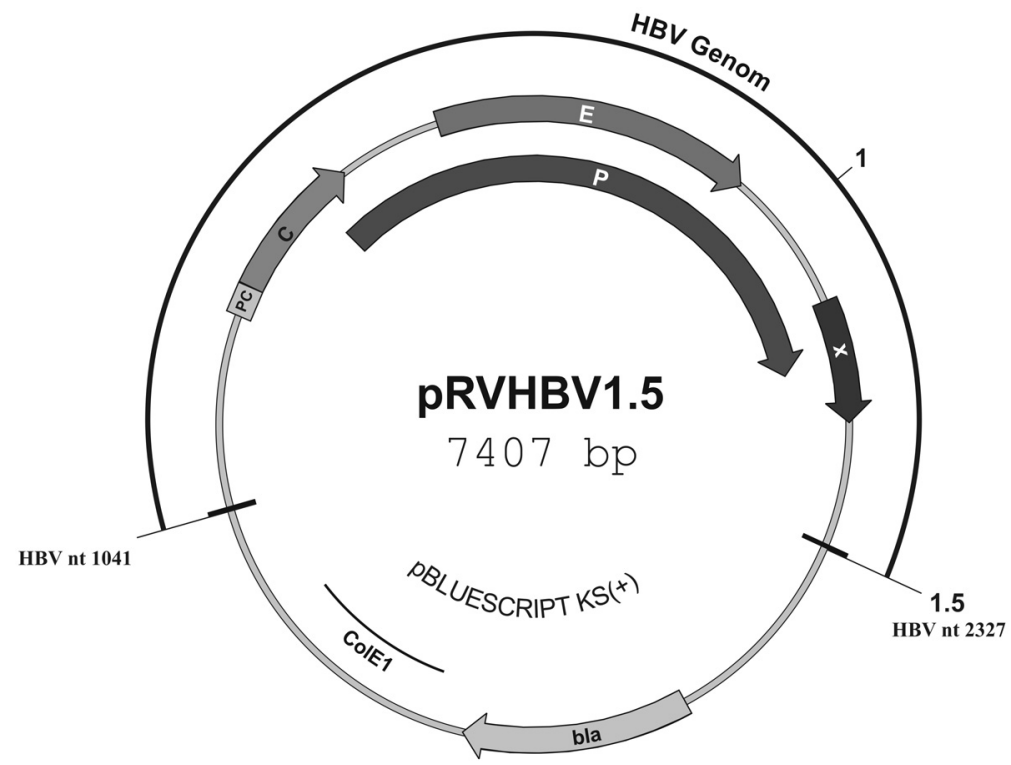

Abb. 8: Graphische Darstellung des Plasmides pRVHBV1.5.

bla: $\beta$-Laktamase (Ampicillinresistenz), ColE1: prokaryotischer Replikationsurspung, PC: Leserahmen des Präcore-Bereichs, C: Leserahmen des Core-Proteins, P: Leserahmen des P-Proteins, E: Leserahmen der Hüllproteine, X: Leserahmen des X-Proteins

pRVHBV1.5core- (KOSCHEL et al., 2000)

Dieses Plasmid ist auf Basis von pRVHBV1.5 generiert worden, in dem ein Nukleotidaustausch an nt 2012 (HBV) vorgenommen wurde. Dabei wurde das Basentriplett TAT (Tyrosin) des Coregens mit TAG (Stopkodon) durch in vitro Mutagenese substitutiert. Somit kann kein funktionelles Core-Protein exprimiert werden, während die anderen HBV Proteine ohne Beeinträchtigung bleiben.

pRVHBV1.5core' ${ }^{-}$(diese Arbeit)

In das Konstrukt pRVHBV1.5core- wurde ein 1687 bp großes Fragment aus dem Plasmid pDrive-HBx-, welches das mit einem Stop-Kodon versehene X-Gen des HBV trägt, über die Restriktionsschnittstellen HpaI und NgoMIV eingefügt. Bis auf das Coreund das X-Protein können von diesem Konstrukt alle HBV-Proteine und das Prägenom exprimiert werden. 
pRVHBV1.5core'x pol $^{-}$(diese Arbeit)

Das Plasmid pRVHBV1.5core`x̄pol- trägt ein HBV-Genom, welches neben dem Prägenom nur noch die viralen Hüllproteine exprimieren kann. Das Plasmid entstand durch die Integration eines 492 bp großen Fragmentes aus pDrive-HBVpol- über die Schnittstellen BstEII und BspEI in den Vektor pRVHBV1.5core ${ }^{-}{ }^{-}$.

pSVHBV1.5 (PONSEL \& BRUSS, 2003)

Das Plasmid pSVHBV1.5 wurde aus dem Plasmid pRVHBV1.5 generiert. Der endogene Core-Promotor der HBV-DNA wurde durch einen SV40-early-Promotor ersetzt, wodurch das Start-Kodon des Präcore-Proteins nicht mehr vorhanden ist. Von diesem Konstrukt werden alle viralen Proteine mit Ausnahme des Präcore-Proteins exprimiert.

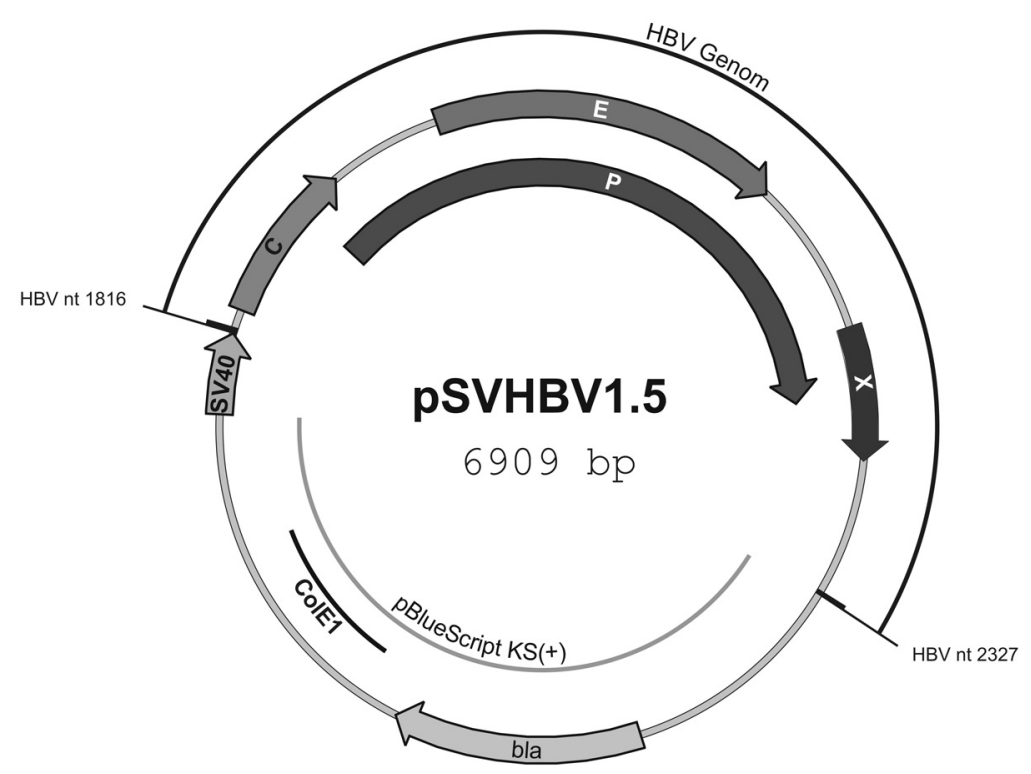

Abb. 9: Graphische Darstellung des Plasmides pSVHBV1.5.

bla: $\beta$-Laktamase (Ampicillinresistenz), ColE1: prokaryotischer Replikationsurspung, SV40: SV40-early-Promoter, C: Leserahmen des Core-Proteins, P: Leserahmen des PProteins, E: Leserahmen der Hüllproteine, X: Leserahmen des X-Proteins 
pSVHBV1.5core- ${ }^{-}$PONSEL \& BRUSS, 2003)

Das Plasmid pSVHBV1.5core` beruht auf dem Plasmid pSVHBV1.5, jedoch wurde das Kodon der Aminosäure Tyr38 (TAT) des Coregens zu einem Stop-Kodon (TAG) mutiert, so dass von diesem Plasmid alle Virusproteine mit Ausnahme des Präcore- und des Core-Proteins exprimiert werden.

\section{pSVHBV1.5pol' (diese Arbeit)}

Das Plasmid pSVHBV1.5pol- wurde durch Insertion eines 492 bp Fragments aus dem Klonierungsvektor pDrive-HBVpol ${ }^{-}$in das Plasmid pSVHBV1.5 generiert. Der Austausch erfolgte über die Restriktionsschnittstellen BspEI und BstEII. Bis auf das PProtein können von diesem Plasmid alle viralen Proteine exprimiert werden.

pSVHBV1.5core'x- pol$^{-}$(diese Arbeit)

Das Plasmid pSVHBV1.5core ${ }^{-}$pol $^{-}$wurde durch Insertion eines 3542 bp großen Fragmentes, welches die $\mathrm{x}^{-}$und $\mathrm{pol}^{-}$Mutationen trägt, aus pRVHBV1.5core ${ }^{-} \mathrm{pol}^{-}$in pSVHBV1.5core` hergestellt. Die Umsetzung erfolgte über die Restriktionsschnittstellen BspEI und NgoMIV.

pSVcore (Koschel et al., 2000)

Das Plasmid pSVcore wurde als transienter Expressionsvektor für das HBV CoreProtein in eukaryotischen Zellen verwendet, wobei das Core-Protein unter Kontrolle des SV40-early-Promoters exprimiert wurde. Bei der Herstellung wurde ein 930 bp großes HBV-Fragment, welches das Coregen trägt, aus dem Plasmid pMKVIII (KOSCHEL et al., 2000) über die Restriktionsschnittstellen BamHI und BstEII in das Plasmid pSVBX24H (BRUSS \& GANEM, 1991a) eingesetzt. In dieses Plasmid wurden mittels PCR-Mutagenese alle in dieser Arbeit generierten Coreprotein-Mutanten inseriert. 


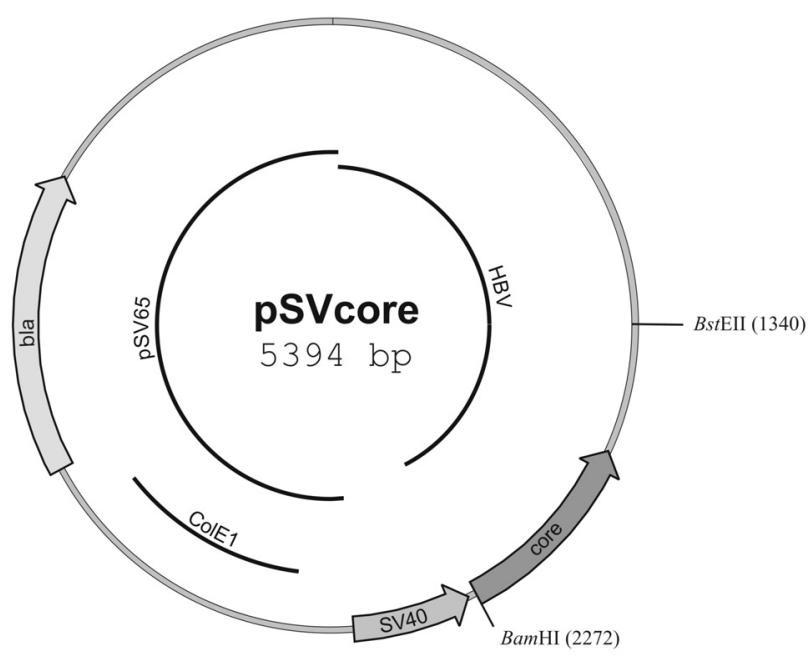

Abb. 10: Graphische Darstellung des Plasmids pSVcore.

bla: $\beta$-Lactamase (Ampicillinresistenz), ColE1: prokaryotischer Replikationsursprung, SV40: SV40-early-Promoter, core: Leserahmen des Coreproteins

pczVSV-G wt (PIETSChMANn et al., 1999)

Das Plasmid pczVSV-G wt ist ein eukaryotischer Vektor für die CMV-Promoter getriebene Expression des Glykoprotein G des vesikulären Stomatitis Virus (VSV). Das Glykoprotein G dient als Hüllprotein bei der Bildung von Viren innerhalb des ,Drei-Plasmid-Expressions-Systems' für die Produktion von MuLV-Retroviren (SONEOKA et al., 1995). Das Glykoprotein G des VSV wurde für diese Arbeit aufgrund seines sehr breiten Wirtsspektrums ausgesucht, so dass eine effiziente Transduktion von HuH7-Zellen gewährleistet sein sollte. 


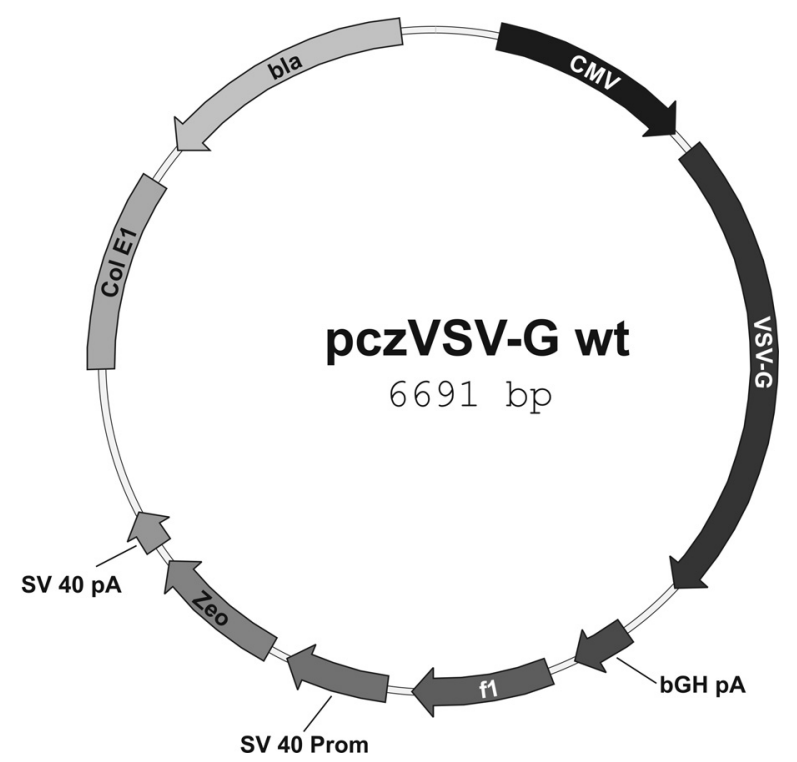

Abb. 11: Graphische Darstellung des Plasmides pczVSV-G wt.

CMV: CMV Promoter, VSV-G: Glykoprotein G des vesikulären Stomatitis Virus, bGH pA: Rinder Wachstumshormon Polyadenylierungssignal (bovine growth hormone polyadenylation signal), f1: Replikationsursprung des f1-Phagens, SV40 Prom: SV40 Promoter, Zeo: Zeocinresistenz, SV40 pA: SV40 Polyadenylierungsstelle, ColE1: prokaryotischer Replikationsursprung, bla: $\beta$-Laktamase (Ampicillinresistenz)

pHIT 60 (SONEOKA et al., 1995)

Das Plasmid pHIT 60 ist ein eukaryotischer Expressionvektor, der unter der Kontrolle des CMV-Promoter das gag- (gruppenspezifisches Antigen) und das pol-Protein (Polymerase) des murinen Leukämie-Virus exprimiert. Beide Proteine werden bei dem ,Drei-Plasmid-Expressions-System’ für die Produktion von MuLV-Retroviren benötigt (SONEOKA et al., 1995). 


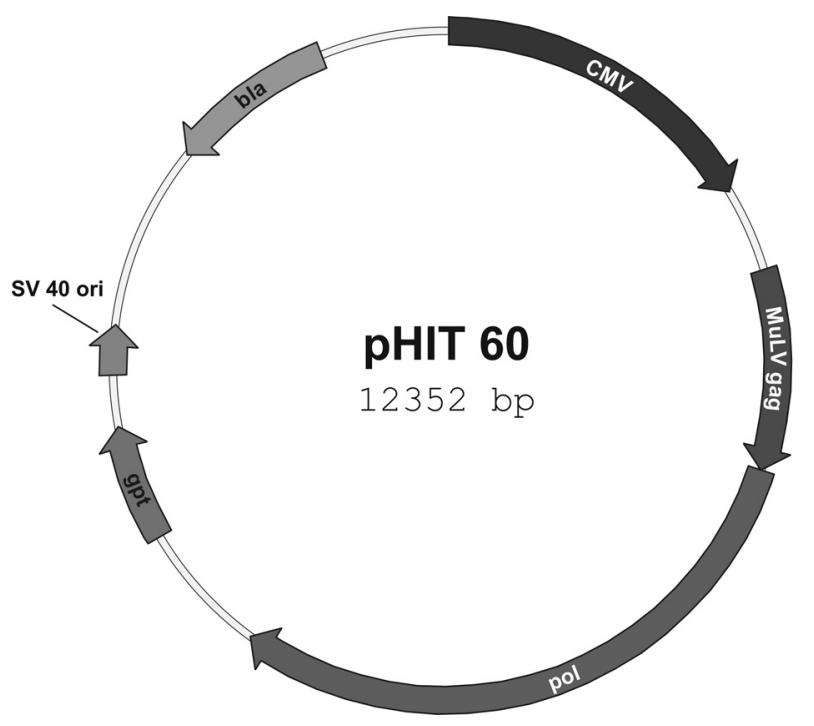

Abb. 12: Graphische Darstellung des Plasmides pHIT 60.

CMV: CMV Promoter, MuLV gag: gruppenspezifisches Antigen des MuLV, pol: MuLV Polymerase, gpt: Xhantin Guanin Phosphoribosyl Transferase, SV40 ori: SV40 Replikationsursprung, bla: $\beta$-Laktamase (Ampicillinresistenz)

pczCFG5 IEGZ (Knödel et al., 1999)

Das Plasmid pczCFG5 IEGZ ist ein retroviraler Vektor für die MuLV getriebene konstitutive Expression eines im Polylinker inserierten Gens unter Kontrolle des CMVPromoters. Die vorhandene interne Ribosom-Eintrittsstelle (internal ribosome entry site; IRES) erlaubt die zusätzliche Expression eines eGFP-Zeocinresistenz (EGZ)Fusionsproteins als Selektionsmarker. Zur Vermehrung in prokaryotischen Zellen besitzt es den ColE1-Replikationsursprung und zur dortigen Selektion einen Ampicillinresistenz-Marker. Werden eukaryotische Zellen (HEK-293T) mit pczCFG5 IEGZ, pczVSV-G wt und pHIT 60 kotransfiziert (SONEOKA et al., 1995), so werden Retroviren produziert, die nach Transduktion und anschließender Integration ins Genom der transduzierten Zellen das EGZ-Fusionsprotein exprimieren. 


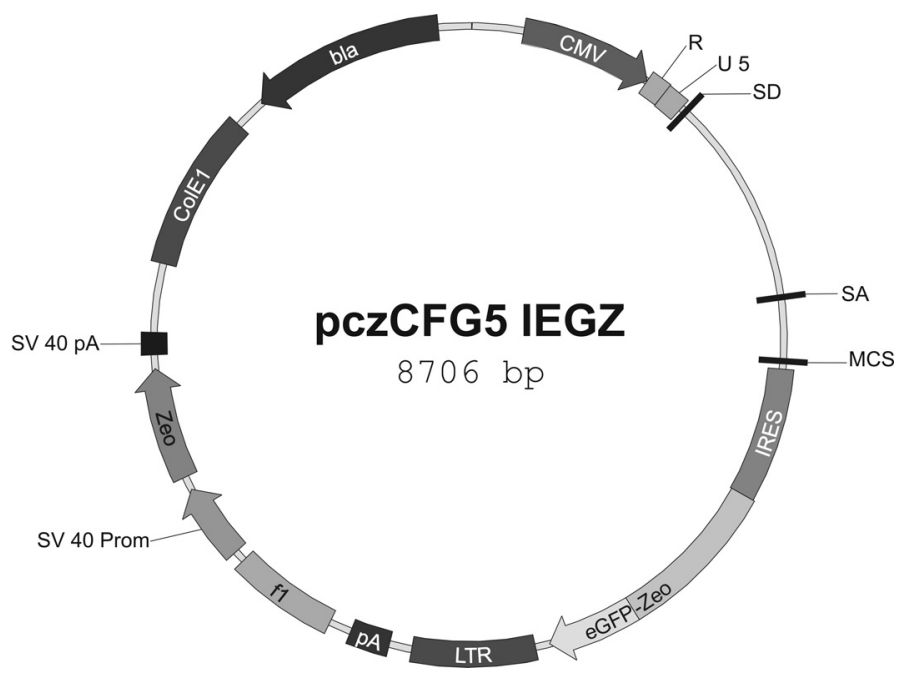

Abb. 13: Graphische Darstellung des Plasmides pczCFG5 IEGZ.

CMV: CMV Promoter, R: 5'-terminale Redundanz, U5: besondere 5' Region, SD: Spleiß Donor, SA: Spleiß Akzeptor, MCS: multiple Klonierungsstelle, IRES: interne RibosomEintrittsstelle, eGFP-Zeo: eGFP-Zeocinresistenz Fusionsprotein, LTR: lange terminale Wiederholung, pA: Polyadenylierungsstelle, f1: Replikationsursprung des f1-Phagens, SV40 Prom: SV40 Promoter, Zeo: Zeocinresistenz, SV40 pA: SV40 Polyadenylierungsstelle, ColE1: prokaryotischer Replikationsursprung, bla: $\beta$-Laktamase (Ampicillinresistenz)

\section{pczCFG5 IEGZ-HBVpol (diese Arbeit)}

Das Plasmid pczCFG5 IEGZ-HBVpol trägt das funktionelle HBV-Polymerase-Gen mit einer zusätzlichen Kozak-Sequenz (GCC ACC) vor dem Startkodon (KozAK, 1986). Integriert wurde das 2556 bp große Fragment über mittels PCR eingeführter NruISchnittstellen und der SwaI-Schnittstelle im Vektor. Nach Generierung von Retroviren, Transduktion von HuH7-Zellen und Integration der retroviralen DNA ins Wirtsgenom wird neben EGZ auch die HBV-Polymerase exprimiert.

pczCFG5 IEGZ-HBVcore ${ }^{\text {WT }}$ (diese Arbeit)

Das Plasmid pczCFG5 IEGZ-HBVcore ${ }^{\mathrm{WT}}$ führt zur Expression des funktionellen HBV Coreproteins. Zur Herstellung wurde ein 706 bp großes Fragment aus pSVcore mit den Restriktions-Enzymen $A p a I$ und BamHI herausgeschnitten und die überhängenden Enden mit Hilfe des Klenow-Fragments aufpolymerisiert. Anschließend erfolgte eine Ligation des Fragments in den mit SwaI linearisierten und mit SAP dephosphorylierten Vektor pczCFG5 IEGZ. Nach Generierung von Retroviren, Transduktion von HuH7- 
Zellen und Integration der retroviralen DNA ins Wirtsgenom wird neben EGZ auch das HBV-Coreprotein exprimiert.

pczCFG5 IEGZ-HBVcore ${ }^{\text {I126A }}$ (diese Arbeit)

Das Plasmid pczCFG5 IEGZ-HBVcore ${ }^{\mathrm{I} 26 \mathrm{~A}}$ exprimiert die HBV Core-Mutante I126A. Die Herstellung erfolgte analog dem Plasmid pczCFG5 IEGZ-HBVcore ${ }^{\mathrm{WT}}$, die Insertion wurde jedoch aus dem Plasmid der Core-Mutante I126A (pSVcore ${ }^{\mathrm{I} 126 \mathrm{~A}}$ ) gewonnen. Nach Generierung von Retroviren, Transduktion von HuH7-Zellen und Integration der retroviralen DNA ins Wirtsgenom wird neben EGZ auch die HBV-Core-Mutante I126A exprimiert.

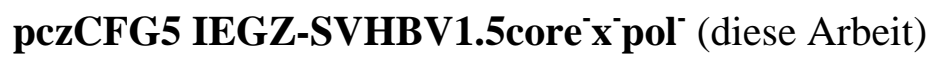

Das Plasmid-Konstrukt pczCFG5 IEGZ-SVHBV1.5core“-”pol- trägt das funktionelle HBV-Genom, welches aber defizient für das Core-Protein, das P-Protein und das XProtein ist. In die dephosphorylierte SwaI-Schnittstelle des Vektors pczCFG5 IEGZ wurde ein mit ClaI und NgoMIV aus dem Plasmid pSVHBV1.5core ${ }^{-}$pol $^{-}$ herausgeschnittenes HBV-Genom Fragment (4344 bp) ligiert. Nach Generierung von Retroviren, Transduktion von HuH7-Zellen und Integration der retroviralen DNA ins Wirtsgenom wird neben EGZ auch das HBV-Genom transkribiert.

pczCFG5 IEGN (KNÖDEL et al., 1999)

Das Plasmid pczCFG5 IEGN entspricht in Funktion und Aufbau dem Plasmid pczCFG5 IEGZ. Jedoch wurde das Gen für das eGFP-Zeocinresistenz-Fusionsprotein gegen ein Gen für das eGFP-Geneticinresistenz-Fusionsprotein (EGN) ausgetauscht. 


\section{pczCFG5 IEGN-HBVpol (diese Arbeit)}

Das Plasmid pczCFG5 IEGN-HBVpol trägt das funktionelle HBV-Polymerasegen. Für die Herstellung des Konstrukts wurde zunächst der Vektor mit SwaI linearisiert und die Enden mit SAP dephosphoryliert. Mittels PCR wurde das P-Proteingen vor dem StartKodon mit Hilfe der Oligonukleotide \#424 und \#425 mit einer Kozak-Sequenz (GCC ACC) (KoZAK, 1986) sowie flankierenden NruI-Schnittstellen versehen. Über diese Schnittstellen wurde das 2556 bp große PCR-Fragment in den linearisierten Vektor ligiert. Nach Generierung von Retroviren, Transduktion von HuH7-Zellen und Integration der retroviralen DNA ins Wirtsgenom wird neben EGN auch die HBVPolymerase exprimiert.

\subsection{Nukleotide}

Nukleotide (dATP, dCTP, dGTP und dTTP; je 100 mM Stammkonzentration) wurden von den Firmen PanBiotech (Aidenbach) und Roche Diagnostics (Mannheim) bezogen. Für den Einsatz in einer PCR (3.4.4.5) wurde eine dNTP-Lösung hergestellt, in der alle vier Nukleotide in $10 \mathrm{mM}$ Konzentration vorlagen. Für eine ,endogene Polymerase Reaktion’ (EPR, 3.4.6.2) wurde eine Lösung mit den drei Nukleotiden dATP, dGTP und dTTP (je $10 \mathrm{mM}$ ) benutzt.

\subsection{Oligonukleotide}

Alle verwendeten Oligonukleotide wurden von den Firmen Sigma-Ark (Darmstadt) oder Purimex (Staufenberg) bezogen und vor dem Gebrauch in der PCR auf eine Konzentration von $10 \mathrm{pmol} / \mu \mathrm{l}$ eingestellt.

Tab. 6: Verwendete Oligonukleotide

\begin{tabular}{l|l|l}
\hline Nummer & Bezeichnung & Sequenz $\left(5^{\prime} \rightarrow 3\right.$ ') \\
\hline$\# 150$ & SV40-Pro & CCCATTCTCCGCCCCATGGC \\
\hline$\# 177$ & sv40 out & TCGGCCTCTGAGCTATTCCA \\
\hline$\# 178$ & core_lo & GATTAAAGATAGGTACTG \\
\hline$\# 216$ & RV PCR rev & GTCCCCAGTCCTCGC \\
\hline$\# 284$ & core_lo & GAAGGAGTTTGCCATTCAGG \\
\hline
\end{tabular}




\begin{tabular}{|c|c|c|}
\hline Nummer & Bezeichnung & Sequenz (5' $\rightarrow$ 3') \\
\hline \#309 & RV PCR for & CATACTCTTTGGAAGGCTGG \\
\hline \#346 & i126v & CGGAGTGTGGGTTCGCACTCCTCC \\
\hline$\# 347$ & $\mathrm{i} 126 \mathrm{l}$ & CGGAGTGTGGCTTCGCACTCCTCC \\
\hline \#348 & $\mathrm{i} 126 \mathrm{~m}$ & CGGAGTGTGGATGCGCACTCCTCC \\
\hline \#349 & i126g & CGGAGTGTGGGGTCGCACTCCTCC \\
\hline$\# 350$ & i126f & CGGAGTGTGGTTTCGCACTCCTCC \\
\hline \#351 & i126y & CGGAGTGTGGTATCGCACTCCTCC \\
\hline \#352 & i126w & CGGAGTGTGGTGGCGCACTCCTCC \\
\hline \#353 & i126p & CGGAGTGTGGCCTCGCACTCCTCC \\
\hline \#354 & $\mathrm{i} 126 \mathrm{~s}$ & CGGAGTGTGGAGTCGCACTCCTCC \\
\hline \#355 & $\mathrm{i} 126 \mathrm{t}$ & CGGAGTGTGGACTCGCACTCCTCC \\
\hline \#356 & i126c & CGGAGTGTGGTGTCGCACTCCTCC \\
\hline \#357 & i126q & CGGAGTGTGGCAGCGCACTCCTCC \\
\hline \#358 & i126n & CGGAGTGTGGAATCGCACTCCTCC \\
\hline \#359 & $\mathrm{r} 127 \mathrm{k}$ & GGAGTGTGGATTAAAACTCCTCCAGC \\
\hline \#360 & r127h & GGAGTGTGGATTCACACTCCTCCAGC \\
\hline \#361 & r127l & GGAGTGTGGATTCTCACTCCTCCAGC \\
\hline \#362 & $\mathrm{r} 127 \mathrm{~g}$ & GGAGTGTGGATTGGCACTCCTCCAGC \\
\hline \#363 & r127d & GGAGTGTGGATTGACACTCCTCCAGC \\
\hline \#364 & $\mathrm{r} 127 \mathrm{~s}$ & GGAGTGTGGATTTCCACTCCTCCAGC \\
\hline \#365 & $195 \mathrm{i}$ & ACTAACATGGGTATAAAGATCAGG \\
\hline \#366 & $195 g$ & ACTAACATGGGTGGAAAGATCAGG \\
\hline \#367 & $195 \mathrm{~s}$ & ACTAACATGGGTTCAAAGATCAGG \\
\hline \#368 & $195 \mathrm{v}$ & ACTAACATGGGTGTAAAGATCAGG \\
\hline \#370 & RT-PCR for & CCTGAATGGCAAACTCCTTCC \\
\hline \#372 & X-Prot for & GGAAGTTGGGGAACTTTGCC \\
\hline \#373 & X-Prot rev & GCACTAAATCGGAACCCTAAAGG \\
\hline \#374 & X-Prot Mut & GCTAGGCTGTACTGCTAACTGGATCC \\
\hline \#376 & s21t & GACGGAAGGAAAGAAGTCAGTAGGCAAAAAGC \\
\hline \#377 & s21g & GACGGAAGGAAAGAAGTCACCAGGCAAAAAGC \\
\hline \#378 & s21i & GACGGAAGGAAAGAAGTCAATAGGCAAAAAGC \\
\hline \#379 & s21h & GACGAAAGGAAAGAAGTCATGAGGCAAAAAGC \\
\hline \#380 & n90d & CAATTATGTTGATACTAACATGG \\
\hline \#381 & n90g & CAATTATGTTGGTACTAACATGG \\
\hline \#382 & n90i & CAATTATGTTATTACTAACATGG \\
\hline \#383 & n90s & CAATTATGTTTCTACTAACATGG \\
\hline \#384 & $\mathrm{d} 22 \mathrm{q}$ & GACGGAAGGAAAGAACTGAGAAGGCAAAAAGC \\
\hline \#385 & d22g & GACGGAAGGAAAGAAGCCAGAAGGCAAAAAGC \\
\hline \#386 & $\mathrm{d} 22 \mathrm{i}$ & GACGGAAGGAAAGAAGATAGAAGGCAAAAAGC \\
\hline \#387 & $\mathrm{d} 22 \mathrm{~h}$ & GACGGAAGGAAAGAAGTGAGAAGGCAAAAAGC \\
\hline \#391 & Pol $^{-}$for & GGTTTAAAGATCAGGCAACTATTGTGG \\
\hline \#392 & Mut Pol${ }^{-}$ & CCAAGAATATGGTGACCCTCAAAATGATGC \\
\hline \#395 & k96h & AACATGGGTTTACACATCAGGCAATTG \\
\hline \#396 & k96r & AACATGGGTTTAAGGATCAGGCAATTG \\
\hline \#397 & k96l & AACATGGGTTTATTGATCAGGCAATTG \\
\hline
\end{tabular}




\begin{tabular}{l|l|l}
\hline Nummer & Bezeichnung & Sequenz (5' $\rightarrow$ 3') \\
\hline$\# 398$ & k96g & AACATGGGTTTAGGGATCAGGCAATTG \\
\hline$\# 399$ & k96s & AACATGGGTTTATCGTACAGGCAATTG \\
\hline$\# 400$ & k96d & ACCATGGGTTTAGACATCAGGCAATTG \\
\hline$\# 401$ & f122g & ATTTGGTCTCTGGCGGAGTGTGG \\
\hline$\# 402$ & f122v & ATTTGGTCTCTGTCGGAGTGTGG \\
\hline$\# 403$ & f122w & ATTTGGTCTCTTGGGGAGTGTGG \\
\hline$\# 405$ & f122s & ATTTGGTCTCTTCCGGAGTGTGG \\
\hline$\# 406$ & f122k & ATTTGGTCTCTAAGGGAGTGTGG \\
\hline$\# 410$ & RT-PCR rev & GATTGGTCTCTTACGGAGTGTGG \\
\hline$\# 412$ & s17t & GGAGTTACTAACCTTTTTGCCTTCTG \\
\hline$\# 413$ & s17g & GGAGTTACTAGGCTTTTTGCCTTCTG \\
\hline$\# 414$ & s17i & GGAGTTACTAATCTTTTTGCCTTCTG \\
\hline$\# 415$ & s17h & GGAGTTACTACACTTTTTGCCTTCTG \\
\hline$\# 416$ & s17d & GGAGTTACTAGACTTTTTGCCTTCTG \\
\hline$\# 417$ & r98h & GGGTTTAAAGATCCACCAATTGTTG \\
\hline$\# 418$ & r98k & GGGTTTAAAGATCAAGCAATTGTTG \\
\hline$\# 419$ & r98d & GGGTTTAAAGATCGACCAATTGTTG \\
\hline$\# 420$ & r98l & GGGTTTAAAGATCCTGCAATTGTTG \\
\hline$\# 421$ & r98q & GGGTTTAAAGATCCAGCAATTGTTG \\
\hline$\# 424$ & P-Start+K+N & GATGTCGCGATACGCCACCATGCCCCTATC \\
\hline$\# 425$ & P-Ende+N & CCTGTCGCGACGTTCACGGTGGTCTC
\end{tabular}

\subsection{Antikörper}

anti-Hepatitis B Core Antigen (HBcAg) (DAKO, Hamburg)

anti-HBc, polyklonales Kaninchen-Serum

anti-Hepatitis B Surface Antigen (HBsAg) (DAKO, Hamburg)

anti-HBs, polyklonales Ziegen-Serum

anti-Hepatitis B Surface Antigen (HBsAg) (Abt. Virologie, Universität Göttingen) anti-HBs, polyklonales Schaf-Serum

anti-Kaninchen, HRPO-konjugiert (Dianova, Hamburg)

anti-Kaninchen-IgG $(\mathrm{H}+\mathrm{L})$, HRPO-markiertes F(ab') $)_{2}$-Fragment, polyklonales Eselserum 


\subsection{DNA-Längenstandards}

Lambda DNA /Eco91I (BstEII) Marker, 15 (MBI Fermentas, St. Leon-Rot) 8454 bp - 7242 bp - 6369 bp - 5686 bp - 4822 bp - 4324 bp - 3675 bp - 2323 bp 1929 bp - 1371 bp - 1264 bp - 701 bp - 244 bp - 117 bp

Generuler $^{\mathrm{TM}} 100$ bp DNA Ladder Plus (MBI Fermentas, St. Leon-Rot) 3000 bp - 2000 bp - 1500 bp - 1200 bp - 1031 bp - 900 bp - 800 bp - 700 bp 600 bp -500 bp -400 bp -300 bp -200 bp - 100 bp

\subsection{Radionuklide}

$\alpha^{32}$ P-dCTP (PerkinElmer LAS, Rodgau-Jügesheim), spez. Aktivität $3000 \mathrm{Ci} / \mathrm{mmol}$ $\alpha^{32} \mathrm{P}$-dCTP (Amersham Buchler, Braunschweig), spez. Aktivität $3000 \mathrm{Ci} / \mathrm{mmol}$

\subsection{Chemikalien}

Sofern nicht anders angegeben, wurden die Chemikalien der Firmen Sigma (Steinheim), Roche Diagnostics (Mannheim), Roth (Karlsruhe), Serva (Heidelberg) und Merck (Darmstadt) verwendet.

Die verwendeten Chemikalien wiesen den Reinheitsgrad ,reinst’ oder ,zur Analyse’ auf. Alle Medien, Puffer und Lösungen wurden mit $\mathrm{H}_{2} \mathrm{O}_{\text {bidest }}$ aus einer Destille oder der Wasseraufbereitungsanlage Seralpur Delta (USF Seral, Ransbach-Baumbach) angesetzt.

Tab. 7: Verwendete Chemikalien

\begin{tabular}{l|l}
\hline Name & Hersteller / Lieferant \\
\hline Acrylamid (2 x) & Serva, Heidelberg \\
\hline Agar & Oxoid, Hampshire, England \\
\hline Agarose & Peqlab, Erlangen \\
\hline
\end{tabular}




\begin{tabular}{|c|c|}
\hline Name & Hersteller / Lieferant \\
\hline Ammoniumacetat & Merck, Darmstadt \\
\hline Ampicillin & Sigma, Steinheim \\
\hline APS (Ammoniumperoxodisulfat) & Roth, Karlsruhe \\
\hline Bacto-Hefeextrakt & Difco, Detroit, USA \\
\hline Bacto-Trypton & Difco, Detroit, USA \\
\hline Bacto-Hefeextrakt & $\begin{array}{l}\text { Becton-Dickinson, Franklin Lakes, } \\
\text { USA }\end{array}$ \\
\hline Bacto-Trypton & $\begin{array}{l}\text { Becton-Dickinson, Franklin Lakes, } \\
\text { USA }\end{array}$ \\
\hline Borat & Merck, Darmstadt \\
\hline Bromphenolblau & Merck, Darmstadt \\
\hline BSA (Rinderserumalbumin) & Paesel \& Lorei, Hanau \\
\hline Calciumchlorid $\left(\mathrm{CaCl}_{2} \cdot 2 \mathrm{H}_{2} \mathrm{O}\right)$ & Sigma, Steinheim \\
\hline Chloroform & Merck, Darmstadt \\
\hline DTT (Dithiotreitol) & Serva, Heidelberg \\
\hline EDTA (Ethylendiamintetraessigsäure) & Paesel \& Lorei, Hanau \\
\hline Entwickler & Kodak, Rochester, USA \\
\hline Essigsäure & Merck, Darmstadt \\
\hline Ethanol & Merck, Darmstadt \\
\hline Ethidiumbromid & Serva, Heidelberg \\
\hline Fixierer & Kodak, New Haven, USA \\
\hline Glukose & Merck, Darmstadt \\
\hline Glycerin (87 \%) & Merck, Darmstadt \\
\hline Harnstoff & Merck, Darmstadt \\
\hline $\begin{array}{l}\text { HEPES (2-[4-(2-Hydroxyethyl-1-piperazinyl]- } \\
\text { ethansulfonsäure) }\end{array}$ & Biochrom, Berlin \\
\hline IPTG (Isopropylthiogalaktosid) & Roche, Mannheim \\
\hline Isopropanol & Merck, Darmstadt \\
\hline $\mathrm{K}_{2} \mathrm{HPO}_{4} \cdot 3 \mathrm{H}_{2} \mathrm{O}$ & Merck, Darmstadt \\
\hline Kalium-Acetat & Merck, Darmstadt \\
\hline $\mathrm{KCl}$ & Merck, Darmstadt \\
\hline $\mathrm{KH}_{2} \mathrm{PO}_{4}$ & Merck, Darmstadt \\
\hline $\mathrm{MnCl}_{2}$ & Merck, Darmstadt \\
\hline
\end{tabular}




\begin{tabular}{|c|c|}
\hline Name & Hersteller / Lieferant \\
\hline Methanol & Merck, Darmstadt \\
\hline $\mathrm{MgCl}_{2} \cdot 6 \mathrm{H}_{2} \mathrm{O}$ & Merck, Darmstadt \\
\hline $\mathrm{MgSO}_{4}$ & Merck, Darmstadt \\
\hline Milchpulver (Sucofina) & Glücksklee, Zeven \\
\hline $\mathrm{MnCl}_{2}$ & Merck, Darmstadt \\
\hline MOPS (3-[N-Morpholino]propansulfonsäure) & Sigma, Steinheim \\
\hline N, N'-Methylenbisacrylamid 2x & Serva, Heidelberg \\
\hline $\mathrm{Na}_{2} \mathrm{HPO}_{4} \cdot 2 \mathrm{H}_{2} \mathrm{O}$ & Merck, Darmstadt \\
\hline $\mathrm{NaCl}$ & Merck, Darmstadt \\
\hline $\mathrm{NaH}_{2} \mathrm{PO}_{4}$ & Merck, Darmstadt \\
\hline $\mathrm{NaOH}$ & Merck, Darmstadt \\
\hline Natriumacetat & Merck, Darmstadt \\
\hline Natriumbutyrat & Merck, Darmstadt \\
\hline Natriumcitrat & Merck, Darmstadt \\
\hline$\left(\mathrm{NH}_{4}\right)_{2} \mathrm{SO}_{4}$ & Merck, Darmstadt \\
\hline Nonidet P 40 & Merck, Darmstadt \\
\hline Polyethylenglykol (PEG) 6000 & Sigma, Steinheim \\
\hline Polyethylenglykol (PEG) 8000 & Sigma, Steinheim \\
\hline Phenol (pH 8,0) & Sigma, Steinheim \\
\hline Phenol-Chloroform-Isoamylalkohol (25:24:1) & Sigma, Steinheim \\
\hline Protein A-Sepharose & Sigma, Steinheim \\
\hline SDS & Serva, Heidelberg \\
\hline TEMED (N,N,N',N',-Tetramethylethylendiamin) & Sigma, Steinheim \\
\hline Tris-Base & Paesel \& Lorei, Hanau \\
\hline Tris-HCl & Paesel \& Lorei, Hanau \\
\hline Triton X-100 & Sigma, Steinheim \\
\hline Universal-Agarose & PeqLab, Erlangen \\
\hline X-Gal (5-Chlor-4-Brom-3-indolyl-D-Galaktosid) & PeqLab, Erlangen \\
\hline Xylencyanol FF & Biorad, Richmond \\
\hline
\end{tabular}




\subsection{Lösungen und Puffer}

Tab. 8: Verwendete Lösungen und Puffer

\begin{tabular}{|c|c|}
\hline Name & Zusammensetzung \\
\hline $\begin{array}{l}\text { CaCl}_{2} \text {-Lösung I } \\
(\mathrm{HuH7})\end{array}$ & $\begin{aligned} 250 \mathrm{mM} & \mathrm{CaCl}_{2} \\
& \text { mit NaOH auf pH 7,1 }\end{aligned}$ \\
\hline $\begin{array}{l}\text { CaCl }_{2} \text {-Lösung II } \\
(\mathrm{HEK}-293 \mathrm{~T})\end{array}$ & $\begin{array}{l}\qquad 2 \mathrm{M} \mathrm{CaCl} \\
\text { Aliquotieren und Lagerung bei }-20^{\circ} \mathrm{C}\end{array}$ \\
\hline COS-Lysispuffer & $\begin{array}{rl}150 \mathrm{mM} & \mathrm{NaCl} \\
50 \mathrm{mM} & \text { Tris/Cl, pH 7,5 } \\
5 \mathrm{mM} & \mathrm{MgCl}_{2} \\
0,2 \%(\mathrm{v} / \mathrm{v}) & \mathrm{NP} 40\end{array}$ \\
\hline $\begin{array}{l}\text { Denaturierungs-Puffer } \\
\text { (Southern Blot) }\end{array}$ & $\begin{array}{ll}0,5 \mathrm{M} & \mathrm{NaOH} \\
1,5 \mathrm{M} & \mathrm{NaCl}\end{array}$ \\
\hline EB-Puffer & $10 \mathrm{mM} \quad$ Tris/Cl, $\mathrm{pH} 8,5$ \\
\hline Ethidiumbromid-Stammlösung & $10 \mathrm{mg} / \mathrm{ml}$ in $\mathrm{H}_{2} \mathrm{O}_{\text {bidest }}$ \\
\hline FACS-Puffer & $\begin{aligned} 1,5 \%(\mathrm{v} / \mathrm{v}) & \text { FKS } \\
0,1 \%(\mathrm{w} / \mathrm{v}) & \text { Natriumazid } \\
& \text { in PBS }\end{aligned}$ \\
\hline $\begin{array}{l}\text { HBS-Puffer I (2x) } \\
\text { (HuH7) }\end{array}$ & $\begin{array}{rl}50 \mathrm{mM} & \text { HEPES } \\
280 \mathrm{mM} & \mathrm{NaCl} \\
1,5 \mathrm{mM} & \mathrm{Na}_{2} \mathrm{HPO}_{4} \\
& \text { mit } \mathrm{NaOH} \text { auf } \mathrm{pH} 7,1\end{array}$ \\
\hline $\begin{array}{l}\text { HBS-Puffer II (2x) } \\
(\text { HEK-293T) }\end{array}$ & $\begin{array}{rl}50 \mathrm{mM} & \text { HEPES } \\
10 \mathrm{mM} & \mathrm{KCl} \\
12 \mathrm{mM} & \text { Glukose } \\
280 \mathrm{mM} & \mathrm{NaCl} \\
1,5 \mathrm{mM} & \mathrm{Na}_{2} \mathrm{HPO}_{4} \\
& \text { mit } \mathrm{HCl} \text { auf } \mathrm{pH} 7,05 \\
\text { Aliquotieren und Lagerung bei }-20^{\circ} \mathrm{C}\end{array}$ \\
\hline inc. Polymerase-Puffer (2x) & $\begin{aligned} 100 \mathrm{mM} & \text { Tris/Cl, pH 7,5 } \\
150 \mathrm{mM} & \mathrm{NH}_{4} \mathrm{Cl} \\
2 \mathrm{mM} & \text { EDTA }\end{aligned}$ \\
\hline
\end{tabular}




\begin{tabular}{|c|c|c|}
\hline Name & Zusammenset & ung \\
\hline $\begin{array}{l}\text { Milchpuffer-Lösung } \\
\text { (Western-Blot) }\end{array}$ & $10 \%(\mathrm{w} / \mathrm{v})$ & $\begin{array}{l}\text { Magermilchpulver in } \\
\text { PT-Waschpuffer }\end{array}$ \\
\hline NaB-Lösung (50x) & $500 \mathrm{mM}$ & $\begin{array}{l}\text { Natriumbutyrat } \\
\text { in PBS }\end{array}$ \\
\hline $\begin{array}{l}\text { Neutralisierungs-Puffer } \\
\text { (Southern Blot) }\end{array}$ & $\begin{array}{l}0.5 \mathrm{M} \\
1,5 \mathrm{M} \\
\end{array}$ & $\begin{array}{l}\text { Tris/Cl, pH 7,5 } \\
\mathrm{NaCl}\end{array}$ \\
\hline PBS & $\begin{array}{r}2,2 \mathrm{mM} \\
8,5 \mathrm{mM} \\
130 \mathrm{mM}\end{array}$ & $\begin{array}{l}\mathrm{KH}_{2} \mathrm{PO}_{4} \\
\mathrm{Na}_{2} \mathrm{HPO}_{4} \\
\mathrm{NaCl}\end{array}$ \\
\hline PBS/NP40-Puffer & $\begin{array}{r}1 \%(\mathrm{v} / \mathrm{v}) \\
0,2 \%(\mathrm{w} / \mathrm{v})\end{array}$ & $\begin{array}{l}\text { NP40 } \\
\text { DTT } \\
\text { in PBS }\end{array}$ \\
\hline PCR-Puffer (10x) & $\begin{array}{r}200 \mathrm{mM} \\
100 \mathrm{mM} \\
100 \mathrm{mM} \\
25 \mathrm{mM} \\
1 \%(\mathrm{v} / \mathrm{v})\end{array}$ & $\begin{array}{l}\text { Tris/Cl, pH 8,8 } \\
\mathrm{KCl} \\
\left(\mathrm{NH}_{4}\right)_{2} \mathrm{SO}_{4} \\
\mathrm{MgSO}_{4} \\
\text { Triton X-100 }\end{array}$ \\
\hline Polybrene (100x) & $40 \mathrm{mg}$ & $\begin{array}{l}\text { Hexadimethrin-Bromid } \\
\text { in } 50 \mathrm{ml} \text { PBS }\end{array}$ \\
\hline $\begin{array}{l}\text { PP-Lösung I } \\
\text { (Plasmidpräparation) }\end{array}$ & $\begin{array}{l}50 \mathrm{mM} \\
25 \mathrm{mM} \\
10 \mathrm{mM}\end{array}$ & $\begin{array}{l}\text { Glukose } \\
\text { Tris/Cl, pH 8,0 } \\
\text { EDTA }\end{array}$ \\
\hline $\begin{array}{l}\text { PP-Lösung II } \\
\text { (Plasmidpräparation) }\end{array}$ & $\begin{array}{r}0,2 \mathrm{M} \\
1 \%(\mathrm{w} / \mathrm{v})\end{array}$ & $\begin{array}{l}\mathrm{NaOH} \\
\mathrm{SDS}\end{array}$ \\
\hline $\begin{array}{l}\text { PP-Lösung III } \\
\text { (Plasmidpräparation) }\end{array}$ & $\begin{array}{l}3 \mathrm{M} \\
5 \mathrm{M}\end{array}$ & $\begin{array}{l}\mathrm{K}^{+} \\
\text {Acetat }^{-}, \text {mit Eisessig auf } \mathrm{pH} \text { 5,5 }\end{array}$ \\
\hline $\begin{array}{l}\text { PP-Lösung IV } \\
\text { (Plasmidpräparation) }\end{array}$ & $\begin{array}{r}13 \%(\mathrm{w} / \mathrm{v}) \\
1,6 \mathrm{M}\end{array}$ & $\begin{array}{l}\text { PEG } 6000 \\
\mathrm{NaCl}\end{array}$ \\
\hline $\begin{array}{l}\text { Probenauftragspuffer I (1x) } \\
\text { (DNA) }\end{array}$ & $\begin{array}{l}5 \text { Teile } \\
1 \text { Teil }\end{array}$ & $\begin{array}{l}\text { TE-Puffer } \\
\text { Probenauftragspuffer I (6x) }\end{array}$ \\
\hline
\end{tabular}




\begin{tabular}{|c|c|c|}
\hline Name & Zusammenset & ung \\
\hline Probenauftragspuffer I (6x) & $10 \mathrm{mM}$ & Tris/Cl, pH 7,6 \\
\hline (DNA) & $0,03 \%(\mathrm{w} / \mathrm{v})$ & Bromphenolblau \\
\hline & $0,03 \%(\mathrm{w} / \mathrm{v})$ & Xylencyanol FF \\
\hline & $60 \%(\mathrm{v} / \mathrm{v})$ & Glycerin (87 \%) \\
\hline & $60 \mathrm{mM}$ & EDTA \\
\hline Probenauftragspuffer II (6x) & $10 \mathrm{mM}$ & Tris/Cl, pH 7,6 \\
\hline (Western Blot) & $0,03 \%(\mathrm{w} / \mathrm{v})$ & Bromphenolblau \\
\hline & $0,03 \%(w / v)$ & Xylencyanol FF \\
\hline & $60 \%(\mathrm{v} / \mathrm{v})$ & Glycerin (87 \%) \\
\hline Proteinase K-Puffer (2x) & $20 \mathrm{mM}$ & Tris/Cl, pH 7,5 \\
\hline & $20 \mathrm{mM}$ & EDTA \\
\hline & $2 \%(\mathrm{w} / \mathrm{v})$ & SDS \\
\hline PT-Waschpuffer & $0,1 \%(\mathrm{v} / \mathrm{v})$ & Tween 20 \\
\hline (Western Blot) & & in PBS \\
\hline SSC-Puffer (20x) & $3 \mathrm{M}$ & $\mathrm{NaCl}$ \\
\hline & $300 \mathrm{mM}$ & Natrium-Citrat \\
\hline & & mit $\mathrm{NaOH}$ auf $\mathrm{pH} 7,0$ \\
\hline Stoppbad & $5 \%(v / v)$ & Essigsäure \\
\hline (Röntgenfilmentwicklung) & & in $\mathrm{H}_{2} \mathrm{O}_{\text {bidest }}$ \\
\hline TAE-Puffer (50x) & $2 \mathrm{M}$ & Tris-Acetat, $\mathrm{pH}$ 7,8 \\
\hline & $50 \mathrm{mM}$ & EDTA \\
\hline TBE-Puffer (10x) & $900 \mathrm{mM}$ & Tris \\
\hline & $900 \mathrm{mM}$ & Borat \\
\hline & $20 \mathrm{mM}$ & EDTA \\
\hline TE-Puffer & $10 \mathrm{mM}$ & Tris/Cl, pH 8,0 \\
\hline & $1 \mathrm{mM}$ & EDTA \\
\hline TE/RNase-Lösung & $10 \mathrm{mM}$ & Tris/Cl, pH 8,0 \\
\hline & $1 \mathrm{mM}$ & EDTA \\
\hline & $50 \mu \mathrm{g} / \mathrm{ml}$ & RNase A \\
\hline TNE-Puffer & $100 \mathrm{mM}$ & $\mathrm{NaCl}$ \\
\hline & $0,1 \mathrm{mM}$ & EDTA \\
\hline & $10 \mathrm{mM}$ & Tris/Cl, pH 8,0 \\
\hline
\end{tabular}




\begin{tabular}{|c|c|c|}
\hline Name & Zusammenset & ung \\
\hline $\begin{array}{l}\text { Transformationspuffer I } \\
\text { (TFB I) }\end{array}$ & $\begin{array}{r}30 \mathrm{mM} \\
100 \mathrm{mM} \\
10 \mathrm{mM} \\
50 \mathrm{mM} \\
15 \%(\mathrm{v} / \mathrm{v})\end{array}$ & $\begin{array}{l}\text { Kaliumacetat } \\
\mathrm{KCl} \\
\mathrm{CaCl}_{2} \\
\mathrm{MnCl}_{2} \\
\text { Glycerin } \\
\text { mit Essigsäure auf pH 5,8 }\end{array}$ \\
\hline $\begin{array}{l}\text { Transformationspuffer II } \\
\text { (TFB II) }\end{array}$ & $\begin{array}{r}10 \mathrm{mM} \\
75 \mathrm{mM} \\
10 \mathrm{mM} \\
15 \%(\mathrm{v} / \mathrm{v})\end{array}$ & $\begin{array}{l}\text { MOPS } \\
\mathrm{CaCl}_{2} \\
\mathrm{KCl} \\
\text { Glycerin }\end{array}$ \\
\hline $\begin{array}{l}\text { Waschpuffer A } \\
\text { (Southern Blot) }\end{array}$ & $\begin{array}{r}2 \mathrm{M} \\
0,1 \%(\mathrm{w} / \mathrm{v}) \\
50 \mathrm{mM} \\
150 \mathrm{mM} \\
10 \mathrm{mM} \\
0,2 \%(\mathrm{w} / \mathrm{v})\end{array}$ & $\begin{array}{l}\text { Harnstoff } \\
\mathrm{SDS} \\
\mathrm{NaH}_{2} \mathrm{PO}_{4}, \mathrm{pH} 7,0 \\
\mathrm{NaCl} \\
\mathrm{MgCl}_{2} \\
\text { Blocking Reagenz, aus ,AlkPhos } \\
\text { Direct Labelling Reagents'-Kit }\end{array}$ \\
\hline $\begin{array}{l}\text { Waschpuffer B } \\
\text { (Southern Blot) }\end{array}$ & $\begin{array}{r}50 \mathrm{mM} \\
100 \mathrm{mM} \\
2 \mathrm{mM}\end{array}$ & $\begin{array}{l}\text { Tris/Cl, pH 10,0 } \\
\mathrm{NaCl} \\
\mathrm{MgCl}_{2}\end{array}$ \\
\hline
\end{tabular}

\subsection{Kommerzielle Kits}

Tab. 9: Verwendete kommerzielle Kits

\begin{tabular}{l|l}
\hline Name & Hersteller \\
\hline $\begin{array}{l}\text { AlkPhos Direct Labelling Reagents mit } \\
\text { CDP-Star Detection Reagents }\end{array}$ & Amersham Biosciences, Freiburg \\
\hline Deoxyribonuklease I AMP-D1 Kit & Sigma, Steinheim \\
\hline ECL Western Blotting Detection Reagents & Amersham Biosciences, Freiburg \\
\hline NucleoBond PC 500 & Macherey \& Nagel, Düren \\
\hline OneStep RT-PCR Kit & QIAGEN, Hilden \\
\hline
\end{tabular}




\begin{tabular}{l|l}
\hline Name & Hersteller \\
\hline PCR Cloning Kit & QIAGEN, Hilden \\
\hline $\begin{array}{l}\text { Prism Ready Reaction DyeDeoxy Terminator } \\
\text { Cycle Sequencing Kit }\end{array}$ & Applied Biosystems, Weiterstadt \\
\hline QIAGEN Plasmid Maxi Kit & QIAGEN, Hilden \\
\hline QIAprep Spin Miniprep Kit & QIAGEN, Hilden \\
\hline QIAquick Gel Extraction Kit & QIAGEN, Hilden \\
\hline
\end{tabular}

\subsection{Laborgeräte}

Tab. 10: Verwendete Laborgeräte

\begin{tabular}{l|l}
\hline Name & Hersteller \\
\hline Autoradiographie-Film BIOMAX MR & Kodak, New Haven, USA \\
\hline Brutschrank CO -Auto-Zero, Hera Cell 240 & Heraeus, Hanau \\
\hline Destille Seralpur Delta UV/UF & USF Seral, Ransbach-Baumsbach \\
\hline Elektroblot-Kammer & Biorad, München \\
\hline BioPhotometer & Eppendorf, Hamburg \\
\hline FACS Epics XL-MCL & Coulter, Krefeld \\
\hline Feinwaage Handy & Sartorius, Göttingen \\
\hline Geldokumentation: Gel Jet Imager 2000 & INTAS, Göttingen \\
\hline Gelkassette & Biorad, München \\
\hline Geltrockner & Biotec Fischer, Reiskirchen \\
\hline Grobwaage Universal & Sartorius, Göttingen \\
\hline Heiz-Wasserbad & GFL, Burgwedel \\
\hline Hochvakuumpumpe & Leybold Heraeus, Osterode \\
\hline Hoefer UVC500 Ultraviolet Crosslinker & Amersham Biosciences, Freiburg \\
\hline Horizontalschüttler GFL 3016 & GFL, Burgwedel \\
\hline Hybridisierungsofen & Hybaid, Heidelberg \\
\hline Kodak-Screen & Biorad, München \\
\hline Kühlfalle & Leybold Heraeus, Osterode \\
\hline Kühlzentrifuge 5402 & Eppendorf, Hamburg \\
\hline Kühlzentrifuge RC 26 plus & Sorvall, Bad Homburg \\
\hline
\end{tabular}




\begin{tabular}{|c|c|}
\hline Name & Hersteller \\
\hline Kühlzentrifuge Rotina 35R & Hettich, Tuttlingen \\
\hline Kühlzentrifuge Sigma 2MK & Schütt Labortechnik, Göttingen \\
\hline Kühlzentrifuge Universal 30RF & Hettich, Tuttlingen \\
\hline Laufkammer für Agarosegelelektrophoresen & Eigenbau, Abt. Virologie \\
\hline Magnetrührer & IKA Schütt, Göttingen \\
\hline Mikroskop Leica DMR & Leica, Wetzlar \\
\hline Mikroskop Zeiss Axiovert 10 & Carl Zeiss Jena, Jena \\
\hline Mikrowelle Micromat & AEG, Nürnberg \\
\hline Neubauer-Zählkammer & Carl Zeiss Jena, Jena \\
\hline pH-Meter Mettler Toledo MP225 & Mettler, Schwerzenbach, CH \\
\hline Phosphoimager Molecular Imager FX & Biorad, München \\
\hline Probenmischer (Vortexgerät) & Bender und Hobein, $\mathrm{CH}$ \\
\hline Refraktometer & Carl Zeiss Jena, Jena \\
\hline Rotor SA 300 & Sorvall, Bad Homburg \\
\hline Rotor SLA-3000 & Sorvall, Bad Homburg \\
\hline Schüttelinkubator Certomat U mit Certomat H & B. Braun, Melsungen \\
\hline Sequenziergerät ABI 373 A DNA-Sequencer & Applied Biosystems, Weiterstadt \\
\hline Spannungsgerät E883 & Peqlab, Erlangen \\
\hline Spektralphotometer DU70 & Beckman, München \\
\hline Sterilbank HERAsafe & Heraeus, Hanau \\
\hline Thermoblock Thriller & PEQLAB, Erlangen \\
\hline Thermo-Cycler GeneAmp PCR System 9600 & Perkin Elmer, Norwalk, USA \\
\hline $\begin{array}{l}\text { Thermo-Wasserbad Frigomix } 1495 \\
\text { mit Thermix } 141\end{array}$ & B. Braun, Melsungen \\
\hline Tischinkubator & Eppendorf, Hamburg \\
\hline Tischzentrifuge C5415 & Eppendorf, Hamburg \\
\hline Überkopfroller, Test-Tube Rotator & Snijders, Tilburg, NL \\
\hline Ultrazentrifugenrotor $70.1 \mathrm{Ti}$ & Beckman, München \\
\hline Ultrazentrifugenrotor SW41 & Sorvall, Bad Homburg \\
\hline Vertikalelektrophorese-System & Hofer Sci, Ins., Heidelberg \\
\hline XL-70 Ultracentrifuge & Beckman, München \\
\hline
\end{tabular}




\subsection{Verbrauchsmaterialien}

Tab. 11: Verwendete Verbrauchsmaterialien

\begin{tabular}{|c|c|}
\hline Name & Hersteller / Lieferant \\
\hline Bottle Top Filter, $150 \mathrm{ml}, 0,45 \mu \mathrm{m}$ & Corning Inc., Corning NY, USA \\
\hline Bottle Top Filter, $500 \mathrm{ml}, 0,45 \mu \mathrm{m}$ & Corning Inc., Corning NY, USA \\
\hline Gel-Blotting-Papier GB002, 0,37 mm & $\begin{array}{l}\text { Schleicher \& Schuell Biosciences, } \\
\text { Dassel }\end{array}$ \\
\hline $\begin{array}{l}\text { Hybond-N+ (positive geladene Nylon Transfer } \\
\text { Membran), Porengröße } 0,45 \mu \mathrm{m}\end{array}$ & Amersham Biosciences, Freiburg \\
\hline Hybridisierungsbeutel & $\begin{array}{l}\text { GIBCO BRL (Invitrogen Corp.), } \\
\text { England }\end{array}$ \\
\hline Kodak BioMax MR Film, MR-1 & Sigma-Aldrich, Steinheim \\
\hline $\begin{array}{l}\text { Protran BA } 85 \text { (Nitrozellulose Transfer } \\
\text { Membran), Porengröße 0,45 } \mu \mathrm{m}\end{array}$ & $\begin{array}{l}\text { Schleicher \& Schuell Biosciences, } \\
\text { Dassel }\end{array}$ \\
\hline Syringe Filter $26 \mathrm{~mm}, 0,20 \mu \mathrm{m}$ & Corning Inc., Corning NY, USA \\
\hline Syringe Filter $26 \mathrm{~mm}, 0,45 \mu \mathrm{m}$ & Corning Inc., Corning NY, USA \\
\hline $\begin{array}{l}\text { Ultrazentrifugenröhrchen Quick-Seal Centrifuge } \\
\text { Tubes (16 x } 76 \text { mm) }\end{array}$ & Beckman, München \\
\hline $\begin{array}{l}\text { Zellkulturschalen, } 100 \text { mm x } 20 \text { mm, } \\
\text { Corning } 100 \text { mm TC-Treated Culture Dish }\end{array}$ & Corning Inc., Corning NY, USA \\
\hline Zellkulturschalen, 12 Well Cell Cultur Cluster & Corning Inc., Corning NY, USA \\
\hline Zellkulturschalen, 24 Well Cell Cultur Cluster & Corning Inc., Corning NY, USA \\
\hline Zellkulturschalen, 48 Well Cell Cultur Cluster & Corning Inc., Corning NY, USA \\
\hline $\begin{array}{l}\text { Zellkulturschalen, } 6 \text { x } 35 \text { mm x } 20 \text { mm, } \\
\text { Costar } 6 \text { well TC-Treated Microplates }\end{array}$ & Corning Inc., Corning NY, USA \\
\hline $\begin{array}{l}\text { Zellkulturschalen, } 60 \text { mm x } 20 \text { mm, } \\
\text { Corning } 60 \text { mm TC-Treated Culture Dish }\end{array}$ & Corning Inc., Corning NY, USA \\
\hline Zellkulturschalen, 96 Well Cell Cultur Cluster & Corning Inc., Corning NY, USA \\
\hline
\end{tabular}




\section{Methoden}

\subsection{Vorbehandlung von Puffern, Lösungen und Materialien}

Hitzestabile Puffer und Lösungen wurden vor Gebrauch bei $121^{\circ} \mathrm{C}$ und ca. $2100 \mathrm{mbar}$ für 20 min. autoklaviert. Handelte es sich um hitzelabile Komponenten von Lösungen oder Puffern, so wurden konzentrierte Stammlösungen zubereitet, die durch einen 0,2 $\mu \mathrm{m}$ Membranfilter (2.15) sterilfiltriert und erst nach dem Autoklavieren der übrigen Lösung zugegeben wurden. Hitzeempfindliche Materialien und Geräte wurden vor Benutzung sorgfältig mit 70 \% (v/v) Ethanol gereinigt und getrocknet.

\subsection{Mikrobiologische Methoden}

\subsubsection{Kultur und Umgang mit Bakterien}

\subsubsection{Anzucht von Escherichia coli-Bakterien}

Die in dieser Arbeit verwendeten Escherichia coli-Stämme (E.coli) DH5 $\alpha$ und TOP10F' (2.1) wurden bei $37^{\circ} \mathrm{C}$ und ausreichender Luftzufuhr entweder im Brutraum (Agarplatten) oder im Schüttelinkubator bei 110 - 150 rpm (Flüssigmedien) bebrütet. Für die Anzucht von Flüssigkulturen wurden je nach Bedarf Reagenzglasröhrchen (bis $5 \mathrm{ml}$ Kulturvolumen) oder Erlenmeyerkolben mit Schikanen (30, 50 oder $100 \mathrm{ml}$ Kulturvolumen) verwendet. Bei Bakterien mit plasmidkodierten Resistenzgenen wurden LB-Agarplatten und LB- bzw. TB-Flüssigmedien (2.3.1) mit einer AmpicillinSupplementation von $100 \mu \mathrm{g} / \mathrm{ml}$ verwendet.

\subsubsection{Bestimmung der relativen Zelldichte}

Die Bestimmung der relativen Zelldichte erfolgte indirekt durch Vermessen der optischen Dichte einer Flüssigkultur bei $600 \mathrm{~nm}$ im Photometer (DU70 
Spektralphotometer, Beckman, München oder Biophotometer, Eppendorf, Hamburg). Die Kultur musste vorher mit Flüssigmedium mindestens bis zu einer $\mathrm{OD}_{600}$ von 1 verdünnt werden.

\subsubsection{Dauerkultur und Stammhaltung}

Zur längerfristigen Lagerung von E.coli-Kulturen wurde eine sich in der logarithmischen Wachstums-Phase befindende Schüttelkultur 1:1 (v/v) mit sterilem Glycerin vermischt und bei $-20^{\circ} \mathrm{C}$ gelagert. Für die kurzfristige Aufbewahrung wurden Agarplatten verwendet, die mit Hilfe von Parafilm von der Luftzufuhr abgeschnitten und anschließend bei $4^{\circ} \mathrm{C}$ gelagert wurden.

\subsubsection{Herstellung kompetenter E. coli-Bakterien}

Eine Bakterien-Zelle, die in der Lage ist, ein DNA-Molekül aufzunehmen und transformiert zu werden, wird als kompetent bezeichnet. Den kompetenten Zustand erreichen die Bakterien, wenn sie mit einer hohen Konzentration an Kalziumionen behandelt und anschließend kalt gelagert werden (HANAHAN et al., 1983).

Aus einer E. coli-Übernachtkultur wurden $100 \mathrm{ml}$ LB-Medium angeimpft und bei $37^{\circ} \mathrm{C}$ und 110 rpm auf dem Schüttler (Certomat U/H, B. Braun, Melsungen) inkubiert. Nach dem Erreichen einer $\mathrm{OD}_{600}$ von 0,4 wurde die Kultur kurz auf Eis inkubiert und anschließend für $5 \mathrm{~min}$. bei $3.000 \mathrm{rpm}$ und $4^{\circ} \mathrm{C}$ (Rotina 35R, Hettich, Tuttlingen) abzentrifugiert. Das entstandene Zellpellet wurde in $40 \mathrm{ml}$ sterilem, eiskaltem Transformations-Puffer I (2.12) resuspendiert und für 40 min. auf Eis inkubiert. Nach erneuter fünfminütiger Zentrifugation bei $3.000 \mathrm{rpm}$ und $4^{\circ} \mathrm{C}$ wurde das Pellet in $4 \mathrm{ml}$ sterilem, eiskaltem Transformations-Puffer II (2.12) aufgenommen. Die Zellsuspension wurde in vorgekühlte Eppendorf-Reaktionsgefäße aliquotiert (jeweils 70 - $100 \mu \mathrm{l}$ ) und sofort in flüssigen Stickstoff schockgefroren. Die Lagerung bis zur Transformation erfolgte bei $-80^{\circ} \mathrm{C}$. 


\subsubsection{Transformation kompetenter E. coli-Bakterien durch Hitzschock}

Für eine Transformation wurden $70-100 \mu$ l kompetente Bakterienzellen auf Eis aufgetaut. Nach Zugabe der Plasmid-DNA (10 pg - 1 ng) oder eines Ligationsansatzes (5 - $20 \mu \mathrm{l}$ ) wurden die Zellen mit der DNA vorsichtig vermengt und für $30 \mathrm{~min}$. im Eis inkubiert. Danach wurde der Ansatz für 60 sec. bei $42^{\circ} \mathrm{C}$ und anschließend nochmals für 2 min. auf Eis inkubiert. Nach der Zugabe von $200 \mu$ l SOC-Medium (2.3.1) wurde der Transformationsansatz für $1 \mathrm{~h}$ bei $37^{\circ} \mathrm{C}$ inkubiert, bevor der komplette Ansatz auf $\mathrm{LB}_{\mathrm{amp}}$-Platten bzw. auf $\mathrm{LB}_{\mathrm{amp}}$-X-Gal-IPTG-Platten (für die Blau/Weiß-Selektion) ausplattiert wurde. Die Bebrütung erfolgte über Nacht (üN) bei $37^{\circ} \mathrm{C}$.

\subsection{Zellkulturtechniken}

Alle Arbeiten wurden unter der Sterilbank (HERAsafe, Heraeus, Hanau) durchgeführt. Zur Kultivierung der adhärent wachsenden Zelllinien wurden beschichtete Zellkulturschalen (Corning Inc., USA) verwendet.

\subsubsection{Kultivierung von eukaryotischen Zellen}

Die adhärent wachsenden, eukaryotischen Zelllinien HEK-293T und HuH7 (2.2) wurden im Brutschrank (Hera Cell 240, Heraeus, Hanau) bei $37^{\circ} \mathrm{C}, 5 \% \mathrm{CO}_{2}$ und wasserdampfgesättigter Atmosphäre, wenn nicht anders angegeben, in $10 \mathrm{~cm}$ Schalen (Corning Inc., USA) kultiviert. Für das Umsetzen, Transfizieren und Waschen der Zellen wurden stets auf $37^{\circ} \mathrm{C}$ temperierte Lösungen (2.3.2) verwendet.

Die Zellen wurden, wenn nicht anders angegeben, alle 2 - 3 Tage passagiert. Dazu wurde der Zellkulturüberstand verworfen und die Zellen mit $10 \mathrm{ml}$ PBS gewaschen. Nach Zugabe von 1,5 ml Trypsin/EDTA und kurzer Einwirkphase wurde die Trypsin/EDTA-Lösung wieder entfernt. Bei kleineren Zellkulturschalen wurde entsprechend weniger Trypsin/EDTA-Lösung verwendet. Anschließend wurden die Zellen durch Zugabe von DMEM und durch mehrmaliges Auf- und Abpipettieren 
suspensiert. Es wurden je nach Zelldichte und Zelllinie zwischen 1/6 und 1/10 der Zellen in eine frische Schale gegeben und mit Medium auf $10 \mathrm{ml}$ Volumen aufgefüllt.

\subsubsection{Einfrieren und Auftauen von eukaryotischen Zellen}

Um Zelllinien längerfristig lagern zu können, wurden sie in flüssigem Stickstoff aufbewahrt. Hierzu wurden 1 x $10^{6}$ Zellen in mit $10 \%$ DMSO supplimiertem DMEM resuspendiert und in Einfrierröhrchen aliquotiert. Daran anschließend erfolgte eine kurze Lagerung der Zellen auf Eis, dann für $2 \mathrm{~h}$ bei $-20^{\circ} \mathrm{C}$ und letztlich über Nacht bei $-70^{\circ} \mathrm{C}$, bevor sie in Tanks mit flüssigem Stickstoff überführt wurden.

Bei der Rekultivierung der eingefrorenen Zellen wurden diese zunächst langsam auf Eis aufgetaut und anschließend mit $10 \mathrm{ml}$ DMEM sehr langsam ausverdünnt. Das für die Zellen schädliche DMSO wurde durch einen Zentrifugationsschritt (2 min., 1.000 rpm) entfernt und das Zellpellet in $12 \mathrm{ml}$ Medium vorsichtig resuspendiert. Die komplette Suspension wurde letztlich zur Kultivierung in eine $10 \mathrm{~cm}$ Schale überführt.

\subsubsection{Zellzahlbestimmung}

Die Zellzahlbestimmung erfolgte mit Hilfe einer Neubauer-Zählkammer (Zeiss, Jena). Ein Tropfen der auszuzählenden Zellsuspension wurde in die Gitternetzkammer gegeben, die ein definiertes Volumen besitzt. Die durchschnittliche Anzahl an Zellen innerhalb von 16 ,B-Quadraten' (Fläche: 0,0625 mm²; Volumen: 6,25 x 10-6 ml), multipliziert mit dem Kammerfaktor 1,6 x 105 , ergibt die Anzahl der Zellen pro ml.

\subsubsection{Transfektion von eukaryotischen Zellen}

Eukaryotische Zellen können unter bestimmten Bedingungen freie DNA aufnehmen. Die in dieser Arbeit verwendeten Zelllinien lassen sich sowohl erfolgreich mit Hilfe von Kalziumphosphatpräzipitaten mit DNA transfizieren (durch Koaufnahme), als auch mit kommerziellen Reagenzien, die die DNA mit einem lipidhaltigen Micell umschließen und so die Aufnahme der DNA in die Zelle fördern. 


\subsubsection{Transfektion von HuH7-Zellen mit Kalziumphosphatpräzipitation}

HuH7-Zellen wurden einen Tag vor der Transfektion so umgesetzt, dass sie zum Zeitpunkt der Transfektion ca. 70 bis $80 \%$ der Kulturfläche bewachsen hatten. Für die Transfektion in $10 \mathrm{~cm}$ Schalen wurden insgesamt $10 \mu \mathrm{g}$ Plasmid-DNA mit $500 \mu \mathrm{l}$ $250 \mathrm{mM} \mathrm{CaCl}_{2}$ vermischt und tropfenweise unter Vortexen zu $500 \mu \mathrm{l} 2$ x HBS I-Puffer (2.12) gegeben. Die Lösung wurde für 30 min. bei RT inkubiert, bevor sie gleichmäßig über die Zellen verteilt wurde. Sollte die Transfektion in kleineren Schalen stattfinden, wurde analog dem oben genannten Verfahren gearbeitet, jedoch geringere Mengen verwendet: Für $6 \mathrm{~cm}$ Schalen wurden $6 \mu \mathrm{g}$ Plasmid-DNA und je $300 \mu \mathrm{l}$ der Transfektionslösungen verwendet, und für $2 \mathrm{~cm}$ Näpfe (6-Well-Schalen) $2 \mu$ g PlasmidDNA und je $100 \mu \mathrm{l}$ der Transfektionslösungen. Acht Stunden nach Zugabe des Transfektionsgemisches wurde das präzipitathaltige Medium abgenommen, die Zellen zweimal mit PBS gewaschen und eine entsprechende Menge frisches DMEM zugegeben.

\subsubsection{Transfektion von HuH7-Zellen mit FuGENE (Roche Diagnostics, Mannheim)}

HuH7-Zellen waren am Tag vor der Transfektion so umgesetzt worden, dass sie zum Zeitpunkt der Transfektion ca. 60 bis 80 \% der Kulturfläche bewachsen hatten. Pro zu transfizierenden $2 \mathrm{~cm}$-Napf (6-Well-Schale) wurden 95,5 $\mu \mathrm{l}$ serum- und antibiotikumfreies DMEM mit 4,5 $\mu$ l FuGENE versetzt. Nach kurzem Mischen wurden $2 \mu \mathrm{g}$ DNA zugegeben und erneut gemischt. Nach einer Inkubation für 30 min. bei RT wurde die Lösung tropfenweise zu dem Zellkulturmedium gegeben. Ein gesonderter Mediumwechsel war nicht nötig.

\subsubsection{Transfektion von HEK-293T-Zellen mit Kalziumphosphatpräzipitation}

Einen Tag vor der Transfektion wurden HEK-293T Zellen auf eine Zelldichte von $4 \times 10^{5}$ Zellen/ml verdünnt und $5 \mathrm{ml}$ dieser Suspension in eine $6 \mathrm{~cm}$ Schale gegeben. Am nächsten Tag erfolgte ein Austausch des Zellkulturüberstands gegen $4 \mathrm{ml}$ frisches 
DMEM. Für die sich direkt anschließende Transfektion wurden $15 \mu$ g Plasmid-DNA mit $\mathrm{H}_{2} \mathrm{O}_{\text {bidest }}$ auf ein Gesamtvolumen von $438 \mu \mathrm{l}$ gebracht und $62 \mu \mathrm{l} 2 \mathrm{M} \mathrm{CaCl}_{2}$ hinzugegeben, vermischt und zentrifugiert. Während schwachem Vortexens erfolgte die tropfenweise Zugabe von $500 \mu \mathrm{l} 2$ x HBS II-Lösung (2.12). Nach mehrmaligem Schwenken der Lösung wurde sie gleichmäßig über die Zellen verteilt, und die Inkubation erfolgte für $8 \mathrm{~h}$ im Brutschrank. Anschließend wurde das Medium vorsichtig abgenommen und durch $4 \mathrm{ml}$ frisches DMEM ersetzt.

\subsubsection{Bestimmung von HBeAg und HBsAg}

Die Effizienz einer Transfektion mit HBV-DNA konnte in den meisten Fällen anhand der Bestimmung von HBeAg- oder HBsAg-Konzentrationen im Zellkulturüberstand abgeschätzt werden. Dazu wurde abzentrifugiertes Medium 1:50 mit PBS verdünnt und in entsprechende ELISA-Tests (HBsAg- und HBeAg-Test der Firma Sorin Biomedica, Saluggia, Italien) eingesetzt. Anhand von Standardverdünnungen konnte die Antigenkonzentration abgeschätzt werden.

\subsubsection{Herstellung von Zelllysaten}

Drei bis fünf Tage nach Transfektion von HuH7-Zellen wurde der Zellkulturüberstand abgenommen und entsprechend weiter behandelt. Der Zellkulturrasen wurde einmal mit $10 \mathrm{ml}$ PBS/10-cm-Schale, $6 \mathrm{ml}$ PBS/6-cm-Schale bzw. $2 \mathrm{ml}$ PBS/6-Well-Napf gewaschen und das PBS wieder entnommen. Die Lyse der Zellen erfolgte durch Zugabe von $1 \mathrm{ml} \mathrm{COS-Lysispuffer} \mathrm{(2.12)} \mathrm{und} \mathrm{anschließender} \mathrm{Inkubation} \mathrm{für} 10 \mathrm{~min}$. bei $4^{\circ} \mathrm{C}$ (Western-Blot, 3.4.8.3) oder bei Raumtemperatur auf dem Horizontal-Schüttler (EPR, 3.4.6.2). Die so hergestellten Zelllysate wurden vor Weiterverwendung für $10 \mathrm{~min}$. bei $14.000 \mathrm{rpm}$ abzentrifugiert, um die Lysate von Zelltrümmern und groben Zellbestandteilen zu trennen. Bis zur Weiterverwendung wurden die geklärten Zelllysate auf Eis gelagert. 


\subsubsection{Herstellung von retroviralen Vektoren}

Mit Hilfe eines drei Plasmide umfassenden Transfektionssystems können in HEK293T-Zellen MuLV-Retroviren hergestellt werden, die in ihrem viralen Genom ein spezifisches, rekombinantes Gen oder ,DNA-Fragment' tragen (SONEOKA et al., 1995). Diese Retroviren haben je nach verwendetem Hüllprotein ein mehr oder weniger breites Wirtsspektrum. Nach Transduktion von eukaryotischen Zellen und der Integration des retroviralen Provirus in das Wirtsgenom wird das rekombinante Gen oder die Informationen des ,DNA-Fragments', sowie das im Retrovirus gelegene eGFPZeocin/Geneticin-Gen zur Expression gebracht. Für diese Arbeit wurden entweder pczCFG5 IEGZ oder pczCFG5 IEGN zusammen mit pczVSV-G wt und pHIT 60 (2.5) als Basis für das Transfektionssystem verwendet. Die mit dem System generierten Retroviren sind nach dem Gentechnikgesetz in die Sicherheitstufe S2 eingruppiert.

Nach der Transfektion von HEK-293T-Zellen (3.3.4.3) mit den drei Plasmiden (pczCFG5 IEGZ, pczCFG5 IEGN oder Derivate: $6 \mu \mathrm{g}$ [6 cm Schalen] oder $10 \mu \mathrm{g}$

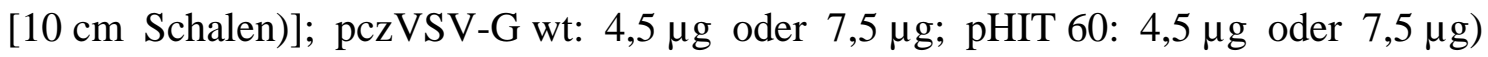
wurde dem Medium am nächsten Tag NaB-Puffer (2.12) bis zu einer Endkonzentration von $10 \mathrm{mM}$ zugegeben, um die Transkription, die von CMV-Promotern reguliert wird, zu verstärken. Nach $10 \mathrm{~h}$ im Brutschrank wurde der Zellkulturüberstand abgenommen, die Zellen einmal mit je nach Kulturschalengröße $3 \mathrm{ml}$ oder $9 \mathrm{ml}$ DMEM gewaschen und weitere $3 \mathrm{ml}$ oder $9 \mathrm{ml}$ DMEM zur Kultivierung im Brutschrank üN zu den Zellen gegeben. Am darauffolgenden Tag wurde der Retroviren-enthaltende Zellkulturüberstand abgenommen, durch einen 0,45 $\mu$ m Filter (2.15) filtriert und bis zu einer Endkonzentration von $8 \mu \mathrm{g} / \mathrm{ml}$ mit Polybrene (2.12) versetzt. Das Filtrat/Polybrene-Gemisch konnte direkt zur Transduktion eingesetzt werden. Für eine weitere Retrovirusgewinnung wurden die HEK-293T-Zellen erneut mit 3 ml oder $10 \mathrm{ml}$ DMEM überschichtet, um einen Tag später analog eine weitere in vitro Transduktion durchführen zu können. 


\subsubsection{Transduktion von HuH7-Zellen mit retroviralen Vektoren}

Einen Tag vor der Transduktion wurden $2 \times 10^{5}$ HuH7-Zellen pro Napf in 6-WellSchalen ausgesät. Am Tag der Transduktion wurde das Filtrat/Polybrene-Gemisch (3 bzw. $9 \mathrm{ml}$ ), das die Retroviren enthielt (3.3.7), direkt auf die vom Medium befreiten HuH7-Zellen gegeben und nach 6 - $8 \mathrm{~h}$ im Brutschrank wieder durch $5 \mathrm{ml}$ frisches DMEM ersetzt. Bei Bedarf wurde die Transduktion am nächsten Tag wiederholt. Zwei Tage nach der initialen Transduktion konnte mit Hilfe des Fluoreszenz-Mikroskop (3.3.12) oder einer FACS-Analyse (3.3.11) vom Retrovirusgenom exprimiertes eGFP und eine erfolgreiche in vitro Transduktion nachgewiesen werden. Während einer Transduktion von Zellen, die bereits unter Selektionsdruck durch AB standen, wurde für den Zeitraum der weiteren Transduktion DMEM ohne Antibiotika verwendet.

\subsubsection{Vereinzelung und Kultivierung transduzierter HuH7-Zellen}

Transduzierte HuH7-Zellen sollten nicht nur eGFP exprimieren (3.3.6), sondern auch ein Fusionsprotein (2.5), welches eine Resistenz gegenüber den Antibiotika (AB) Geneticin oder Zeocin aufbaut. Wurde ein Fremdgen eingesetzt, so sollte auch dieses exprimiert und mit geeigneten Mitteln nach erfolgreichem Anwachsen der transduzierten Einzelzell-Klone nachgewiesen werden können.

Die HuH7-Zellen wurden am zweiten Tag nach der Transduktion verdünnt passagiert und mit dem entsprechenden Antibiotikum versetzt. Zur Kontrolle der TransduktionsEffizienz wurden die HuH7-Zellen einer FACS-Analyse (3.3.11) unterzogen, um exprimiertes eGFP nachzuweisen. Der Selektionsdruck mit AB wurde je nach Wachstum 7 - 14 Tage aufrechterhalten, um alle nicht resistenten Zellen absterbern zu lassen, wobei alle drei Tage das Medium (DMEM + AB) erneuert wurde. Nach der ersten Selektionsphase wurden die Zellen erneut verdünnt passagiert, und am nächsten Tag wurden Einzelzell-Klone mit Hilfe von sterilen Pipettenspitzen in 96-Well-Platten überführt. Diese wurden je nach Wachstum jeweils weitere 14-21 Tage mit ABSelektionsdruck bebrütet, um dann in die nächst größeren Kulturschalen umgesetzt werden zu können. Die sechs vitalsten Klone mit dem schnellsten Wachstum wurden letztlich bis zum vollständigen Bewachsen von 2 cm Näpfen (6-Well-Schale) unter 
Selektionsdruck kultiviert und auch weiterhin in dieser Kulturgröße gehalten. Ab dieser Zellzahl konnten Experimente wie z.B. Western Blot (3.4.8.3) oder ,endogene Polymerase Reaktion' (3.4.6.2) zum Nachweis exprimierter Fremdgene durchgeführt werden

\subsubsection{Nachweis der Grenzempfindlichkeit von HuH7-Zellen gegenüber Geneticin und Zeocin mittels Verdünnungsreihe}

Am Tag vor der Antibiotikum-Zugabe wurden die Zellen so in 6-Well-Schalen umgesetzt, dass sie am nächsten Morgen eine Konfluenz von ca. 25 - 40 \% aufwiesen. Zur Selektion wurden folgende Mengen an Geneticin bzw. Zeocin (2.3.2) dem Kulturmedium zugesetzt: $50 \mu \mathrm{g} / \mathrm{ml}, 100 \mu \mathrm{g} / \mathrm{ml}, 200 \mu \mathrm{g} / \mathrm{ml}, 400 \mu \mathrm{g} / \mathrm{ml}, 600 \mu \mathrm{g} / \mathrm{ml}$, $800 \mu \mathrm{g} / \mathrm{ml}$ und $1.000 \mu \mathrm{g} / \mathrm{ml}$. Als Kontrolle wurde Medium ohne AB-Zusatz verwendet. Der Selektionsdruck wurde für 14 Tage aufrechterhalten, wobei alle 2 - 3 Tagen das Medium gegen frisch angesetztes DMEM/AB ersetzt und durch Mikroskopie die Zahl der aus den eingesäten Zellen entstandenen Foci abgeschätzt. Die AB-Konzentration, bei der nach zwei Wochen gerade keine lebensfähigen Zellen mehr vorhanden waren, wurde für die Selektionsversuche eingesetzt. Für die Erhaltung der Kultur wurde die AB-Konzentration schließlich noch einmal um 100 bis 200 g/ml gesenkt.

\subsubsection{FACS-Analyse}

Bei der FACS (fluorescence-activated cell sorting)-Analyse im Durchflusszytometer ist eine gleichzeitige Messung von Streulicht- und Fluoreszenzsignalen einzelner Zellen möglich, die in einem Flüssigkeitsstrom einen Laserstrahl definierter Wellenlänge passieren. Es werden zwei Streulichtparameter vermessen: Das Vorwärtsstreulicht (forward light scatter, FSC) gibt Aufschluss über die Zellgröße, während das Seitwärtsstreulicht (side light scatter, SSC) von der intrazellulären Granularität der Zellen bestimmt wird. Neben dem Streulicht werden Fluoreszenzsignale detektiert, die von Fluorophoren (z.B. eGFP) emittiert werden, die zuvor von dem Laserstrahl angeregt worden waren. Für die durchgeführten Messungen wurde ein Laserstrahl 
verwendet, der Licht einer Wellenlange von $488 \mathrm{~nm}$ generiert. Sowohl das Streulichtsignal, als auch die emittierte Fluoreszenz wurden von Photodetektoren registriert und für die Auswertung digitalisiert (A/D-Wandler).

Die zu untersuchenden, in 2 cm Näpfen gewachsenen Zellen wurden mit Hilfe von Trypsin/EDTA vereinzelt und mit $4 \mathrm{ml}$ DMEM resuspendiert. Ein Viertel dieser Suspension wurde $2 \mathrm{~min}$. bei $4.000 \mathrm{rpm}$ bei RT zentrifugiert und der Überstand verworfen. Das Zellpellet wurde mit $400 \mu \mathrm{l}$ FACS-Puffer gewaschen und erneut zentrifugiert (2 min., 4.000 rpm, RT). Das Pellet wurde dann in $300 \mu$ FACS-Puffer aufgenommen und für die Analyse in FACS-Röhrchen überführt. Die Analyse der Zellen erfolgte mit dem Durchflusszytometer Epics XL-MCL (Coulter, Krefeld).

\subsubsection{Untersuchung nativer Zellen mittels Fluoreszenzmikroskopie}

HuH7-Zellen sollten nach erfolgreicher Transduktion mit Retroviren (3.3.7 und 3.3.8) eGFP exprimieren. Zum Nachweis von eGFP wurden die Zellen zweimal mit PBS gewaschen und mit einem halben Kulturvolumen PBS überschichtet. Nach Platzierung der geeigneten des FITC-Fluoreszenzfilters (Anregung 450 - 490 nm, Farbteiler 510 nm, Emission $>520 \mathrm{~nm}$ ) wurden die nativen Zellen mit Hilfe des Fluoreszenzmikroskops (Zeiss Axiovert 10, Hamburg) auf grüne Fluoreszenz hin untersucht.

\subsection{Molekularbiologische Methoden}

\subsubsection{DNA-Präparation aus $E$. coli}

Plasmidtragende E. coli-Bakterien wurden üN in Schüttelkulturen bei $37^{\circ} \mathrm{C}$ in $\mathrm{TB}_{\text {amp}}{ }^{-}$ oder $\mathrm{LB}_{\mathrm{amp}}$-Flüssigmedium auf dem Certomat U/H (B. Braun, Melsungen) bei 110 - 150 rpm inkubiert (3.2.1.1). Das Volumen der Kulturen richtete sich nach der Anwendung. 


\subsubsection{Isolierung von Plasmid-DNA im analytischen Maßstab (alkalische Lyse nach BIRNBOIM \& DOLY, 1979; modifiziert)}

Zwei ml einer 4 ml-üN-Kultur wurden 1 min. bei $14.000 \mathrm{rpm}$ abzentrifugiert und der Überstand verworfen. Das Pellet wurde in $100 \mu$ l PP-Lösung I (2.12) resuspendiert. Zur alkalischen Lyse wurden $200 \mu \mathrm{l}$ PP-Lösung II (2.12) zugegeben und die Suspension wenige Male geschwenkt. Zum Neutralisieren erfolgte die Zugabe von $150 \mu$ l PPLösung III (2.12), und nach kurzem Schwenken wurde die Präparation zur Fällung von Proteinen und chromosomaler DNA für $5 \mathrm{~min}$. auf Eis inkubiert. Nach der anschließenden Zentrifugation (10 min.; $14.000 \mathrm{rpm}$ ) wurde der plasmidhaltige Überstand mit 2 Volumen Ethanol (96 \%) gefällt (3.4.2.2). Das getrocknete DNA-Pellet wurde in 50 - $100 \mu \mathrm{l}$ TE/RNase-Lösung (2.12) aufgenommen, die DNA-Konzentration bestimmt (3.4.2.5) und für analytische Spaltungen mit Restriktionsendonukleasen verwendet (3.4.4.1).

\subsubsection{Isolierung von Plasmid-DNA im analytischen Maßstab mit dem QIAprep Spin Miniprep Kit (Qiagen, Hilden)}

Diese DNA-Aufreinigungsmethode basiert auf dem Prinzip der alkalischen Lyse. Da die DNA-enthaltende Lösung über eine Anionenaustausch-Matrix aus Silica-Gel aufgereinigt wird, erhält man eine reine, zum Sequenzieren gut geeignete DNA-Lösung. Zwei ml einer 4 ml-üN-Kultur wurden 1 min bei $14.000 \mathrm{rpm}$ abzentrifugiert und der Überstand verworfen. Das Zellpellet wurde dann in den entsprechenden Puffern des Herstellers resuspendiert und die Plasmid-DNA isoliert. Die Aufreinigung wurde nach Angaben des Herstellers durchgeführt. Letztlich wurde die Plasmid-DNA mit $50 \mu$ l TEoder EB-Puffer (2.12) eluiert und die DNA-Konzentration der Lösung bestimmt (3.4.2.5). 


\subsubsection{Isolierung von Plasmid-DNA im präparativen Maßstab (alkalische Lyse nach BIRNBOIM \& DOLY, 1979; modifiziert)}

Um eine größere Menge an hochreiner Plasmid-DNA für Zellkulturexperimente aufzureinigen wurde, eine $30 \mathrm{ml} \mathrm{TB} \mathrm{amp}$-Schüttelkultur (üN; $110 \mathrm{rpm}$; 37 $\mathrm{C}$ ) angesetzt und mit den entsprechenden E. coli-Bakterien beimpft (3.2.1.1).

Die über Nacht gewachsene Bakterien-Kultur wurde für $15 \mathrm{~min}$. bei $5.000 \mathrm{rpm}$ und $4^{\circ} \mathrm{C}$ abzentrifugiert (Rotina R35, Hettich, Tuttlingen) und das entstandene Zellpellet in $5 \mathrm{ml}$ PP-Lösung I (2.12) resuspendiert. Die Zellen wurden durch Zugabe von $10 \mathrm{ml}$ frisch angesetzter PP-Lösung II (2.12) alkalisch lysiert und anschließend wurde die Suspension durch Zugabe von 7,5 ml PP-Lösung III (2.12) neutralisiert. Während der nachfolgenden fünfminütigen Inkubation auf Eis fielen Proteine und damit verbundene genomische DNA aus; episomale DNA renaturierte hingegen. Der Überstand, der durch eine anschließende Zentrifugation (15 min.; $5.000 \mathrm{rpm}$; $4^{\circ} \mathrm{C}$ ) gewonnen wurde, wurde zur Fällung der DNA mit 0,7 Volumen Isopropanol (3.4.2.3) versetzt und für 5 min. auf Eis inkubiert. Nach einer weiteren Zentrifugation (15 min.; $5.000 \mathrm{rpm} ; 4^{\circ} \mathrm{C}$ ) wurde das Pellet in $3 \mathrm{ml}$ TE-Puffer gelöst und für eine RNA-Fällung mit gleichem Volumen auf $-20^{\circ} \mathrm{C}$ gekühltes $5 \mathrm{M} \mathrm{LiCl}$ versetzt. Es folgte eine Zentrifugation (15 min.; $5.000 \mathrm{rpm}$; $4^{\circ} \mathrm{C}$ ), nach der der DNA-haltige Überstand mit gleichem Volumen Isopropanol für 15 min. bei RT gefällt wurde. Die anschließende Zentrifugation (15 min.; 5000 rpm; $4^{\circ} \mathrm{C}$ ) pelletierte die DNA, die nach dem Trocknen in 0,5 ml TE-Puffer resuspendiert wurde. Die noch in dem Ansatz vorhandene RNA wurde durch die Zugabe von $10 \mu g$ RNase A während einer 30-minütigen Inkubation bei RT abgebaut. Eine letzte DNA-Fällung folgte durch Zugabe von einem Volumen PP-Lösung IV (2.12) und Zentrifugation für 5 min. bei 14000 rpm bei RT. Das DNA-Pellet wurde anschließend in $400 \mu \mathrm{l}$ TE-Puffer solvatisiert, bevor sie einer dreimaligen Phenol/Chloroform-Extraktion (3.4.2.1) unterzogen wurde. Nach einer abschließenden Ethanol-Fällung (3.4.2.2) wurde das DNA-Pellet in $500 \mu \mathrm{l}$ TE-Puffer aufgenommen und die DNA-Konzentration photometrisch vermessen (3.4.2.5). Die DNA-Ausbeute lag bei dieser Methode zwischen 1 und $4 \mu \mathrm{g} / \mu \mathrm{l}$. 


\subsubsection{Isolierung von Plasmid-DNA im analytischen Maßstab mit dem QIAGEN Plasmid Maxi Kit (Qiagen, Hilden)}

Das QIAGEN Plasmid Maxi Kit wurde verwendet, um größere Mengen an reiner DNA zu gewinnen, die in Zellkulturexperimenten eingesetzt werden konnte.

Einhundert ml einer üN-Kultur wurden $15 \mathrm{~min}$. bei $5.000 \mathrm{rpm}$ und $4^{\circ} \mathrm{C}$ abzentrifugiert und der Überstand verworfen. Das Zellpellet wurde dann in den entsprechenden Puffern des Herstellers resuspendiert und die Plasmid-DNA isoliert. Die Aufreinigung wurde nach Angaben des Herstellers durchgeführt. Letztlich wurde die Plasmid-DNA durch Zugabe von Isopropanol (3.4.2.3) gefällt, die DNA in $500 \mu \mathrm{l}$ TE-Puffer resuspendiert. und die DNA-Konzentration der Lösung bestimmt (3.4.2.5). Die DNA-Ausbeute lag bei dieser Methode zwischen 1 und $4 \mu \mathrm{g} / \mu \mathrm{l}$.

\subsubsection{Reinigung und Konzentrierung von DNA}

\subsubsection{Phenol/Chloroform-Extraktion}

Proteine und Protein-DNA-Komplexe können aus Plasmid-DNA-haltigen, wässrigen Lösungen sehr einfach durch Extraktion mit Phenol/Chloroform entfernt werden.

Die DNA-haltige Lösung wurde 1:1 mit Phenol-Chloroform-Isoamylalkohol (25:24:1; Sigma, Steinheim) versetzt und nach intensivem Mischen 2 min. bei $14.000 \mathrm{rpm}$ abzentrifugiert. Es ergab sich eine Phasentrennung, wobei die untere organische Phase, sowie die Interphase verworfen wurden, während die obere wässrige, DNA-haltige Phase weiterverarbeitet wurde. Zumeist wurde die Extraktion dreimal durchgeführt. Die obere Phase wurde anschließend zur Konzentrierung der DNA, sowie zur Entfernung von Resten der organischen Lösungsmittel mit Ethanol (3.4.2.2) oder Isopropanol (3.4.2.3) gefällt. 


\subsubsection{Ethanol-Fällung von DNA}

Um DNA aus wässrigen Lösungen zu fällen, nutzt man die Möglichkeit, mit Hilfe von Ethanol der Nukleinsäure die Hydrathülle zu entziehen, wodurch die DNA-Moleküle ausfallen. Dieses Verfahren kann zum Konzentrieren von DNA, aber auch zum Pufferwechsel genutzt werden.

Zur Steigerung der Fällungseffizienz wurden 1/10 Volumen 7 bis $10 \mathrm{M}$ Ammoniumacetat und anschließend zum Fällen der DNA 2,5 Volumen 96 \% Ethanol zugegeben. Nach intensivem Mischen erfolgte eine 15 bis 20 -minütige Inkubation bei $-20^{\circ} \mathrm{C}$. Eine anschließende Zentrifugation (15-20 min.; $\left.14.000 \mathrm{rpm} ; 4^{\circ} \mathrm{C}\right)$ pelletierte die ausgefallene DNA, die danach durch einen Waschschritt mit 70 \% Ethanol von restlichen Salzen befreit wurde. Nach Trocknung des Pellets durch Inkubation des Gefäßes mit offenem Deckel bei RT für 10 min. wurde die DNA in der benötigten Menge TE-Puffer oder $\mathrm{H}_{2} \mathrm{O}_{\text {bidest }}$ solvatisiert.

\subsubsection{Isopropanol-Fällung von DNA}

DNA kann aus wässrigen Lösungen mit Hilfe von Isopropanol gefällt werden. Die Vorteile von Isopropanol gegenüber Ethanol sind die geringere Menge (nur 0,7 bis 1 Volumen), die zur Fällung benötigt wird, die Möglichkeit der Inkubation bei RT und dass weniger Salze zusammen mit der DNA ausfallen. Ein Nachteil ist jedoch, dass sich Isopropanol weniger leicht als Ethanol entfernen lässt. Es wurde bei der Fällung ansonsten nach dem gleichen Protokoll wie in Kapitel 3.4.2.2 vorgegangen.

\subsubsection{Isolierung von DNA aus Agarosegelen}

Mit Hilfe von Agarosegelen (3.4.2.6) aufgetrennte oder isolierte DNA bzw. DNAFragmente konnten mit dem ,QIAquick Gel Extraction Kit' (Qiagen, Hilden) von Agaroseresten befreit und anschließend wieder in Lösung gebracht werden. Dieses Verfahren wurde zumeist nach Restriktions-Spaltungen (3.4.4.1) und vor Ligationen (3.4.4.2) angewandt, um Proteinreste und ungewollte DNA-Fragmente zu entfernen. 
Die zu extrahierende DNA wurde auf ein mit Ethidiumbromid versetztes $1 \%$-iges TAEAgarosegel gegeben und durch Stromzufuhr im elektrischen Feld aufgetrennt (3.4.2.6). Anschließend wurde die gewünschte DNA-Bande während kurzer Exposition im UVDurchlicht mit einem sauberen Skalpell ausgeschnitten. Das weitere Vorgehen erfolgte nach Anleitung des Herstellers. Die DNA wurde letztlich mit $30 \mu \mathrm{l}$ TE- oder EB-Puffer eluiert. Die DNA-Konzentration wurde mittels Photometer (3.4.2.5) oder indirekt über ein Agarosegel (3.4.2.6) im Vergleich mit Proben mit bekannten DNA-Konzentrationen bestimmt.

\subsubsection{DNA-Konzentrationsbestimmung in Lösungen}

Die Konzentrationsbestimmung von DNA in einer Lösung wurde entweder mit Hilfe von UV-Spektrophotometrie (Spektralphotometer DU70, Beckman, München oder eppendorf Biophotometer, Eppendorf, Hamburg) oder vergleichender AgarosegelElektrophorese (3.4.2.6) mit standardisierten Proben, z.B. DNA-Längenstandards (2.9), durchgeführt.

Nukleinsäuren besitzen ein Absorptionsmaximum bei einer Wellenlänge von $260 \mathrm{~nm}$. Eine Extinktion von 1 entspricht einer Konzentration von $50 \mu \mathrm{g}$ ds (double-stranded) $\mathrm{DNA} / \mathrm{ml}, \quad 35 \mu \mathrm{g} \quad \mathrm{RNA} / \mathrm{ml}$ oder $33 \mu \mathrm{g}$ ss (single-stranded) DNA/ml bei einer Schichtdicke der Küvette von $1 \mathrm{~cm}$. Die zu vermessende Probe wurde in der Regel 100fach verdünnt und in eine entsprechende Messküvette überführt. Nach der Formel: $\mathrm{c}=\mathrm{E} \cdot \mathrm{f} \cdot \mathrm{K} \quad(\mathrm{c}=$ Konzentration $[\mu \mathrm{g} / \mathrm{ml}], \mathrm{E}=$ Extinktion, $\mathrm{f}=$ Verdünnungsfaktor, $\mathrm{K}=$ nukleinsäurespezifischer Multiplikator) konnte dann die DNA-Konzentration bestimmt werden.

Die Reinheit einer DNA-Lösung konnte durch den Quotienten der Extinktion bei $260 \mathrm{~nm}$ und $280 \mathrm{~nm}$ ermittelt werden, da Proteine, die die Lösung verunreinigen, eine hohe Absorption bei $280 \mathrm{~nm}$ und eine geringe bei $260 \mathrm{~nm}$ aufweisen. Charakteristisch für eine saubere DNA-Lösung war ein Wert des Quotienten zwischen 1,85 und 1,95. 


\subsubsection{Agarosegel-Elektrophorese}

Mit Hilfe der Agarosegel-Elektrophorese können DNA und andere geladene Strukturen nach Größe, Konformation und Ladung getrennt und analysiert werden. Die negativ geladene DNA wandert im elektrischen Feld durch das Netzwerk der Agarose zur Anode. Die Laufstrecke und Geschwindigkeit ist abhängig von der angelegten Spannung, der Konzentration der Agarose, des Laufpuffers, sowie der Ladung, Größe und Konformation der DNA.

Je nach Größe des elektrophoretisch aufzutrennenden DNA-Fragments wurden Gele mit einer Agarose-Konzentration zwischen 0,8 und 1,5 \% (w/v) verwendet; je kleiner die erwarteten Fragmente, desto höher wurde die Agarose-Konzentration gewählt. Für die Herstellung der Gele wurde der gleiche TAE-Puffer (2.12) verwendet, der später auch als Laufpuffer genutzt werden sollte. Zu Darstellung der DNA wurde dem Gel zusätzlich Ethidiumbromid (2.12) bis zu einer Endkonzentration von 0,1 $\mu \mathrm{g} / \mathrm{ml}$ zugegeben. Diese Substanz interkaliert in Nukleinsäuren, und mit Hilfe von UV-Licht können die DNA-Fragmente sichtbar gemacht werden. Um die aufgetragenen DNAProben zu beschweren, wurden sie mit 1/6 Volumen Probenauftragspuffer I (2.12) versetzt, mit dessen Hilfe auch die Lauffront durch zugegebene Farbstoffe markiert wurde. Die Elektrophorese fand bei einer konstanten Spannung, je nach Bedarf zwischen $30 \mathrm{~V}$ und $120 \mathrm{~V}$, statt. Anschließend konnten die aufgetrennten DNAFragmente durch Fluoreszenz im UV-Durchlicht bei einer Wellenlänge von $302 \mathrm{~nm}$ sichtbar gemacht und fotografisch dokumentiert werden. Eine Längenbestimmung und eine ungefähre Mengenabschätzung der auf das Gel aufgetragenen DNA-Fragmente wurde durch gleichzeitiges Beladen mit DNA-Längenstandards mit bekannten Fragmentgrößen und -mengen ermöglicht (2.9).

\subsubsection{DNA-Sequenzierung}

Die Sequenzierungen der DNA wurden entweder von der Firma MWG Biotech AG, Ebersberg oder mit dem ABI 373 DNA-Sequencer (Applied Biosystems, Weiterstadt) durchgeführt. 
Für die Sequenzierungen durch die Firma MWG Biotech wurden $2 \mu$ g Plasmid-DNA, die mit dem QIAprep Spin Miniprep Kit (Qiagen, Hilden) aufgereinigt worden waren (3.4.1.2), und 100 pmol Sequenzier-Oligonukleotid verschickt.

Für Sequenzierungen mit dem ABI 373 DNA-Sequencer wurde das ,Prism Ready Reaction DyeDeoxy Terminator Cycle Sequencing Kit' (Applied Biosystems, Weiterstadt) verwendet. Die als Matrize verwendete Plasmid-DNA wurde mit dem ,QIAprep Spin Miniprep Kit' (3.4.1.2) aufgereinigt. Die Durchführung der Sequenzierungsreaktion, die Sequenziergel-Herstellung, sowie Lauf des Sequenziergels und die Auswertung der Sequenzen erfolgte nach den Angaben des Herstellers.

\subsubsection{DNA-Arbeiten mit Enzymen}

\subsubsection{Spaltung von DNA mit Hilfe von Restriktionsendonukleasen}

Restriktionsendonukleasen (REN) spalten sequenzspezifisch eine meist palindromische DNA-Sequenz und dienen insbesondere bei molekularen Klonierungen als Hilfsmittel. Weiterhin werden sie zum Nachweis von Restriktionsschnittstellen eingesetzt, z.B. zur Identifikation von Plasmiden oder der Kontrolle nach Ligationen. Die Aktivität der REN ist auf spezifische Puffer- und Temperaturbedingungen angewiesen. Sofern erforderlich, wurde zur Stabilisierung und zur Förderung der Aktivität des Enzyms BSA zugegeben. Bei Bedarf konnten bei gleicher Puffer- und Temperaturanforderung zwei Enzyme gleichzeitig in eine Spaltung eingesetzt werden.

Für analytische Spaltungen wurden in einem Ansatz 0,2 $\mu$ g der zu untersuchenden DNA zusammen mit 1-2 U Enzym, $2 \mu$ 10x Puffer und einer entsprechenden Menge $\mathrm{H}_{2} \mathrm{O}_{\text {bidest }}$ eingesetzt, um auf ein Endvolumen von $20 \mu \mathrm{l} \mathrm{zu}$ kommen. Analytische Spaltungen wurden zumeist für $1 \mathrm{~h}$ inkubiert und anschließend gelelektrophoretisch überprüft. Für präparative Spaltungen wurden zwischen 1 und $5 \mu$ Vektor mit den entsprechenden Enzymen nacheinander je in einem Gesamtvolumen von $50 \mu \mathrm{l}$ geschnitten. Die generelle Zusammensetzung des Spaltungsansatzes ist die gleiche wie bei der analytischen Spaltung. Die Inkubationsdauer belief sich bei der erforderlichen Temperatur auf 3 bis 16 h. Nach jeder Spaltung wurde die DNA gelelektrophoretisch 
aufgetrennt und mit Hilfe des ,QIAquick Gel Extraction Kit' aufgearbeitet (3.4.2.4). Analog wurde das zu inserierende DNA-Fragment (PCR-Fragment bzw. aus PlasmidDNA) behandelt. Anschließend konnten die geschnittenen, aufgereinigten DNAFragmente in die Ligation (3.4.4.2) eingesetzt werden.

\subsubsection{Ligation von DNA-Fragmenten}

Während einer Ligation werden DNA-Fragmente über kompatible Enden kovalent miteinander verbunden. Dazu spaltet man ein DNA-Fragment (z.B. Amplifikat einer PCR) und einen Vektor mit geeigneten Restriktionsendonukleasen (3.4.4.1). Nach Aufreinigung beider Komponenten verknüpft die T4 DNA-Ligase (2.4) unter ATPVerbrauch die 5'-Phosphat- und die 3'-Hydroxylgruppe der DNA-Enden über eine Phosphodiesterbindung miteinander.

Zumeist wurde ein Ligations-Gesamtvolumen von $20 \mu$ l angesetzt. Dieses setzte sich zusammen aus 5 U T4 DNA-Ligase, $2 \mu 10$ x T4 DNA Ligase-Puffer, $2 \mu$ l PEG4000 (50\% [w/v]), ca. 0,1 $\mu \mathrm{g}$ Vektor-DNA und dem zu inserierenden DNA-Fragment im molaren Verhältnis 1:5, sowie $\mathrm{H}_{2} \mathrm{O}_{\text {bidest }}$ Nach intensivem Mischen wurde der Ansatz für $16 \mathrm{~h}$ bei $15^{\circ} \mathrm{C}$ im Wasserbad inkubiert, um anschließend direkt in DH5 $\alpha$-Zellen transformiert (3.2.1.5) zu werden.

\subsubsection{Aufpolymerisierung von überhängenden DNA-Enden}

Bei Restriktionsspaltungen von dsDNA entstehen oft bis zu 5 Nukleotide lange einzelsträngige DNA-Überhänge. Um 5'-Überhänge $\mathrm{zu}$ stumpfen Enden aufzupolymerisieren und 3'-Überhänge abzuspalten, benutzt man das N-terminale Fragment der E. coli DNA-Polymerase I (Klenow-Fragment) (2.4). Diese Methode wird genutzt, um z.B. Restriktionsschnittstellen zu entfernen, oder um DNA-Fragmente mit inkompatiblen Enden miteinander verbinden zu können.

Die Aufpolymerisierung erfolgte nach einer präparativen Restriktionsspaltung, von der direkt $45 \mu \mathrm{l}$ eingesetzt wurden. Um ein Gesamtvolumen von 54,4 $\mu \mathrm{l} \mathrm{zu}$ erreichen, wurden schließlich noch 5,4 $\mu \mathrm{l} 10 \mathrm{x}$ Klenow-Puffer, $2 \mu \mathrm{dNTP}$ (je $1 \mathrm{mM}$; 


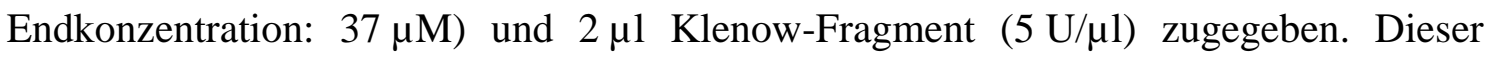
Ansatz wurde für $15 \mathrm{~min}$. bei $25^{\circ} \mathrm{C}$ inkubiert. Die Reaktion wurde durch Zugabe von $1,2 \mu \mathrm{l}$ 0,5 M EDTA und Inkubation für $20 \mathrm{~min}$. bei $75^{\circ} \mathrm{C}$ abgestoppt. Der gesamte Ansatz wurde schließlich gelelektrophoretisch aufgetrennt (3.4.2.6), das gewünschte DNA-Fragment aus dem Gel eluiert (3.4.2.4) und in nachfolgende Experimente eingesetzt.

\subsubsection{Dephosphorylierung von DNA}

Plasmid-DNA und insbesondere Vektoren, die mit nur einer Restriktionsendonuklease gespalten wurden, neigen während einer Ligation zur Rezirkularisation. Mit Hilfe einer alkalischen Phosphatase (shrimp alkaline phosphatase; SAP) können die Phosphatgruppen an beiden 5'-Enden entfernt und damit eine Religation verhindert werden.

Die Dephosphorylierung erfolgte stets nach der Restriktionsspaltung, indem der $50 \mu \mathrm{l}$ Ansatz mit $2 \mu \mathrm{l} \mathrm{SAP}(1 \mathrm{U} / \mu \mathrm{l})$ und 5,7 $\mu \mathrm{l} 10$ x SAP-Puffer versetzt wurde. Nach einer 30-minütigen Inkubation bei $37^{\circ} \mathrm{C}$ und einer anschließenden Inaktivierung des Enzyms für $25 \mathrm{~min}$. bei $80^{\circ} \mathrm{C}$ wurde der Ansatz auf ein präparatives Agarosegel (3.4.2.6) gegeben und das benötigte DNA-Fragment aus dem Gel eluiert (3.4.2.4). Danach konnte die aufgereinigte, dephosphorylierte Vektor-DNA in die Ligation (3.4.4.2) eingesetzt werden.

\subsubsection{Polymerase-Kettenreaktion (SAIKI et al., 1985)}

Mit Hilfe der Polymerase-Kettenreaktion (polymerase chain reaction; PCR) ist es möglich, definierte DNA-Sequenzen mit Hilfe von spezifisch bindenden Oligonukleotidprimern in vitro zu amplifizieren. Dies wird durch spezielle Puffer- und Temperaturbedingungen unter Verwendung einer thermostabilen DNA-Polymerase erreicht. Zumeist werden hierfür die Taq-Polymerase (aus dem marinen, thermophilen Prokaryonten Thermus aquaticus) oder Derivate verwendet.

Für eine PCR, die in dieser Arbeit stets ein Gesamtvolumen von $50 \mu$ umfasste, wurden pg- bis ng-Mengen an DNA als Matrize benutzt. Desweiteren zwei 
Oligonukleotidprimer (je 10 pmol), die mit ihren 3'-Enden nach Hybridisierung an die Ziel-DNA aufeinander zuweisen, $200 \mu \mathrm{M}$ dNTP-Mix (2.6), 10 x Polymerase-Puffer, 1,5 - 3 mM $\mathrm{MgCl}_{2}$ und 1 - 2 U Polymerase. Die Zusammensetzung des Puffers, sowie die $\mathrm{MgCl}_{2}$-Konzentration waren je nach verwendeter Polymerase (2.4) verschieden. Die PCR selbst wurde in einem Thermocycler der Firma Perkin Elmer (GeneAmp PCR System 9600) durchgeführt.

Es wurden je nach Bedarf zwischen 20 und 35 Amplifikations-Zyklen, bestehend aus Denaturierung $\left(94^{\circ} \mathrm{C}\right)$, Annealing (Temperatur je nach Oligonukleotid) und Elongation $\left(72^{\circ} \mathrm{C}\right)$ durchgeführt.

\subsubsection{Molekulare Klonierung mit dem PCR Cloning Kit (Qiagen, Hilden)}

Das PCR Cloning Kit (Qiagen, Hilden) erlaubt die schnelle Insertion von PCRFragmenten mit 3'-A-Überhängen, die mit der Taq-Polymerase (Roche Diagnostics, Mannheim) oder der PowerScript Long DNA Polymerase (PanBiotech, Aidenbach) in der PCR amplifiziert worden sind, in den im Kit enthaltenen Vektor pDrive (2.5). Die Ligation wurde nach Angaben des Herstellers durchgeführt. Nach der anschließenden Transformation in E. coli DH5 $\alpha$ konnte mit Hilfe von LB amp $_{-X}-$ Gal-IPTG-Platten nicht nur auf Antibiotikaresistenz selektiert werden, sondern auch mit Hilfe der Blau/WeißDetektion.

\subsubsection{DNA-Nachweismethoden}

\subsubsection{Southern-Blot (SOUTHERN, 1975)}

Mit Hilfe des Southern-Blots wurde virale DNA aus Nukleokapsiden auf eine Nylonmembran übertragen, dort fixiert und nachgewiesen. 


\subsection{DNA-Isolierung und Gelelektrophorese}

HBV-Nukleokapside aus Zelllysaten (3.3.6) wurden zunächst immunpräzipitiert (3.4.8.1) und anschließend die verpackten viralen Nukleinsäuren isoliert (3.4.6.3). Die erhaltenen getrockneten DNA-Pellets wurden in $13 \mu \mathrm{l} 1$ x Probenauftragspuffer I (2.12) resuspendiert und über ein TAE-Agarosegel elektrophoretisch aufgetrennt (3.4.2.6). Als Größen- und Positivkontrolle wurden 50 - 100 pg eines 3,2 kb großen, mit EcoRV geschnittenen HBV-Fragments in einer parallelen Spur aufgetragen. Nach der Gelelektrophorese wurde das Gel zweimal für 15 min. in Denaturierungs-Puffer (2.12) geschwenkt, um für die spätere Hybridisierung der Sonde die Doppelstränge der DNA voneinander zu trennen.

\subsection{DNA-Transfer auf eine Nylonmembran}

Der DNA-Transfer aus dem Agarosegel erfolgte mittels Kapillarblot über Nacht auf die positiv geladene Nylonmembran Hybond-N+, die eine Porengröße von 0,45 $\mu \mathrm{m}$ besaß (Amersham Biosciences, Freiburg; 2.15). Dabei wurde durch die Blotting-Vorrichtung ein Flüssigkeitsstrom erzeugt, der die von der Pufferlösung (Denaturierungs-Puffer; 2.12) mitgetragene denaturierte DNA durch das Agarosegel auf die Membran beförderte. Nach dem Blotten wurde die DNA-tragende Nylonmembran zweimal für 15 min. in Neutralisations-Puffer (2.12) geschwenkt. Anschließend wurde die Membran kurz getrocknet und die DNA-Fragmente für eine Minute mit $125 \mathrm{~mJ} / \mathrm{cm}^{2}$ durch UVLicht im Hoefer UVC500 UV Crosslinker (Amersham Biosciences, Freiburg) auf die Membran fixiert. Die Membran wurde nun bis zur Hybridisierung trocken und lichtgeschützt gelagert.

\subsection{Herstellung der mit alkalischer Phosphatase markierten Sonde}

Zum Nachweis der HBV-DNA wurde als Sonde das vollständige HBV Genom aus dem Plasmid pRVHBV1.5 (2.5) mit Hilfe von EcoRV ausgeschnitten (3.4.4.1) und aufgereinigt (3.4.2.4). Die Herstellung von etwa $100 \mathrm{ng}$ Sonde erfolgte nach der Vorgabe des Herstellers mit dem ,AlkPhos Direct Labelling Reagents’ Kit (Amersham 
Biosciences, Freiburg). Dabei wurde eine thermostabile alkalische Phosphatase (AP) an die HBV-DNA-Sonde gekoppelt, die nach der Hybridisierung an die Proben-DNA (3.4.6.1.4) mit Hilfe des ,CDP-Star Detection Reagents' (Amersham Biosciences, Freiburg; 2.15) über Chemiluminiszenz nachgewiesen werden konnte.

\subsection{Hybridisierung}

Für die Hybridisierung der Proben-DNA mit der AP-markierten HBV-Sonde wurde zunächst der im ,AlkPhos Direct'-Kit vorhandene Hybridisierungspuffer mit $\mathrm{NaCl}$ und Blocking Reagenz bis zu einer Endkonzentration von 0,5 M bzw. 4 \% (w/v) supplimiert und bei $65^{\circ} \mathrm{C}$ unter Rühren suspensiert. Die Membran wurde mit der DNA-fixierten Seite nach innen in eine Hybridisierungsröhre überführt und mit $0,125 \mathrm{ml} / \mathrm{cm}^{2}$ Membranfläche supplimierten Hybridisierungspuffer mindestens $30 \mathrm{~min}$. bei $65^{\circ} \mathrm{C}$ unter Rotieren im Hybridisierungsofen (Hybaid, Heidelberg) präinkubiert. Anschließend wurde die AP-markierte HBV-Genom-Sonde zu der Prähybridisierungslösung gegeben und üN zur Hybridisierung bei $65^{\circ} \mathrm{C}$ drehend inkubiert. Während dieser Zeit sollte genügend Sondenmaterial an die auf der Membran fixierte, zur Sonde komplementären Proben-DNA hybridisiert haben, um ein nachweisbares Signal zu generieren.

\subsection{Detektion der Sonde}

Die Membran in der Hybridisierungsröhre wurde zunächst dreimal für 15 min. mit frisch angesetztem, auf $65^{\circ} \mathrm{C}$ temperierten Waschpuffer A (2.12) gewaschen (2- $5 \mathrm{ml} / \mathrm{cm}^{2}$ ). Anschließend erfolgten zwei weitere Waschschritte für jeweils $10 \mathrm{~min}$. mit Waschpuffer B (2.12) in einer Plastikschale bei RT auf dem Horizontal-Schüttler (GFL, Burgwedel). Die Detektion der AP-markierten Sonde erfolgte durch Inkubation der noch feuchten Nylonmembran für 2 - 5 min mit $30-40 \mu \mathrm{l} / \mathrm{cm}^{2}$,CDP-Star detection reagents’ (2.13). Nach der Inkubation wurde die Flüssigkeit von der Membran durch Abtropfen entfernt, die Membran in einen Hybridisierungsbeutel (Hybridization Bag, GIBCO BRL) eingeschweißt und in einer Gelkassette mit Röntgenfilm (Kodak BioMax 
MR Film, MR-1; Sigma, Steinheim) inkubiert. Die Exposition erfolgte über einen Zeitraum von 5 - 60 min., bevor der Röntgenfilm entwickelt wurde (3.4.6.1.6).

\subsection{Entwicklung von Röntgenfilmen}

Die Entwicklung der Röntgenfilme (Kodak BioMax MR Film, MR-1; Sigma, Steinheim) erfolgte in der Dunkelkammer. Zunächst wurde der Röntgenfilm für 2 min. in ein ,Entwickler'-Bad (2.16) getaucht, dem sich eine kurze Inkubation in einem Stoppbad (5\%-ige Essigsäure) anschloss. Anschließend wurde der Film für 2 min. in eine Fixierungslösung (2.16) gegeben, bevor er mit $\mathrm{H}_{2} \mathrm{O}_{\text {bidest }}$ gut gewässert wurde. Letztendlich wurde der Film bei Raumtemperatur getrocknet.

\subsubsection{Nachweis von HBV-DNA mittels der, endogenen Polymerase Reaktion'}

Die in viralen Nukleokapsiden und Virus-Partikeln vorhandene endogene virale Polymerase gestattet nach Zugabe von in $\alpha$-Stellung mit ${ }^{32} \mathrm{P}$ radioaktiv markierten Nukleotiden einen Nachweis der HBV-DNA. Während der , endogenen Polymerase Reaktion’ (EPR) werden diese Nukleotide von der viralen Polymerase zur Verlängerung des inkompletten (+)-Stranges des partiell doppelsträngigen HBV-Genoms benutzt, welches dadurch radioaktiv markiert wird und mit entsprechenden Methoden nachweisbar ist. Gleichzeitig dient dieses Verfahren sowohl als indirekter Nachweis für eine funktionelle Polymerase, als auch für intakte Nukleokapside.

Zunächst wurden Nukleokapside aus Zelllysaten (3.3.6) und Virionen aus Zellkulturüberständen von HBV-transfizierten HuH7-Zellen immunpräzipitiert (3.4.8.1). Nach einem Waschschritt mit PBS und anschließender Zentrifugation wurde das Sepharosepellet mit Hilfe einer dünnen Pasteurpipette restlos von Flüssigkeitsresten befreit.

Die radioaktive Markierung des HBV-Genoms wurde durch Zugabe von $\alpha^{32} \mathrm{P}$-dCTP (2.11) erreicht, das zu den anderen Nukleotiden dGTP, dATP und dTTP (2.6) in den Reaktionsansatz zugegeben wurde. Der Ansatz mit einem Gesamtvolumen von $50 \mu \mathrm{l}$ setzte sich folgendermaßen zusammen: 


$\begin{array}{lr}2 \text { x inc. Polymerase-Puffer (2.12) } & 25 \mu \mathrm{l} \\ 1 \mathrm{M} \mathrm{MgCl}_{2} & 1 \mu \mathrm{l} \\ 10 \% \text { (v/v) ß-Mercapto-Ethanol } & 0,5 \mu \mathrm{l} \\ 10 \% \text { (v/v) NP40 } & 2,5 \mu \mathrm{l} \\ 30 \mathrm{mM} \mathrm{dATP-dGTP-dTTP-Gemisch} & 2 \mu \mathrm{l} \\ \alpha^{32} \mathrm{P}-\mathrm{dCTP}(10 \mu \mathrm{Ci} / \mu \mathrm{l}) & 1 \mu \mathrm{l} \\ \mathrm{H}_{2} \mathrm{O}_{\text {bidest }} & 18 \mu \mathrm{l}\end{array}$

Nach Zugabe des Reaktionsansatzes zu den Sepharosepellets erfolgte eine Inkubation über Nacht bei $37^{\circ} \mathrm{C}$, in deren Verlauf die radioaktiv markierten Nukleotide in das virale, partiell doppelsträngige Genom eingebaut wurden. Anschließend wurde die DNA aus den Proben isoliert (3.4.6.3), nach dem Trocknen in $13 \mu \mathrm{l}$ 1 x Probenauftragspuffer I aufgenommen und auf ein $1 \%$-iges TAE-Agarosegel (ohne Ethidiumbromid) aufgetragen. Nach erfolgter Auftrennung der DNA wurde das Gel auf Whatman-Papier überführt und im Geltrockner (Biotec Fischer, Reiskirchen) unter Vakuum und Hitze getrocknet. Die radioaktiven Signale der markierten HBV-DNA wurden dann für 10 bis 24 h, zum Teil auch länger, in einer Gelkassette auf einem Kodak-Screen (Biorad, München, 3.1.8) gesammelt. Ausgewertet wurden die Signale mit Hilfe des Phosphoimagers, Molecular Imager FX' und der Software ,Quantity One 4.3.0 Build 019’ (Biorad, München).

\subsubsection{DNA-Isolierung aus angereicherten Nukleokapsiden und Virionen}

Nukleokapside aus Zelllysaten (3.3.6) und Virionen aus Zellkulturüberständen wurden mittels Immunpräzipitation (3.4.8.1) angereichert, bevor die HBV-DNA isoliert wurde. Das Ausgangsvolumen betrug $50 \mu \mathrm{l}$ aus einem EPR-Ansatz (3.4.6.2), oder das Sepharosepellet wurde mit PBS/2x inc. Polymerase-Puffer (1:1) auf $50 \mu$ l aufgefüllt.

Zunächst wurde die DNA, die außerhalb der Kapside vorhanden war, enzymatisch mit Hilfe von DNase I entfernt, um unspezifische Signale zu minimieren. Dafür wurde für jede Probe folgender Ansatz mit einem Gesamtvolumen von $20 \mu \mathrm{l}$ hergestellt, zu dem $50 \mu$ l Ausgangsvolumen hinzupipettiert und für $30 \mathrm{~min}$. bei $37^{\circ} \mathrm{C}$ inkubiert wurden: 


$\begin{array}{lr}\text { DNase I }(10 \mathrm{mg} / \mathrm{ml}) & 0,5 \mu \mathrm{l} \\ \text { 2x inc. Polymerase-Puffer } & 10 \mu \mathrm{l} \\ \mathrm{H}_{2} \mathrm{O}_{\text {bidest }} & 9,5 \mu \mathrm{l}\end{array}$

Um an die Nukleinsäure im Inneren der Kapside zu gelangen, schloss sich eine Proteinase K-Inkubation an, während der die Nukleokapsid-Proteine gespalten und die DNase I inaktiviert wurden. Es wurden hierfür pro Ansatz die folgenden Komponenten vorgemischt und gemeinsam zu den Proben pipettiert:

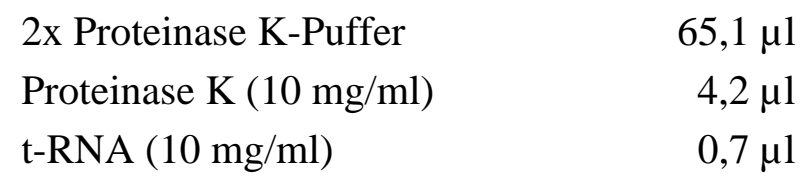

Wieder wurden die Proben für $30 \mathrm{~min}$. bei $37^{\circ} \mathrm{C}$ inkubiert. Um die DNA aufzureinigen, erfolgte eine Extraktion mit einem Volumen Phenol/Chloroform (3.4.2.1). Die wässrigen Phasen der Proben wurden zweimal mit dem 2,75-fachen Volumen 96 \% Ethanol/10 M Ammoniumacetat (10:1) für jeweils 15 min. bei $-20^{\circ} \mathrm{C}$ gefällt (3.4.2.2) und anschließend jeweils für $15 \mathrm{~min}$. bei $14.000 \mathrm{rpm}$ bei RT abzentrifugiert. Zwischen den Fällungen wurde das DNA-Pellet in $100 \mu \mathrm{l}$ TE-Puffer resuspendiert. Nach der abschließenden Zentrifugation wurde das DNA-Pellet bei $37^{\circ} \mathrm{C}$ im Heizblock getrocknet und in $13 \mu \mathrm{l} 1 \mathrm{x}$ Probenauftragspuffer (2.12) aufgenommen.

\subsubsection{Nachweis von HBV-RNA mittels RT-PCR-Technik}

Um zu überprüfen, ob Nukleokapside pgRNA verpackt haben, kann man sich der Reversen Transkriptase (RT)-PCR-Technik bedienen. Diese erlaubt es, RNA in cDNA umzuschreiben, die anschließend mittels PCR (3.4.4.5) amplifiziert werden kann.

Die zu untersuchenden zytosolischen Nukleokapside wurden durch Zelllyse (3.3.6) und anschließende Immunpräzipitation (3.4.8.1) angereichert. Nach Waschen des Sepharosepellets mit PBS folgte ein enzymatischer Abbau der Nukleinsäuren außerhalb der Nukleokapside durch eine kombinierte DNase I/RNase A-Inkubation. Dafür wurde 
für jede Probe folgender Ansatz mit einem Gesamtvolumen von $70 \mu \mathrm{l}$ hergestellt, zu den Proben pipettiert und für $1 \mathrm{~h}$ bei $37^{\circ} \mathrm{C}$ inkubiert:

$\begin{array}{lr}\text { 2x inc. Polymerase-Puffer } & 35 \mu \mathrm{l} \\ 1 \mathrm{M} \mathrm{MnCl}_{2} & 1,5 \mu \mathrm{l} \\ 10 \%(\mathrm{v} / \mathrm{v}) \text { ß-Mercapto-Ethanol } & 0,5 \mu \mathrm{l} \\ 10 \%(\mathrm{v} / \mathrm{v}) \mathrm{NP} 40 & 2,5 \mu \mathrm{l} \\ \text { DNase I (10 mg/ml) } & 0,5 \mu \mathrm{l} \\ \text { RNase A (5 mg/ml) } & 1 \mu \mathrm{l} \\ \mathrm{H}_{2} \mathrm{O}_{\text {bidest }} & 29 \mu \mathrm{l}\end{array}$

Um die RNase A vor dem Aufspalten der Nukleokapside zu inaktivieren und damit der Degradation von HBV-RNA vorzubeugen, wurde jede Probe mit $1 \mathrm{U}$,RNasin Plus RNase Inhibitor' (Promega, Mannheim; 2.5) pro $\mu$ l Ansatz versetzt und $1 \mathrm{~h}$ bei $37^{\circ} \mathrm{C}$ inkubiert. Für die anschließende Proteinase K-Inkubation, während der die Aufspaltung der Nukleokapside erfolgte, wurden zu jeder Probe folgende Komponenten hinzupipettiert:

$\begin{array}{lr}\text { 2x Proteinase K-Puffer } & 65,1 \mu \mathrm{l} \\ \text { Proteinase K (10 mg/ml) } & 4,2 \mu \mathrm{l} \\ \text { t-RNA }(10 \mathrm{mg} / \mathrm{ml}) & 0,7 \mu \mathrm{l}\end{array}$

Der Ansatz wurde für $1 \mathrm{~h}$ bei $50^{\circ} \mathrm{C}$ inkubiert, bevor mit einem Volumen Phenol/Chloroform eine Extraktion der Nukleinsäuren durchgeführt wurde (3.4.2.1). Anschließend wurden 2,5 Volumen 96 \% Ethanol und 1/10 Volumen $10 \mathrm{M} \mathrm{NH}_{4} \mathrm{Ac}$ für eine Ethanolfällung (3.4.2.2) zugegeben, intensiv vermischt und für $1 \mathrm{~h}$ bei $-20^{\circ} \mathrm{C}$ gelagert. Nach 30-minütiger Zentrifugation (14.000 rpm, $\left.4^{\circ} \mathrm{C}\right)$ wurde der Überstand verworfen, das Pellet bei $37^{\circ} \mathrm{C}$ getrocknet und in $15 \mu \mathrm{H}_{2} \mathrm{O}_{\text {bidest }}$ aufgenommen. Zehn $\mu \mathrm{l}$ jeder Probe wurden schließlich einer zweiten DNase-Inkubation (,Deoxyribonuklease I AMP-D1'-Kit, Sigma, Steinheim) unterzogen. Dazu wurden jeweils $6 \mu \mathrm{H}_{2} \mathrm{O}_{\text {bidest }}, 2 \mu \mathrm{l}$ DNase I und $2 \mu \mathrm{l}$ 10x DNase-Puffer zugegeben und für $20 \mathrm{~min}$. bei RT inkubiert. Um die DNase I zu inaktivieren, wurden jeweils $2 \mu$ Stop-Puffer hinzu pipettiert und die Ansätze bei $70^{\circ} \mathrm{C}$ für 10 min. inkubiert. Diese Lösung konnte nun direkt in die RT-PCR eingesetzt werden. Dazu wurden die Komponenten, die zum Teil aus dem ,OneStep RT- 
PCR Kit' (Qiagen, Hilden) stammten, zu einem Gesamtvolumen von $50 \mu$ l zusammen pipettiert:

\begin{tabular}{|c|c|}
\hline 5x Puffer (Kit) & $10 \mu \mathrm{l}$ \\
\hline dNTP-Lösung (40 mM) (Kit) & $2 \mu \mathrm{l}$ \\
\hline Oligonukleotid \#370 (10 pmol/ $/ \mathrm{l})$ & \\
\hline Oligonukleotid \#410 (10 pmol/ $/ \mathrm{l})$ & \\
\hline Enzym-Mix (Kit) & \\
\hline RNasin Plus & $0,25 \mu \mathrm{l}$ \\
\hline $\mathrm{H}_{2} \mathrm{O}$, RNase-free’ (Kit) & $17,75 \mu \mathrm{l}$ \\
\hline RNA-Lösung & 10 \\
\hline
\end{tabular}

Das Temperaturprogramm für die Durchführung der PCR war wie folgt:

$\begin{array}{lll}\text { Reverse Transkription } & 35 \text { min. } & 50^{\circ} \mathrm{C} \\ \text { Inaktivierung RT-Polymerase \& } & 15 \text { min. } & 95^{\circ} \mathrm{C} \\ \text { Aktivierung der Polymerase } & & \end{array}$

PCR mit 25 Zyklen:

$\begin{array}{lll}\text { Denaturierung } & 30 \mathrm{sec} . & 94^{\circ} \mathrm{C} \\ \text { Annealing } & 20 \mathrm{sec} . & 53^{\circ} \mathrm{C} \\ \text { Elongation } & 50 \mathrm{sec} . & 72^{\circ} \mathrm{C} \\ & & \\ \text { finale Elongation } & 5 \mathrm{~min} . & 72^{\circ} \mathrm{C}\end{array}$

Zur Kontrolle, dass keine DNA in der Probe nach dem DNase I-Verdau vorhanden war, wurde ein zweiter PCR-Ansatz analog dem oben angeführten angesetzt, der ohne die initiale cDNA-Synthese direkt mit der 15-minütigen Inaktivierung der RT-Polymerase bei $95^{\circ} \mathrm{C}$ begann. Anschließend wurden jeweils $5 \mu \mathrm{l}$ mit $1 \mu \mathrm{l} 6$ x Probenauftragspuffer I (2.12) versetzt und elektrophoretisch aufgetrennt und dokumentiert. 


\subsubsection{Arbeiten mit Proteinen}

\subsubsection{Immunpräzipitation}

HBV-Nukleokapside und Virionen konnten unter Verwendung von spezifischen Antikörpern, gebunden an Protein A-Sepharose (Sigma, Steinheim), aus Zelllysaten respektive Zellkulturüberstanden transfizierter und transduzierter HuH7-Zellen immunpräzipitiert werden. Die Nukleokapside wurden mit polyklonalem Kaninchen anti-HBc-Antikörpern (2.8), die Virionen mit polyklonalem Schaf anti-HBsAntikörpern (2.8) immunpräzipitiert.

Dazu wurde einen Tag vor der Ernte der Zellkultur pro Napf (6-Well-Schale) 3,5 mg Protein A-Sepharose für den Zellkulturüberstand und 2,5 mg für das Zelllysat abgewogen und in PBS aufgequollen. Nach dem Quellen wurde die Sepharose dreimal mit PBS gewaschen und in $100 \mu \mathrm{l}$ PBS aufgenommen. Anschließend wurde sie mit $1 \mu \mathrm{l}$ anti-HBc (Lysat)- bzw. 1,5 $\mu \mathrm{l}$ anti-HBs (Medium)-Antikörper versetzt und üN bei $4^{\circ} \mathrm{C}$ auf dem Überkopf-Probenroller für die Antikörper-Protein A-Bindung inkubiert. Am nächsten Tag wurde die Präinkubation einmal mit PBS gewaschen, um ungebundene Antikörper zu entfernen.

Nach der Zellernte wurden das geklärte Lysat (3.3.6) und der nach Zentrifugation von unspezifischen Proteinen und Zelldebris befreite Zellkulturüberstand $\mathrm{zu}$ dem Antikörper-Protein A-Sepahrosebeads gegeben. Es folgte die Immunpräzipitation üN bei $4^{\circ} \mathrm{C}$ auf dem Überkopf-Probenroller (Snijders, Tilburg, NL). Vor Weiterverwendung wurden Immunpräzipitate mit PBS gewaschen, um unspezifisch gebundene und nicht gebundene Proteine zu entfernen.

\subsubsection{Präparation von Nukleokapsiden}

3.4.8.2.1 Anreicherung durch isopyknische CsCl-Dichtegradienten-Zentrifugation

Mit einem isopyknischen CsCl-Dichtegradienten ist es möglich, Partikel nach ihrer Dichte zu trennen. Mit Hilfe dieser Zentrifugation können Nukleokapside und Virionen 
aus Zellkulturüberständen transfizierter HuH7-Zellen voneinander getrennt und angereichert werden.

Zunächst wurden $12 \mathrm{ml}$ Zellkulturüberstand durch eine Zentrifugation von $10 \mathrm{~min}$. bei $5.000 \mathrm{rpm}$ und $4^{\circ} \mathrm{C}$ von Zelldebris befreit. In $10 \mathrm{ml}$ des Zentrifugationsüberstands wurden 3,84 g CsCl gelöst und in Zentrifugenröhrchen (16 mm x 76 mm, Quick Seal Tubes, Beckman, München) überführt. Luftblasenfrei wurde das Röhrchen mit Mineralöl Bayol F (Serva, Heidelberg) vollständig befüllt, zugeschweißt und in einem 70.1 Ti Rotor (Beckman, München) in der Ultrazentrifuge XL-70 (Beckman, München) für $48 \mathrm{~h}$ bei $48.000 \mathrm{rpm}$ und $20^{\circ} \mathrm{C}$ zentrifugiert. Anschließend wurde das Gefäß oben mit einem Skalpell aufgeschnitten, der Gradient vom Mineralöl befreit, von oben in 1 ml Fraktionen aufgeteilt und der jeweilige Brechungsindex der Fraktionen mit einem Refraktometer (Zeiss, Jena) bestimmt. Anhand des Brechungsindex’ konnte die Dichte der Fraktionen bestimmt werden, wobei sich im Gradienten Nukleokapside bei einer Dichte von 1,33-1,37 g/ml und Virionen bei einer Dichte von 1,22-1,26 g/ml befanden.

Vor der sich anschließenden PEG-Fällung (3.4.8.2.2) für einen nativen Western Blot (3.4.8.3) wurden die Fraktionen mit einem Volumen PBS/NP40-Puffer (1\% [v/v] NP40; 0,2 \% [w/v] DTT) versetzt.

\subsection{Anreicherung durch PEG-Fällung}

Das nicht-ionische, wasserlösliche Polyethylenglykol (PEG) ist in der Lage, hochmolekulare Proteinaggregate aus Lösungen zu fällen, wobei die biologische Struktur und Aktivität nahezu unverändert bleibt. HBV-Nukleokapside konnten aus Zelllysaten und nach Entfernen der Virionen-Hülle mit NP40 aus Zellkulturüberstanden präzipitiert werden.

Die geklärten Überstande einer Zelllyse $(1 \mathrm{ml})$ (3.3.6) oder die mit PBS/NP40 versetzten Fraktionen eines CsCl-Dichtegradienten (2 ml) (3.4.8.2.1) wurden mit $10 \%$ (w/v) PEG8000 und $2 \%$ (w/v) $\mathrm{NaCl}$ versetzt und über Nacht bei $4^{\circ} \mathrm{C}$ auf dem ProbenÜberkopfroller (Snijders, Tilburg, Holland) inkubiert. Nach einer Zentrifugation (1 h; $4.000 \mathrm{rpm} ; 4^{\circ} \mathrm{C}$ ) wurde der Überstand verworfen und das Pellet in $20 \mu \mathrm{l}$ TNE-Puffer im 
Thermoheizblock (Thriller, PEQLAB, Erlangen) für $15 \mathrm{~min}$. bei $1.400 \mathrm{rpm}$ und $30^{\circ} \mathrm{C}$ resuspendiert. Nach einer anschließenden 15-minütigen Zentrifugation (4.000 rpm; $4^{\circ} \mathrm{C}$ ) wurde der kapsidhaltige Überstand bis zur Agarosegel-Elektrophorese für den WesternBlot (3.4.8.3) bei $4^{\circ} \mathrm{C}$ gelagert.

\subsubsection{Western-Blot von Nukleokapsiden unter nativen Bedingungen}

Hochmolekulare Proteinkomplexe wie z.B. HBV-Nukleokapside können aufgrund ihrer Größe und Ladung im nativen Agarosegel aufgetrennt werden, ohne dass dabei ihre Struktur denaturiert bzw. verändert wird. Anschließend können die im Gel vorhandenen Proteine auf eine Nitrozellulose-Membran transferiert (Western Blot) und mittels Immunoblot (3.4.8.4) nachgewiesen werden.

Die mit der PEG-Fällung (3.4.8.2.2) angereicherten Kapside eines Zelllysats (3.3.6) oder von CsCl-Gradient-Fraktionen (3.4.8.2.1) wurden auf ein 1\%-iges TAEAgarosegel aufgetragen. Die Proben wurden vor dem Auftrag zum Beschweren mit 1/6 Volumen 6 x Probenauftragspuffer II (2.12) versetzt. Nach der Gelelektrophorese wurden, analog zum Southern Blot (3.4.6.1), mit Hilfe eines Kapillarblots die aufgetrennten Proteine auf eine Nitrozellulose-Membran (Protran BA 85, Schleicher \& Schuell, Dassel) transferiert, indem ein Flüssigkeitsstrom aus einem 10x SSC-PufferVorrat durch das Gel und der aufliegenden Membran aufgebaut wurde. Der Transfer der Proteine aus dem Gel auf die Membran erfolgte üN bei RT.

\subsubsection{Immunoblot}

Mit Hilfe des Immunoblots können durch Verwendung von spezifischen Antikörpern auf Membranen immobilisierte Proteine nachgewiesen werden.

Die im Western-Blot (3.4.8.3) mit Proteinen beladene Nitrozellulose-Membran wurde zunächst für $1 \mathrm{~h}$ bei RT mit Milchpuffer-Lösung (2.12) schwenkend inkubiert, um unspezifische Bindungen abzusättigen. Anschließend folgten drei Waschschritte mit PT-Waschpuffer (2.12) für jeweils 15 min. bei RT auf dem Schüttler. Der Primärantikörper (anti-HBcAg, polyklonales Kaninchen-Serum, DAKO, Hamburg) 
wurde in einer 1:2.000 Verdünnung in $0,05 \mathrm{ml} / \mathrm{cm}^{2}$ Milchpuffer-Lösung $\mathrm{zu}$ der Membran gegeben und für 2 h bei RT in der rotierenden Hybridisierungsröhre inkubiert. Es folgten wiederum drei Waschschritte à 15 min. mit PT-Waschpuffer. Der HRPO (horseradish peroxidase)-konjugierte Sekundärantikörper (anti-Kaninchen, IgG $[\mathrm{H}+\mathrm{L}], \mathrm{F}[\mathrm{ab}]_{2}$-Fragment, Esel; Dianova, Hamburg) wurde in einer Verdünnung von 1:50.000 in Milchpuffer-Lösung $\left(0,4 \mathrm{ml} / \mathrm{cm}^{2}\right)$ zu der Membran gegeben und für $1,5 \mathrm{~h}$ auf dem Schüttler inkubiert. Anschließend wurde die Nitrozellulose-Membran dreimal für je 15 min. mit PT-Waschpuffer und zweimal für je 10 min. mit PBS gewaschen.

Die Detektion des Peroxidase-konjugierten Antikörpers erfolgte mit den ,ECL Western Blotting Detection Reagents’ (Amersham Biosciences, Freiburg; 2.13). Es wurden je $0,025 \mathrm{ml} / \mathrm{cm}^{2}$ der Lösungen 1 (Luminol) und 2 (Enhancer) vermischt und auf die noch leicht feuchte Membran gegeben. Nach einer einminütigen Inkubation wurde überschüssige Lösung entfernt und die Membran in einen Plastikbeutel (2.15) eingeschweißt. Anschließend wurde ein Röntgenfilm (Kodak BioMax MR Film, MR-1; Sigma, Steinheim) auf der Membran in einer Gelkassette für 1 min. bis 2 h exponiert. 


\section{ERGEBNISSE}

\subsection{Funktionelle Oberflächen des HBV-Kapsids}

Für die Bildung von infektiösen Hepatitis-B-Virionen ist eine Umhüllung reifer Nukleokapside an Kompartimenten von intrazellulären Membranen (wahrscheinlich Post-ER, Prä-Golgi oder multivesicular bodies) absolut essentiell (PATZER et al., 1986; Huovila et al., 1992; Freed, 2002; von SCHWEdLER et al., 2003). Mittels Mutationsanalysen wurde die Oberfläche des HBV Nukleokapsides auf mögliche Interaktionspartner mit der N-terminalen Schleife des LHBs hin analysiert. Durch kurze, ungerichtete Deletionen oder Insertionen im Coregen (Koschel et al., 1999; KosCHEL et al., 2000), sowie durch gezielte Alanin-Substitutionen von 52 auf der Kapsidoberfläche exponierten AS-Positionen (PONSEL \& BRUSS, 2003) konnten Mutanten generiert werden, die die Verpackung der pgRNA, die Kapsidassemblierung und die virale DNA Synthese erlaubten, die Umhüllung jedoch blockierten. Elf der 52 getesteten Alanin-Mutanten zeigten die beschriebene Blockade der Umhüllung.

Zur Validierung der Variabilität und zur Bestimmung der funktionellen Bedeutung der Positionen, an denen die Substitution mit Alanin einen umhüllungsdefizienten Phänotyp hervorbrachte, wurden in dieser Arbeit sechs dieser elf Positionen, die von Ponsel und Bruss (PONSEL \& BRUSS, 2003) bestimmt worden waren, mit weiteren AS-Resten substituiert und analysiert. Dies erfolgte in Hinblick auf die Fähigkeit der Umhüllungskompetenz bzw. der direkten Beteiligung des AS-Restes an der Umhüllung durch die viralen Hüllproteine während Transfektions-Experimenten in der Zellkultur. Weiterhin wurden vier Positionen aus dem Alanin-Screening ausgewählt, die nach dem AS-Austausch einen WT-ähnlichen Phänotyp aufwiesen. Auch diese Positionen wurden durch weitere AS-Reste substituiert und auf ihre Beteiligung an dem Umhüllungsprozess hin untersucht. Nach Auswahl der Positionen wurden insgesamt 56 Mutanten hergestellt und in der Zellkultur getestet.

In einem weiteren Projekt sollte, ausgehend von einer einzelnen umhüllungsdefizienten Coreprotein-Mutante (I126A), eine komplementierende Mutation innerhalb der Matrix- 
Domäne des postulierten Bindungspartners LHBs gefunden werden, die die Blockade der Umhüllung aufheben kann. Dazu wurde ein Zellkultursystem entwickelt, welches mit Hilfe eines MuLV (murine leukemia virus)-Retrovirus Transduktionssystems erlaubt, ein replikationsnegatives, aber verpackungskompetentes HBV-Genom in HuH7-Zellen überführen zu können. Dieses Genom erlaubte nur die Expression der Hüllproteine und diente als Matrize für die in das HBV-Kapsid zu verpackende pgRNA, während die Core- und die Polymerase-Proteine in trans zugeführt wurden. Die mit Retroviren, die das HBV-Genom mit dem WT LHBs trugen, transduzierten HuH7Zellen sollten bei gleichzeitiger Expression des WT Coreproteins und der Polymerase in der Lage sein, Virionen zu bilden und in den Kulturüberstand zu sezernieren. Bei Expression der Core-Mutante hingegen sollte es nur zur Bildung reifer Nukleokapside im Zytosol kommen, während der Umhüllungsprozess blockiert sein würde. Durch Zufallssubstitutionen von einzelnen AS innerhalb der Matrix-Domäne (AS 103 - 124) des LHBs sollte es später mit diesem Transduktionssystem möglich sein, die Umhüllungskompetenz der Core-Mutante wieder herzustellen und sezernierte VirusPartikel nachzuweisen.

\subsection{Charakterisierung von oberflächenexponierten AS-Positionen des Coreproteins}

\subsubsection{Selektion der zu mutierenden AS-Positionen des Coreproteins}

Das HBV Nukleokapsid besteht, abhängig von der Symmetrie, aus 90 ( $\mathrm{T}=3$ ) bzw. 120 $(\mathrm{T}=4)$ Coreprotein-Homodimeren. Die Darstellung der Kristallstruktur von $\mathrm{T}=4$ Kapsiden bis zu einer Auflösung von 3,3 Å erfolgte 1999 (Wynne et al., 1999). Die dort ermittelten Strukturdaten sind in der ,ProteinDataBank' (http://www.rcsb.org/pdb/) als Datei (,1qgt.pdb’) allgemein verfügbar und wurden während dieser Arbeit mit der 3D-Visualisierungssoftware DeepView/Swiss-PdbViewer v3.7 der Firma GlaxoSmithKline (http://www.expasy.org/spdbv) bearbeitet.

Auf Basis dieser Kristallstrukturdaten wurden in einer Mutagenese-Studie elf oberflächenexponierte AS-Reste ermittelt, die nach Substitution zu Alanin die einzelnen 
Morphogenese-Schritte bis zum reifen Nukleokapsid erlaubten, die Umhüllung jedoch blockierten (PONSEL \& BRUSS, 2003). Wie in Abbildung 14 a) zu erkennen ist, gruppierten sich die AS-Reste in zwei Bereichen. Der erste Bereich (L60, L95 und K96) bildete eine Art ringförmige Struktur um die Basis des Spikes, während der zweite Bereich (S17, F18, F122, I126, R127, N136, A137 und I139) eine flächige Struktur an den Interdimer-Kontaktstellen darstellt (Abb. 14 b und c).

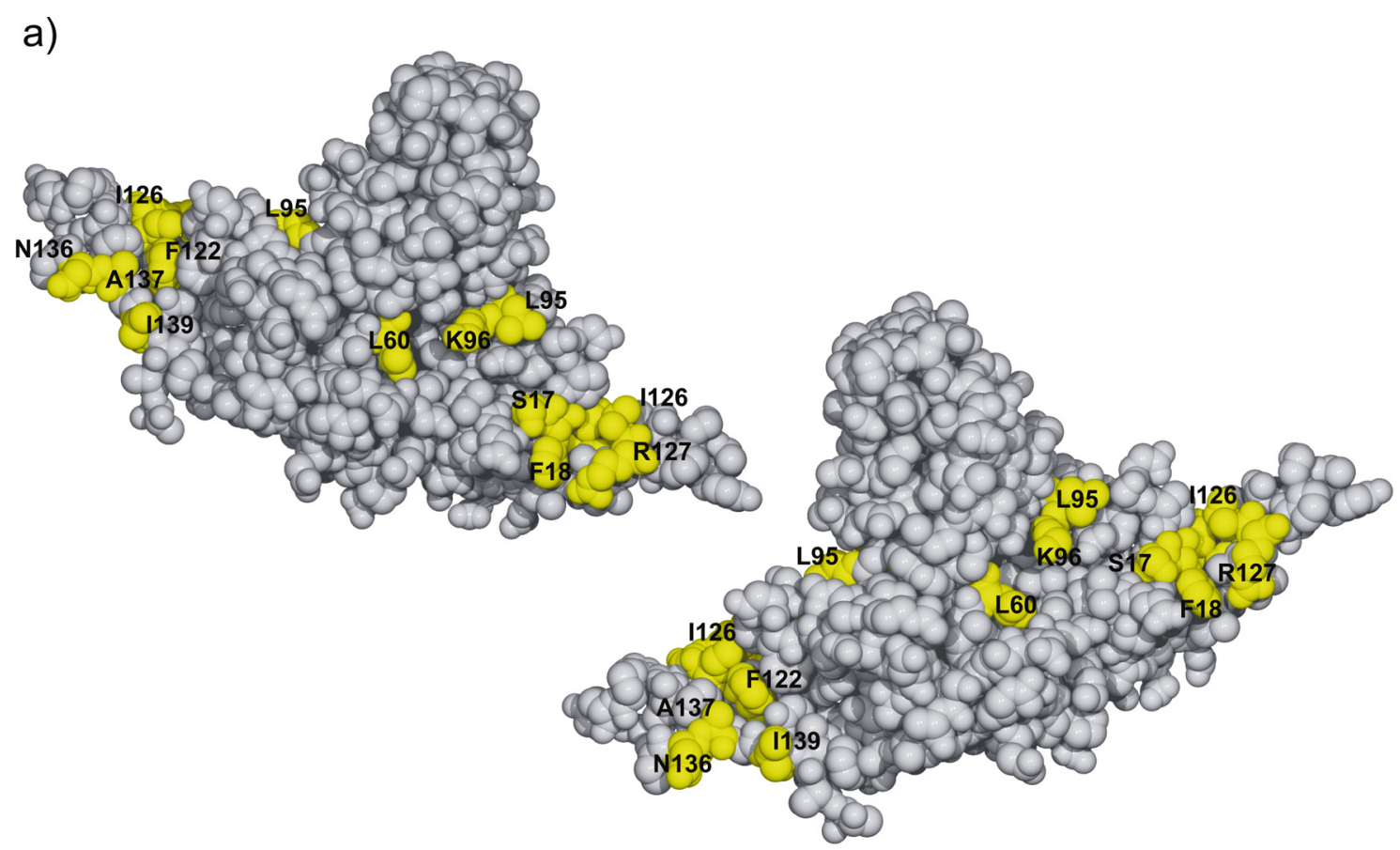

b)

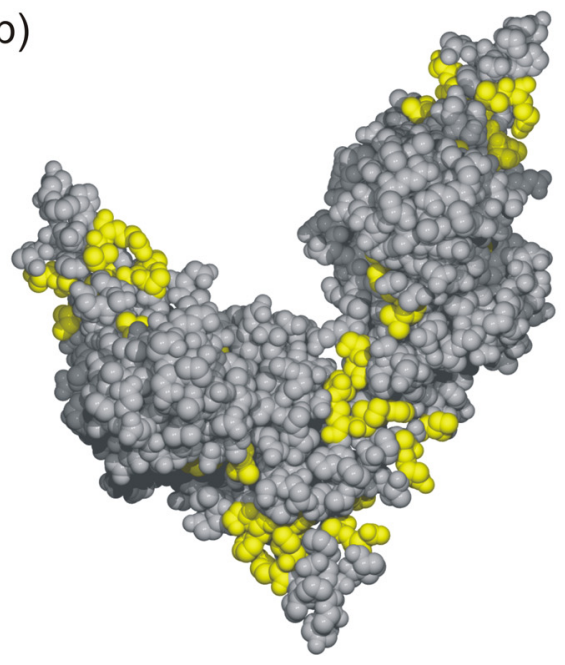

c)

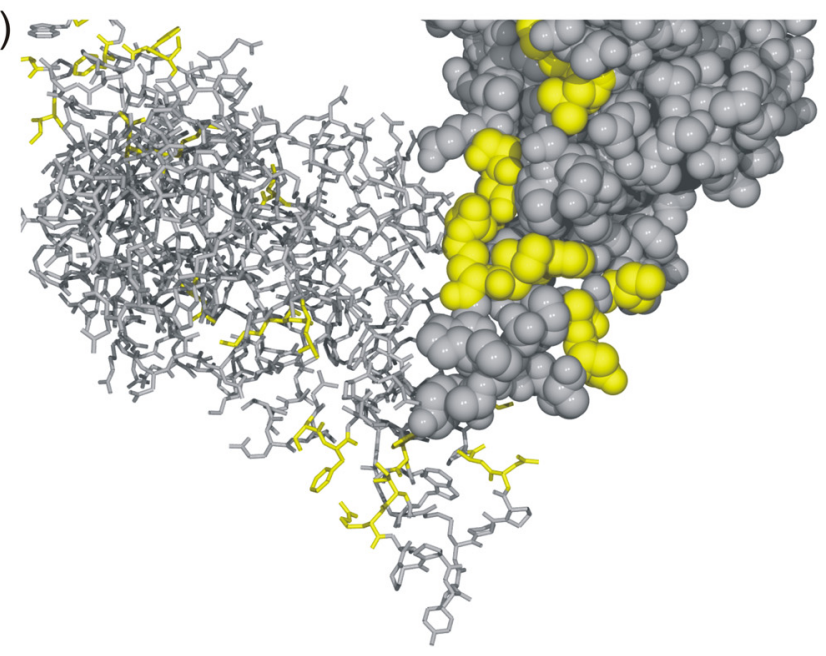

Abb. 14: Darstellung eines Coreprotein-Homodimers aus zwei verschiedenen Blickwinkeln im Kugelmodell (a), zweier Coreprotein-Homodimere während Dimer-Dimer-Kontakt im Kugelmodell (b) und die Kontaktregion vergrößert im Kugel- und Stiftmodell (c). 
Teilabbildung a) zeigt die Verteilung der elf AS-Positionen, die nach Alanin-Substitution den umhüllungsdefizienten Phänotyp generierten und hier in Gelb eingefärbt sind. Die restlichen AS-Reste sind in Grau gehalten. In Teilabbildung b) sieht man zwei Homodimere im direkten Kontakt miteinander im Blick von oben. Die Darstellung der Teilabbildung c) zeigt diesen Kontakt im Ausschnitt vergrößert. Gut sichtbar sind die in Gelb eingefärbten AS-Reste des rechten Homodimers (S17, F18, I126 und R127), die in den direkten Interdimer-Kontakt involviert sind.

Für diese Arbeit wurden die folgenden sechs AS-Positionen ausgewählt, die nach Alanin-Substitution die Umhüllung der Nukleokapside blockierten: S17, L95, K96, F122, I126 und R127. S17 liegt am Ende der Helix $\alpha 1$, L95 und K96 befinden sich in der Spike-abwärts gelegenen Helix a4b, und F122, I126 sowie R127 sind in der Helix a5 lokalisiert, wobei sie eine Art Ring um die lateralen Enden des Dimers bilden. Neben diesen sechs Positionen, wurden vier AS-Reste ausgewählt, die nach der AlaninSubstitution einem WT-ähnlichen Phänotyp entsprachen. Dies waren die AS-Positionen S21, D22, N90 und R98. Während S21 und D22 zwischen $\alpha$-Helix 1 und 2a und R98 innerhalb der Helix $\alpha 4 \mathrm{~b}$ gelegen sind, befindet sich N90 zwischen den $\alpha$-Helices 4a und 4b. Mit der Auswahl dieser Positionen sollte ein Großteil der Bereiche der Oberflächen der Coreprotein-Homodimere abgedeckt sein, die für die Umhüllung wichtig sein könnten (Abb.15 a und b).

a)

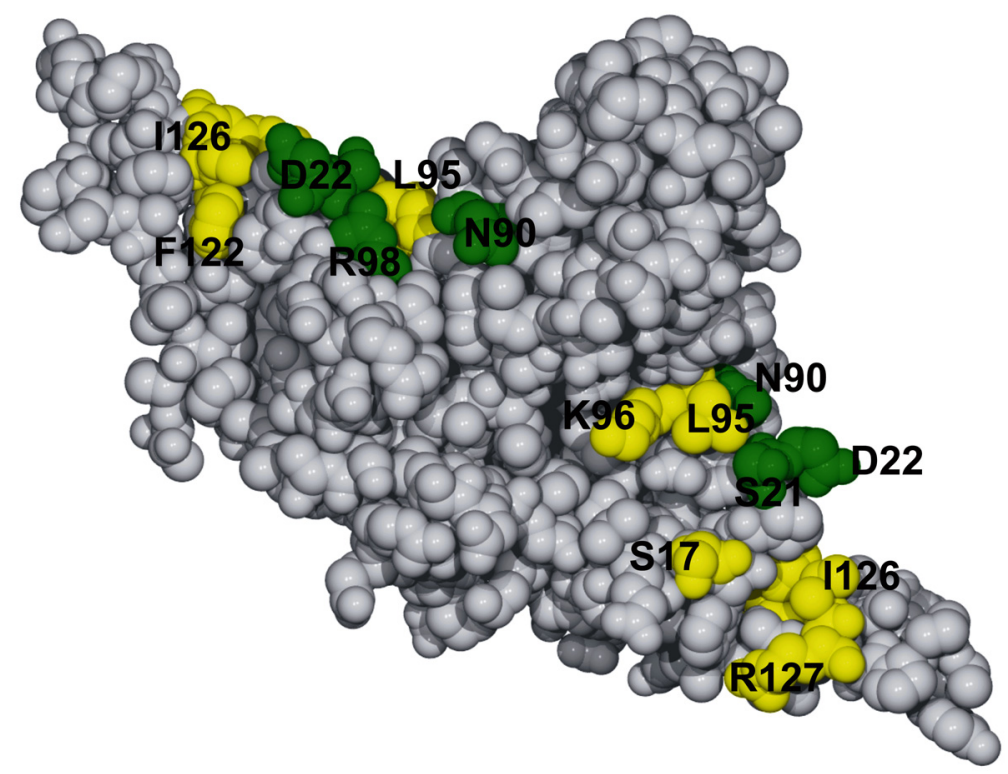




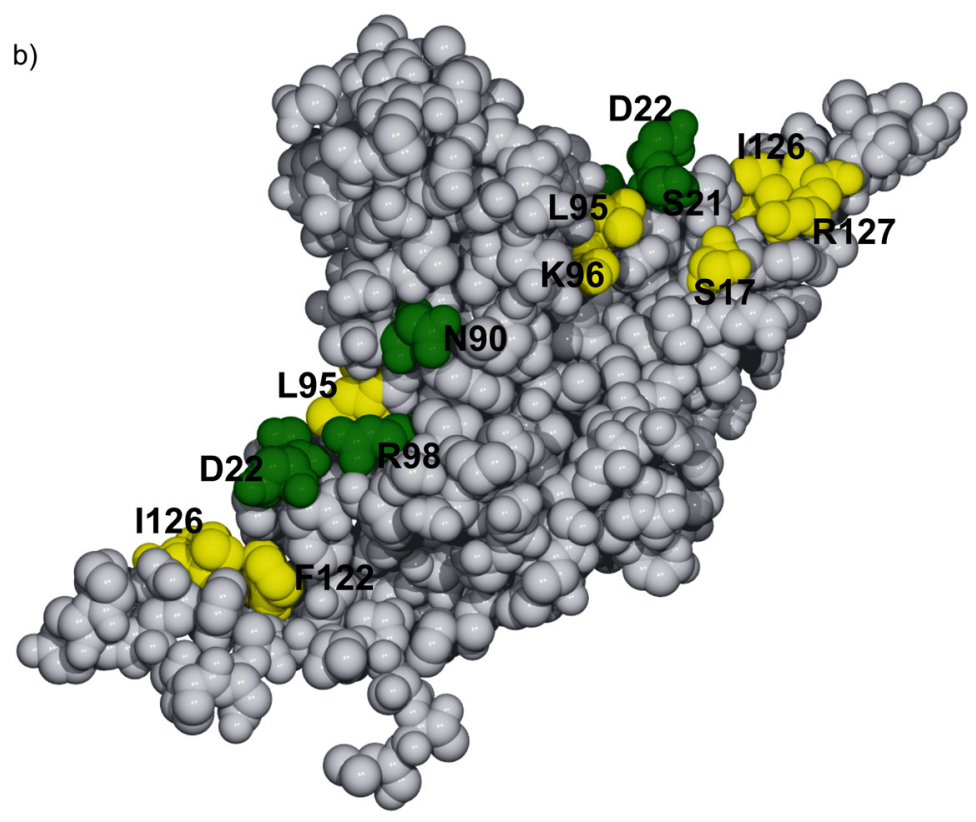

Abb. 15 (diese und vorherige Seite): Darstellung der ausgewählten zehn zu untersuchenden AS-Positionen im Kugelmodell eines Coreprotein-Homodimers aus zwei verschiedenen Blickwinkeln.

Gezeigt sind die Vorder (a)- und Rückansicht (b) eines Coreprotein-Homodimers. Die vier AS-Reste, die nach der Alanin-Substitution den WT Phänotyp zeigten, sind in Grün dargestellt, während die, die den umhüllungsdefizienten Phänotyp zeigten, in Gelb angefärbt worden sind.

\subsubsection{Generierung der Coreprotein-Mutanten}

An den zehn ausgewählten Positionen wurden insgesamt 56 AS-Substitutionen vorgenommen, wobei die Auswahl der Substituenten für jede Position unterschiedlich war. Generell wurde darauf geachtet, dass die eingesetzten AS-Reste ein möglichst breites Spektrum an Eigenschaften wie Ladung, Struktur oder Polarität abdeckten. Mit Hilfe dieser Mutanten sollten die benötigten Eigenschaften der mutierten AS-Positionen hinsichtlich der Umhüllungskompetenz sowie der Kapsidassemblierung ermittelt werden können.

Die Expression der Coreproteine erfolgte mit Hilfe des Vektors pSVcore (2.5), der nach Transfektion von HuH7-Zellen unter Kontrolle des SV40-early-Promoters große Mengen Coreprotein exprimiert. Mit der Expression von Coreproteinen alleine wäre nur getestet worden, inwieweit die Mutanten zur Bildung von Kapsiden fähig sind, nicht aber die Funktionalität in Hinblick auf die vollständige virale Morphogenese. Um dies 
mit den verschiedenen Core-Mutanten in vitro testen zu können, mussten alle weiteren benötigten HBV-Proteine und Nukleinsäuren in der Zellkultur gleichzeitig in trans produziert werden. Dies erfolgte mit Hilfe des Plasmids pSVHBV1.5core- (2.5), welches die ca. 1,5-fache Kopie des viralen Genoms trägt und bis auf das Coreprotein alle viralen Proteine und Nukleinsäuren zur Verfügung stellt. Die Kotransfektion mit dem Coreprotein-Expressionsvektor war nötig, da die Sequenz des Coregens im Genom funktionell doppelt belegt ist (Polyadenylierungssignal, DR1 und N-terminaler Bereich der Polymerase) und deshalb in pSVHBV1.5 (2.5) selbst keine Mutationen in das Gen eingeführt werden konnten.

Die Substitutionen der AS wurden in vitro mittels PCR-Mutagenese durchgeführt. Dazu war es nötig, ein bis drei Basen des Coregens auszutauschen, um das gewünschte, für die neue AS kodierende Basentriplett zu generieren. Die Mutagenese bestand aus drei PCR-Schritten (3.4.4.5), der Ligation des PCR-Fragments über BamHI und BspEI in den Expressionsvektor (3.4.4.2) und der anschließenden Sequenzierung des Coregens (3.4.3).

Die erste PCR wurde mit dem flankierenden Oligonukleotid \#177, welches 5' vor dem Coregen hybridisiert, und dem entsprechenden Mutagenese-Oligonukleotid durchgeführt, wenn die zu mutierende Position im N-terminalen Bereich des Coregens lag. Befand sich die Mutationsstelle C-terminal, wurde das Oligonukleotid \#178, welches 3' vom Coregen bindet, zusammen mit dem jeweiligen Mutagenese-Primer zur Amplifikation verwendet. Wenn sich die zu mutierende AS-Position im distalen 3'Bereich des Coregens und dadurch hinter der BspEI-Schnittstelle befand, wurde das Oligonukleotid \#244 anstelle von \#178 verwendet. Dieses hybridisierte ca. 500 bp stromabwärts des Coregens und bot so die Möglichkeit, die Schnittstelle der REN BstEII für die anschließende Klonierung zu verwenden. 


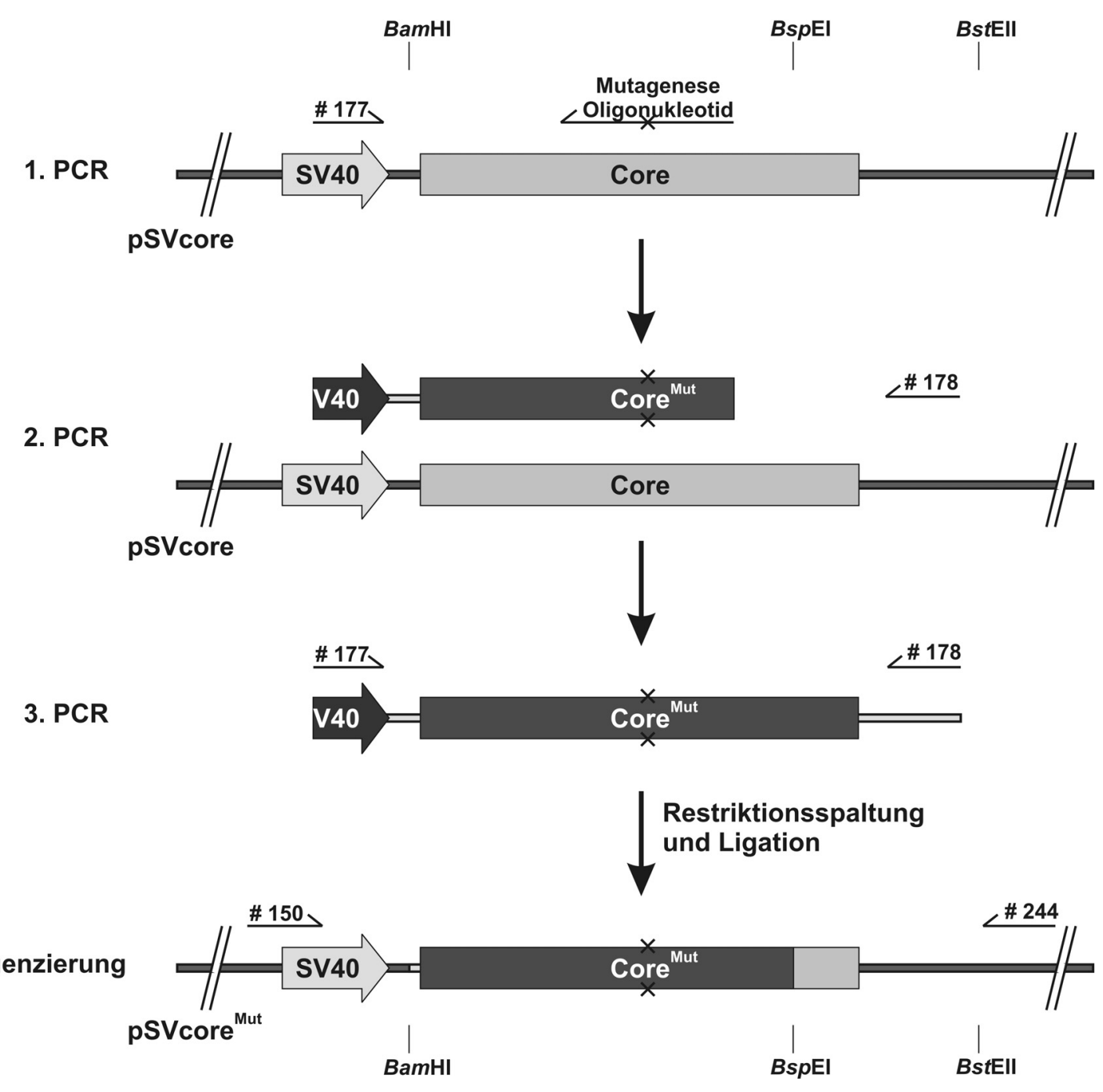

Abb. 16: Schematische Darstellung der Herstellung der Core-Mutanten mit den Oligonukleotiden \#177 und \#178.

Die Matrize der ersten PCR war der Expressionsvektor pSVcore. Zusammen mit einem flankierenden Oligonukleotid (\#177 oder \#178 / \#244) und dem jeweils benötigten Mutagenese-Primer wurde ein Fragment hergestellt, das nach Auftrennung über ein Agarosegel (3.4.2.6) und anschließender Aufreinigung aus dem Gel (3.4.2.4) als mutationstragender Megaprimer in die zweite PCR eingesetzt werden konnte. Auch in der zweiten PCR diente pSVcore wieder als Matrize. Während dieser Amplifikation wurde, je nachdem welcher flankierende Primer in der ersten PCR eingesetzt wurde, der 5'- oder 3'-fehlende Teil des Coregens mit Hilfe des zweiten flankierenden Oligonukleotids an den Megaprimer angehängt. Das entstandene Fragment wurde 
wiederum über ein Agarosegel aufgereinigt und einer dritten PCR mit den Oligonukleotiden \#177 und \#178 (oder \#244) unterzogen.

Die Einsetzung des aufgereinigten, mutationstragenden Fragments in den Expressionsvektor erfolgte über die REN BamHI und BspEI (oder BstEII), wobei der Vektor vor der Ligation dephosphoryliert wurde (3.4.4.2; 3.4.4.4). Dabei erfolgte letztendlich ein Austausch eines 439 bp (oder 932 bp) großen Teils von pSVcore (Sequenzbereich 1833 bp - 2272 bp [oder 1340 bp - 2272 bp]) mit einem Fragment, das bis auf die Mutation identisch war (bezeichnet als Core ${ }^{\mathrm{Mut}}$ ). Nach erfolgter Ligation, Transformation und analytischer DNA-Präparation wurden die Mutanten mit den Oligonukleotiden \#150 und \#244 sowohl auf die eingeführte Mutation, als auch auf die ordnungsgemäße Gesamtsequenz hin untersucht (3.4.3). Dabei zeigte sich, dass die gewünschten Mutationen in ca. $80 \%$ der generierten Plasmide enthalten waren, während nicht intendierte Mutationen in ca. 30 \% vorlagen. Als letzter Schritt erfolgte schließlich die Präparation der DNA im präparativen Maßstab (3.4.1.3 und 3.4.1.4). Alle erstellten Coremutanten sind in Tabelle 12 dargestellt.

Tab. 12: Zusammenfassung der hergestellten Coremutanten, sowie deren Eigenschaften und Lage im Coreprotein

\begin{tabular}{|c|c|c|c|c|}
\hline Position & $\begin{array}{c}\text { Phänotyp } \\
\text { Ala-Mutante }\end{array}$ & $\begin{array}{c}\text { Lage im } \\
\text { Coreprotein }\end{array}$ & Substituent & Eigenschaften des Substituenten \\
\hline \multirow[t]{5}{*}{ S17 } & \multirow[t]{5}{*}{$\mathrm{K}+/ \mathrm{V}-$} & \multirow[t]{5}{*}{ Helix $\alpha 1$} & $\mathrm{~T}$ & polar, hydrophil \\
\hline & & & G & unpolar, hydrophob, aliphatisch, klein \\
\hline & & & $\mathrm{I}$ & unpolar, hydrophob, aliphatisch \\
\hline & & & $\mathrm{H}$ & basisch, polar, hydrophil, aromatisch \\
\hline & & & $\mathrm{D}$ & sauer, polar, hydrophil \\
\hline \multirow[t]{4}{*}{ S21 } & \multirow[t]{4}{*}{$\mathrm{K}+/ \mathrm{V}+$} & \multirow{4}{*}{$\begin{array}{l}\text { zwischen } \\
\text { Helix } \alpha 1 \text { und } \\
\alpha 2 \mathrm{a}\end{array}$} & $\mathrm{T}$ & polar, hydrophil \\
\hline & & & G & unpolar, hydrophob, aliphatisch, klein \\
\hline & & & I & unpolar, hydrophob, aliphatisch \\
\hline & & & $\mathrm{H}$ & basisch, polar, hydrophil, aromatisch \\
\hline \multirow[t]{3}{*}{$\overline{\mathrm{D} 22}$} & \multirow[t]{3}{*}{$\mathrm{K}+/ \mathrm{V}+$} & \multirow{3}{*}{$\begin{array}{l}\text { zwischen } \\
\text { Helix } \alpha 1 \text { und } \\
\alpha 2 \mathrm{a}\end{array}$} & G & unpolar, hydrophob, aliphatisch, klein \\
\hline & & & $\mathrm{I}$ & unpolar, hydrophob, aliphatisch \\
\hline & & & $\mathrm{H}$ & basisch, polar, hydrophil, aromatisch \\
\hline \multirow[t]{4}{*}{ N90 } & \multirow[t]{4}{*}{$\mathrm{K}+/ \mathrm{V}+$} & \multirow{4}{*}{$\begin{array}{l}\text { zwischen } \\
\text { Helix } \alpha 4 \mathrm{a} \\
\text { und } \alpha 4 \mathrm{~b}\end{array}$} & $\mathrm{D}$ & sauer, polar, hydrophil \\
\hline & & & G & unpolar, hydrophob, aliphatisch, klein \\
\hline & & & I & unpolar, hydrophob, aliphatisch \\
\hline & & & $\mathrm{S}$ & polar, hydrophil, klein \\
\hline \multirow[t]{4}{*}{ L95 } & \multirow{4}{*}{$\mathrm{K}+/ \mathrm{V}-$} & \multirow[t]{4}{*}{ Helix $\alpha 4 b$} & $\mathrm{~V}$ & unpolar, hydrophob, aliphatisch \\
\hline & & & G & unpolar, hydrophob, aliphatisch, klein \\
\hline & & & I & unpolar, hydrophob, aliphatisch \\
\hline & & & $\mathrm{S}$ & polar, hydrophil, klein \\
\hline
\end{tabular}




\begin{tabular}{|c|c|c|c|c|}
\hline \multirow[t]{6}{*}{ K96 } & \multirow[t]{6}{*}{$\mathrm{K}+/ \mathrm{V}-$} & \multirow[t]{6}{*}{ Helix $\alpha 4 b$} & $\mathrm{H}$ & basisch, polar, hydrophil, aromatisch \\
\hline & & & $\mathrm{R}$ & basisch, polar, hydrophil \\
\hline & & & $\mathrm{L}$ & unpolar, hydrophob, aliphatisch \\
\hline & & & $\mathrm{G}$ & unpolar, hydrophob, aliphatisch, klein \\
\hline & & & $\mathrm{S}$ & polar, hydrophil, klein \\
\hline & & & $\mathrm{D}$ & sauer, polar, hydrophil \\
\hline \multirow[t]{5}{*}{ R98 } & \multirow[t]{5}{*}{$\mathrm{K}+/ \mathrm{V}+$} & \multirow[t]{5}{*}{ Helix $\alpha 4 b$} & $\mathrm{H}$ & basisch, polar, hydrophil, aromatisch \\
\hline & & & $\mathrm{K}$ & basisch, polar, hydrophil \\
\hline & & & $\mathrm{D}$ & sauer, polar, hydrophil \\
\hline & & & $\mathrm{L}$ & unpolar, hydrophob, aliphatisch \\
\hline & & & $\mathrm{Q}$ & polar, hydrophil \\
\hline \multirow[t]{6}{*}{ F122 } & \multirow[t]{6}{*}{$\mathrm{K}+/ \mathrm{V}-$} & \multirow[t]{6}{*}{ Helix $\alpha 5$} & G & unpolar, hydrophob, aliphatisch, klein \\
\hline & & & $\mathrm{V}$ & unpolar, hydrophob, aliphatisch \\
\hline & & & $\mathrm{W}$ & unpolar, hydrophob, aromatisch \\
\hline & & & $\mathrm{S}$ & polar, hydrophil, klein \\
\hline & & & $\mathrm{K}$ & basisch, polar, hydrophil \\
\hline & & & $\mathrm{Y}$ & polar, hydrophob, aromatisch \\
\hline \multirow[t]{13}{*}{ I126 } & \multirow[t]{13}{*}{$\mathrm{K}+/ \mathrm{V}-$} & \multirow[t]{13}{*}{ Helix $\alpha 5$} & $\mathrm{~V}$ & unpolar, hydrophob, aliphatisch \\
\hline & & & $\mathrm{L}$ & unpolar, hydrophob, aliphatisch \\
\hline & & & $\mathrm{M}$ & unpolar, hydrophob \\
\hline & & & $\mathrm{G}$ & unpolar, hydrophob, aliphatisch, klein \\
\hline & & & $\mathrm{F}$ & unpolar, hydrophob, aromatisch \\
\hline & & & $\mathrm{P}$ & unpolar, hydrophob \\
\hline & & & $\mathrm{W}$ & unpolar, hydrophob, aromatisch \\
\hline & & & $\mathrm{Y}$ & polar, hydrophob, aromatisch \\
\hline & & & $\mathrm{S}$ & polar, hydrophil, klein \\
\hline & & & $\mathrm{T}$ & polar, hydrophil \\
\hline & & & $\mathrm{C}$ & polar, hydrophil \\
\hline & & & $\mathrm{Q}$ & polar, hydrophil \\
\hline & & & $\mathrm{N}$ & polar, hydrophil \\
\hline \multirow[t]{6}{*}{ R127 } & \multirow[t]{6}{*}{$\mathrm{K}+/ \mathrm{V}-$} & \multirow[t]{6}{*}{ Helix $\alpha 5$} & $\mathrm{~K}$ & basisch, polar, hydrophil \\
\hline & & & $\mathrm{H}$ & basisch, polar, hydrophil, aromatisch \\
\hline & & & $\mathrm{L}$ & unpolar, hydrophob, aliphatisch \\
\hline & & & $\mathrm{G}$ & unpolar, hydrophob, aliphatisch, klein \\
\hline & & & $\mathrm{D}$ & sauer, polar, hydrophil \\
\hline & & & $\mathrm{S}$ & polar, hydrophil, klein \\
\hline
\end{tabular}

\subsubsection{Nachweis der Umhüllungskompetenz mittels ,endogener Polymerase Reaktion'}

Für die Untersuchungen dieser Arbeit war es wichtig zu beurteilen, inwieweit die hergestellten Coremutanten in der Lage waren, an den sechs ausgesuchten Positionen den Phänotyp der Umhüllungskompetenz des Alanin-Screenings (PonsEL \& BRUSS, 2003) zu reproduzieren. Sollte der Phänotyp der Alanin-Substitution mehrfach bestätigt werden, so bestärkt dies die Hypothese einer direkten Beteiligung dieser AS-Position an 
der Umhüllung des Kapsids. Weiterhin musste untersucht werden, inwieweit andere Substituenten an den vier Positionen mit WT Phänotyp im Alanin-Screening wiederum umhüllungskompetent oder etwa umhüllungsdefizient bzw. letal waren. Auch dieses sollte Rückschlüsse auf die Variabilität dieser Positionen bzw. die Beteiligung an der Kapsidassemblierung oder dem Umhüllungsprozess zulassen.

Virionen, ebenso wie reife Nukleokapside, besitzen im Inneren des Core-Partikels das partiell doppelsträngige DNA-Genom, an das kovalent das P-Protein gebunden ist. Der unvollständige (+)-DNA-Strang des Genoms kann durch Zugabe von Nukleotiden von der endogenen viralen Polymerase verlängert werden. Dieser Effekt wird genutzt, um Virionen und reife Kapside sowohl aus Zellkulturüberständen als auch aus Zelllysaten indirekt über ihre DNA nachzuweisen, indem radioaktiv markierte Nukleotide zugegeben werden, die nach Einbau das DNA-Genom markieren. Weiterhin ist die ,endogene Polymerase Reaktion’ (EPR) (3.4.6.2) ein Nachweis für eine funktionelle HBV-Polymerase und intakte Kapside.

Um die Fähigkeit, reife Kapside zu bilden, sowie die Umhüllungskompetenz zu untersuchen, wurden die Core-Mutanten (pSVcore ${ }^{\mathrm{Mut}}$ ) mit dem corenegativen, replikationsfähigen HBV-Genom (pSVHBV1.5core-) in HuH7-Zellen kotransfiziert (3.3.4.1). Beide Plasmide wurden von dem SV40-early-Promoter kontrolliert, um eine vergleichbare Expressionseffizienz zu erzielen. Fünf Tage nach der Transfektion wurden die Zellkulturüberstände sowie die geklärten Zelllysate (3.3.6) mit anti-HBsSerum (polyklonal, aus Schaf [Abt. Virologie, Universität Göttingen]) respektive antiHBc-Serum (polyklonal, aus Kaninchen [DAKO, Hamburg]) immunpräzipitiert (3.4.8.1). Die Präzipitate wurden in die EPR (3.4.6.2) eingesetzt und anschließend die virale DNA isoliert (3.4.6.3). Nach elektrophoretischer Auftrennung der DNA über ein TAE-Agarosegel (3.4.2.6) wurde das Gel getrocknet und die radioaktiven Signale mit dem Phosphoimager ,Molecular Imager FX' ausgewertet. Als Positiv-Kontrolle für eine funktionierende EPR wurden stets ca. 2 × $10^{6}$ Genomäquivalente aus einem hochtitrigen humanen Serum (ca. $2 \mu \mathrm{l} \mathrm{Serum)} \mathrm{eingesetzt.} \mathrm{Als} \mathrm{weitere} \mathrm{Positiv-Kontrolle} \mathrm{für} \mathrm{die}$ erfolgte Bildung von Kapsiden und Sekretion von Virionen diente die Kotransfektion des Expressionsvektors für das WT Coreprotein mit dem corenegativen HBV-Genom. Die Negativkontrolle war die alleinige Transfektion des Plasmids pSVHBV1.5core`. 


\subsubsection{Untersuchung der Positionen mit umhüllungsdefizientem Phänotyp nach Alanin-Substitution}

Zunächst werden die EPR-Ergebnisse für die AS-Positionen dargestellt, bei denen der Austausch gegen Alanin die Kapsidassemblierung gestattete, die Umhüllung jedoch blockierte. Für Vergleichszwecke wurde die Alanin-Mutante mit in den Versuch eingebunden. Stets sind in der linken Bildhälfte die Signale von sezernierten Virionen aus den Kulturüberständen abgebildet, auf der rechten Seite die Signale von zytoplasmatischen Nukleokapsiden.

a)

Virionen

Nukleokapside

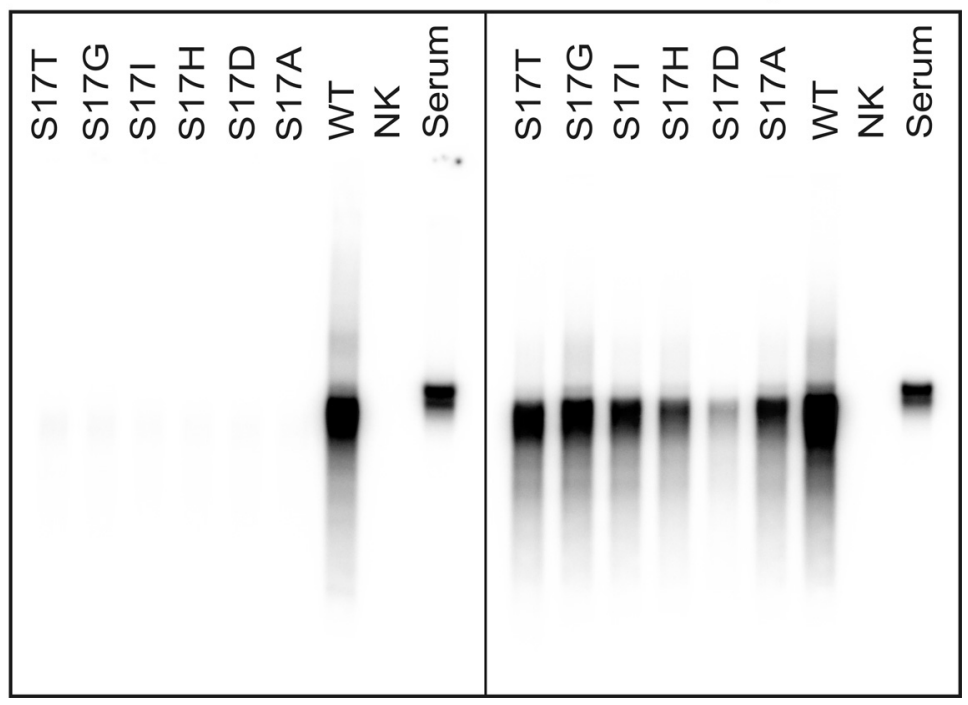

b)

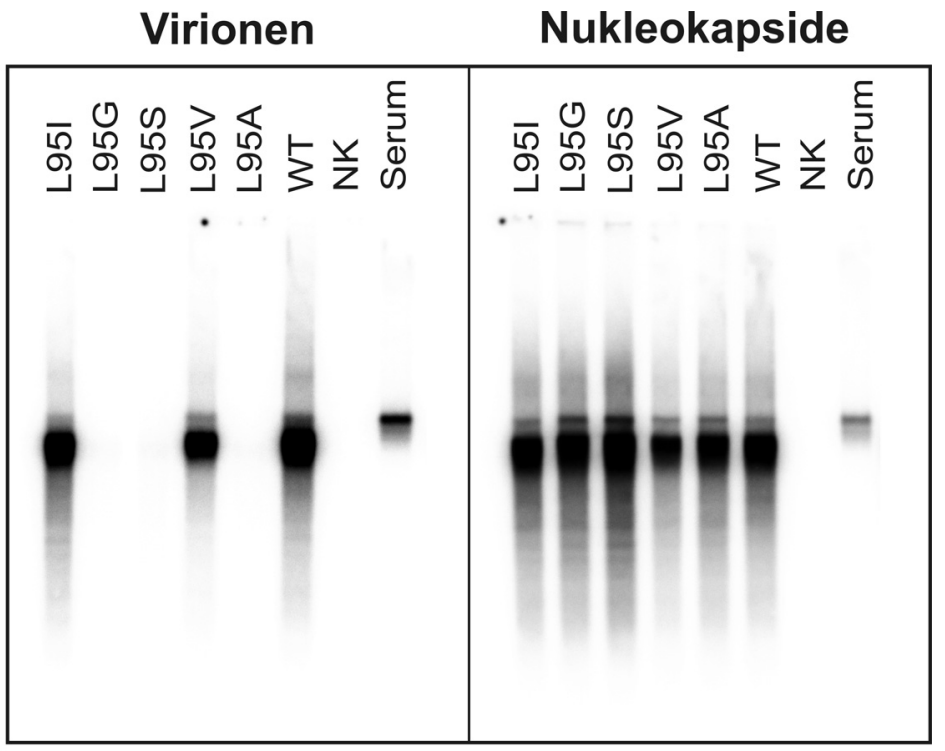


c) Virionen

Nukleokapside

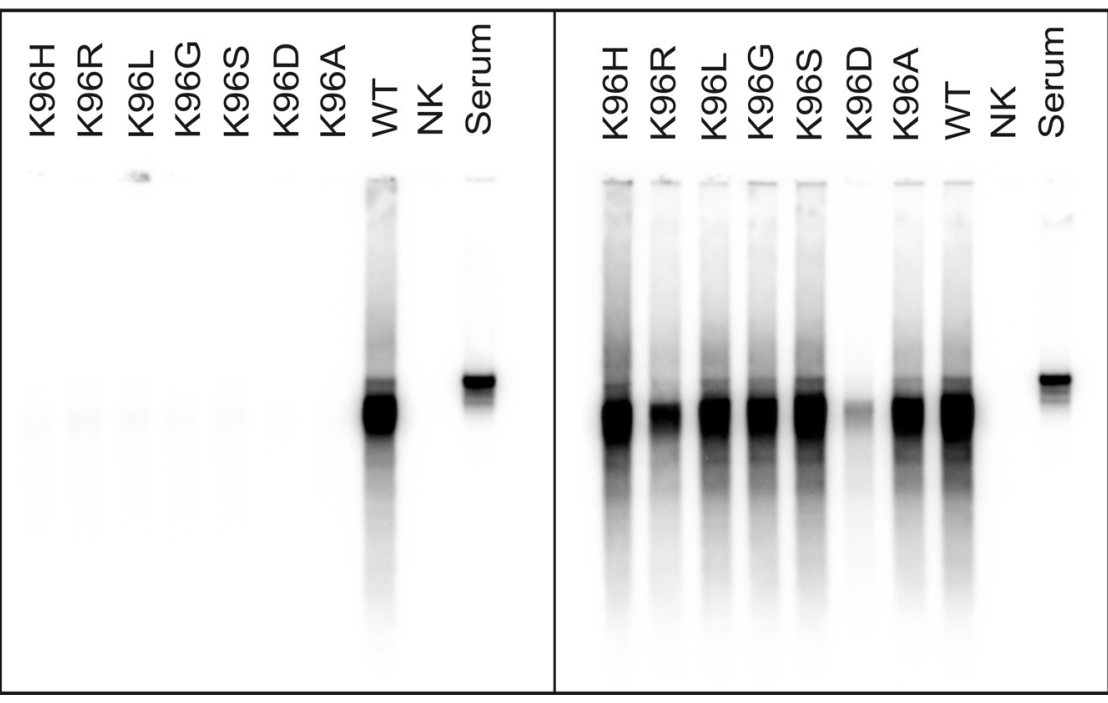

d)

Virionen Nukleokapside

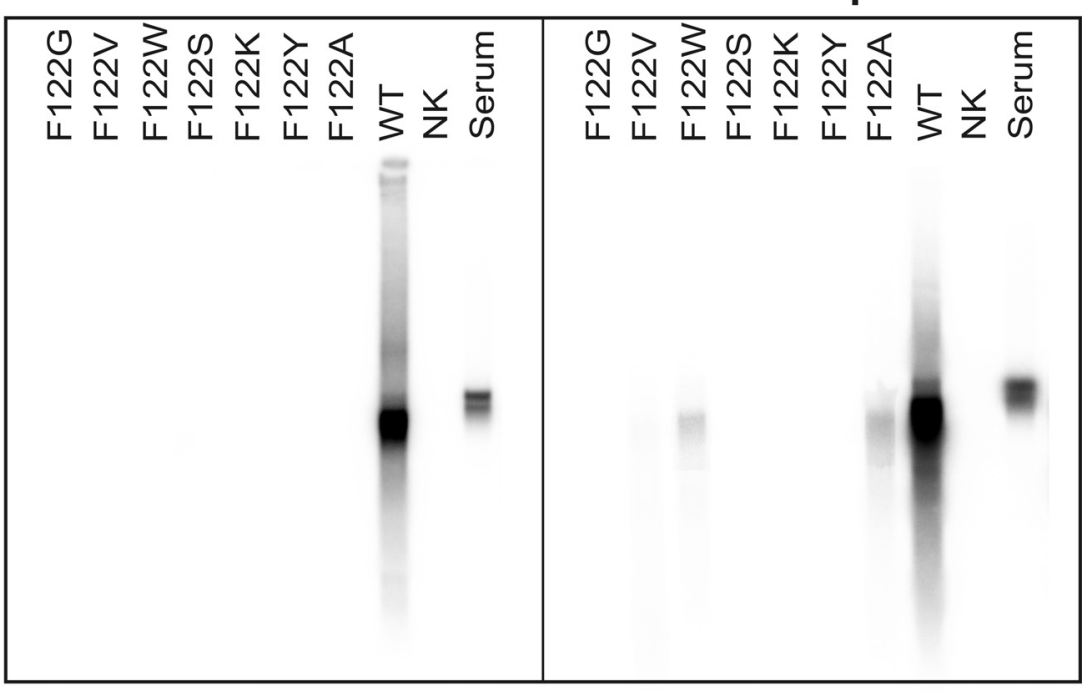

e)

Virionen

Nukleokapside

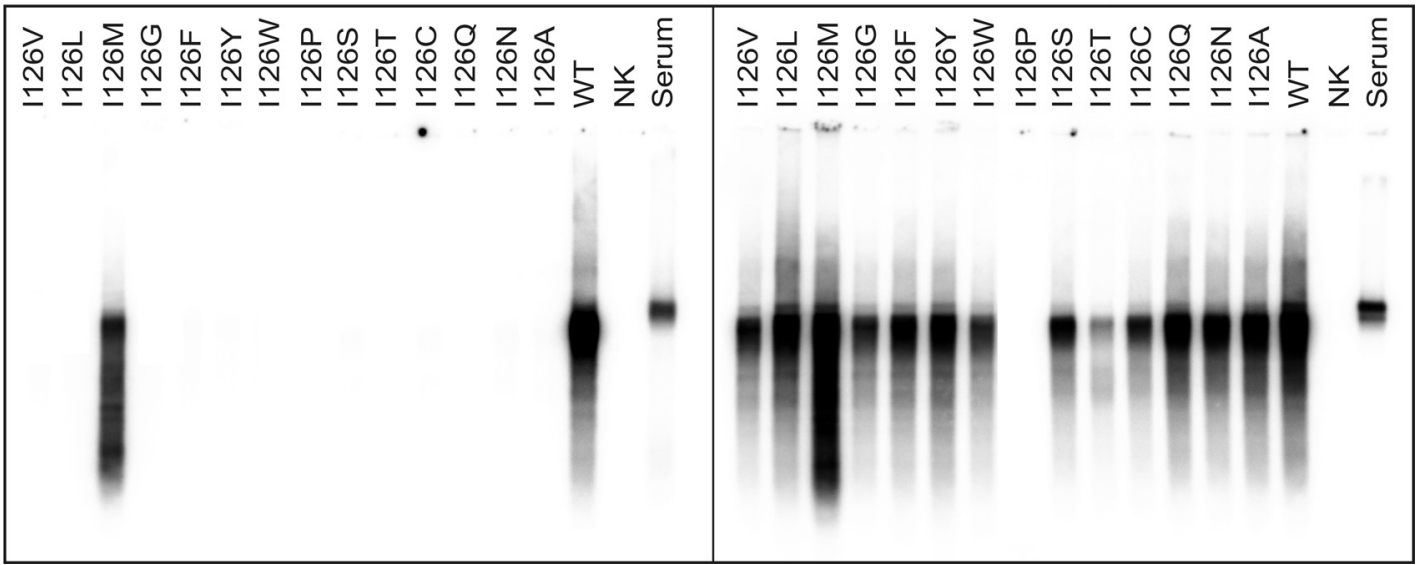


f) Virionen Nukleokapside

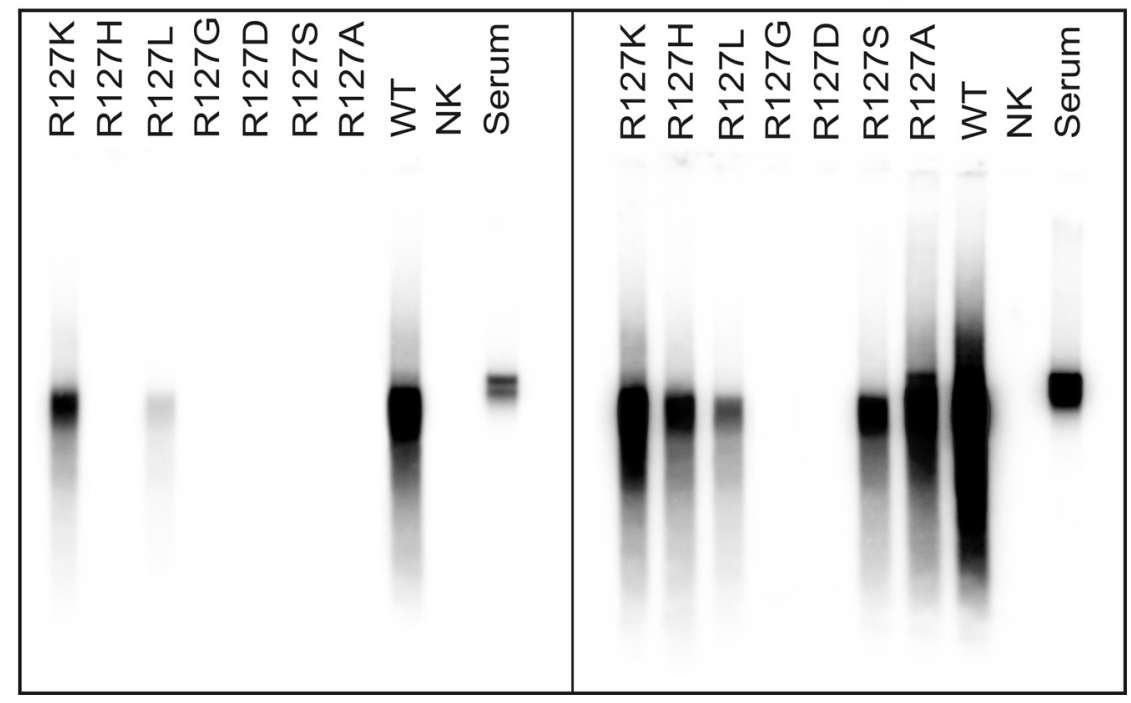

Abb. 16 (diese und vorherige Seiten): Repräsentative Ergebnisse der EPR mit Mutanten der Position a) S17, b) L95, c) K96, d) F122, e) I126 und f) R127.

Fünf Tage nach Kotransfektion von HuH7-Zellen mit corenegativen Genom (pSVHBV1.5core-) und den Core-Mutanten wurden Virionen aus Zellkulturüberständen und Nukleokapside aus Zelllysaten immunpräzipitiert, in eine EPR eingesetzt und die virale DNA isoliert. Nach Agarosegel-Elektrophorese und Trocknen der Gele wurden die radioaktiven Signale ausgewertet. In der linken Hälfte der Abbildungen sind die Signale von Virionen aus den Zellkulturüberständen, in der rechten Hälfte die Signale der zytosolischen Nukleokapside zu sehen. WT: Kotransfektion des corenegativen Genoms und Expressionsvektor für WT Coreprotein; NK: Transfektion des corenegativen Genoms; Serum: ca. 2 x $10^{6}$ Genomäquivalente aus humanem Serum.

Die Position Serin 17 (Helix a1) wurde mit Threonin, Glycin, Isoleucin, Histidin und Asparaginsäure substituiert. In Abbildung 16 a) sind die Autoradiographie-Signale der EPR dargestellt. Deutlich war zu sehen, dass S17A und die fünf weiteren Mutanten den gleichen Phänotyp besaßen: Sie waren alle in der Lage Kapside zu bilden, blockierten jedoch die Umhüllung. Die Intensitäten der Kapsid-Signale waren unterschiedlich, wobei die dem Serin sehr ähnliche AS Glycin dem WT-Signal am nächsten kam, während ein Austausch mit der sauren Asparaginsäure das schwächste Signal zeigte. Bei keiner Mutante kam es zu Signalen von Virionen aus dem Medium. Anhand dieser Ergebnisse wurde deutlich, dass Serin an dieser Position nicht für die Stabilität der Kapside, aber für deren Umhüllung essentiell ist.

Für die Experimente dieser Arbeit wurde die AS-Position Leucin 95 (Helix a4b) mit Isoleucin, Glycin, Serin und Valin substituiert und mit Hilfe der EPR phänotypisiert. Alle Mutanten zeigten Signale von zytosolischen Nukleokapsiden, die im gleichen 
Intensitätsbereich lagen wie die Signale des WT (Abb. 16 b). Neben den Kapsiden der Alanin-Mutante waren auch die Kapside der ebenfalls als kleine AS-Reste einzustufenden Serin- und die Glycin-Substitution nicht in der Lage, umhüllt zu werden. Hingegen zeigten die hydrophoben, unpolaren Isoleucin- und Valin-Mutanten etwa gleich starke Signale von Virionen aus dem Medium wie der WT. Der Leucin-Rest konnte an dieser Position durch AS mit ähnlichen Eigenschaften bzw. Strukturen funktionell ersetzt werden, während kleine AS-Reste zu einem Umhüllungsblock führten.

Die ebenfalls in der Helix a4b befindliche Position Lysin 96 wurde mit Histidin, Arginin, Leucin, Glycin, Serin und Asparaginsäure substituiert. Alle getesteten Mutanten dieser Position waren in der Lage, intrazelluläre Kapside zu generieren, blockierten jedoch die Sekretion von Virionen (Abb. 16 c). Die Intensität der KapsidSignale war unterschiedlich stark: Während K96H, K96L, K96G und K96S ebenso wie K96A ein mit dem WT vergleichbares Signal hervorbrachten, zeigten der basische K96R- und der saure K96D-Austausch eine schwache, respektive starke Verringerung der Intensität. Alle sechs neu generierten Mutanten zeigten an dieser Position die gleiche Umhüllungsdefizienz wie die Alanin-Mutante, was auf eine direkte Beteiligung des Lysins an der Umhüllung schließen lässt.

Sechs Mutanten wurden an Position Phenylalanin 122, die in der Helix $\alpha 5$ des Coreproteins liegt, hergestellt: F122G, F122V, F122W, F122S, F122K und F122Y. Diese wurden neben der umhüllungsdefizienten F122A-Mutante auf Assemblierung von Kapsiden und Sezernierung von Virionen phänotypisiert. Neben der hydrophoben Alanin-Substitution war nur die ebenfalls hydrophobe, aber aromatische TryptophanMutante in der Lage, zytoplasmatische Kapside zu generieren (Abb. $16 \mathrm{~d}$ ). Beide Signale waren jedoch sehr viel schwächer als die der WT-Kontrolle. Entsprechend konnte bei keiner der sechs Mutanten Virionen in den Kulturüberständen nachgewiesen werden. Diese Ergebnisse zeigten, dass F122 strukturelle Funktionen für die Stabilität der Kapside besitzt, wobei eine Beteiligung an der Umhüllung nicht ausgeschlossen werden kann (F122A und F122W).

Die Position Isoleucin 126 wurde mit insgesamt 13 AS-Resten substituiert: V, L, M, G, F, Y, W, P, S, T, C, Q und N. Die EPR-Ergebnisse zeigten, dass elf der 13 Mutanten 
Kapside assemblieren konnten, deren Umhüllung jedoch blockiert war (Abb. 16 e). Die Signalintensität war bei nahezu allen Mutanten der des WT sehr ähnlich. Der einzige AS-Rest, der eine Umhüllung zuließ, war das hydrophobe, unpolare Methionin, während die mit einem Pyrrolidin-Ring ausgestattete Prolin-Mutante der einzige Austausch war, bei dem keine Kapsidbildung nachzuweisen war. Die große Anzahl an Mutanten, die ebenso wie die Alanin-Substitution umhüllungsdefizient waren, deutet auf eine essentielle Funktion des Isoleucins an dieser Position während der Umhüllung.

Die AS Arginin 127 wurde gegen sechs AS-Reste ausgetauscht: Lysin, Histidin, Leucin, Glycin, Asparaginsäure und Serin. Es zeigte sich, dass die Substitutionen mit basischem Histidin und polarem Serin, ebenso wie die Alanin-Mutante, in der Lage waren Kapside zu assemblieren, deren Umhüllung aber blockierten (Abb. 16 f). Das hydrophobe, unpolare Glycin und die Asparaginsäure hemmten hingegen schon die Kapsidformation. Die wie der WT basische Lysin-Mutante zeigte sowohl Signale von zytosolischen Nukleokapsiden als auch von sezernierten Virionen. Die Signalintensität war jedoch schwächer als beim WT. Die Substitution mit hydrophobem Leucin führte zu einem WT-ähnlichen Assemblierungs- und Sekretionstyp, jedoch mit starker Reduktion der Signale. Die EPR-Ergebnisse der Mutanten an Position R127 weisen auf eine Beteiligung sowohl an der Kapsidstabilität, als auch an dem Umhüllungsprozess hin.

\subsubsection{Untersuchung der Positionen mit WT-Phänotyp nach Alanin-Substitution}

Analog der Analyse der Positionen, bei denen die Kapside nach der Alanin-Substitution umhüllungsdefizient waren (4.1.3.1), wurden die Positionen, die nach AlaninSubstitution den WT-Phänotyp zeigten (PonSEL \& BRUSS, 2003), mit Hilfe der EPR phänotypisiert. 
a) Virionen

Nukleokapside

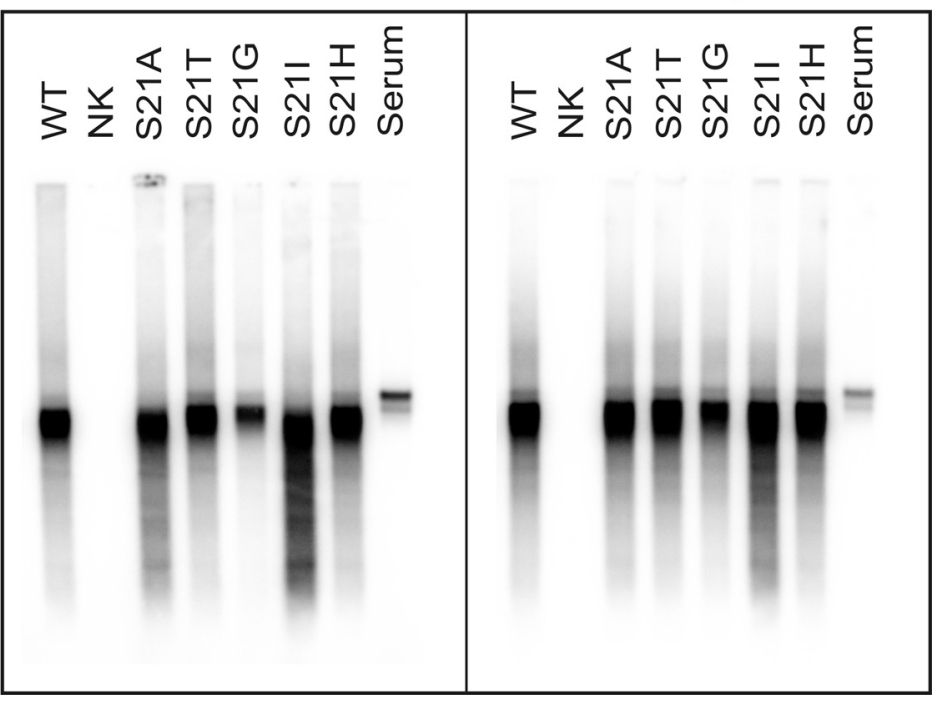

b)

Virionen

Nukleokapside

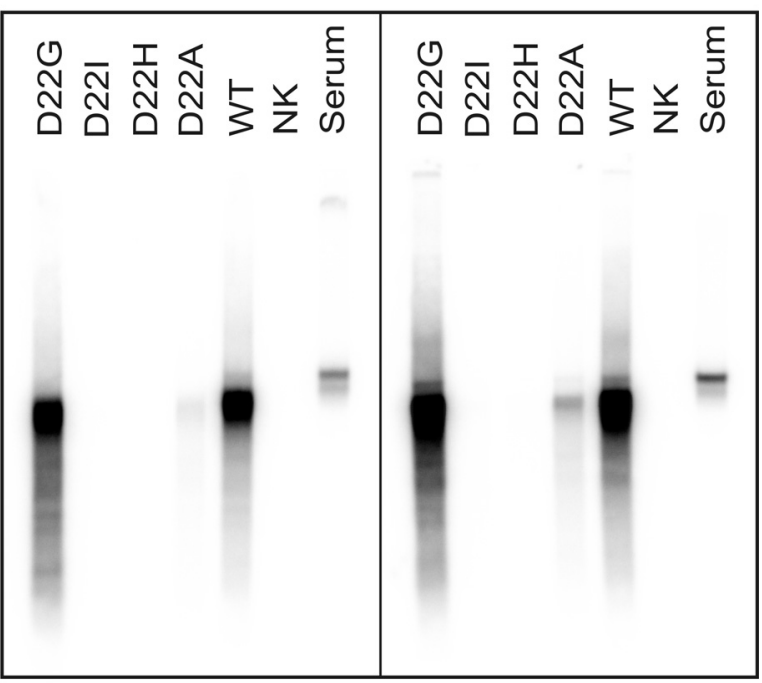

c)

Virionen

Nukleokapside

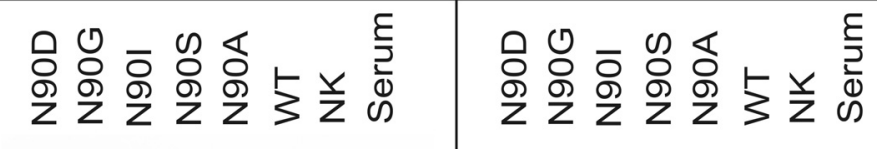

....." 
d) Virionen Nukleokapside

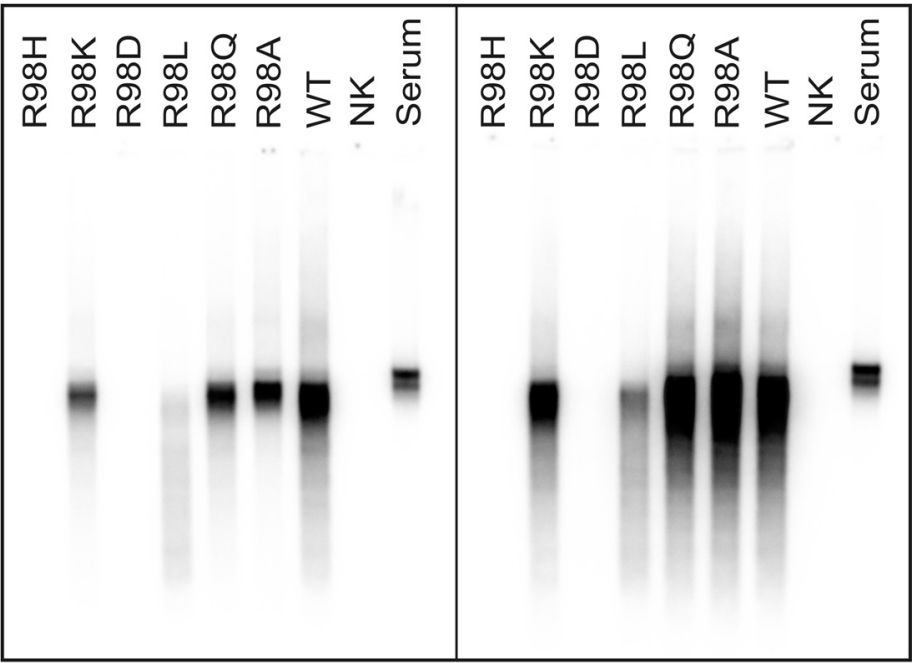

Abb. 17 (diese und vorherige Seite): Repräsentative Ergebnisse der EPR mit Mutanten der Positionen a) S21, b) D22, c) N90 und d) R98.

Fünf Tage nach Kotransfektion von HuH7-Zellen mit corenegativen Genom (pSVHBV1.5core) und den entsprechenden Core-Mutanten wurden Virionen aus Zellkulturüberständen und Nukleokapside aus Zelllysaten immunpräzipitiert, in eine EPR eingesetzt und die virale DNA isoliert. Nach Agarosegel-Elektrophorese und Trocknen der Gele wurden die radioaktiven Signale ausgewertet. In der linken Hälfte der Abbildungen sind die Signale von Virionen aus den Zellkulturüberständen, in der rechten Hälfte die Signale der zytosolischen Nukleokapside zu sehen. WT: Kotransfektion des corenegativen Genoms und Expressionsvektor für das WT Coreprotein; NK: Transfektion des corenegativen Genoms; Serum: ca. 2 × $10^{6}$ Genomäquivalente aus humanem Serum.

Die Position Serin 21 wurde mit den folgenden vier AS-Resten substituiert: Threonin, Glycin, Isoleucin und Histidin. Alle Mutanten der Position S21 konnten den WTPhänotyp reproduzieren (Abb. 17 a). Die Signale fast aller Substituenten waren sowohl bei den Nukleokapsiden aus den Zelllysaten, als auch bei den Virionen aus Zellkulturüberständen dem WT entsprechend stark. Nur die Glycin-Mutante zeigte reduzierte Signale. Die Ergebnisse ließen den Schluss zu, dass Serin an dieser Position weder für die Kapsidstabilität noch für die Umhüllung nötig war.

Drei Mutanten wurden an der Position Asparaginsäure 22 hergestellt und auf Umhüllungskompetenz getestet: Glycin, Isoleucin und Histidin. Diese drei besaßen nach der EPR unterschiedliche Phänotypen (Abb.17 b): Die hydrophobe GlycinMutante zeigte sowohl im Lysat als auch im Zellkulturüberstand Signale in der gleichen Intensität wie die WT-Kontrolle. Sowohl der hydrophobe Isoleucin-, als auch der basische Histidin-Substituent blockierten hingegen schon die zytosolische Kapsid- 
formation. Kleine AS-Reste wie Alanin und Glycin, nicht aber größere Strukturen (Isoleucin und Histidin), waren in der Lage, die Asparaginsäure zu ersetzen. Dies lässt auf eine eher funktionelle Bedeutung dieser Position schließen.

Der AS-Rest Asparagin 90 wurde in dieser Arbeit mit vier Resten substituiert: Asparaginsäure, Glycin, Isoleucin und Serin. Nach Kotransfektion mit dem corenegativen Genom zeigten alle vier Mutanten unterschiedlich starke Signale von zytosolischen Nukleokapsiden (Abb. 17 c). Dabei erreichten N90D und N90I annähernd die Signalintensität des WT, während die Kapsid-Signale von N90G und N90S etwas schwächer waren. Sezernierte Virionen ließen sich ebenfalls bei allen vier Mutanten nachweisen. Die Asparaginsäure-Substitution erreichte ungefähr das Signal-Niveau des WT, die anderen drei zeigten jedoch eine deutliche Reduktion bei der Umhüllungseffizienz. Neben der Alanin-Substitution waren auch die weiteren vier Mutanten fähig, die Funktionen des Asparagins während der Kapsidbildung und -umhüllung zu übernehmen.

Die AS Arginin 98 wurde gegen fünf AS-Reste ausgetauscht und mit Hilfe der EPR phänotypisiert. Die eingesetzten Reste waren Histidin, Lysin, Asparaginsäure, Leucin und Glutamin. Nach Auswertung war zu sehen, dass die drei Mutanten R98K, R98Q und R98L sowohl Kapsidassemblierung, als auch die Umhüllung erlaubten (Abb. 17 d). Während die polare Glutamin-Mutante annähernd gleich starke Signale zeigte wie der WT, generierte die basische Mutante R98K schwächere Signale. Die hydrophobe Leucin-Substitution zeigte sehr schwache Signale in den Experimenten. Die basische Substitution R98H blockierte, ebenso wie der Austausch gegen den sauren Rest Asparaginsäure, die Kapsidbildung. Das Arginin an Position 98 konnte durch vier ASReste funktionell substituiert werden, während zwei Mutationen die Kapsidstabilität beeinträchtigten. Dabei zeigte sich, dass nicht die Ladung des eingebrachten Restes das Hauptkriterium für eine mögliche Substitution war. 


\subsubsection{Zusammenfassung der EPR-Ergebnisse der untersuchten AS-Positionen und deren Darstellung im 3D-Modell}

Die Signalstärken der EPR-Ergebnisse der Core-Mutanten, die nach Alanin-Substitution einen umhüllungsdefizienten Phänotyp (S17, L95, K96, F122, I126 und R127) bzw. WT Phänotyp (S21, D22, N90 und R98) aufwiesen, wurden mit Hilfe der Software ,Quantity One’ (4.3.0 Build 019) der Firma BIO-RAD analysiert. Um den Grad der Umhüllungseffizienz zu bestimmen, wurden die Quotienten aus dem Signal des Mediums (M) und dem Signal des Lysats (L) ermittelt.

Mit Hilfe dieser Auswertung wurden die Mutanten in drei Phänotyp-Gruppen unterteilt: 1) Mutanten, die sowohl die Kapsidassemblierung (K), als auch die Bildung der Virionen (V) zuließen (WT-Phänotyp; $\mathrm{K}+/ \mathrm{V}+$ ), wiesen einen M/L-Quotienten $\geq 0,05$ auf, 2) Mutanten, die nur die Formation der Kapside gestatteten, deren Umhüllung aber blockierten (umhüllungsdefizienter Phänotyp; K+/V-), besaßen einen M/L-Quotienten von $\leq$ 0,04 und 3) Mutanten, die die Assemblierung reifer Nukleokapside hemmten (Kapsidassemblierungs-defizienter Phänotyp; K-/V-). Die Mutanten wurden dieser Gruppe zugeordnet, wenn das Signal der Kapside weniger als 5 \% des Signals der WTKapside betrug, bei gleichzeitiger Umhüllungsdefizienz. Eine Zusammenfassung der Daten ist in Tabelle 13 dargestellt.

Tab. 13: Zusammenfassung der EPR-Auswertung für die Mutanten der analysierten Positionen. _ $^{\mathrm{a}}$ : Angabe nicht sinnvoll; ${ }^{\mathrm{b}}$ : gemittelter Wert aus elf Experimenten

\begin{tabular}{|c|c|c|c|c|}
\hline \multirow[t]{2}{*}{ Position } & \multicolumn{2}{|c|}{ Phänotyp } & \multicolumn{2}{|c|}{$\begin{array}{c}\text { Signalintensität } \\
\text { Virionen/Nukleokapside }(M / L)\end{array}$} \\
\hline & Nukleokapside & Virionen & Experiment 1 & Experiment 2 \\
\hline S17A & + & - & 0,02 & 0,01 \\
\hline S17D & + & - & 0,01 & 0,02 \\
\hline S17G & + & - & 0,00 & 0,01 \\
\hline $\mathrm{S} 17 \mathrm{H}$ & + & - & 0,00 & 0,01 \\
\hline S17I & + & - & 0,00 & 0,01 \\
\hline $\mathrm{S} 17 \mathrm{~T}$ & + & - & 0,01 & 0,02 \\
\hline S21A & + & + & 0,92 & 0,92 \\
\hline S21G & + & + & 0,70 & 0,70 \\
\hline $\mathrm{S} 21 \mathrm{H}$ & + & + & 0,96 & 0,84 \\
\hline S21I & + & + & 0,90 & 0,92 \\
\hline $\mathrm{S} 21 \mathrm{~T}$ & + & + & 0,90 & 0,86 \\
\hline
\end{tabular}




\begin{tabular}{|c|c|c|c|c|}
\hline D22A & + & + & 0,25 & 0,44 \\
\hline D22G & + & + & 0,73 & 0,74 \\
\hline $\mathrm{D} 22 \mathrm{H}$ & - & - & $-^{\mathrm{a}}$ & $-^{\mathrm{a}}$ \\
\hline D22I & - & - & $-^{\mathrm{a}}$ & $-^{\mathrm{a}}$ \\
\hline N90A & + & + & 0,48 & 0,46 \\
\hline N90D & + & + & 0,77 & 0,92 \\
\hline N90G & + & + & 0,53 & 0,62 \\
\hline N90I & + & + & 0,48 & 0,46 \\
\hline N90S & + & + & 0,52 & 0,81 \\
\hline L95A & + & - & 0,01 & 0,01 \\
\hline L95G & + & - & 0,00 & 0,01 \\
\hline L95I & + & + & 0,21 & 0,58 \\
\hline L95S & + & - & 0,00 & 0,00 \\
\hline L95V & + & + & 0,20 & 0,65 \\
\hline K96A & + & - & 0,01 & 0,01 \\
\hline K96D & + & - & 0,01 & 0,01 \\
\hline K96G & + & - & 0,01 & 0,01 \\
\hline $\mathrm{K} 96 \mathrm{H}$ & + & - & 0,01 & 0,01 \\
\hline K96L & + & - & 0,01 & 0,01 \\
\hline K96R & + & - & 0,02 & 0,01 \\
\hline K96S & + & - & 0,00 & 0,01 \\
\hline R98A & + & + & 0,47 & 0,28 \\
\hline R98D & - & - & $-^{\mathrm{a}}$ & $-^{\mathrm{a}}$ \\
\hline $\mathrm{R} 98 \mathrm{H}$ & - & - & $-^{\mathrm{a}}$ & $-^{\mathrm{a}}$ \\
\hline R98K & + & + & 0,45 & 0,29 \\
\hline R98L & + & + & 0,21 & 0,16 \\
\hline R98Q & + & + & 0,50 & 0,34 \\
\hline F122A & + & - & 0,01 & 0,02 \\
\hline F122G & - & - & $-^{\mathrm{a}}$ & $-^{\mathrm{a}}$ \\
\hline F122K & - & - & $-^{\mathrm{a}}$ & $-^{\mathrm{a}}$ \\
\hline F122S & - & - & $-^{\mathrm{a}}$ & $-^{\mathrm{a}}$ \\
\hline F122V & - & - & $-^{\mathrm{a}}$ & $-^{\mathrm{a}}$ \\
\hline F122W & + & - & 0,02 & 0,02 \\
\hline F122Y & - & - & $-^{\mathrm{a}}$ & $-^{\mathrm{a}}$ \\
\hline I126A & + & - & 0,00 & 0,01 \\
\hline I126C & + & - & 0,00 & 0,00 \\
\hline I126F & + & - & 0,02 & 0,01 \\
\hline I126G & + & - & 0,02 & 0,01 \\
\hline I126L & + & - & 0,01 & 0,01 \\
\hline $\mathrm{I} 126 \mathrm{M}$ & + & + & 0,84 & 0,49 \\
\hline I126N & + & - & 0,01 & 0,00 \\
\hline I126P & - & - & $-^{\mathrm{a}}$ & $-^{\mathrm{a}}$ \\
\hline I126Q & + & - & 0,00 & 0,03 \\
\hline I126S & + & - & 0,01 & 0,00 \\
\hline I126T & + & - & 0,00 & 0,00 \\
\hline I126V & + & - & 0,02 & 0,04 \\
\hline
\end{tabular}




\begin{tabular}{|l|c|c|c|c|}
\hline I126W & + & - & 0,01 & 0,03 \\
\hline I126Y & + & - & 0,01 & 0,00 \\
\hline R127A & + & - & 0,01 & 0,00 \\
\hline R127D & - & - & $-^{\mathrm{a}}$ & $-^{\mathrm{a}}$ \\
\hline R127G & - & - & $-^{\mathrm{a}}$ & $-^{\mathrm{a}}$ \\
\hline R127H & + & - & 0,00 & 0,01 \\
\hline R127K & + & + & 0,50 & 0,54 \\
\hline R127L & + & + & 0,54 & 0,56 \\
\hline R127S & + & - & 0,02 & 0,00 \\
\hline WT & + & + & $0,77^{\mathrm{b}}$ & $0,85^{\mathrm{b}}$ \\
\hline
\end{tabular}

Abbildung 18 zeigt die zehn analysierten AS-Positionen innerhalb eines 3D-Modells eines Coreprotein-Homodimer aus zwei verschiedenen Blickwinkeln. Die mutierten AS-Reste sind farblich markiert, die nicht veränderten grau eingefärbt. Die Positionen, deren Mutanten überwiegend dem WT-Phänotyp $(\mathrm{K}+/ \mathrm{V}+)$ zuzuordnen waren, wurden hellgrün eingefärbt (S21, N90 und R98), während die, bei denen die Mutanten mehrheitlich den $\mathrm{K}+/ \mathrm{V}$ - der ursprünglichen Alanin-Substitution reproduzierten, in Orange dargestellt sind (S17, L95, K96 und I126). Die Mutationen der in Lila dargestellten Positionen D22 und R127 verteilten sich annähernd gleichmäßig auf die drei Phänotyp-Gruppen. In Hellblau wurde Position F122 eingefärbt, als Zeichen für Mutanten, die überwiegend die Kapsidassemblierung blockierten.

Die Ergebnisse verdeutlichen, dass an vier der sechs Positionen mit umhüllungsdefizienter Alanin-Mutation dieser Phänotyp auch nach Mehrfachsubstitution reproduziert werden konnte. Diese Positionen wurden daher als essentiell für den Umhüllungsprozess eingestuft. Bei drei der vier Positionen, die den WT-Phänotyp nach Alanin-Substitution besaßen, zeigte sich die Mehrheit der in dieser Arbeit generierten Mutationen ebenfalls umhüllungskompetent, so dass sie weder für die Kapsidstabilität, noch für die Umhüllung als nötig erscheinen. Die drei weiteren getesteten Positionen lassen keine eindeutige Zuordnung zu. 
a)

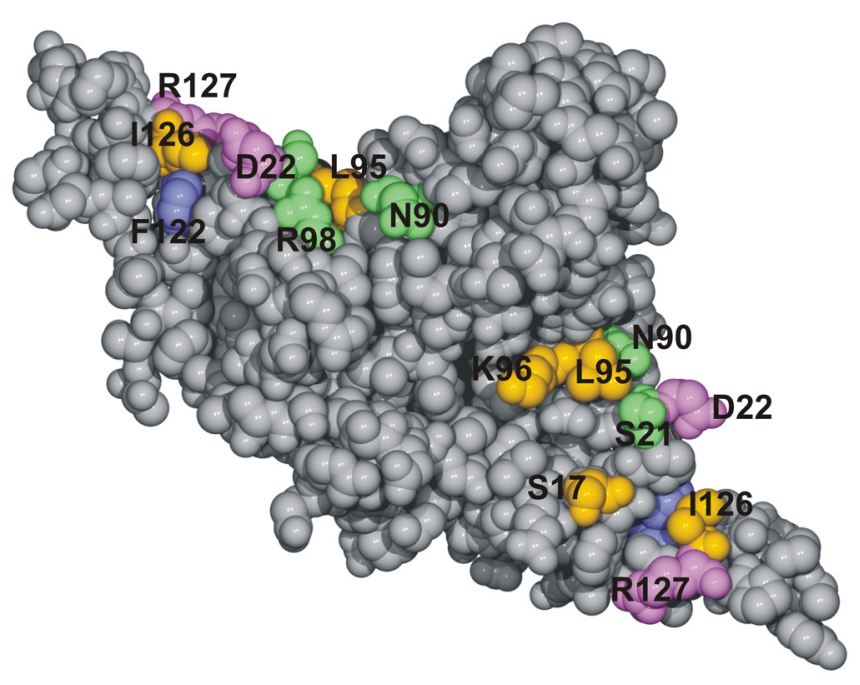

b)

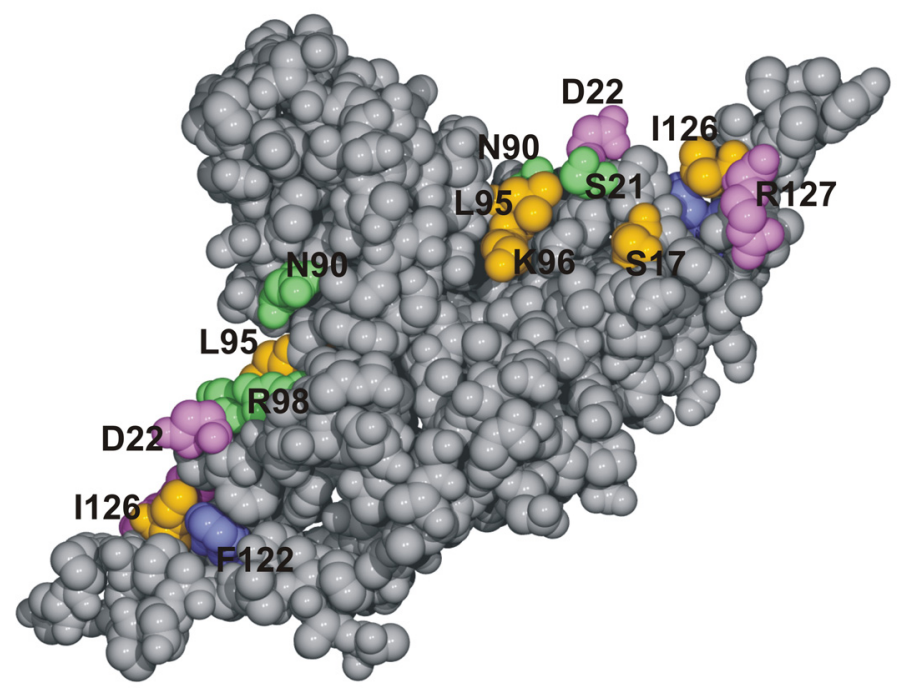

Abb. 18: Darstellung der Phänotypen der zehn getesteten AS-Positionen im Kugelmodell des Coreproteins von Vorder- (a) und Rückseite (b) mit Hilfe einer Farbkodierung.

Die Positionen, deren Mutation nach der EPR-Analyse überwiegend den K+/V+ Phänotyp zeigten (S21, N90 und R98), sind hellgrün eingefärbt, und die mit vorwiegend K-/VPhänotyp (F122) hellblau. Die AS-Positionen, deren Mutationen zumeist K+/V- waren (S17, L95, K96 und I126), sind in Orange dargestellt, während die, bei denen die Mutationen verschiedene Phänotypen zeigten, in Lila abgebildet sind (R127 und D22). 


\subsection{5 Überprüfung der Mutationen an der Position I126 auf transdominant negative Wirkung}

Ein wichtiger Punkt bei der Mutationsanalyse von strukturellen und funktionellen Proteinen ist die Frage, ob das zu untersuchende Protein durch die eingeführte Mutation bei gleichzeitiger Expression des WT-Proteins einen transdominant negativen Einfluss auf dessen Funktion nimmt.

Die Grundbausteine der Kapsidassemblierung sind die Coreproteine, die direkt nach der Synthese Homodimere ausbilden. Es ist möglich, dass dabei die umhüllungsdefizienten Core-Mutanten zusammen mit den WT Coreproteinen neben Homo- auch Heterodimere bilden und dass die drei verschiedenen Dimer-Typen (WT, WT/Mutante und Mutante) auch bei den Interdimer-Kontakten in Berührung kommen können. Dadurch könnten die Mutanten transdominant negative Auswirkungen in Form einer Blockierung sowohl auf die Umhüllungsfähigkeit, als auch auf die Kapsidassemblierung des WT Coreprotein ausüben. Wenn sich Mutante und WT nicht ausreichend mischen, sondern getrennt zu Partikeln assemblieren, sollte kein transdominant negativer Effekt zu beobachten sein. Ebenso sollte kein Effekt entstehen, wenn für die Umhüllung eines Kapsids wenige WT Homodimere ausreichen.

Die mit 13 Mutanten am umfangreichsten analysierte Position I126 wurde auf einen transdominant negativen Effekt hin untersucht. Dazu wurde ein replikationsfähiges HBV-Genom (pSVHBV1.5; 2.5) mit den Expressionsvektoren für die Core-Mutanten kotransfiziert. Zur Kontrolle wurde das WT Coreprotein mit diesem Genom exprimiert. Um auszuschließen, dass eine Transfektion mit einem zweiten Plasmid generell hemmende oder fördernde Auswirkungen auf die Expressionseffizienz und Funktionalität des Proteins besitzt, wurde ein Plasmid (pEF/Myc-His A; 2.5) ohne HBV Coregen kotransfiziert.

Fünf Tage nach der Transfektion von HuH7-Zellen mit der Kalziumphosphat-Methode (3.3.4.1) wurden die zytosolischen Kapside mit anti-HBc (2.8) und die sezernierten Virionen mit anti-HBs (2.8) aus den Zelllysaten (3.3.6) bzw. den Zellkulturüberständen immunpräzipitiert (3.4.8.1) und in die EPR eingesetzt (3.4.6.2). Nach Aufreinigung der viralen DNA (3.4.6.3), Auftrennung über ein Agarosegel (3.4.2.6) und Trocknen der Gele wurden die radioaktiven Signale mit Hilfe des Phosphoimagers ausgewertet. 


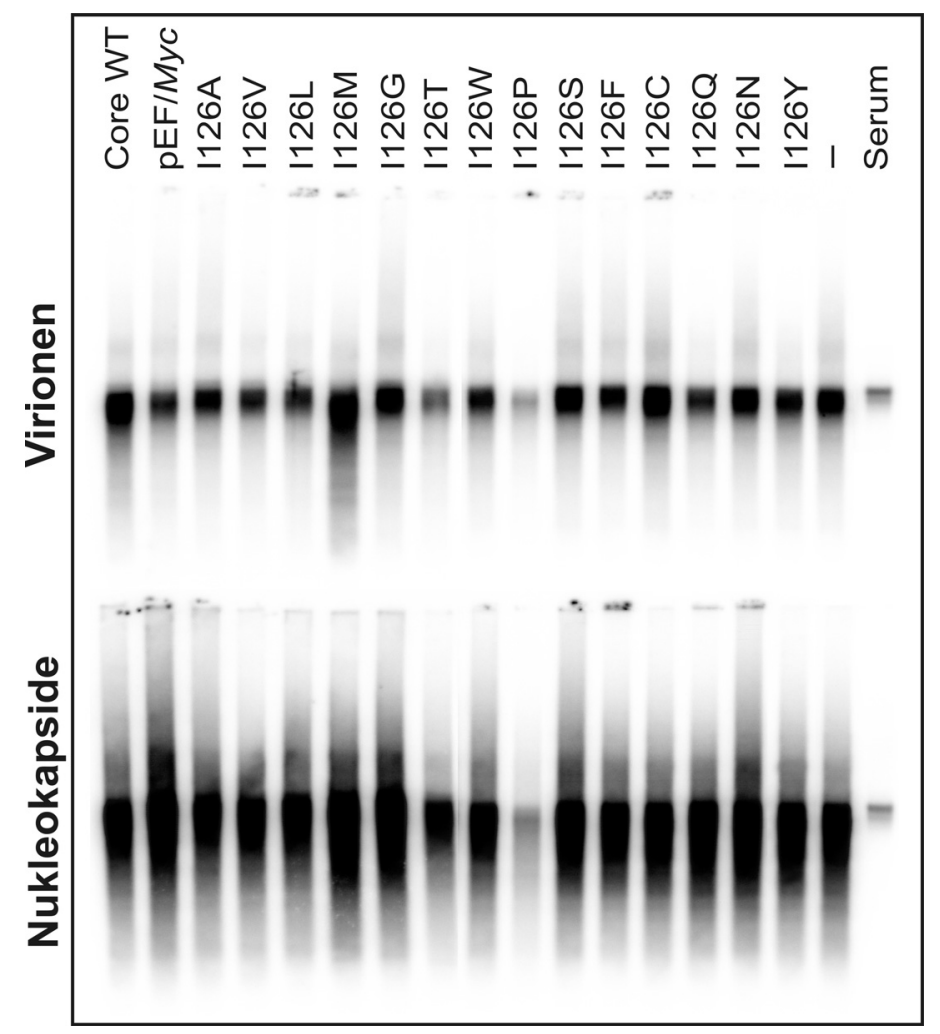

Abb. 19: Untersuchung auf transdominant negative Wirkung der Core-Mutanten der Position I126 auf das WT Coreprotein bei der Kapsidumhüllung.

HuH7-Zellen wurden mit dem Wildtyp HBV-Genom (pSVHBV1.5) alleine (-), zusammen mit dem WT Coreprotein (Core WT), dem Vektor pEF/Myc-His A ohne Coreprotein (pEF/Myc) oder den Core-Mutanten der Position I126 transfiziert. Fünf Tage später wurden Virionen aus Zellkulturüberständen und Nukleokapside aus Zelllysaten immunpräzipitiert, in eine EPR eingesetzt und mit dem Phosphoimager ausgewertet. Im oberen Bereich der Abbildung sind die Signale von Virionen, im unteren Bildbereich die Signale der Nukleokapside zu sehen. Core WT: Kotransfektion mit pSVcore ${ }^{\text {WT }}$; - : Transfektion von pSVHBV1.5; Serum: ca. 2 x $10^{6}$ Genomäquivalente aus humanem Serum.

Die Kotransfektion des HBV-Genoms mit WT Coreprotein (Core WT) erhöhte die Menge an sezernierten Virionen, im Vergleich zur Transfektion des HBV-Genoms alleine (-) (Abb. 19). Der gleiche Effekt war auch bei der umhüllungskompetenten Core-Mutante I126M zu sehen. Bei der umhüllungsdefizienten Mutante I126T und der Mutante I126P, die die Kapsidformation blockierte, kam es sowohl im Lysat, als auch im Medium zu einer schwachen respektive starken Reduktion der Signale. Die weiteren zehn Core-Mutanten, wie auch die Kotransfektion mit dem Kontroll-Plasmid pEF/MycHis A zeigten keinen signifikanten Unterschied in der Signalstärke im Vergleich zu der alleinigen Transfektion von pSVHBV1.5. Bei keiner der getesteten Core-Mutanten ergab sich ein transdominant negativer Phänotyp in Bezug auf die Umhüllungseffizienz. 


\subsubsection{Untersuchung der Konzentrationsabhängigkeit der Core-Mutanten für die Ausprägung der Umhüllungsdefizienz}

Das Kapsid des HBV besteht je nach Symmetrie aus $90(\mathrm{~T}=3)$ bzw. $120 \quad(\mathrm{~T}=4)$ Coreproteinen Homodimeren. Somit kommt eine Mutation auf der Oberfläche eines Kapsides in 180-, respektive 240-facher Anzahl vor. Da es sowohl während der Bildung von Homodimeren, als auch von Kapsiden zu einem engen Kontakt zwischen den WT Coreproteinen und den Core-Mutanten kommen kann, stellt sich die Frage, welchen phänotypischen Einfluss verschiedene molare Mengenverhältnisse von Mutante und WT mit sich bringen. Daher wurde die Ausprägung der Umhüllungsdefizienz in Abhängigkeit von der Konzentration an Core-Mutanten ermittelt.

Für einen experimentellen Nachweis wurde eine Kotransfektion mit dem corenegativen HBV Genom und einer Verdünnungsreihe aus WT Coreprotein und der Core-Mutante I126A durchgeführt. Dafür wurden in $10 \%$-Schritten 50 bis $100 \%$ pSVcore $^{\mathrm{I} 26 \mathrm{~A}}$ mit den entsprechenden Mengen an pSVcore (WT) gemischt und wie oben (4.2.5) analysiert.

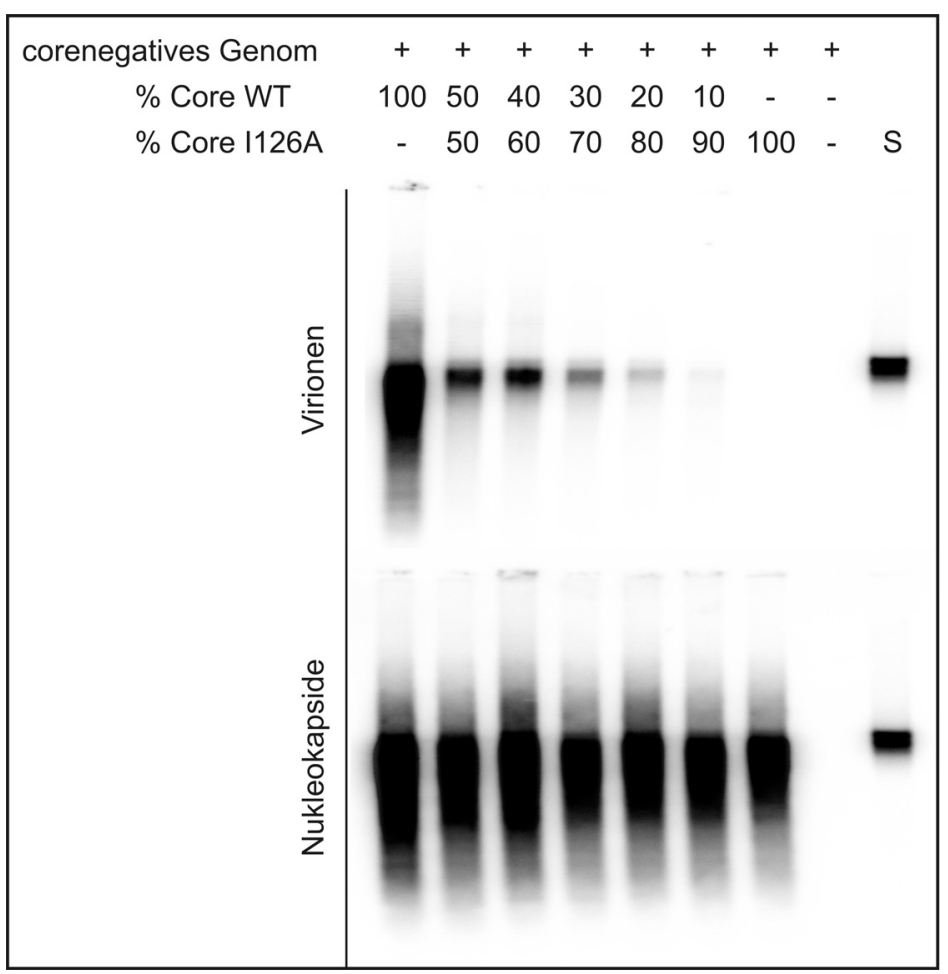

Abb. 20: Untersuchung auf transdominant negativen Einfluss der Core-Mutation I126A auf das WT Coreprotein während der Kapsidumhüllung. 
HuH7-Zellen wurden mit dem corenegativen HBV-Genom (pSVHBV1.5core`) alleine, zusammen mit dem WT Coreprotein (Core WT), der Core-Mutante I126A oder einem Gemisch aus beiden transfiziert. Am fünften Tag nach der Transfektion wurden Virionen aus Zellkulturüberständen und Nukleokapside aus Zelllysaten immunpräzipitiert, einer EPR unterzogen und mit dem Phosphoimager ausgewertet. Im oberen Bereich der Abbildung sind die Signale von sezernierten Virionen, im unteren Bildbereich die Signale der zytosolischen Nukleokapside zu sehen. Core WT: Kotransfektion mit pSVcore ${ }^{\text {WT }}$; Core I126A: Kotransfektion mit pSVcore ${ }^{\mathrm{I} 126 \mathrm{~A}}$; S: ca. 2 × $10^{6}$ Genomäquivalente aus humanem Serum.

Die Kotransfektion des corenegativen Genoms zusammen mit WT Coreprotein ergab die erwartet starken Signale von Nukleokapsiden und sezernierten Virionen. Ebenso zeigte die Kotransfektion mit der Mutante I126A den erwarteten Umhüllungsblock, und die alleinige Transfektion des corenegativen Genoms ergab, wie antizipiert, weder ein Signal im Medium noch im Lysat. Die Dreifach-Transfektionen zeigten durchweg starke Nukleokapsid-Signale im Zelllysat, reduzierten aber deutlich die Sekretion von reifen Virionen. Die Transfektionsverhältnisse von 50:50 und 60:40 (WT:I126A) sezernierten etwa gleiche Mengen an Virionen, jedoch ca. $80 \%$ weniger als der WT. Die Signalintensität von Virus-Partikeln nahm bei den folgenden drei Proben (70:30, 80:20 und 90:10) sukzessiv ab, wodurch eine Verringerung der Umhüllungsfähigkeit deutlich wird.

\subsubsection{Untersuchung der Kapsidassemblierung-blockierenden Mutanten}

Neben der Umhüllungskompetenz können Mutationen im Coreprotein die Kapsidstabilität, den Beginn der Kapsidassemblierung, die Dimerbildung oder auch andere Funktionen beeinträchtigen. Auch muss eine Beeinträchtigung der reversen Transkription der pgRNA in das partiell doppelsträngige DNA-Genom, ebenso wie eine Blockierung der Generierung des Reifesignals des Kapsids berücksichtigt werden, welches vermutlich für die Umhüllung essentiell ist (GERELSAIKHAN et al., 1996; WEI et al., 1996; PERLMAN \& HU, 2003).

Bei der EPR-Analyse der Core-Mutanten auf Umhüllungskompetenz (4.1.3) waren neben Mutanten, die einen WT Phänotyp zeigten $(\mathrm{K}+/ \mathrm{V}+)$ oder die Umhüllung blockierten (K+/V-), auch zwölf Mutanten vorhanden, die keine detektierbaren Kapside bildeten: D22H, D22I, R98D, R98H, F122G, F122K, F122S, F122V, F122Y, I126P, 
R127D und R127G. Mit Hilfe der PEG-Fällung zytosolischer Kapside (3.4.8.2.2) und anschließender Western Blot-Analyse (3.4.8.3) sollte zunächst untersucht werden, ob die Mutanten die Assemblierung stabiler Kapside zuließen. Mittels Southern Blot (3.4.6.1) und RT-PCR (3.4.7) sollte dann geprüft werden, ob diese Kapside das DNAGenom respektive die pgRNA enthalten. Durch CsCl-Fraktionierung von Zellkulturüberstanden (3.4.8.2.1) mit anschließender PEG-Fällung (3.4.8.2.2) und Western Blot (3.4.8.3) sollten eventuell vorhandene leere oder DNA- bzw. RNAhaltige, umhüllte Kapside nachgewiesen werden.

\subsubsection{Nachweis assemblierter Nukleokapside mittels nativem Western Blot}

Mit Hilfe der PEG-Fällung (3.4.8.2.2) lassen sich assemblierte Nukleokapside aus Zelllysaten anreichern. Der Nachweis dieser Kapside erfolgte durch nativen Western Blot mit anschließender Detektion durch Immunoblot.

HuH7-Zellen wurden mit dem WT Coreprotein (pSVcore ${ }^{\mathrm{WT}}$ ) oder mit je einer der zwölf Core-Mutanten und dem corenegativen Genom (pSVHBV1.5core`) kotransfiziert. Als negative Kontrolle diente die alleinige Transfektion des corenegativen Genoms. Fünf Tage nach der Transfektion wurden die Zellen lysiert (3.3.6) und einer PEG-Fällung unterzogen. Nach der Aufarbeitung der Kapside (3.4.8.2.2) erfolgte eine elektrophoretische Auftrennung im nativen TAE-Agarosegel (3.4.2.6). Zur Mengenabschätzung wurden 1 und 10 ng rekombinantes Coreprotein (E.coli) aufgetragen. Anschließend erfolgte der Transfer der Proteinkomplexe auf eine Nitrozellulosemembran (3.4.8.3) und der Nachweis assemblierter Kapside mittels Immunoblot über polyklonales anti-HBc-Kaninchenserum sowie HRPO-gekoppelten anti-Kaninchen-IgG (2.8). 


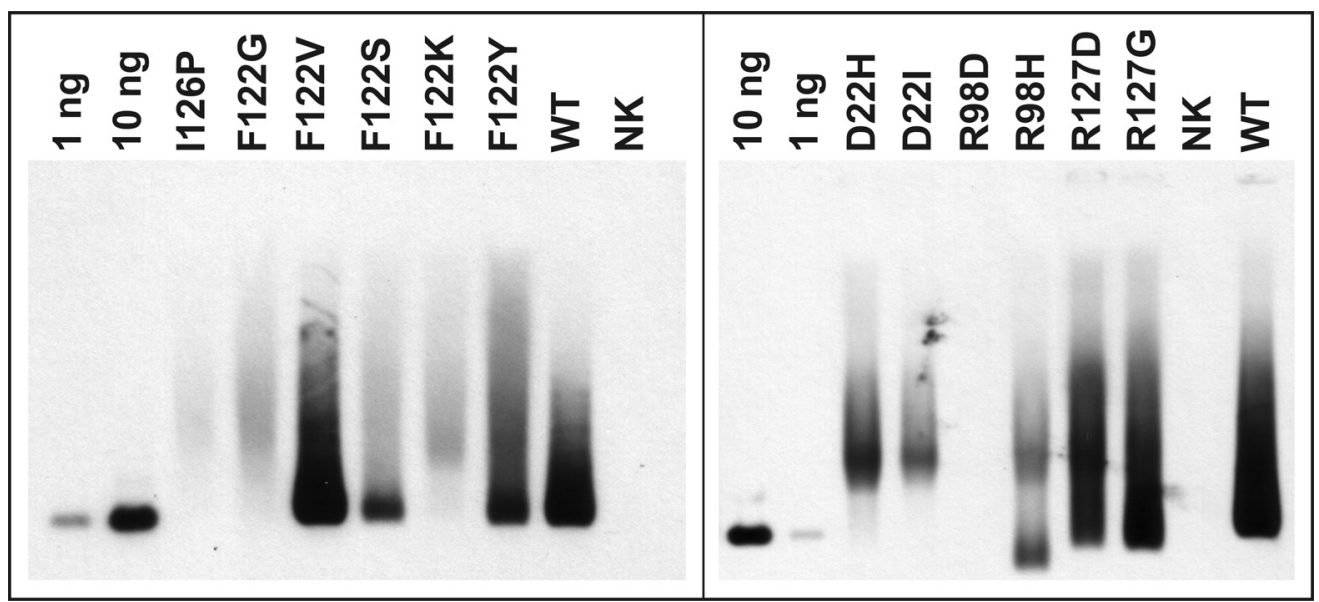

Abb. 21: Darstellung der Western Blots zum Nachweis assemblierter Nukleokapside.

Fünf Tage nach Transfektion wurden die Zellen lysiert und mit PEG präzipitiert. Nach Aufarbeitung der Proben erfolgte eine native Agarosegel-Elektrophorese, der Transfer der Proteine auf eine Nitrozellulosemembran durch Western Blot und die Detektion des Coreproteins im Immunoblot. Als Mengenkontrolle fungierten 1 und 10 ng rekombinantes Coreprotein aus E. coli. WT: Kotransfektion von WT Coreprotein und corenegativem Genom; NK: Transfektion des corenegativen Genoms.

Abbildung 21 zeigt die im Gel aufgetrennten und auf Nitrozellulose transferierten Proben nach Detektion mit den ,ECL Western Blotting Detection Reagents' (Amersham Biosciences, Freiburg). Die Core-Mutante F122V zeigte ein sehr starkes, WT-ähnliches Signal. Weiterhin ließen auch R127D, R127G und F122Y deutliche Signale erkennen, die etwa im gleichen Intensitätsbereich lagen, wie die in der Kontrollspur befindlichen 10 ng von rekombinanten Coreproteinen. Auffällig war dabei, dass die Kapside der R127-Mutanten schneller im Gel migriert waren als die WT-Kapside. R98H und F122S waren ebenfalls in der Lage, detektierbare Kapside zu assemblieren, jedoch mit sehr viel geringerer Effizienz im Vergleich zum WT. Die Signalintensitäten dieser beiden Mutanten lagen im Bereich zwischen 1 und 10 ng Coreprotein. Besonders auffällig war ein bedeutend schnelleres Gel-Laufverhalten bei der Mutante R98H. Es zeigte sich insgesamt, dass die Coreproteine von sechs der zwölf Mutanten, die keine detektierbaren Signale von reifen Kapsiden in der EPR aufwiesen, dennoch zu Kapsiden assemblierten. 


\subsubsection{Nachweis von HBV-DNA in zytosolischen Kapsiden mittels Southern Blot}

Als Grund für einen negativen Phänotyp in der EPR kommt neben einem Block der Kapsidbildung z.B. eine Hemmung der viralen DNA-Synthese in Betracht. Um diesen Punkt zu untersuchen, wurden zwölf EPR-negative, Kapsid-positive und -negative Mutanten (4.2.7.1) im Southern Blot auf Anwesenheit viraler DNA in den Kapsiden getestet. Dabei würden sowohl DNA-Intermediate (ssDNA), als auch DNA-Genome (partiell dsDNA) nachweisbar sein.

Die zwölf Mutanten und die WT-Kontrolle $\left(\mathrm{pSVcore}^{\mathrm{WT}}\right)$ wurden mit dem corenegativen, replikationsfähigen HBV-Genom (pSVHBV1.5core-) in HuH7-Zellen kotransfiziert. Als Negativkontrollen dienten zum einen untransfizierte HuH7-Zellen (Mock), zum anderen HuH7-Zellen, die nur mit pSVHBV1.5core ${ }^{-}$transfiziert worden waren. Fünf Tage nach der Transfektion wurden die Zellen mittels Zelllyse (3.3.6) geerntet. Nach der anschließenden Immunpräzipitation (3.4.8.1) mit polyklonalem antiHBc Serum (2.8) wurde die virale Nukleinsäure isoliert und elektrophoretisch im TAEAgarosegel aufgetrennt (3.4.2.6). Neben den Proben wurden als Kontrollen 50 pg und 100 pg eines 3,2 kb großen, mit EcoRV geschnittenen HBV-Genoms eingesetzt. Zusätzlich wurden jeweils $100 \mathrm{pg}$ der ungeschnitten Plasmide pSVcore $^{\mathrm{WT}}$ und pSVHBV1.5core ${ }^{-}$auf das Gel mit aufgetragen, um eventuell vorhandenes Transfektions-Plasmid, das während der Waschschritte nicht entfernt wurde, identifizieren zu können. Die DNA wurde schließlich über Nacht mittels Kapillarblot auf eine positiv geladene Nylonmembran (Hybond-N+, Amersham Biosciences, Freiburg) transferiert und mit UV-Bestrahlung fixiert (3.4.6.1.2). Die Detektion der viralen DNA erfolgte mit einer mit alkalischer Phosphatase gekoppelten Sonde (3.4.6.1.5). 


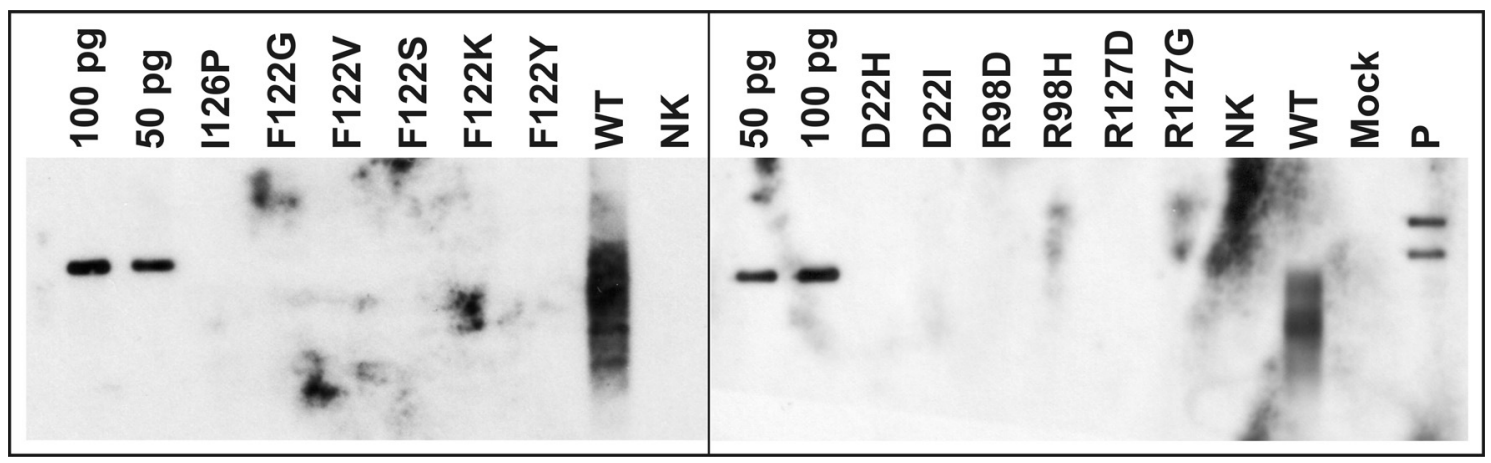

Abb. 22: Darstellung der Southern Blots zum Nachweis viraler DNA aus zytosolischen Kapsiden.

Fünf Tage nach Transfektion des corenegativen Genoms (pSVHBV1.5c") alleine (NK), mit dem WT Coreprotein (WT) oder den Core-Mutanten wurden die HuH7-Zellen lysiert und die Lysate mit anti-HBc immunpräzipitiert. Die DNA der Präzipitate wurde aufgereinigt, auf Nitrozellulose geblottet und mit einer peroxydasegekoppelten HBV-Sonde im Southern Blot nachgewiesen. Als Größen- und Mengenkontrollen wurden 50 und 100 pg von 3,2 kb HBV-Fragmenten verwendet. Mock: untransfizierte Zellen; P: je 100 pg ungeschnitte Plasmide pSVcore ${ }^{\mathrm{WT}}$ und pSVHBV1.5c-.

In Abbildung 22 zeigten die WT-Kontrollen das erwartete Muster von deutlichen Signalen in Höhe der 3,2 kb HBV-Fragmente und von schneller im Agarosegel migrierten replikativen Intermediaten (LE PoGAM \& SHIH, 2002). Die Banden der ungeschnittenen Kontrollplasmide, auf deren Höhe bei keiner der Proben Signale zu sehen waren, sind gut zu erkennen. Bei keiner Mutante waren Signale von HBV-DNA detektiert worden. Keine der Mutanten war also in der Lage, in den Kapsiden virale einzelsträngige oder partiell doppelsträngige DNA zu generieren.

\subsubsection{Nachweis von pgRNA in zytosolischen Kapsiden mittels RT-PCR}

Der Grund für den negativen DNA-Nachweis (4.2.7.2) könnte in einer fehlenden Verpackung des Prägenoms oder in einer blockierten reversen Transkription liegen. Um dies zu untersuchen, wurde das virale RNA Prägenom mit Hilfe der RT-PCR-Technik nachgewiesen (3.4.7). Durch Oligonukleotide, die stromabwärts des HBV-Coregens, aber vor dem Startpunkt der subgenomischen RNA hybridisierten, wurde ein Bereich der pgRNA, nicht aber der subgenomischen RNA oder der mRNA des CoreproteinExpressionsvektors amplifiziert. 
Die sechs Core-Mutanten (R98H, F122S, F122V, F122Y, R127D und R127G), die in der EPR keine detektierbaren Signale von Nukleokapsiden besaßen, im nativen Western Blot jedoch ihre Fähigkeit zur Kapsidassemblierung zeigten, wurden für die RT-PCR ausgewählt. Neben den zu untersuchenden Proben wurden folgende Kontrollen in das Experiment mit einbezogen: Als WT-Kontrolle wurde pSVcore ${ }^{\text {WT }}$ zusammen mit dem corengativen HBV-Genom (pSVHBV1.5core`) kotransfiziert. Eine weitere Positivkontrolle war ein HBV-Genom (pSVHBV1.5RT'env; 2.5), welches eine Polymerase exprimiert, die durch eine eingeführte Punktmutation keine RT-Aktivität mehr besitzt. Da durch diese Mutation auch der ORF der Hüllproteine (env-Gen) verändert wurde und es dadurch zur Expression von nicht funktionellen Hüllproteinen kommen könnte, wurde zusätzlich eine Stopp-Mutation im gemeinsamen C-terminalen Bereich des env-Gens eingeführt. Dadurch entstehen Nukleokapside, die die pgRNA beherbergen und in diesem Schritt der Morphogenese arretiert sind. Als NegativKontrolle wurden das corenegative Genom allein transfiziert, wodurch pgRNA in den transfizierten Zellen vorhanden ist, jedoch keine Coreproteine für die Kapsidassemblierung. Eine zweite Negativkontrolle war die Transfektion des WT Coreprotein-exprimierenden Plasmids pSVcore $^{\mathrm{WT}}$, wodurch es zur spontanen Assemblierung von Kapsiden kam, die jedoch aufgrund des Fehlens der pgRNA unspezifisch RNA verpacken sollten. Neben einer weiteren Negativ-Kontrolle, bei der die Zellen nicht transfiziert wurden, um die Spezifität der RT-PCR zu abzuschätzen (Mock), wurden zum Beweis der Funktionalität der PCR eine DNA-Positivkontrolle in Form von 10 pg des Plasmides pSVHBV1.5core ${ }^{-}$und eine Negativkontrolle, bei der keine DNA vorhanden war, mit einbezogen.

Fünf Tage nach Transfektion wurden die Zellen lysiert (3.3.6) und die Nukleokapside über Nacht mit anti-HBc immunpräzipitiert (3.4.8.1). Am nächsten Tag folgte eine kombinierte DNase I/RNase A-Inkubation, um außerhalb der Kapside befindliche Nukleinsäuren abzubauen. Nach Zugabe eines RNase-Inhibitors wurde ein Proteinase K-Verdau angeschlossen, um die Kapside aufzuspalten. Es folgten eine Phenol/Chloroform-Extraktion (3.4.2.1), eine Ethanolfällung (3.4.2.2) und die

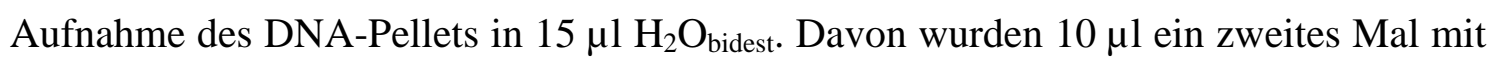
DNase I inkubiert (Gesamtansatz $20 \mu \mathrm{l}$ ), und je $10 \mu \mathrm{l}$ wurden in den RT-PCR- bzw. den Kontroll-PCR-Ansatz gegeben (3.4.7). Nach erfolgter Amplifikation wurden die Proben 
elektrophoretisch im 1,5\%-igen TAE-Agarosegel aufgetrennt (3.4.2.6) und mit der Geldokumentation ,Gel Jet Imager 2000’ (INTAS, Göttingen) digital fotografiert.

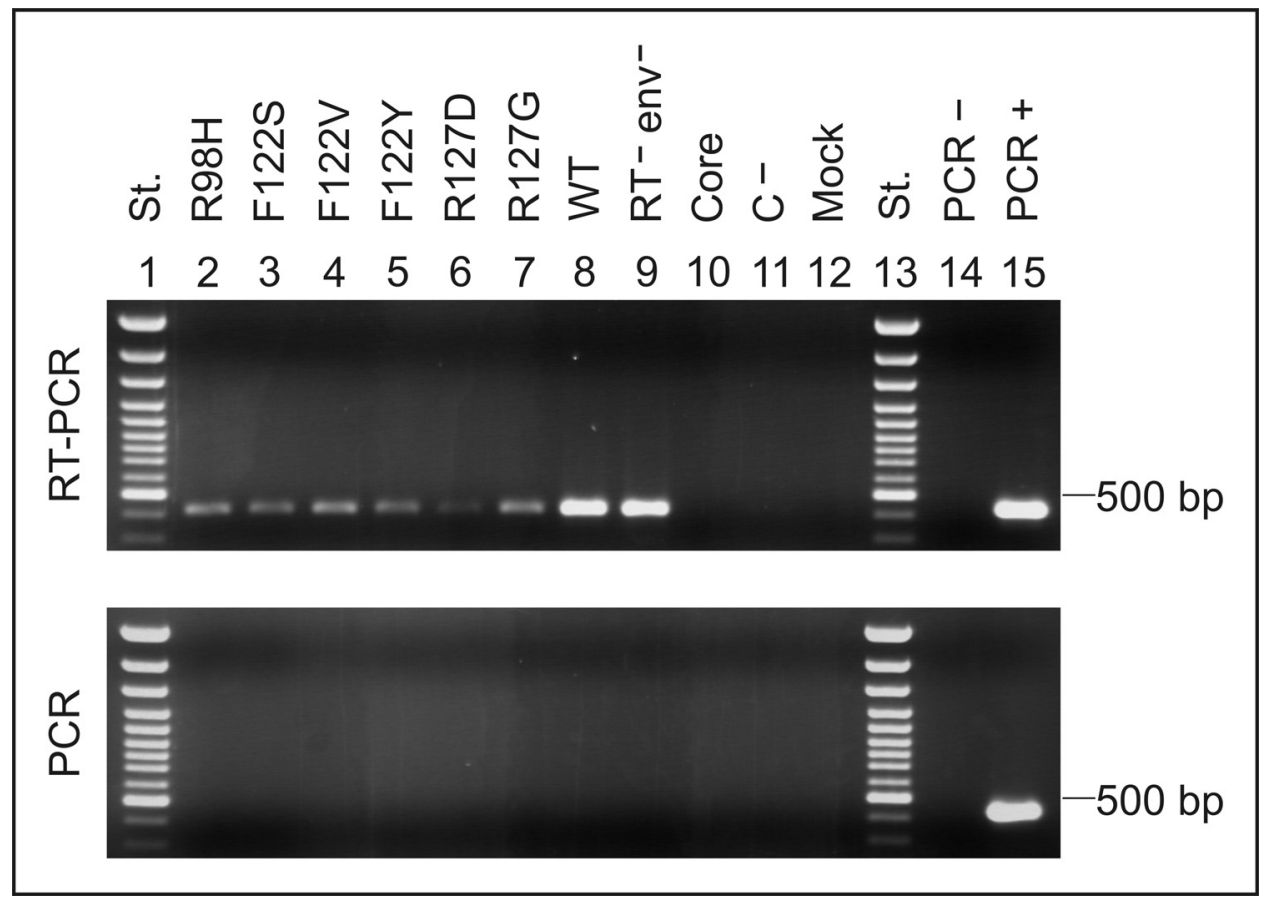

Abb. 23: Darstellung des RNA-Nachweises aus Nukleokapsiden mittels RT-PCR (oberes Bild) und PCR (unteres Bild).

In den Spuren 1 und 13 ist der Längenstandard (St.) Generuler ${ }^{\mathrm{TM}} 100$ bp DNA Ladder Plus (MBI Fermentas, St. Leon-Rot) aufgetragen und in den Spuren 2 bis 8 die PCRAmplifikate der Kotransfektionen der Core-Mutanten (2 - 7) oder des WT Coreproteins (8) mit dem corenegativen Genom. Die Spuren 9 bis 11 wurden mit den PCR-Produkten der Transfektionen der RT-PCR Positiv-Kontrolle pSVHBV1.5RT'env' (RT'env'), der RT-PCR Negativ-Kontrollen pSVcore WT (Core) und pSVHBV1.5c (C) beladen. Die PCR der untransfizierten Kontroll-Zellen (Mock) befindet sich in Spur 12. Die beiden PCR Negativ(PCR -) und Positiv- (PCR +) Kontrollen sind in den Spuren 14 und 15 zu sehen.

In Abbildung 23 sind die elektrophoretischen Auftrennungen der RT-PCR (oben) und der Kontroll-PCR (unten) dargestellt. In den drei Spuren der Positivkontrollen (RTPCR) konnte man deutliche Signale in Höhe von 430 bp erkennen, die auf eine erfolgreiche Amplifikation von RNA (Spuren 8 und 9) bzw. DNA (Spur 15) hinwiesen, während die vier Negativkontrollen keine Signale erkennen ließen. In jeder Spur der sechs Core-Mutanten waren Banden mit unterschiedlicher Intensität in der erwarteten Höhe sichtbar. Während R98H, F122V und R127G die stärksten Signale aufwiesen, waren die Signalstärken der Core-Mutanten F122S und F122Y deutlich geringer. Die 
schwächste Bande war bei R127D zu sehen. Es zeigte sich, dass sich in den Kapsiden aller Core-Mutanten pgRNA befinden musste, da in der Kontroll-PCR keinerlei Signale von viraler DNA zu erkennen waren. Bei allen sechs Mutanten, die zur Kapsidassemblierung fähig waren (4.2.6.1), deren Kapside jedoch keine virale DNA enthielten (4.2.6.2), war mit unterschiedlicher Effizienz verpackte prägenomische RNA nachweisbar.

\subsubsection{Nachweis sezernierter Virionen mittels CsCl-Gradienten und nativem Western Blot}

Mit Hilfe der isopyknischen CsCl-Dichtegradientenzentrifugation war es möglich, im Zellkulturüberstand von transfizierten HuH7-Zellen befindliche Virionen von nackten Kapsiden aufgrund ihrer verschiedenen Dichten zu trennen. Nach Fraktionierung der Gradienten und Aufspaltung der Hüllen der Virionen konnten vorhandene Kapside durch nativen Western Blot detektiert werden. Damit sollten umhüllte Nukleokapside unabhängig von ihrem Reifegrad oder Nukleinsäuregehalt nachzuweisen sein. Da HuH7-Zellen aus unbekannten Gründen auch nackte Kapside in den Kulturüberstand sezernieren, mussten diese zuvor abgetrennt werden. Bei dieser Analyse wurden die sechs Core-Mutanten verwendet, die in der EPR keine detektierbaren Signale im Lysat aufwiesen (4.1.3), aber im Western Blot Kapsidbildung zeigten (4.1.6.1).

HuH7-Zellen wurden mit den Core-Mutanten R98H, F122S, F122V, F122Y, R127D und R127G und jeweils dem corenegativen HBV-Genom (pSVHBV1.5core`) kotransfiziert. Als Positivkontrolle diente das WT Coreprotein, kotransfiziert mit pSVHBV1.5core-, als Negativkontrolle die Transfektion des corenegativen Genoms alleine. Fünf Tage nach der Transfektion wurden die Zellkulturüberstände mit CsCl versetzt und in der Ultrazentrifuge zentrifugiert (3.4.8.2.1). Nach Fraktionierung der Gradienten und PEG-Fällung (3.4.8.2.2) wurden die Präzipitate in einen Western Blot (3.4.8.3) eingesetzt und Kapside mittels Immunoblot (3.4.8.4) detektiert. 
a)

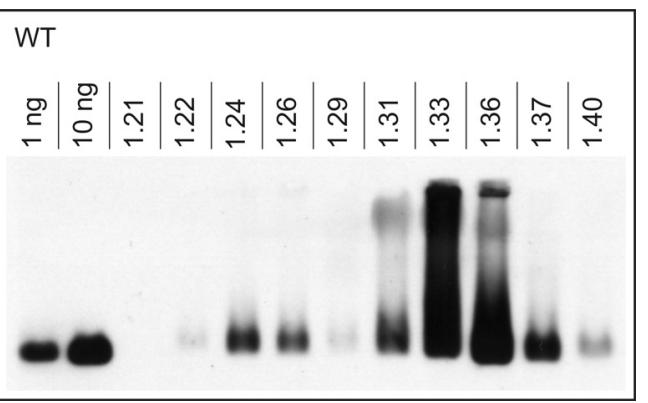

c)

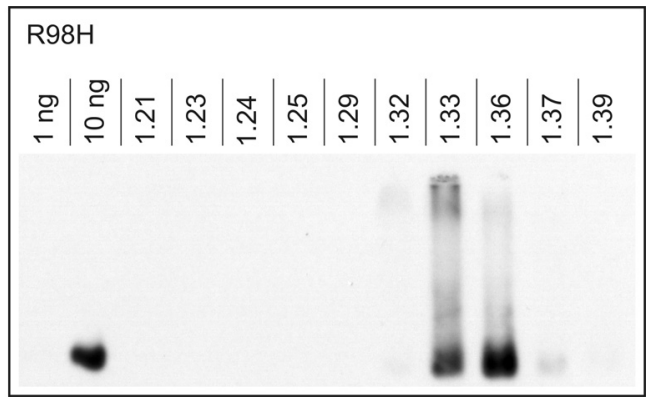

e)

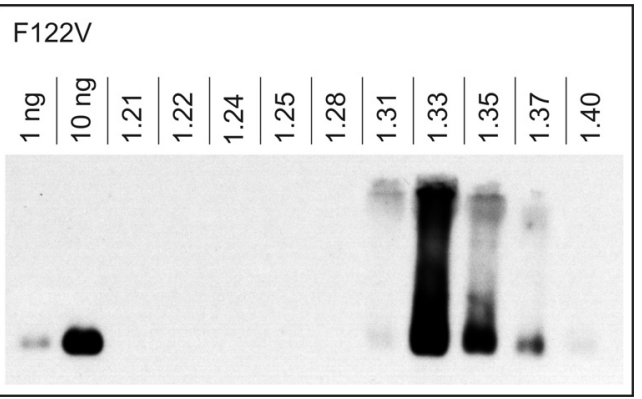

g)

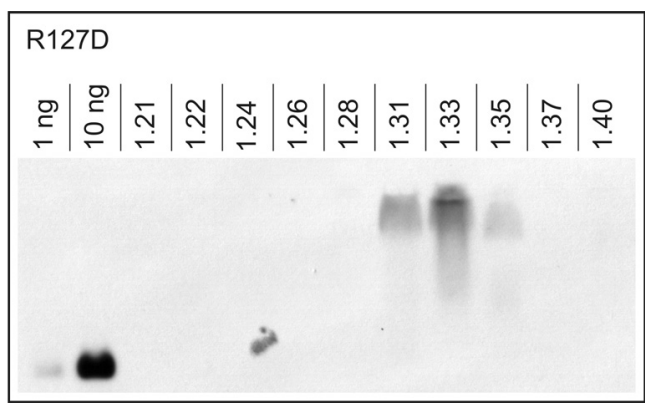

b)

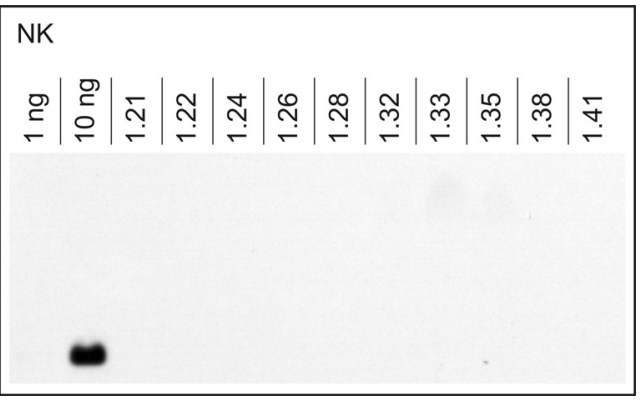

d)

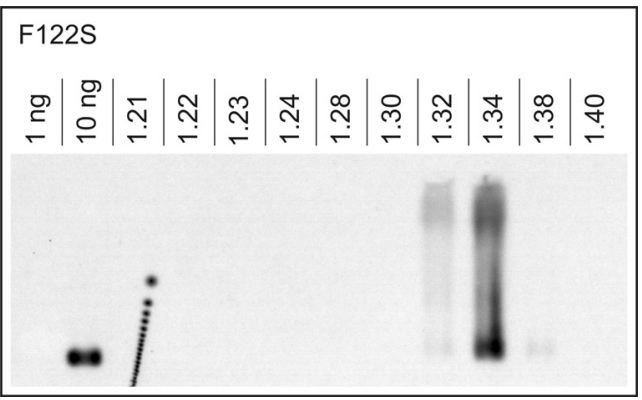

f)

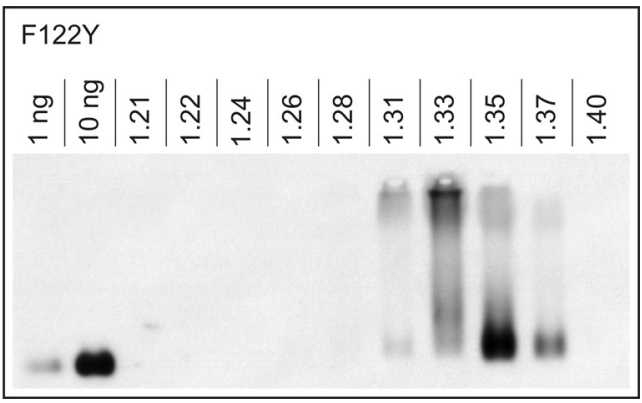

h)

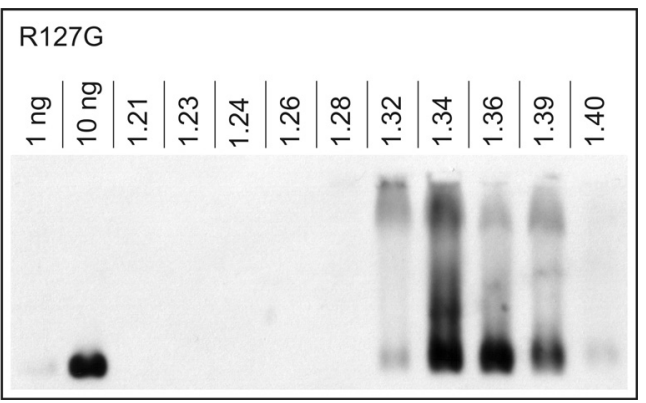

Abb. 24: Nachweis von Kapsiden im Kulturmedium durch CsCl-Gradient und Western Blot der Proben: a) WT, b) NK, c) R98H, d) F122S, e) F122V, f) F122Y, g) R127D und h) R127G.

Fünf Tage nach Transfektion des corenegativen Genoms allein (NK) oder zusammen mit dem WT Coreprotein (WT) oder Core-Mutanten wurde der Zellkulturüberstand nach CsClGradientenzentrifugation fraktioniert. Die dem Gradienten von oben abgenommenen Fraktionen wurden nach PEG-Fällung von links nach rechts ihrer Dichte entsprechend, zusammen mit 1 und 10 ng rekombinanten Coreprotein aus E. coli im TAE-Agarosegel elektrophoretisch aufgetrennt, auf eine Nitrozellulosemembran geblottet und assemblierte Kapside mit Hilfe eines Immunoblots detektiert. Die Zahlen geben die Dichte der Fraktionen in $\mathrm{g} / \mathrm{ml}$ an. 
Abbildung 24 a) zeigt die Signale der WT-Kontrolle. Die relativ starken Signale bei 1,31 bis $1,37 \mathrm{~g} / \mathrm{ml}$ stammen von nackten Kapsiden, die von den HuH7-Zellen ins Medium sezerniert worden waren. Signale von den im Medium vorhandenen Virionen waren bei einer Dichte von 1,24 und 1,26 g/ml beim WT (a) deutlich zu sehen. Die Negativkontrolle (b) zeigte wie erwartet keine Signale. Bei der Core-Mutante R98H (c) waren Signale von Nukleokapsiden bei einer Dichte von 1,33 und 1,36 g/ml zu sehen, die jedoch im Vergleich zu denen des WT deutlich schwächer waren. Nur sehr schwache Signale von Kapsiden zeigten sich bei der Mutante F122S (d) bei einer Dichte von 1,32 bis 1,38 g/ml mit einem Maximum bei 1,34 g/ml. Annähernd gleich starke Nukleokapsid-Signale wie beim WT waren bei Dichten von 1,33 und 1,35 g/ml bei der Core-Mutante F122V (e) zu sehen, neben einer etwas schwächeren bei einer Dichte von 1,37 g/ml. Core-Mutante F122Y (f) zeigte ein gut sichtbares Kapsid-Signal bei einer CsCl-Konzentration von 1,35 g/ml. Schwächere Banden waren bei 1,31, 1,33 und 1,37 g/ml zu sehen. R127D (g) war mit nur einem Signal von sehr geringer Intensität bei einer Dichte von 1,31 g/ml die Mutante, die die wenigsten und auch schwächsten Signale generieren konnte. Die sechste Mutante R127G (h) zeigte Signale im Bereich von 1,32 bis 1,40 g/ml, wobei das meiste Coreprotein im Bereich von 1,34 - 1,36 g/ml nachgewiesen werden konnte. Keine der sechs Core-Mutanten ließ Signale von Virionen erkennen, während fünf deutliche bis sehr starke Signale von nackten, von den HuH7-Zellen ins Medium sezernierten Nukleokapsiden zeigten.

Es zeigte sich, dass alle sechs Mutanten, die nach der EPR als umhüllungsinkompetent phänotypisiert worden waren, die Kapsidbildung und Prägenomverpackung mit unterschiedlicher Effizienz erlaubten, jedoch die virale DNA-Genomsynthese und Umhüllung der Kapside blockierten. 


\subsection{Generierung eines MuLV-Retrovirus-Transduktionssystems für die intergenomische Transkomplementation der I126A Core-Mutation durch das env-Gen}

Die Arbeitshypothese bezüglich der Umhüllung von Nukleokapsiden besagt, dass eine direkte Interaktion zwischen der Oberfläche der Kapside und den transmembran gelegenen, viralen Hüllproteinen entsteht. Zwei Bereiche innerhalb der Hüllproteine wurden kartiert, die nach Mutation die Formation von Virionen blockierten. Der erste Bereich, die sogenannte Matrix-Domäne, befindet sich in der C-terminalen Region der PräS1-Domäne des LHBs und umfasst eine 22 AS lange, lineare Sequenz von AS 103 bis 124 (BRuss, 1997; LE SEYec et al., 1998; LE SEYEc et al., 1999). Die zweite für die Umhüllung essentielle Sequenz umfasst zwölf AS und liegt im N-terminalen Bereich des SHBs (AS 35 - 46) (LÖFFLER-MARY et al., 2000). Das Kapsid wurde ebenfalls mittels Mutationsanalysen auf die Umhüllungsfähigkeit hin untersucht. Neben zwei Deletionen und einer Insertion, die ohne die Kapsidstabilität zu beeinflussen die Umhüllung blockierten (KOSCHEL et al., 2000), konnten auch elf oberflächenexponierte AS-Positionen bestimmt werden, die nach Alanin-Substitution den gleichen Phänotyp aufwiesen (Ponsel \& BRUSS, 2003). Eine dieser Positionen war Isoleucin 126. Während dieser Arbeit wurden an dieser Position elf weitere Substitutionen generiert, die ebenfalls den Phänotyp der Alanin-Mutante (K+/V-) aufwiesen (4.1.3.1). Es kann daher angenommen werden, dass die AS-Position I126 des Coreproteins eine wichtige Rolle während der Umhüllung des Nukleokapsides spielt.

Um eine mögliche, direkte Interaktion zwischen Kapsid und LHBs nachweisen zu können, sollte innerhalb dieser Arbeit ein Zellkultursystem etabliert werden, welches eine intergenomische Transkomplementation der I126A Core-Mutation durch ein in der Matrix-Domäne zufallsmutiertes LHBs-Gen erlaubt. Dazu mussten HuH7-Zellen generiert werden, die konstitutiv die HBV-Polymerase und die Core-Mutante I126A exprimieren. Im Zuge der Komplementations-Experimente sollte ein HBV-Genom, das replikationsinkompetent aber verpackungskompetent war und einzig die Expression der Hüllproteine inklusive des mutagenisierten LHBs (LHBs ${ }^{\text {Mut }}$ ) erlaubte, in trans zugeführt werden. Nach Einführung des defekten Genoms in die Zellen mit Hilfe eines MuLV- 
Retrovirus-Transduktionssystems sollten dann Viren sezerniert werden, wenn das Genom für ein LHBs $^{\text {Mut }}$ kodiert, das die Core-Mutation I126A transkomplementieren kann. Nach Anreicherung der sezernierten Virionen im Medium und Analyse des verpackten Genoms sollte die komplementierende LHBs-Mutation bestimmt werden können.

Für die Transduktionsexperimente sowie für die Einbringung der Core- und P-Proteine in die HuH7-Zellen wurde ein System verwendet, welches auf dem ,Drei-PlasmidExpressionssystem’ für die Produktion von MuLV-Retroviren basiert (SONEOKA et al., 1995). Dieses System zeichnet sich dadurch aus, dass nach Transfektion von drei Plasmiden funktionelle, rekombinante Retroviren hergestellt werden. Nach Transduktion wird das retrovirale Provirus in das Wirtszellgenom integriert, und die ,Fremd'-DNA wird ebenso wie die Transduktions- und Selektionsmarker exprimiert (3.3.7). Die zu transduzierende HBV-DNA musste in das Plasmid integriert werden, welches das defekte Genom des Retrovirus bereitstellt: pczCFG5 IEGZ bzw. pczCFG5 IEGN (KNÖDEL et al., 1999). Beide Plasmide kodieren für ein eGFPZeocinresistenz- bzw. eGFP-Geneticinresistenz-Fusionsprotein, welches als Transduktionskontrolle und Selektionsmarker fungiert. Mit Hilfe einer FACS-Analyse lässt sich schnell die Anzahl eGFP-exprimierender und damit infizierter Zellen bestimmen. Die beiden weiteren Plasmide, die für die Retrovirus-Herstellung benötigt werden, sind pHIT 60 und pczVSV-G wt (2.5), die für die Strukturproteine des Kapsids (gag), eine reverse Transkriptase und Integrase (pol) (SONEOKA et al., 1995) bzw. für die Hüllproteine (PIETSCHMANN et al., 1999) kodieren, die das Wirtsspektrum bestimmen. Durch Verwendung des Glykoprotein G des vesikulären Stomatitis-Virus (VSV-G), welches über ein sehr breites Wirtsspektrum verfügt, ist es möglich, eine große Anzahl von Zelllinien zu transduzieren. Ein entscheidender Vorteil einer Transduktion gegenüber einer Transfektion ist die Möglichkeit, durch die Wahl einer geeigneten MOI (multiplicity of infection) quasi einzelne Gene, statt eines ,GenGemisches’ in Zellen einbringen zu können.

Mit Hilfe dieser MuLV-Retroviren sollte für Kontrollexperimente zunächst ein LHBsexprimierendes und für spätere Komplementierungs-Experimente ein LHBs $^{\text {Mut }}$ exprimierendes HBV-Genom in HuH7-Zellen eingebracht werden. Aus molekularbiologischen und sicherheitsrelevanten Aspekten sollte die Expression des 
LHBs/LHBs ${ }^{\text {Mut }}$ nicht von dem gleichen Genom erfolgen wie die Expression der HBVPolymerase und der Coreproteine. Zum einen würde durch die Einbringung von Mutationen in den ORF des LHBs gleichsam der Leserahmen der Polymerase gestört werden, wodurch defekte Proteine gebildet werden könnten, die die Morphogenese beeinflussen. Zum anderen sollte das sich in den Retroviren befindliche HBV Genom, soweit wie möglich funktionell eingeschränkt werden, da durch das große Wirtszellspektrum des retroviralen Hüllproteins eine Infektion außerhalb der Zellkultur möglich sein könnte. Daher wurden die Gene für das Coreprotein, die Polymerase und das X-Protein mit Stopp-Kodons versehen, so dass das Genom verpackungskompetent blieb, aber replikationsinkompetent wurde. Die Bereitstellung der für die Morphogenese wichtigen Core- und P-Proteine sollte konstitutiv innerhalb der zu transduzierenden HuH7-Zellen erfolgen. Dafür mussten für die Experimente zwei HuH7-Zelllinien generiert werden: Die erste sollte für Kontrollexperimente konstitutiv das WT Coreprotein $\left(\right.$ core $^{\mathrm{WT}}$ ) und das P-Protein (pol) exprimieren. Nach Zugabe des LHBs exprimierenden HBV-Genoms in die HuH7-HBVcore ${ }^{\text {WT }}$-pol Zellen sollten Virionen in das Medium sezerniert werden können, während die Zugabe von LHBs $^{\text {Mut }}$ die Umhüllung blockieren würde. Für die Komplementations-Experimente musste dann eine zweite Zelllinie generiert werden, die statt des WT Coreproteins die Core-Mutante I126A (core ${ }^{\text {I126A }}$ ) konstitutiv zur Verfügung stellt. Nach Zugabe von LHBs $^{\text {Mut }}$ exprimierenden Genomen in diese Zellen sollten dann Virionen in den Kulturüberstand sezerniert werden, wenn eine LHBs $^{\text {Mut }}$ die Core-Mutante I126A funktionell komplementieren kann.

\subsubsection{Herstellung des Hüllprotein-exprimierenden HBV-Genoms und Integration in das Retrovirus-Transduktionssystem}

Für die Selektion des intergenomisch komplementierenden HBV-Hüllproteins wurde ein HBV-Genom geschaffen, das defizient für das Core-, P- und X-Expression war. Anschließend wurde dieses Genom in den retroviralen Vektor pczCFG5 IEGZ eingefügt, um mit Hilfe des Retrovirus-Transduktionssystems in HuH7-Zellen eingebracht zu werden. 
Als Basiskonstrukt fungierte ein corenegatives HBV-Genom (pRVHBV1.5core-[2.5]), in das die beiden weiteren Stopp-Kodons eingeführt wurden. Das X-Gen wurde mittels PCR-Mutagenese an AS-Position 8 mit einem Stopp-Kodon versehen, wobei pRVHBV1.5core- als Matrize und die Oligonukleotide \#372, \#373 und \#374 (2.7) für die Amplifizierung verwendet wurden. Dabei kam es an HBV nt 1393 zu einem Austausch eines Cysteins gegen ein Thymin, wodurch das Basentriplett für Glutamin (CAA) zu einem Stop-Kodon (TAA) verändert wurde. Das bei der PCR entstandene 1817 bp große Fragment wurde zunächst in den Vektor pDrive eingesetzt (pDrive$\mathrm{HBx}^{-}$) (3.4.5). Anschließend wurde über die REN HpaI und NgoMIV (3.4.4.1) ein 1687 bp Fragment in pRVHBV1.5c $c^{-}$ligiert (3.4.4.2), wodurch pRVHBV1.5c ${ }^{-} \mathrm{x}^{-}$generiert wurde.

Für die Ausschaltung des Polymerasegens wurde durch PCR-Mutagenese eine Punktmutation an HBV nt 2817 von Cytosin nach Adenin vorgenommen, wodurch an AS-Position 171 ein Cystein (TGC) gegen ein Stopp-Kodon (TGA) ausgetauscht wurde. Mit Hilfe der Oligonukleotide \#391 und \#392 und pRVHBV1.5c ${ }^{-} \mathrm{x}^{-}$als Matrize wurde ein 658 bp Fragment amplifiziert und in den Vektor pDrive überführt (pDrive-HBVpol') (3.4.5). Nachfolgend wurde ein 492 bp Fragment, welches die Mutation trug, über die Schnittstellen BspEI und BstEII aus pDrive-HBVpol- in pRVHBV1.5core- $\mathrm{x}^{-}$integriert. Letztlich wurde das entstandene Plasmid pRVHBV1.5core-̄opol- (2.5) an den Restriktionsschnittstellen BspEI und NgoMIV geschnitten und ein 3542 bp Fragment, welches die beiden Stopp-Kodons des X- und des Polymerasegens enthielt, wurde über die gleichen REN in den Vektor pSVHBV1.5core ${ }^{-}$(2.5) eingesetzt. Das für diese Arbeit weiter verwendete Plasmid war pSVHBV1.5core ${ }^{-} \mathrm{xpol}^{-}$.

Das unter der Kontrolle des SV40-early-Promoter stehende HBV-Genom, das defizient für die Expression des Core-, P- und X-Proteins war, die Hüllproteine aber weiterhin exprimierte (Daten nicht gezeigt), wurde abschließend in den Vektor pczCFG5 IEGZ (2.5) und damit in das Retrovirus-Transduktionssystem integriert. Dafür wurde zunächst der das Retrovirus-Genom enthaltende Vektor pczCFG5 IEGZ mit SwaI linearisiert (3.4.4.1). Das zu inserierende HBV-Genom wurde mit Hilfe der REN ClaI und NgoMIV aus dem Plasmid pSVHBV1.5core-xpol- ausgeschnitten und die überhängenden Enden wurden mit dem Klenow-Fragment aufgefüllt (3.4.4.3). Durch die anschließende Ligation (3.4.4.2) entstand das Konstrukt pczCFG5 IEGZ- 
SVHBV1.5core'x-pol', das kotransfiziert mit pHIT 60 und pczVSV-G wt in HEK293T-Zellen die Produktion von MuLV-Retroviren ermöglicht, die das defekte HBVGenom tragen.

\subsubsection{Herstellung von HBV Coreprotein-exprimierenden HuH7-Zelllinien}

Es wurden zwei HuH7-Zelllinien generiert, die nach stabiler Transduktion das WT Coreprotein respektive die Core-Mutante I126A konstitutiv exprimieren, so dass nach Zugabe eines corenegativen HBV-Genoms reife Virionen sezerniert werden.

Für die Herstellung von MuLV-Retroviren (3.3.7), die das jeweilige Core-Gen tragen, wurde neben den beiden Plasmiden pHIT 60 und pczVSV-G wt das Plasmid pczCFG5 IEGZ (2.5) benötigt. Dies stellte das spätere retrovirale Genom zur Verfügung, das sich nach Transduktion in das Wirtszellgenom integrierte. Zur Herstellung von Coregen-tragenden (WT oder I126A) pczCFG5 IEGZ wurde ein 714 bp großes Fragment mit Hilfe der Restriktionsenzyme ApaI und BamHI aus den Coreprotein-Expressionsvektoren pSVcore ${ }^{\text {WT }}$ bzw. pSVcore ${ }^{1126 \mathrm{~A}}$, welches das entsprechende Coregen trug, herausgeschnitten (3.4.4.1). Die überhängenden Enden wurden mit dem Klenow-Fragment aufgefüllt (3.4.4.3) und das Fragment in den mit SwaI geschnitten Vektor pczCFG5 IEGZ ligiert (3.4.4.2). Die beiden generierten Plasmide pczCFG5 IEGZ-HBVcore ${ }^{\text {WT }}$ und pczCFG5 IEGZ-HBVcore ${ }^{\mathrm{I} 26 \mathrm{~A}}$ konnten dann zur Herstellung von MuLV-Retroviren verwendet werden. Dazu wurden die beiden Plasmide jeweils mit pHIT 60 und pczVSV-G wt transient in HEK-293T-Zellen transfiziert (3.3.4.3). Als Kontrollen wurden zum einem das unveränderte pczCFG5 IEGZ (Positiv-Kontrolle) kotransfiziert, und zum anderen wurde eine Kotransfektion von pHIT 60 und pczVSV-G wt ohne pczCFG5 IEGZ durchgeführt (Negativ-Kontrolle). Die hergestellten rekombinanten Retroviren wurden für $6 \mathrm{~h}$ mit den zu transduzierenden HuH7-Zellen im Brutschrank inkubiert (3.3.8). Für dieses Experiment wurde keine definierte MOI verwendet, sondern die maximale Menge rekombinanter Retroviren zu den Zielzellen gegeben. Am zweiten Tag nach der Transduktion wurden die Zellen passagiert und das Medium mit Zeocin (600 $\mu \mathrm{g} / \mathrm{ml})$ versetzt. Zur Kontrolle der Transduktionseffizienz wurde mittels FACS-Analyse 
exprimiertes eGFP in den HuH7-Zellen nachgewiesen (Abb. 25) (3.3.11). Die Messung erfolgte mit dem Durchflusszytometer Epics XL-MCL (Coulter, Krefeld).

a)

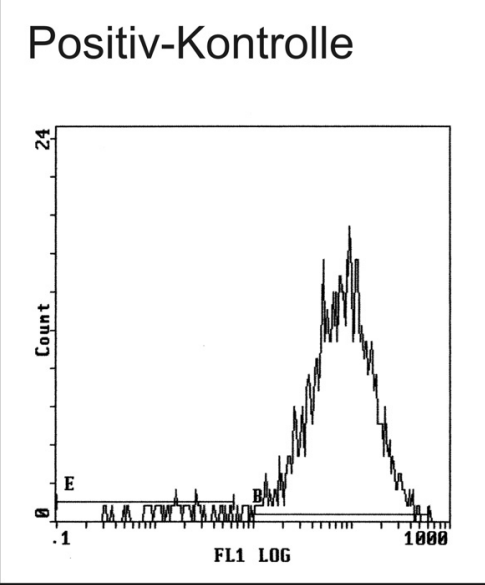

c)

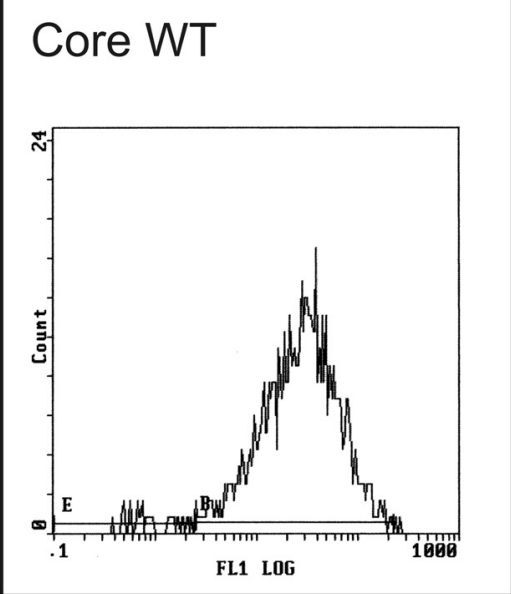

b)

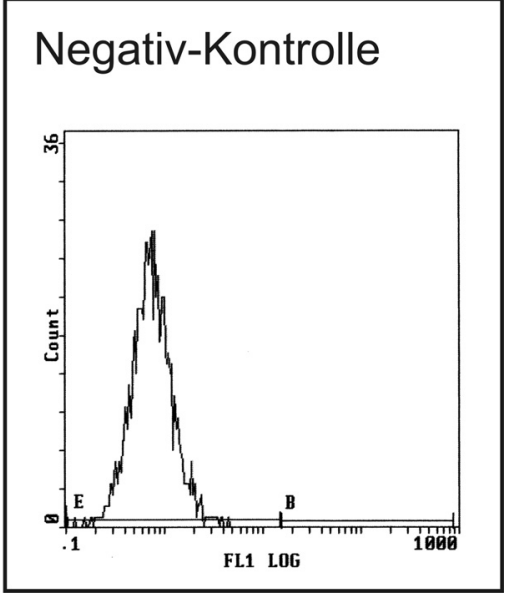

d)

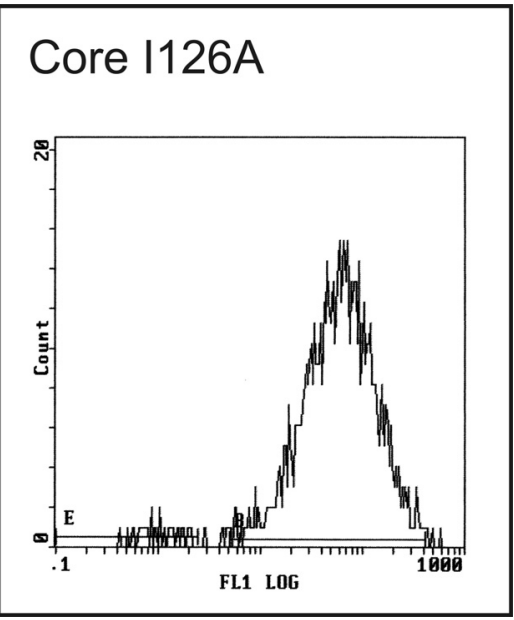

Abb. 25: FACS-Analyse von HuH7-Zellen nach Transduktion a) mit MuLV-Retroviren, ohne Insertion (Positiv-Kontrolle), b) ohne Retroviren als Negativ-Kontrolle, c) mit MuLVRetroviren, die das WT-Coregen trugen oder d) mit MuLV-Retroviren, die das Gen der Core-Mutante I126A trugen.

Zwei Tage nach der Transduktion von HuH7-Zellen mit MuLV-Retroviren, die neben dem eGFP-Gen das HBV WT-Coregen oder das Gen der Core-Mutante I126A trugen, bzw. eGFP-tragenden WT MuLV-Retroviren und einer Negativ-Kontrolle (keine Viren) wurden die Zellen durchflusszytometrisch analysiert. Die Ein-parametrige Darstellung der Histogramme gibt die Anzahl der Zellen (Count; Ordinate) in Abhängigkeit von der Fluoreszenzintensität in logarithmischer Darstellung (FL1 LOG; Abszisse) wieder.

In den Histogramm-Darstellungen der FACS-Analysen waren stets relativ einheitliche Zellpopulationen zu sehen. Bei der Positiv-Kontrolle, bei der HuH7-Zellen mit 
Retroviren ohne HBV-Insertion transduziert wurden, waren 96,3 \% der Zellen eGFPpositiv (Abb. 25 a). Die HuH7-Zellen, die von Retroviren mit dem WT Coregen transduziert wurden, waren zu 90,4 \% eGFP-positiv (Abb. 25 c), während die Zellen, die mit den MuLV-Retroviren transduziert wurden, die das Gen der Core-Mutante I126A trugen, zu 93,2 \% eGFP-positiv waren. Der Nachweis der Expression von eGFP zeigte, dass eine Transduktion der HuH7-Zellen mit Core-Gen-tragenden MuLVRetroviren erfolgt war.

Vierzehn Tage nach der ersten Zugabe des AB wurden jeweils 40 Zeocin-resistente Einzelzellklone mit sterilen Pipettenspitzen in 96-Well-Platten überführt (3.3.9) und wöchentlich ein Mediumswechsel durchgeführt, wobei der Selektionsdruck mit Zeocin stets aufrechterhalten wurde. Nach weiteren 24 Tagen wurden sowohl von den mit dem WT-Coregen, als auch den mit der Core-Mutante I126A transduzierten Zellen jeweils 20 Klone in 24-Well-Platten überführt. Letztlich wurden die sechs am schnellsten gewachsenen und damit vitalsten AB-resistenten Zellklone (ZK) zur weiteren Kultivierung in 6-Well-Näpfe überführt. Die Coreprotein-Expression und Kapsidassemblierung wurde mit Hilfe von PEG-Fällung (3.4.8.2.2) und anschließender Western Blot-Analyse (3.4.8.3) untersucht. Dazu wurden die ZK zunächst in $6 \mathrm{~cm}$ Schalen umgesetzt und für fünf Tage im Brutschrank inkubiert. Nach erfolgter Zelllyse (3.3.6) wurden die geklärten Lysate mit $10 \%$ (w/v) PEG8000 und $2 \%$ (w/v) $\mathrm{NaCl}$ versetzt und die zytosolischen Proteine präzipitiert (3.4.8.2.2). Anschließend wurde ein nativer Western Blot (3.4.8.3) durchgeführt und assemblierte Kapside mittels Immunoblot (3.4.8.4) nachgewiesen. Zur Mengen-Kontrolle wurden 1 und $10 \mathrm{ng}$ rekombinantes Coreprotein (E. coli) eingesetzt. Als Positiv-Kontrollen fungierten mit den Coreprotein-Expressionsvektoren pSVcore $^{\text {WT }}$ oder pSVcore $^{\mathrm{I} 126 \mathrm{~A}}$ transient transfizierte HuH7-Zellen (3.3.4.1), während die Negativ-Kontrolle (NK) untransfizierte HuH7-Zellen waren. 


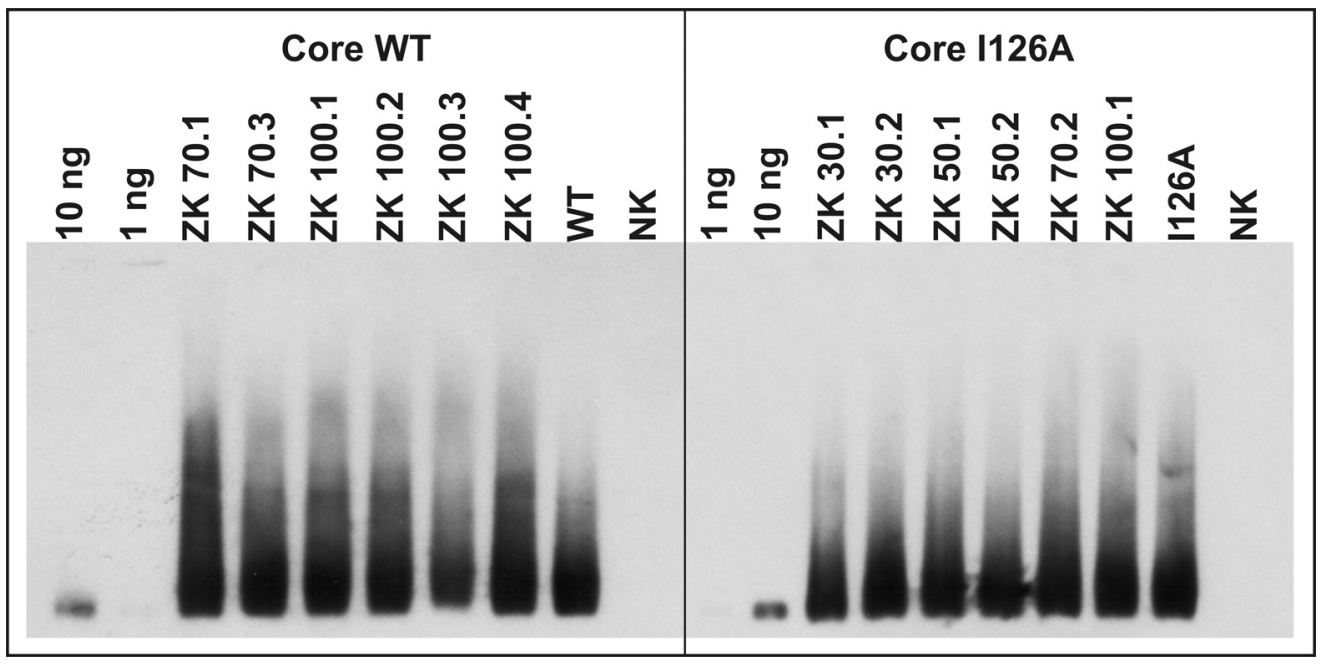

Abb. 26: Nachweis von assemblierten Kapsiden in den WT oder I126A Coregen transduzierten HuH7-Zellen mittels nativer Gel-Elektrophorese und Western-Blot.

Jeweils sechs ZK wurden lysiert und mit PEG präzipitiert. Anschließend wurde eine native Agarosegel-Elektrophorese durchgeführt, mittels Western Blot die Proben auf eine Nitrozellulose-Membran geblottet und assemblierte Kapside mit Hilfe eines Immunoblots detektiert. Als Kontrollen wurden 1 bzw. 10 ng rekombinantes Coreprotein eingesetzt. ZK: Zellklon; WT: Transfektion mit pSVcore ${ }^{\text {WT }}$; I126A: Transfektion mit pSVcore ${ }^{\text {I126A }}$; NK: untransfizierte HuH7-Zellen

In Abbildung 26 ist zu sehen, dass alle zwölf ZK annähernd die gleichen Mengen an assemblierten Kapsiden aufwiesen wie der WT. Anhand der gleichzeitig aufgetragenen rekombinanten Coreproteine aus E. coli wurde deutlich, dass mehr als $10 \mathrm{ng}$ in jedem ZK und den WT-Kontrollen vorhanden waren. Zur Überprüfung der Funktionalität der assemblierten Kapside wurde mit jeweils drei Klonen (WT: ZK 70.3, ZK 100.1 und ZK 100.2; I126A: ZK 70.3, ZK 100.1 und ZK 100.2) eine EPR-Analyse (3.4.6.2) durchgeführt. Dafür wurden die Zellen in 2 cm-Näpfen (6-Well-Schale) kultiviert und transient mit dem corenegativen HBV-Genom (pSVHBV1.5core) mit der Kalziumphosphat-Methode transfiziert (3.3.4.1). Die Analyse erfolgte wie in Kapitel 4.2.3 beschrieben. 
a) Virionen Nukleokapside

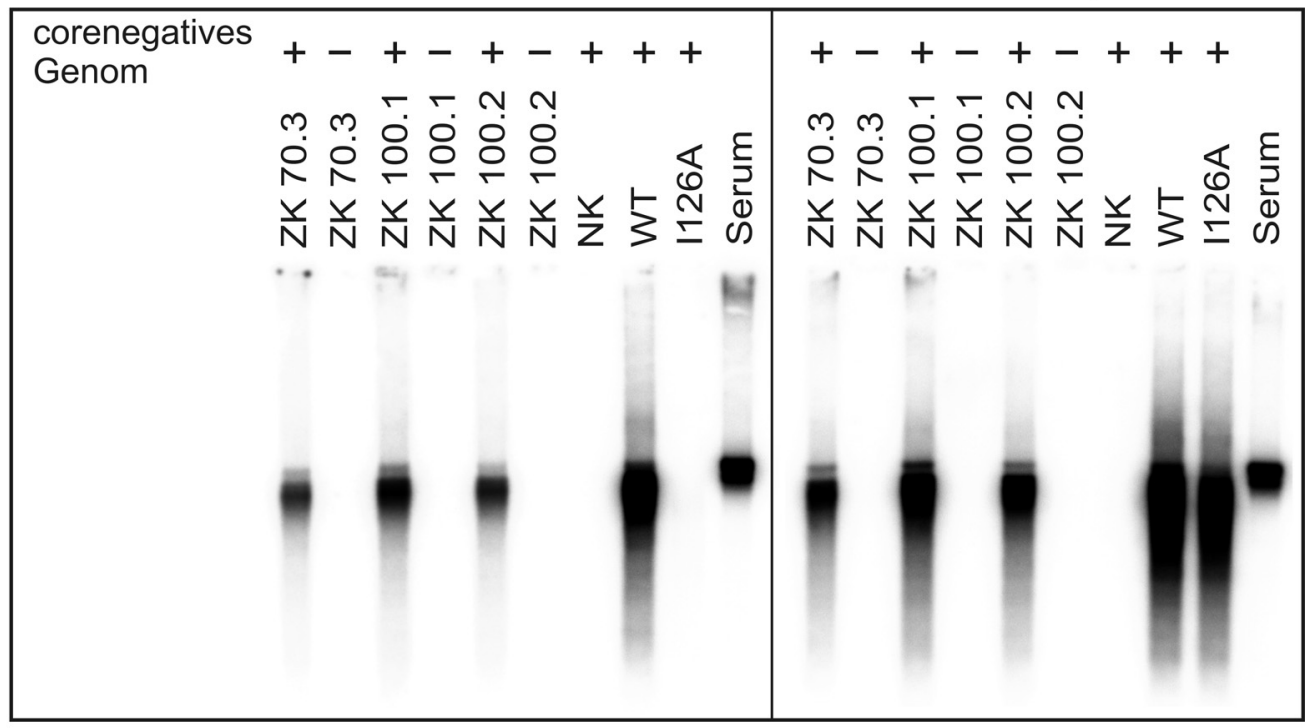

b) Virionen

Nukleokapside

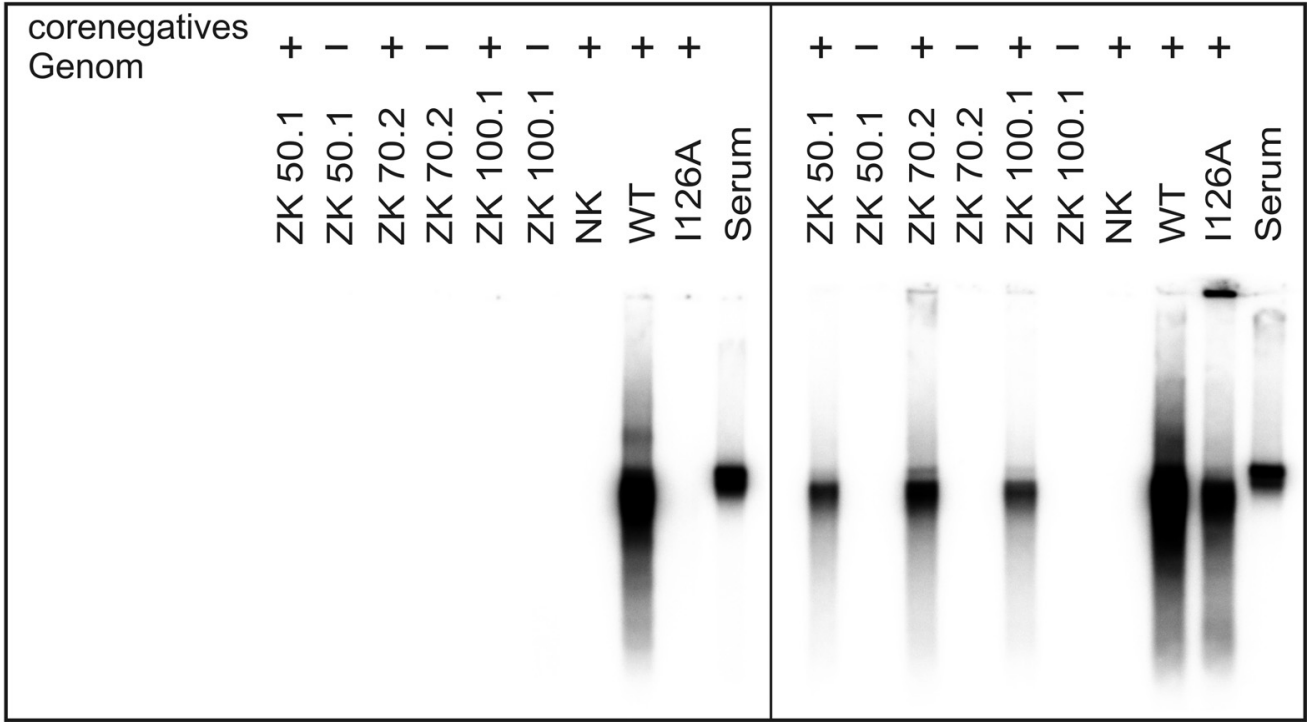

Abb. 27: Ergebnis der EPR von den ZK mit transduziertem a) WT-Coregen und b) Gen der Core-Mutante I126A nach Transfektion mit einem corenegativem HBV-Genom.

Fünf Tage nach Transfektion von ZK bzw. HuH7-Zellen mit pSVHBV1.5core- allein (ZK und Negativ-Kontrolle [NK]) oder zusammen mit pSVcore ${ }^{\text {WT }}$ (WT) oder pSVcore ${ }^{\text {I126A }}$ (I126A) wurden Virionen aus Zellkulturüberständen und Nukleokapside aus Zelllysaten immunpräzipitiert, in eine EPR eingesetzt und die virale DNA isoliert. Nach AgarosegelElektrophorese und Trocknen der Gele wurden die radioaktiven Signale mit dem Phosphoimager ausgewertet. In der linken Hälfte der Abbildungen sind die Signale von Virionen, in der rechten Hälfte die Signale der Nukleokapside zu sehen. Als Kontrolle wurden ca. $2 \times 10^{6}$ Genomäquivalente aus humanem Serum verwendet.

In Abbildung 27 a) ist zu sehen, dass die ZK, die das WT-Coreprotein exprimierten, in der Lage waren, das corenegative HBV-Genom zu transkomplementieren. Es waren 
Banden sowohl von zytosolischen Kapsiden, als auch von sezernierten Virionen zu sehen. Dabei generierte Klon ZK 100.1 die stärksten Signale. Die ZK, die die CoreMutante I126A exprimierten (Abb. 27 b), zeigten Signale im Zelllysat von zytosolischen Nukleokapsiden und aufgrund des erwarteten Umhüllungsblocks keine von sezernierten Virionen. Zwischen den einzelnen Klonen gab es geringe Unterschiede bei der Signalintensität. Während ZK 50.1 und ZK 100.1 etwa gleich starke Signale zeigten, war das des ZK 70.2 deutlich stärker, jedoch immer noch schwächer als die Kotransfektions-Kontrollen (WT und I126A).

Damit konnte gezeigt werden, dass alle untersuchten Klone in der Lage waren, konstitutiv funktionelles Coreprotein zu exprimieren. Die Zelllinien ZK 100.1 (HuH7HBVcore $^{\mathrm{WT}}$ ) und ZK 70.2 (HuH7-HBVcore ${ }^{\mathrm{I} 126 \mathrm{~A}}$ ) wurden für weitere Experimente verwendet.

\subsubsection{Herstellung von HuH7-Zellen mit konstitutiver Expression von HBV Core- und P-Proteinen}

Nach Generierung der HuH7-Zellen, die konstitutiv das WT-Coreprotein (HuH7HBVcore $^{\text {WT }}$ ) bzw. die Core Mutante I126A (HuH7-HBVcore ${ }^{\mathrm{I} 126 \mathrm{~A}}$ ) exprimieren, wurden diese Zelllinien zusätzlich stabil mit dem Polymerasegen des HBV transduziert. Auf diese Weise sollte später das nur für die Hüllproteine codierende HBV-Genom (pSVHBV1.5core ${ }^{-}{ }^{-} \mathrm{pol}^{-}$; 4.2.1) funktionell transkomplementiert werden können.

Aufgrund der Tatsache, dass das WT Coreprotein bzw. die Core-Mutante I126A durch den Selektionsdruck von Zeocin konstitutiv in den HuH7-Zellen exprimiert wurden, musste die stabile Expression eines zweiten, mit dem Retrovirus-System transduzierten Gens unter Selektionsdruck eines anderen AB erfolgen. Daher wurde das zu transduzierende Polymerasegen in den Vektor pczCFG5 IEGN (2.3.2) integriert werden, da dieser eine Selektion über Geneticin erlaubte.

Mit Hilfe der zwei Oligonukleotide \#424 und \#425 wurde das vollständige P-Gen aus dem das ca. 1,5-fache HBV-Genom tragende Plasmid pRVHBV1.5 (2.5) amplifiziert. Durch die Oligonukleotide wurde eine Kozak-Sequenz (GCC ACC; Kozak, 1986) vor das Start-Kodon des Gens eingefügt, sowie am 5' und 3’ Ende des Amplifikats je eine 
NruI-Restriktionsschnittstelle. Nach der PCR (3.4.4.5) wurde das 2570 bp große Amplifikat in den Vektor pDrive eingesetzt (3.4.5). Anschließend wurde das HBV Polymerasegen mittels NruI aus pDrive-HBVpol herausgeschnitten, der Vektor pczCFG5 IEGN mit SwaI linearisiert (3.4.4.1) und nach Dephosphorylierung des Vektors (3.4.4.4) die beiden Fragmente ligiert (3.4.4.2). Das resultierende Konstrukt pczCFG5 IEGN-HBVpol wurde anschließend zur Generierung von MuLV-Retroviren eingesetzt.

HEK-293T-Zellen wurden transient mit pczCFG5 IEGN-HBVpol, pczVSV-G wt und pHIT 60 kotransfiziert (3.3.4.3). Für die Positiv-Kontrolle wurde das parentale pczCFG5 IEGN mit pczVSV-G wt und pHIT 60 kotransfiziert, für die NegativKontrolle erfolgte eine Kotransfektion ohne pczCFG5 IEGN. Nach Generierung der rekombinanten Retroviren wurden diese $\mathrm{zu}$ den $\mathrm{zu}$ transduzierenden HuH7HBV ${ }^{\text {WT }}$ - (ZK 100.1) und HuH7-HBVcore ${ }^{\text {I126A }}$ - (ZK 70.2) -Zellen (4.2.2) gegeben (3.3.8). Zwei Tage nach der Transduktion wurden die jeweiligen ZK passagiert und das Kulturmedium mit je $600 \mu \mathrm{g} / \mathrm{ml}$ Geneticin und Zeocin versetzt. Damit konnten die Zellen selektioniert werden, die sowohl das P-Protein, als auch das WT Coreprotein bzw. die Core-Mutante I126A exprimierten. Da die HuH7-HBVcore ${ }^{\text {WT }}$ - und HuH7HBVcore ${ }^{\mathrm{I126A}}$-Zellen bereits eGFP exprimierten, konnte keine direkte optische Auswertung der Transduktionseffizienz erfolgen. Aus diesem Grund wurden in einem Parallelansatz naive HuH7-Zellen ebenfalls mit den P-Proteingen tragenden Retroviren sowie der Positiv- und Negativ-Kontrolle transduziert und visuell mit Hilfe des Fluoreszenz-Mikroskops Axiovert 10 (Carl Zeiss Jena, Jena) ausgewertet (3.3.12). Sowohl die HuH7-Zellen der Positiv-Kontrolle, als auch die HuH7-Zellen, die mit den Polymerasegen-tragenden Retroviren transduziert worden waren, zeigten deutliche Signale von exprimiertem eGFP. Die Zellen der Negativ-Kontrolle ließen hingegen keine vergleichbaren Signale erkennen (Daten nicht gezeigt). Ausgehend von dem Parallelansatz konnte angenommen werden, dass auch die Transduktion der beiden Zellklone HuH7-HBVcore ${ }^{\text {WT }}$ und HuH7-HBVcore ${ }^{\text {I126A }}$ erfolgreich war.

Zwei Wochen nach der initialen Zugabe des Geneticin-Zeocin-Gemisches wurden jeweils 40 Einzelzellklone steril in 96-Well-Platten überführt (3.3.9). Wöchentlich wurde das Medium gewechselt, wobei stets der Selektionsdruck durch die beiden AB (je $600 \mu \mathrm{g} / \mathrm{ml}$ ) erhalten blieb. Nach 28 Tagen Inkubation wurden jeweils 20 Klone in 
24-Well-Platten überführt. Die sechs am schnellsten gewachsenen und damit vitalsten Zellklone (ZK) wurden nach weiterer 14-tägiger Inkubation in 6-Well-Näpfe überführt und bis zum vollständigen Bewuchs des Napfbodens weiterkultiviert.

Der beste Nachweis für die Expression von funktionellen P-Proteinen und die Kontrolle für weiterhin bestehende Expression der beiden Coreproteine (WT und I126A) war die ,endogene Polymerase Reaktion’ (3.4.6.2). Dazu wurden jeweils drei der sechs ZK in je zwei 6-Well-Näpfe überführt. Dies waren die ZK 4, 5 und 6 von den Zellen, die das WT Coreprotein und die Polymerase exprimierten und die ZK 1, 2 und 3 der Zellen, die zusätzlich zur Polymerase die Core-Mutante I126A produzierten. Während jeweils ein Napf untransfiziert blieb, wurde der zweite Napf eines jeden ZK mit pczCFG5 IEGZSVHBV1.5core- ${ }^{-}$pol $^{-}$mit Hilfe von FuGENE (Roche Diagnostics, Mannheim) transfiziert (3.3.4.2). Als Positiv-Kontrollen wurden zum einen eine dreifach Transfektion von HuH7-Zellen mit pczCFG5 IEGZ-SVHBV1.5core`x”ol', pczCFG5 IEGZ-HBVcore ${ }^{\text {WT }}$ oder pczCFG5 IEGZ-HBVcore ${ }^{\mathrm{I126A}}$ und pczCFG5 IEGNHBVpol durchgeführt, zum anderen eine Transfektion des von den endogenen Promotoren regulierten HBV-Genoms (pRVHBV1.5; 2.5). Für die Negativ-Kontrollen wurde das Plasmid pczCFG5 IEGZ-SVHBV1.5core ${ }^{-} \mathrm{x}^{-} \mathrm{pol}^{-}$alleine oder zusammen mit pczCFG5 IEGZ-HBVcore ${ }^{\mathrm{WT}}$, pczCFG5 IEGZ-HBVcore ${ }^{\text {I126A }}$ oder pczCFG5 IEGNHBVpol in HuH7-Zellen transfiziert. Fünf Tage später wurden die Zellen lysiert (3.3.6) und die geklärten Lysate, sowie die Kulturüberstände mit anti-HBc bzw. anti-HBs immunpräzipitiert (3.4.8.1). Die Präzipitate wurden in die EPR eingesetzt (3.4.6.2). Nach Isolierung der viralen DNA und Separation der Proben im TAE-Agarosegel wurden die radiaktiven Signale gesammelt und mit Hilfe des Phosphoimagers ,Molecular Imager FX’ (Biorad, München) ausgewertet. 

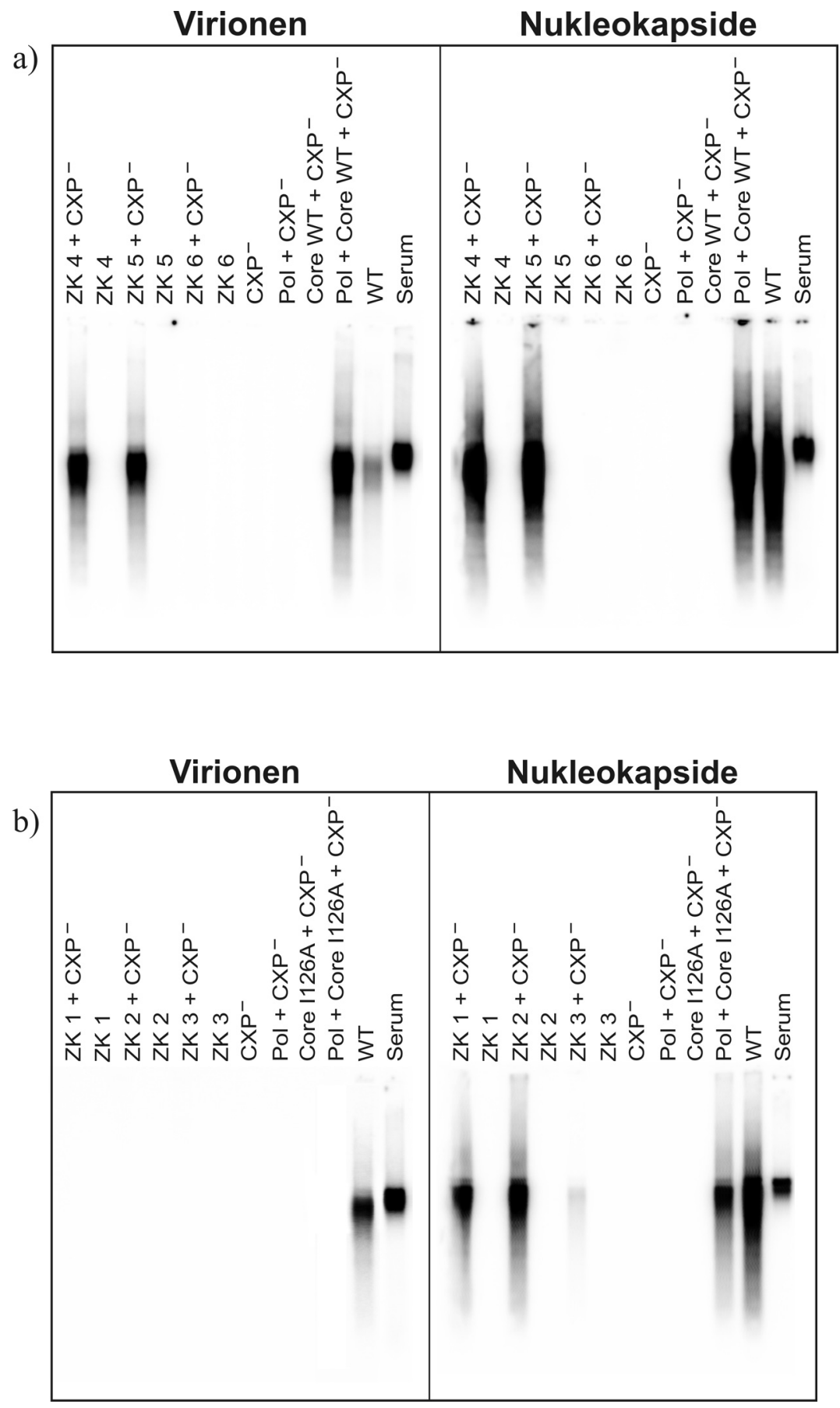

Abbildung 28: Ergebnisse der EPR-Auswertung der Coreprotein- und Polymeraseexprimierenden HuH7-Zellklone (a) 4, 5 und 6 (WT) sowie (b) 1, 2 und 3 (I126A) nach Transfektion mit dem Hüllprotein-exprimierenden HBV Genom.

P-Protein und WT Coreprotein (a) oder Core-Mutante I126A (b) exprimierende ZK wurden mit pczCFG5 IEGZ-SVHBV1.5core $x^{-}$pol $^{-}\left(\mathrm{CXP}^{-}\right)$transfiziert. Als Kontrolle wurden HuH7-Zellen entweder mit dem Hüllprotein-exprimierenden HBV-Genom (CXP') alleine transfiziert oder kotransfiziert mit den Coreprotein (Core WT oder Core I126A)- oder Polymerase (Pol)-exprimierenden Vektoren. Als WT-Kontrolle wurde pRVHBV1.5 transfiziert (WT) und eine Funktionskontrolle der EPR stellten ca. 2 x $10^{6}$ Genom- 
äquivalente aus hochtitrigem, humanen Serum dar. Fünf Tage nach Transfektion wurden Nukleokapside aus Zelllysaten und Virionen aus Zellkulturüberständen immunpräzipitiert, in die EPR eingesetzt und autoradiographisch ausgewertet.

Abbildung 28 a) zeigt die EPR-Ergebnisse der Zellklone 4, 5 und 6 (WT), die mit dem Hüllprotein exprimierenden Genom transfiziert worden waren. Sowohl ZK 4 als auch ZK 5 waren in der Lage, zytosolische Nukleokapside zu generieren. Diese besaßen annähernd die gleiche Signalintensität wie die WT-Kontrolle (WT) und die DreifachTransfektion (Pol + Core WT + CXP'). In der Zelllysat-Probe des ZK 6 hingegen zeigte sich, wie auch bei den drei Negativkontrollen, keinerlei Aktivität, was z.B. auf eine defekte Polymerase-Expression zurückzuführen sein könnte. Die linke Seite der Abbildung zeigt die Signale der Zellkulturüberstande. Hier waren bei den ZK 4 und 5 wie auch bei der Dreifach-Transfektion Signale von sezernierten Virionen zu sehen. In der Spur der WT-Kontrolle zeigte sich im Vergleich dazu ein schwächeres Signal. Nachdem ZK 6 keine zytosolischen Nukleokapside generieren konnte, war dementsprechend auch kein Signal von Virionen zu detektieren. In Abbildung 28 b) sind die EPR-Ergebnisse der Proben der ZK 1 bis 3 (I126A) dargestellt. Alle drei Klone waren mit unterschiedlicher Effizienz in der Lage, Nukleokapside zu assemblieren. Während ZK 2 und auch ZK 1 annähernd an die Signalintensität der Positiv-Kontrollen heranreichten, produzierte ZK 3 ein deutlich schwächeres Signal. Möglicherweise war bei diesem ZK die Polymerase-Expression beeinträchtigt. Auf der linken Seite der Abbildung zeigten sich bei den ZK der umhüllungsdefizienten Mutante I126A wie erwartet keine Signale von sezernierten Virionen. Nur die WT-Kontrolle besaß die Kompetenz, Nukleokapside zu umhüllen und ins Medium zu sezernieren.

Es zeigte sich, dass es möglich war, zwei (ZK 4 und ZK 5) der drei WT Core- und PProtein exprimierenden ZK (HuH7-HBVcore ${ }^{\mathrm{WT}}$-pol) durch Hüllproteine in trans zu komplementieren. Bei den ZK der HuH7-Zelllinien, die die Core-Mutante I126A und die Polymerase exprimierten (HuH7-HBVcore ${ }^{\mathrm{I} 126 \mathrm{~A}}$-pol), konnte gezeigt werden, dass erwartungsgemäß keiner der drei ZK in trans komplementiert wurde, da die Umhüllung mit WT LHBs durch die Core-Mutante blockiert worden war. Es wurden aber funktionelle zytosolische Kapside nachgewiesen, was zeigte, dass das eingebrachte HBV-Genom verpackt werden konnte. Für weitere Versuche wurden ZK 4 (HuH7HBV core $^{\text {WT }}$-pol) und ZK 2 (HuH7-HBVcore ${ }^{\text {I126A }}$-pol) verwendet. 


\subsubsection{Herstellung von Retroviren mit Hüllprotein-exprimierendem HBV-Genom}

Nachdem gezeigt worden war, dass die WT Coreprotein- und Polymeraseexprimierenden HuH7-Zellen erfolgreich transkomplementiert werden konnten und die die Core-Mutante I126A produzierenden Zellen reife Nuleokapside generieren konnten, wurde das Hüllprotein-exprimierende HBV-Genom (4.2.1) mittels Transduktion von Retroviren in den ZK 4 (HuH7-HBVcore ${ }^{\mathrm{WT}}$-pol) und ZK 2 (HuH7-HBVcore ${ }^{\mathrm{I} 126 \mathrm{~A}}$-pol) eingebracht. Anschließend sollte mit Hilfe von Immunpräzipitation von sezernierten Virionen und nachfolgender PCR-Analyse gezeigt werden, dass nach Transduktion des ZK 4 reife Virionen produziert worden waren, während der Umhüllungsprozess bei ZK 2 blockiert sein sollte.

Ein großer Vorteil der Transduktion gegenüber einer Transfektion ist, dass durch eine geeignete Infektionsdosis eine Einbringung von mehreren Kopien des HBV-Genoms in eine Zelle verhindert werden kann. Bei einer MOI von 0,5 Retroviren pro Zelle ist es statistisch relativ unwahrscheinlich, dass eine Doppelinfektion erfolgt, wodurch ungewollte inter- und intragenomische Rekombinationen bei dem in 1,5-facher Kopie vorliegenden HBV-Genom reduziert werden können. Weiterhin wird dadurch die Möglichkeit verringert, dass ein HBV-Genom verpackt und sezerniert wird, welches nicht für die komplementierenden Hüllproteine kodiert, die von einem zweiten, in der gleichen Zelle vorkommenden Genom in trans beigesteuert wurden.

Für die Herstellung der Retroviren mit Hüllprotein-exprimierendem HBV-Genom wurden HEK-293T-Zellen in $10 \mathrm{~cm}$-Schalen transient mit den Plasmiden pczCFG5 IEGZ-SVHBV1.5core'x- pol' $^{-}$(4.2.1), pczVSV-G wt und pHIT 60 transfiziert (3.3.4.3). Zur Generierung von funktionellen Kontrollretroviren ohne HBV-Insertion wurde pczCFG5 IEGZ zusammen mit pczVSV-G wt und pHIT 60 transfiziert, während als Negativ-Kontrolle nur die beiden letztgenannten Plasmide in die HEK-293T-Zellen eingebracht wurden. Jede Kotransfektion wurde dreifach angesetzt, um später sowohl HuH7-Zellen als auch die beiden ZK 4 (HuH7-HBVcore ${ }^{\text {WT }}$-pol) und ZK 2 (HuH7HBVcore ${ }^{\mathrm{I} 126 \mathrm{~A}}$-pol) parallel transduzieren zu können. Nach Generierung des Retrovirushaltigen Filtrats $(9 \mathrm{ml})$ wurde dieses zu den Zielzellen gegeben und für $6 \mathrm{~h} \mathrm{im}$ Brutschrank inkubiert (3.3.8). Für eine funktionelle Kontrolle wurde je ein 6-Well-Napf der ZK 4 und ZK 2 sowie HuH7-Zellen mit dem Plasmid pczCFG5 IEGZ- 
SVHBV1.5core“ ${ }^{-} \mathrm{pol}^{-}$mit Hilfe von FuGENE transfiziert (3.3.4.2). Am nächsten Tag fand analog zur ersten eine zweite Transduktionsrunde statt. Ein Tag nach der zweiten Transduktion erfolgte die Zugabe der beiden AB Geneticin und Zeocin (je 600 g/ml).

Zur Überprüfung der erfolgreichen Transduktion konnte aufgrund der bereits in den Zellen vorhandenen, konstitutiven Expression von eGFP keine Auswertung von ZK 2 (HuH7-HBVcore ${ }^{\mathrm{I} 126 \mathrm{~A}}$-pol) und ZK 4 (HuH7-HBVcore ${ }^{\mathrm{WT}}$-pol) mit Hilfe der FACSAnalyse oder Fluoreszenz-Mikroskopie vorgenommen werden. Dies war nur für die parallel transduzierten bzw. transfizierten HuH7-Zellen möglich. Bei der Betrachtung dieser Zellen mit dem Fluoreszenz Mikroskop Axiovert 10 (Carl Zeiss Jena, Jena) zeigten sich bei der Transduktions-Kontrolle (pczCFG5 IEGZ) und der TransfektionsKontrolle (pczCFG5 IEGZ-SVHBV1.5core ${ }^{-}{ }^{-} \mathrm{pol}^{-}$) starke Signale von exprimiertem eGFP. Bei den Zellen, die mit den HBV-Genom-tragenden Retroviren transduziert wurden, waren im Vergleich sehr viel schwächere Signale zu sehen. Dies war vermutlich auf die Insertion des großen HBV-Fragmentes (ca. 4300 bp) in das Retrovirus-Genom zurückzuführen. Bei den Zellen der Negativ-Kontrollen war keine Fluoreszenz zu beobachten (Daten nicht gezeigt).

\subsubsection{Nachweis der Transduktion von ZK 4 (HuH7-HBVcore ${ }^{\mathrm{WT}}$-pol) und ZK 2 (HuH7-HBVcore ${ }^{\mathrm{I126A}}$-pol) mittels PCR}

Für den Nachweis einer erfolgreichen Transkomplementation des Hüllproteinexprimierenden HBV-Genoms mit den Coreproteinen (WT und Mutante I126A) und der Polymerase, und damit einer funktionsfähigen Virus-Morphogenese, wurde eine PCR für sezernierte Virionen durchgeführt. Dazu wurden spezifisch im Genom bindende Oligonukleotide (\#216 und \#309; 2.12) verwendet, die einen Bereich von 607 bp (HBV nt 2755 bis 140) amplifizieren. In diesem Bereich befindet sich sowohl die vollständige PräS1-, als auch die nahezu vollständige PräS2-Region. Auch die Matrixdomäne (AS 103-124 des LHBs) ist dort lokalisiert, die später durch randomisierte PCR-Mutagenese für die Komplementations-Experimente verändert werden sollte. Durch eine Sequenzierung dieses Amplifikates sollte es in nachfolgenden Experimenten möglich sein, die mutierte, für die Komplementation der Core-Mutante I126A nötige Mutation in der Matrixdomäne des LHBs zu ermitteln. 
Vier Tage nach der zweiten Transduktion mit den Retroviren, die das Hüllproteinexprimierende HBV-Genom trugen (4.2.4), wurden die Zellkulturüberstände geerntet und die sezernierten Virionen mit anti-HBs immunpräzipitiert (3.4.8.1). Nach Isolierung der viralen DNA (3.4.6.3) und Aufnahme des DNA-Pellets in $15 \mu \mathrm{H}_{2} \mathrm{O}_{\text {bidest }}$ wurden die Proben in eine 25 Zyklen umfassende PCR eingesetzt (3.4.4.5). Die AnnealingTemperatur wurde dabei auf $47^{\circ} \mathrm{C}$ festgesetzt. Als Positiv-Kontrolle fungierten $5 \mathrm{pg}$ eines Plasmids, das die ca. 1,5-fache Kopie des HBV-Genoms trägt (pRVHBV1.5; 2.5), als Negativ-Kontrolle dienten $5 \mu \mathrm{H}_{2} \mathrm{O}_{\text {bidest }}$. Nach der PCR wurden $5 \mu \mathrm{l}$ von jeder Probe mit $1 \mu \mathrm{l} 6 \mathrm{x}$ Probenauftragspuffer I versetzt und auf ein 1,5\%-iges TAE-Agarosegel aufgetragen. Als Größenkontrolle wurde der Längenstandard Generuler ${ }^{\mathrm{TM}} 100$ bp DNA Ladder Plus (MBI Fermentas, St. Leon-Rot) (2.9) flankierend auf das Gel aufgetragen.

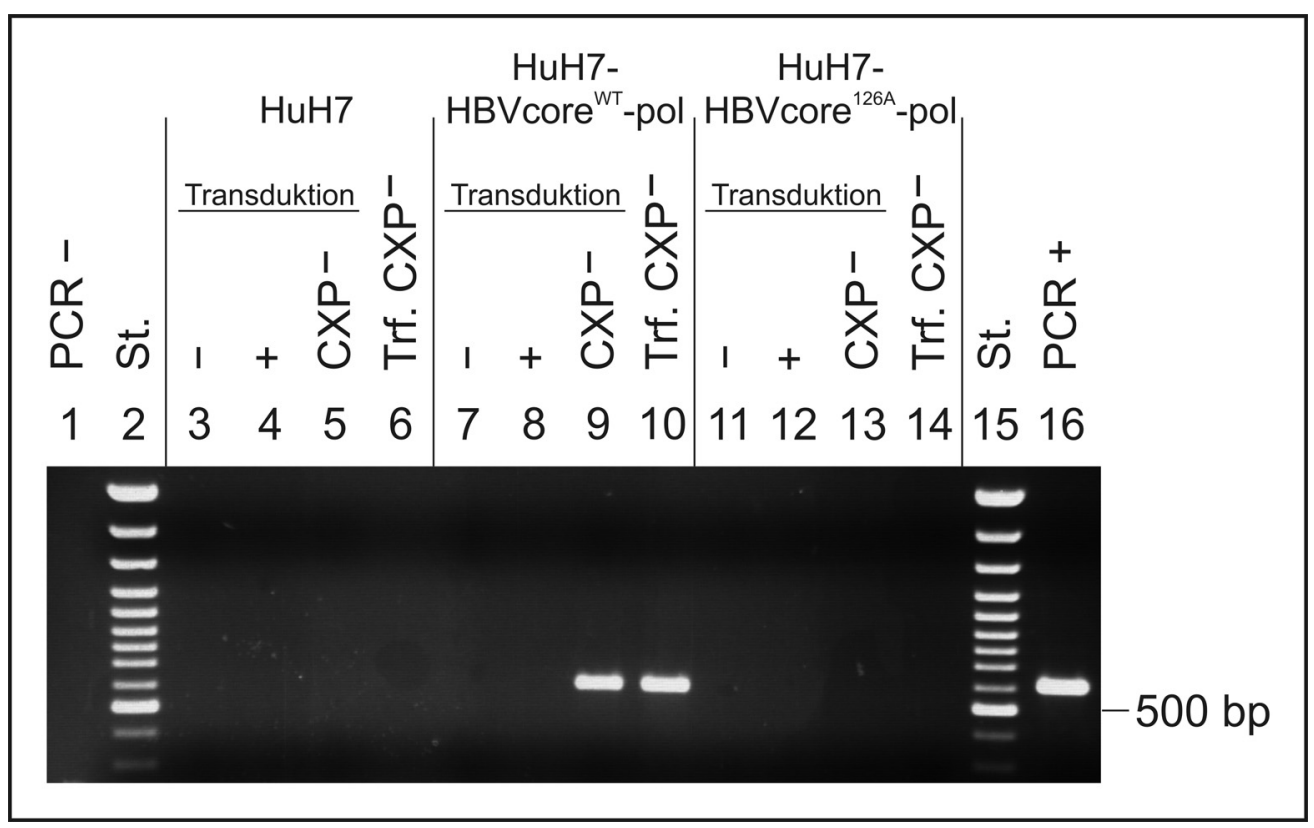

Abbildung 29: PCR-Nachweis des HBV-Genoms nach Transkomplementation des Hüllprotein-exprimierenden Genoms mit Polymerase und WT Coreprotein oder Coreprotein Mutante I126A. PCR -: Negativ-Kontrolle PCR; PCR +: Positiv-Kontrolle PCR; St.: Längenstandard; ,-’ : Negativ-Kontrolle Transduktion; ,+’ : Positiv-Kontrolle Transduktion; CXP: Transduktion des Hüllprotein-exprimierenden HBV-Genom; Trf. CXP': Transfektion des Hüllprotein-exprimierenden HBV-Genom.

In den Spuren 2 und 15 war der Längenstandard aufgetragen und in den Spuren 1 und 16 die PCR-Kontrollen, die wie erwartet negativ bzw. positiv ausfielen. In den Spuren 3 und 4, 7 und 8 sowie 11 und 12, in denen sich die Kontroll-Transduktionen befanden, 
waren keine Banden vorhanden, da kein HBV-Genom in die Zellen eingebracht wurde. In den Spuren 5 und 6 waren ebenfalls keine Signale zu sehen, denn hier fehlten in den HuH7-Zellen nach der Transduktion mit den Retroviren bzw. Transfektion des HBVGenoms die für die Morphogenese nötigen Core- und P-Proteine. Zwei positive Signale zeigten sich in Form von zwei Banden in Höhe der erwarteten 607 bp bei den Proben in den Spuren 9 und 10. Hier komplementierten die in den HuH7-HBVcore ${ }^{\text {WT }}$-pol-Zellen konstitutiv exprimierten WT Coreproteine und P-Proteine das transduzierte (Spur 9) bzw. transfizierte (Spur 10) Hüllprotein-exprimierende virale Genom. Es musste eine funktionelle Virus-Morphogenese mit anschließender Sekretion reifer Virionen erfolgt sein. Erwartungsgemäß wurden in der PCR keine Banden nach der Transduktion (Spur 13) oder Transfektion (Spur 14) des Genoms in die HuH7-HBVcore ${ }^{\mathrm{I} 126 \mathrm{~A}}$-polZellen generiert, da die umhüllungsdefiziente Core-Mutante I126A die Morphogenese der Virionen blockierte.

Es zeigte sich, dass dieses System nach Transduktion eines Hüllprotein-exprimierenden HBV-Genoms eine Transkomplementierung in den Zellen ermöglichte, die konstitutiv das WT Coreprotein und die Polymerase synthetisierten. 


\section{DISKUSSION}

Das Hepatitis-B-Virus ist ein umhülltes DNA-Virus mit einem ikosaedrischen Nukleokapsid und repliziert sich über reverse Transkription (SuMMERS \& MASON, 1982). Die virale Hülle enthält drei Hüllproteine und umschließt das Kapsid, das nur aus einem Baustein, dem Corepotein, besteht. Während der im Zytosol stattfindenden Assemblierung des Kapsids wird die ca. 3,35 kb große prägenomische RNA zusammen mit der viralen Polymerase und anderen zellulären Faktoren verpackt. Diese neu entstandenen Kapside werden nicht verpackt (GERELSAIKHAN et al., 1996; WEI et al., 1996; Perlman, 2003). Erst während oder nach der reversen Transkription des RNA Prägenoms in ein partiell doppelsträngiges DNA Genom wird auf der Oberfläche des Nukleokapsids ein Reifungssignal generiert, wodurch die Kapside kompetent für die Umhüllung werden. Der exakte Ort der Umhüllung bzw. der Knospung (budding) konnte bislang nicht bestimmt werden. Während zum Beispiel Herpesviren an der Kernmembran und einige Retroviren an der Zytoplasmamembran umhüllt werden (Modrow \& FALKe, 1998), geht man bei dem HBV davon aus, dass das budding an intrazellulären Membranen von Kompartimenten wie dem Post-ER, Prä-Golgi oder den multivesicular bodies erfolgt (PATZER et al., 1986; HuOvilA et al., 1992; FREED, 2002).

Sowohl innerhalb des LHBs und SHBs (BRuss, 1997; Le SEYeC et al., 1998; Le SEYEC et al., 1999; LÖFFLER-MARY et al., 2000), als auch auf der Kapsidoberfläche (KOSCHEL et al., 1999; Koschel et al. 2000; PONSEL \& BRUSS, 2003) wurden Bereiche bzw. Positionen bestimmt, die notwendig für den Umhüllungsprozess der zytosolischen Nukleokapside sind. Insbesondere die Matrix-Domäne des LHBs wird als Interaktionspartner für spezifische Protein-Protein-Interaktionen mit der Oberfläche des Nukleokapsids während des Umhüllungsprozesses propagiert. Die hohe Spezifität dieser Interaktion wird deutlich, wenn die Tatsache berücksichtigt wird, dass einzig Nukleokapside mit Reifungssignal umhüllt werden.

Die Arbeitshypothese geht davon aus, dass es während des Umhüllungsprozesses zu einem direkten Kontakt zwischen den transmembran gelegenen Hüllproteinen und den mit einem Reifungssignal versehenen Nukleokapsiden kommt. 


\subsection{Charakterisierung oberflächenexponierter AS-Positionen des $\mathrm{HBV}$ Nukleokapsids}

\subsubsection{Auswahl der zu phänotypisierenden AS-Positionen}

Für diese Arbeit wurden insgesamt sechs AS-Positionen des Coreproteins für Mehrfachsubstitutionen ausgewählt, die nach Alanin-Substitution umhüllungsdefizient waren (Ponsel \& BRUSS, 2003): S17, L95, K96, F122, I126 und R127. Die zwei Positionen L95 und K96 wurden selektiert, da sie maßgeblich an der Bildung einer annähernd ringförmigen Struktur (L60, L95 und K96) an der Basis des Spikes beteiligt sind. Sie befinden sich in der Spike-abwärts gelegenen Helix $\alpha 4 b$, die wenige AS später (ab Position 99) in das Innere des Kapsids eintaucht. Beide AS-Reste sind als stark konserviert einzustufen, da bei einem Vergleich von 125 HBV Coreprotein-Sequenzen, die in der NCBI-Proteindatenbank (http://www.ncbi.nlm.nih.gov/) gelistet sind, jeweils nur eine andere AS vorhanden war: Bei L95 gab es zweimal einen Austausch zu dem ebenfalls hydrophoben Isoleucin, während bei K96 nur eine Substitution gegen das ebenfalls basische Arginin vermerkt war. Auch die AS L60 zeigte den K+/V- Phänotyp nach Austausch gegen Alanin, wurde aber aufgrund der Nähe zu Position C61, die für die Ausbildung der Disulfidbrücke verantwortlich ist, nicht ausgewählt. Diese Brücke ist zwar nicht essentiell für die Dimer- und Kapsidbildung, stabilisiert aber die Strukturen (NASSAL et al., 1992b; ZHENG et al., 1992; ZLOTNICK et al., 1996). Durch eine Veränderung der Größe oder Ladung des AS-Restes an dieser Position hätte es leicht zu einer Blockierung und Destabilisierung der Disulfidbrücken kommen können und dadurch zu Instabilitäten bei der Dimerbildung. Die weiteren vier ausgesuchten Positionen S17, F122, I126 und R127 befinden sich innerhalb der flächigen Struktur an den Dimer-Kontaktstellen und weisen trotz der großen sequentiellen Entfernung von S17 eine enge Lokalisation zueinander auf. Diese vier Positionen bilden dabei eine Art Ring um den lateralen Arm des Coreprotein-Homodimers. S17 liegt am Ende der Helix $\alpha 1$ und ist hoch konserviert; nur ein AS-Austausch gegen Prolin konnte in der Datenbank gefunden werden. Die AS-Reste F122, I126 und R127 befinden sich in der Helix $\alpha 5$. Bei F122 wurde nur zweimal ein natürlich vorkommender Austausch gegen Valin an dieser Position nachgewiesen, während an Position I126 in der Datenbank kein 
Austausch zu finden war. Position R127 ist hingegen etwas variabler, da je einmal Alanin, Glycin, Histidin und Prolin anstelle des Arginins vorhanden war.

Neben den sechs Positionen, die nach der Alanin-Substitution keine Umhüllung mehr ermöglichten, wurden vier AS-Reste ausgewählt, die nach dem Austausch dem Phänotyp des WT-Coreproteins entsprachen: S21, D22, N90 und R98. Die ASPositionen S21, D22 und R98 befinden sich zwischen $\alpha$-Helix 1 und 2a (S21 und D22), bzw. innerhalb der Helix $\alpha 4 b$ (R98). In der Tertiärstruktur des Proteins decken sie fast vollständig den Oberflächenbereich zwischen dem basalen Spike-Ring und der flächigen Struktur an den Dimer-Kontaktstellen, die von den umhüllungsinkompetenten Mutanten gebildet werden, ab. Während R98 vollständig und D22 mit nur einem nachgewiesenen Austausch gegen Histidin hoch konserviert ist, ist die Position S21 sehr variabel: Von den 125 überprüften Sequenzen enthielten an dieser Position 112 Serin, sieben Threonin, zwei Alanin, zwei Histidin, eine Asparagin und eine Valin. N90 liegt in dem Bereich zwischen den $\alpha$-Helices $4 \mathrm{a}$ und $4 \mathrm{~b}$ und damit direkt oberhalb des angedeuteten Rings, den die Reste L95 und K96 um die Basis des Spikes bilden. Asparagin ist an dieser Position sehr konserviert, nur einmal konnte Lysin gefunden werden.

Mit der Auswahl dieser zehn Positionen sollte ein wichtiger Teil der Oberflächenbereiche, die an der Umhüllung beteiligt sein könnten, abgedeckt sein. Die AS der zehn ausgewählten Positionen wurden gegen verschiedene andere Reste mittels PCR-Mutagenese ausgetauscht. Dabei wurde darauf geachtet, dass die eingeführten Reste ein möglichst breites Spektrum an Eigenschaften wie Ladung, Größe und Polarität abdeckten. Die Untersuchungen umfassten EPR-Experimente zur Beurteilung der Umhüllungsfähigkeit, Western Blot-Analysen zum Nachweis assemblierter Kapside, Southern Blot- und RT-PCR-Experimente zur Bestimmung der intrakapsidären Nukleinsäuren und CsCl-Gradient/Western Blot-Analysen zum Nachweis umhüllter und sezernierter Nukleokapside. 


\subsubsection{Analyse von umhüllungsrelevanten Aminosäure-Positionen des HBV Nukleokapsids}

Die sechs AS-Positionen S17, L95, K96, F122, I126 und R127 wurden während dieser Arbeit mit verschiedenen anderen AS substituiert (4.2.3.1). Diese Validierung sollte weitere Einsichten hinsichtlich der Variabilität und Anforderung der ausgesuchten Positionen in Bezug auf benötigte Eigenschaften während des Umhüllungsprozesses geben. Bei Reproduktionen des umhüllungsdefizienten Phänotyps durch die an diesen Positionen eingeführten AS-Reste sollten weiteren Rückschlüsse auf die Beteiligung dieser AS-Positionen während des Umhüllungsprozesses bzw. bei der Protein-ProteinInteraktion mit dem LHBs (Matrix-Domäne) gezogen werden können. In dem Fall, dass nach dem Austausch der AS keine Kapside detektierbar sind, wäre eine Beteiligung dieser Position an der Umhüllung denkbar, kann jedoch aufgrund der aufgetretenen Kapsidinstabilität nicht bewertet werden. Die strukturelle Bedeutung einer Position lässt sich an der Häufigkeit von letalen Substitutionen ermitteln: Je häufiger die Kapsid- oder Dimerstabilität durch die Mutanten beeinträchtigt ist, desto wichtiger sollte die Position für den Assemblierungsprozess sein.

Der Verlust der Umhüllungskompetenz der Kapside lässt sich nicht nur durch die Möglichkeit des Wegfalles der direkten Interaktionsstelle zwischen den mutierten ASPosition und dem LHBs erklären. Eine weitere Möglichkeit besteht z.B. in der Beeinträchtigung des Reifungssignales des Nukleokapsids. Da dessen Identität bislang nicht geklärt ist, muss die Möglichkeit einer Inhibierung oder einer Zerstörung ebenfalls in Betracht gezogen werden. Auch konnte bisher eine Beteiligung zellulärer Strukturen oder Proteine während des Umhüllungsprozesses oder dem generellen Transport der Nukleokapside zum Post-ER, Prä-Golgi oder den multivesicular bodies nicht ausgeschlossen werden. Deshalb sollte auch ein solcher Bindungsverlust berücksichtigt werden. Neben dem Wegfall der Umhüllungskompetenz kann es durch die Substitutionen auch zu einem Verlust oder einer Beeinträchtigung der Kapsidassemblierung kommen. Dabei muss vor allem der Austausch der spezifischen ASEigenschaften, wie Ladung, Größe oder Polarität berücksichtigt werden, der sich negativ auf die Assemblierungsfähigkeit oder die Stabilität der Dimere oder Multimere auswirken kann. In einem ,Zell-freien’ System konnte gezeigt werden, dass für die 
Kapsidassemblierung intakte Membranen in Form von Vesikeln benötigt werden (LINGAPPA et al., 2005). Das lässt vermuten, dass das Coreprotein ein Signal für einen Membran-gerichteten Transport besitzen könnte und dass deshalb die Kapsidassemblierung nicht wie bisher angenommen im Zytosol erfolgt, sondern an intrazellulären Membranen. Ein solches intrinsisches Signal konnte aber, im Gegenteil zu dem bekannten NLS und Kern-Export-Signal (KANN et al., 1999; MABIT et al., 2001; RABE et al., 2003), bisher nicht identifiziert werden. Daher besteht die Möglichkeit, dass auch dieses Signal unwissentlich durch die AS-Substitutionen zerstört wird, wodurch es zu einem Verlust der Assemblierungsfähigkeit kommen könnte. Den Verlust der Epitope, die während der Versuche für die Nachweisbarkeit von Kapsiden wichtig waren, kann man hingegen nahezu ausschließen, da sich die Hauptepitope zum einen bei AS-Position 80 und zum anderen bei AS-Position 130 befinden (SALFELD et al., 1989; SÄLlberg et al., 1991). Allein letzteres könnte von den Mutanten der Position R127, eventuell auch von denen der Position I126, beeinträchtigt worden sein. Da aber durch die Mutationen nicht beide Epitope betroffen sein sollten, sollte die Verfügbarkeit zumindest von dem Hauptepitop bei AS 80 stets gewährleistet worden sein.

Die AS-Position S17 (Helix $\alpha 1$ ) befindet sich in der Tertiärstruktur des Proteins nahe den Positionen F122, I126 und R127, und ihre Seitenkette zeigt vom Spike in Richtung der lateralen Enden des Homodimers. Alle eingebrachten Mutationen führten zu dem gleichen umhüllungsdefizienten Phänotyp, den auch die Alanin-Mutante aufwies (4.2.3.1, Abb. 16 a). Es zeigte sich, dass das neutral geladene, polare und hydrophile Serin durch keinen anderen AS-Rest, gleich welcher Eigenschaften, während des Umhüllungsprozesses ersetzt werden konnte. Weiterhin blockierte keine der Mutanten die Kapsidassemblierung vollständig, was verdeutlicht, dass die Struktur und Ladung des Serins für die Stabilität des Kapsids an dieser Position zweitrangig ist. Diese Position ist demnach weder strukturell noch funktionell an der Kapsidassemblierung und -umhüllung beteiligt.

Die unpolare, hydrophobe AS Leucin an Position 95 (Helix $\alpha 4 b$ ) besitzt eine Seitenkette, die in Richtung des lateralen Arms des Homodimers zeigt. An dieser Position wird deutlich, dass von den Eigenschaften her nahe verwandte AS-Reste (Isoleucin und Valin) in der Lage waren, den WT Phänotyp zu reproduzieren (4.2.3.1, 
Abb. 16 b). Dies wurde für Isoleucin nicht nur aufgrund der Ähnlichkeit erwartet, sondern auch aus dem Grund, dass in der NCBI-Proteindatenbank natürlich vorkommende Coreproteine mit dem L95I Austausch vorhanden waren. Hingegen blockierten die zwei AS-Reste Alanin und Glycin, die zu den ,kleinen’ AS gezählt werden, ansonsten aber gleiche Eigenschaften aufweisen, komplett die Umhüllung. Hier scheint es notwendig, dass der AS-Rest vor allem eine bestimmte Länge aufweist, um eine Bindung mit dem putativen Bindungspartner LHBs zu ermöglichen oder bei der Generierung des Reifungssignals zu unterstützen. Dass auch eine von den Eigenschaften stark abweichende AS wie Serin in der Lage ist, Kapside assemblieren zu können, weist darauf hin, dass die AS an Position 95 nicht unersetzbar für den Zusammenbau der Kapside ist.

Die neben L95 in Helix a4b befindliche AS-Position K96 besitzt eine Seitenkette, die in einem ca. $60^{\circ}$-Winkel nach oben von dem Spike wegzeigt. Wie schon bei der Position S17 waren auch hier alle Mutanten in der Lage, Kapside zu assemblieren, während der Umhüllungsprozess blockiert war (4.2.3.1, Abb. 16 c). Damit lässt sich auch bei dieser Position der Schluss ziehen, dass K96 keine für die Struktur des Kapsids wichtige, sondern vielmehr eine funktionelle, an der Umhüllung beteiligte AS ist. Eine geringe Störanfälligkeit bei der Kapsidassemblierung ließ sich jedoch bei der AsparaginsäureMutante bemerken. Deutlich konnten hier die wenigsten zytosolischen Core-Partikel nachgewiesen werden, da scheinbar durch die gegensätzliche Ladung zumindest eine Instabilität bei der Dimer- oder Kapsidbildung verursacht wurde. Überraschenderweise zeigte sich aber auch bei der ebenfalls positiv geladenen Arginin-Mutante eine Reduktion in der Menge der zytosolischen Kapside. Interessant ist dabei die Tatsache, dass in der Proteindatenbank von NCBI ein natürlich vorkommender K96R Austausch vorhanden war, während die Arginin-Mutante innerhalb dieser Arbeit einen K+/VPhänotyp besaß. Möglichkeiten der Erklärung hierfür werden in Kapitel 5.1.4 diskutiert.

Die Ergebnisse der Mutationen an den Positionen L95 und K96 deuten darauf hin, dass die beiden Positionen oder zumindest diese Region an der Bereitstellung des Reifungssignals beteiligt sein könnten. Diese These wird unterstützt durch einen ASAustausch an der benachbarten Position I97 (I97L), der scheinbar eine konstitutive oder frühzeitige Bereitstellung des Reifungssignals generiert, was zu einer Sekretion von unreifen Virionen führt (YUAN et al., 1999a). 
Die AS-Position F122 (Helix a5) befindet sich in der Tertiärstruktur direkt neben I126, und ihre aromatische Seitenkette ist aus dem lateralen Arm nach oben exponiert. Nach den Ergebnissen der EPR scheint das Phenylalanin an dieser Position nahezu essentiell für die Struktur des Kapsids oder aber schon für die zytosolische oder eine Membranassoziierte Bildung der Coreprotein-Homodimere oder -Multimere zu sein. Nur die Alanin-Mutante und die ebenfalls aromatische Tryptophan-Mutante waren in der Lage, geringe Mengen an zytosolischen Core-Partikeln zu bilden (4.2.3.1, Abb. 16 d). Bei dieser Position ist eine Beteiligung an der Umhüllung nicht ausgeschlossen, wie die beiden Mutanten F122A und F122W zeigten. Dies konnte aber aufgrund der zum großen Teil vorhandenen Instabilitäten bei der Generierung der Core-Partikel nicht genauer untersucht werden. Bemerkenswerterweise wurde in der Proteindatenbank zweimal der Austausch gegen Valin gefunden, während in dieser Arbeit nach den EPRExperimenten keine Kapsidsignale nachzuweisen waren (vgl. 5.1.4). Die fünf Mutanten mit dem K-/V- Phänotyp wurden in weiteren Experimenten in Hinsicht auf die Kapsidformierung und evtl. vorhandene Nukleinsäuren näher untersucht. Während die Mutanten F122G und F122K im Western Blot zum Nachweis assemblierter Kapside nicht in der Lage waren, Signale zu generieren, zeigten hingegen F122S, F122Y und F122V zum Teil WT-ähnliche Mengen (4.2.7.1, Abb. 21). Diese beinhalteten jedoch keine HBV-DNA, wie eine Southern Blot-Analyse zeigte (4.2.7.2, Abb. 22). Mit Hilfe einer RT-PCR-Analyse konnten aber verschiedene Mengen an intrakapsidärer pgRNA nachgewiesen werden, was darauf hinweist, dass eine Verpackung des viralen Prägenoms erfolgt sein musste, die reverse Transkription innerhalb der Kapside jedoch beeinträchtigt war. Bei Gegenüberstellung der Signalintensität des Western Blots mit der der RT-PCR wird deutlich, dass im Vergleich zu den gebildeten Kapsiden mehr RNA hätte nachweisbar sein müssen. Man kann also davon ausgehen, dass hier schon die Verpackung der RNA gehemmt wurde. Eine Ursache könnte eine beschleunigte Kapsidassemblierungsrate sein, wobei der sonst essentielle Komplex aus P-Protein und pgRNA eventuell nicht mehr benötigt wird. Ein Einfluss auf die protaminähnliche Domäne im C-terminalen Bereich jedes Coreproteins und damit auf die NukleinsäureBindefähigkeit ist, durch die Lokalisation von F122, nicht sehr wahrscheinlich. Weiterhin konnte gezeigt werden, dass die nachweislich RNA-enthaltenden Kapside der drei Mutanten nicht, wie die CsCl-Fraktionierung mit anschließendem Western Blot 
darlegte, als unreife Partikel in den Zellkulturüberstand entlassen wurden (4.2.7.4, Abb. 24 d, e und f). Die erhaltenen Ergebnisse der Mutanten der Position F122 unterstreichen die strukturelle, aber auch funktionelle Bedeutung des Phenylalanins an dieser Position während der viralen Morphogenese. Die Tatsache, dass dieser AS-Rest auf der Kapsidoberfläche lokalisiert ist, weist auf eine komplexe Beziehung zwischen dem Kapsid und dem Replikationskomplex, der offensichtlich nötig für die reverse Transkription des Genoms ist, hin.

Die Seitenkette der in Helix $\alpha 5$ befindlichen AS I126 zeigt vom oberen Teil des lateralen Homodimer-Arms nach oben in Richtung Spike. Die Ergebnisse der EPR mit den Mutanten an der Position I126 lassen darauf schließen, dass das Isoleucin direkt an dem Umhüllungsprozess beteiligt ist (4.2.3.1, Abb. 16 e). Einzig die Methionin-Mutante war in der Lage, den WT Phänotyp zu reproduzieren. Diese ist ebenfalls unpolar und hydrophob, und auch die Länge des eingesetzten Restes ist identisch. Allerdings besitzt das Methionin keine Methyl-Gruppe und ein Schwefel- anstelle des $\mathrm{C}_{3}$-Atoms im Rest. Im Gegensatz dazu ist es erstaunlich, dass die nahezu identische AS Leucin die Umhüllung blockierte. Sie besitzt die gleichen Eigenschaften wie Isoleucin, nur die Methyl-Gruppe befindet sich nicht an $C_{1}$ sondern $C_{2}$ des Restes. Diesen $\mathrm{K}+\mathrm{V}$ Phänotyp des Leucins zeigten, bis auf die Prolin-Mutante, auch die zehn weiteren Substitutionen. Prolin war der einzige AS-Rest, der die Kapsid- oder Dimerstabilität so stark beeinträchtigte, dass sowohl in der EPR als auch im Western Blot keine Kapside nachweisbar waren (4.2.7.1, Abb. 21). Begründet ist dies wahrscheinlich in der einzigartigen Struktur der Iminosäure mit dem Pyrrolidin-Ring. Da von den 13 Mutanten elf den umhüllungsdefizienten Phänotyp der Alanin-Mutante reproduzierten und damit zeigten, dass stabile Kapside gebildet, aber nicht umhüllt werden können, ist davon auszugehen, dass Isoleucin an dieser Position 126 während des Umhüllungsprozesses eine essentielle Rolle spielt. Die Bedeutung dieser Position wird auch dadurch deutlich, dass bei dem Sequenzvergleich mit der NCBI-Proteindatenbank kein natürlich vorkommender Austausch an dieser Position geführt wird.

Die basische, hydrophile und polare Seitenkette des Arginins an der Position 127 (Helix a5) befindet sich seitlich am lateralen Arm des Dimers und zeigt in Richtung Spike. Bei den EPR-Ergebnissen zeigte sich eine nahezu gleichmäßige Verteilung über die drei Phänotypen K+/V+, K+/V- und K-/V- (4.2.3.1, Abb. 16 f). Sowohl das basische, 
hydrophile und polare Lysin, als auch das neutrale, hydrophobe, unpolare Leucin waren in der Lage, Virionen zu generieren. Interessanterweise waren zwar die Signale bei der Leucin-Mutante sowohl im Lysat als auch im Medium stark reduziert, aber das Verhältnis von Virionen zu Kapsiden entsprach dem des WT. Die ebenfalls basische Histidin-Mutante blockierte trotz positiver Ladung, aber komplett anderer Struktur, die Umhüllung der Kapside. Eine Western Blot-Analyse der beiden Mutanten R127D und R127G (K-/V-) ergab, dass beide in der Lage waren Kapside zu assemblieren, jedoch im Vergleich zum WT in geringerer Menge (4.2.7.1, Abb. 21). Keine der beiden Substitutionen zeigte Signale von viraler DNA im Southern Blot (4.2.7.2, Abb. 22), aber eine RT-PCR-Analyse erbrachte bei beiden den Nachweis von pgRNA, jedoch in unterschiedlicher Quantität (4.2.7.3, Abb. 23). Auch hier könnte man wieder vermuten, dass die Kapsidassemblierung schneller als beim WT ablief, so dass weniger RNA verpackt wurde. Denkbar wäre auch, dass der sonst für den Beginn der pgRNAVerpackung verantwortliche P-Protein/pgRNA-Komplex nicht mehr benötigt wurde und es zu gehäuften spontanen Kapsidassemblierungen kam. Wie schon bei den Mutanten F122S, F122V und F122Y konnte nach CsCl-Fraktionierung keine Sekretion von unreifen HBV-Kapsiden gezeigt werden (4.2.7.4, Abb. 24 g und h). Die Signale von R127D waren nach Behandlung mit CsCl so schwach, dass man, ausgelöst durch die Mutation, von weniger stabilen Kapsiden ausgehen muss. Zusammengefasst scheint es an der Position 127 zum Teil möglich, das Arginin durch strukturell ähnliche AS zu substituieren, während Eigenschaften wie gleiche Ladung allein nicht ausreichend sind. R127 scheint gleichermaßen strukturell und funktionell innerhalb des Kapsids wichtig zu sein. Bei Evaluierung der Ergebnisse fällt auf, dass sowohl Alanin (K+/V-), als auch Glycin (K-/V-) und Histidin (K+/V-) entgegen der hier ermittelten Ergebnisse als natürlich vorkommende Substitutionen in der NCBI-Proteindatenbank geführt werden (siehe auch 5.1.4).

Nach der EPR-Analyse kann man die getesteten Positionen in zwei Gruppen einteilen. Die erste Gruppe, bestehend aus F122 und R127, scheint eher strukturelle oder strukturelle und funktionelle Aufgaben während der Kapsidassemblierung zu besitzen. Im 3D-Strukturmodell (Swiss-PdbViewer) zweier Coreprotein-Dimere wird deutlich, dass die Positionen Y132 des ersten Dimers (D1) und F122 des zweiten Dimers (D2) räumlich sehr nah beieinander gelegen sind. Auch wenn sie keine Wasserstoffbrücken 
ausbilden, ist es durchaus vorstellbar, dass es bei Veränderungen von F122 zu Beeinträchtigungen bei der Assemblierung kommen könnte. Zwischen R127 (D1) und D29 (D2) postuliert die 3D-Software eine Wasserstoffbrücke, so dass hier nach Substitution der AS-Reste eine Blockierung der Kapsidbildung möglich ist. Der Verlust oder die Reduktion der Kapsidstabilität lässt sich, aufgrund der Lage der AS-Positionen, eher auf instabile Inter- als auf eingeschränkte Intradimerkontakte zurückführen.

Die zweite Gruppe umfasst die Positionen S17, L95, K96 und I126, die einen eher funktionellen Charakter haben. Mit Ausnahme von I126P waren alle Mutanten dieser Gruppe in der Lage, Kapside zu assemblieren, und 24 von 28 reproduzierten den umhüllungsdefizienten Phänotyp der Alanin-Mutanten. Dies zeigt die Bedeutung dieser Positionen für den Umhüllungsprozess. Interessanterweise scheinen Substitutionen der Position K96 nicht die Stabilität von Coreprotein-Dimeren zu beeinflussen, obwohl im 3D-Modell deutlich wird, dass Wasserstoff-Brücken zwischen K96 des einen Coreproteins (C1) und E64 des zweiten Coreproteins (C2) bestehen. Diese Wechselwirkung scheint für die Bildung von Dimeren jedoch keine wichtige Rolle zu spielen, sondern hat allenfalls eine stabilisierende Wirkung. Betrachtet man die Lokalisierung dieser vier AS-Positionen, so fällt auf, dass sich L95 und K96, wie schon beschrieben, an der Basis des Spikes befinden, I126 am äußeren Ende des lateralen Arms lokalisiert ist und S17 etwas seitlich versetzt genau zwischen den anderen drei Positionen liegt. S17, L95 und I126 sind sehr gut von oben zugänglich, während K96 von N92 etwas verdeckt wird. Die Tatsache, dass diese vier AS räumlich in dieser Art und Weise lokalisiert sind, unterstützt die Hypothese der direkten Interaktion mit dem zytosolisch gelegenen N-terminalen Bereich des LHBs sehr gut. Die Matrix-Domäne (BRUSS, 1997) könnte in die Grube zwischen den Spikes gelangen, mit den analysierten AS zu Beginn des Umhüllungsprozesses in Kontakt treten und das Kapsid würde, nach immer mehr erfolgten Bindungen, von den transmembran gelegenen Hüllproteinen umhüllt werden.

Die im Rahmen dieser Arbeit durchgeführten Experimente haben gezeigt, dass es sinnvoll ist, neben Alanin-Substitutionen auch funktionell andere AS-Seitenketten in die zu untersuchende Position einzusetzen. Dadurch konnte zum Beispiel die Position I126 in Bezug auf die Umhüllungskompetenz und die Kapsidstabilität deutlich von der Position F122 abgegrenzt werden. Neben den sechs ausreichend getesteten Mutanten, 
die die Umhüllung nach der Alanin-Substitution blockierten, sollte es interessant sein, auch die Positionen N136, A137 und I139 mehrfach zu substituieren. Diese drei Positionen zeigten ebenfalls den K+/V- Phänotyp nach Einbringung von Alanin bzw. Glycin (Ponsel \& BRUSS, 2003). Sie befinden sich am C-terminalen Bereich des Coreproteins, kurz bevor die AS in das Lumen des Kapsids abtauchen. Durch diese Lage könnten sie neben der Umhüllung auch an der Generierung des Reifungssignals beteiligt sein, da eine direkte Beteiligung des C-Terminus des Proteins vermutet wird.

\subsubsection{Untersuchung von Aminosäure-Positionen des HBV Nukleokapsids mit WT Phänotyp nach Alanin-Substitution}

Neben den sechs umhüllungsdefizienten Mutanten wurden auch vier Alanin-Mutanten für Mehrfachsubstitutionen ausgewählt (S21A, D22A, N90A und R98A), die in der EPR den WT Phänotyp reproduzierten (4.2.3.2). Die Frage war, ob andere Substituenten diesen Phänotyp ebenfalls generieren können, oder ob sich bei diesen eventuell auch der $\mathrm{K}+/ \mathrm{V}$ - Phänotyp nachweisen lassen würde. Dies könnte auf eine direkte Beteiligung an dem Umhüllungsprozess hinweisen, was durch die AlaninMutante nicht gezeigt werden konnte. Daraus ließe sich weiter folgern, dass der Bereich der für die Interaktion mit den Hüllproteinen wichtigen AS noch mehr Positionen umfassen würde, was für einen noch komplexeren Bindungsvorgang sprechen würde. Würde hingegen der WT-Phänotyp reproduziert werden, so würde die jeweilige Position als strukturell und funktionell eher unwichtig bezeichnet werden können. Die in Kapitel 5.1.1 beschriebenen Möglichkeiten der Umhüllungs- und Assemblierungsinkompetenzen sind auch für die an diesen Positionen generierten Mutanten zu berücksichtigen. Alle vier getesteten Positionen waren zwischen dem Spike und den lateralen Enden des Dimers lokalisiert, so dass die Wahrscheinlichkeit einer Beteiligung an dem Umhüllungsprozess am höchsten war.

Die AS-Position S21 (hydrophil, polar) befindet sich in der Tertiärstruktur des Proteins nicht nur direkt neben D22 zwischen den Helices $\alpha 1$ und $\alpha 2 \mathrm{a}$, sondern auch, obgleich sequentiell weit voneinander entfernt, in unmittelbarer Nähe zu den Positionen N90, L95, K96 und R98. Obwohl S21 genau in der Verbindungslinie zwischen den K+/VPhänotyp Positionen L95 und I126 liegt und man daraus auf eine ähnliche Bedeutung 
bezüglich des Phänotyps schließen könnte, sind alle Mutanten in der Lage, den WT Phänotyp zu reproduzieren (4.2.3.2, Abb. a). Selbst die Substitution mit dem hydrophoben, unpolaren Isoleucin zeigte keine Beeinträchtigung der MorphogeneseSchritte. Bedingt durch ihre Lokalisation sollte sie keine Rolle während der Dimer- oder Kapsidformierung spielen. Weder funktionell noch strukturell scheint die Anwesenheit des Serins an dieser Position erforderlich zu sein.

Die Seitenkette der sauren AS D22 ist weit aus der Kapsidoberfläche exponiert und zeigt in Richtung der lateralen Enden der Dimere. Die Lage lässt zunächst keinen Einfluss auf die Dimerbildung oder Kapsidassemblierung erwarten, aber sowohl die Isoleucin-, als auch die Histidin-Mutanten zeigten sich unfähig, Signale von Nukleokapsiden zu generieren (4.2.3.2, Abb. b). Eine mögliche Erklärung mag die an dieser Position erforderliche negative Ladung sein, wohingegen eine Substitution mit dem basischen Histidin schon in einem natürlich vorkommenden Isolat nachgewiesen wurde. Bei den beiden ,kleinen’ AS Glycin und Alanin waren hingegen WT-ähnliche (G) oder zumindest schwache (A) Signale sowohl von Kapsiden, als auch von Virionen nachzuweisen. Daher kann man davon ausgehen, dass an dieser Position die Größe der Seitenkette eine strukturelle Rolle zu spielen scheint. Auch die Tatsache, dass D22 eine Wasserstoffbrücke mit Y132 des benachbarten Homodimers während der Kapsidassemblierung aufbaut, spricht für eine solche Aufgabe. Sobald der AS-Rest zu weit oder strukturell zu verschieden aus der Coreprotein-Oberfläche herausragt, wird entweder schon die Dimerbildung oder später die Kapsidassemblierung beeinträchtigt. Dies bestätigte sich auch bei der genaueren Analyse der beiden Mutanten mit K-/VPhänotyp (D22H und D22I). Beide generierten Signale, die oberhalb der Kontrollen lagen (4.2.7.1, Abb. 21). Dies bedeutete ein langsameres Laufverhalten im elektrischen Feld des Agarosegels, was vermutlich auf den Austausch der negativ geladenen Asparaginsäure gegen das basische Histidin oder das ungeladene Isoleucin zurückzuführen war. Ein ähnliches Phänomen wurde schon bei den AS-Positionen D29 und D78 nach Austausch gegen Alanin beobachtet (Ponsel, 2003). Auch die Generierung von größeren Strukturen, die im Agarosegel langsamer migrieren, könnte eine Erklärung darstellen.

Alle eingeführten Mutationen an Position N90 erlaubten sowohl Kapsidassemblierung, als auch deren Umhüllung und Sekretion reifer Virionen (4.2.3.2, Abb. c). Es zeigten 
sich jedoch Unterschiede in der Menge der assemblierten Kapside und sezernierten Virus-Partikel. Während die verwandte AS Asparaginsäure WT-ähnliche Signale erzeugte, waren die vier anderen deutlich beeinträchtigt. Aufgrund der Lokalisation zwischen den Helices $\alpha 4 \mathrm{a}$ und $\alpha 4 \mathrm{~b}$ sollte $\mathrm{N} 90$ weder bei Intra- noch bei Interdimerkontakten eine bedeutende Rolle spielen, obgleich vier Mutanten die Kapsidassemblierung beeinträchtigten. Wie die Ergebnisse zeigen, scheint diese Position funktionell nicht essentiell zu sein.

Die gut exponierte, basische Seitenkette der AS-Position R98 (Helix $a 4 b$ ) zeigte vom Spike weg auf die beiden AS-Reste S21 und D22. Vier Mutanten zeigten nach der EPRAnalyse den WT Phänotyp, wobei die Signale unterschiedlich stark ausfielen (4.2.3.2, Abb. d). R98D und R98H hingegen beeinträchtigten die Kapsidbildung. Nach der Western Blot-Analyse zeigte sich, dass der Austausch gegen die saure AS Asparaginsäure die Bildung von Nukleokapsiden vollständig blockierte (4.2.7.1, Abb. 21). Aufgrund der Lokalisation der Position R98 ist eine Beteiligung an der Dimerbildung oder der Kapsidassemblierung eher unwahrscheinlich, vielmehr scheint diese Mutante die stabile Struktur des Coreprotein-Monomer beeinträchtigt zu haben. Der Austausch gegen die basische und aromatische AS Histidin hingegen zeigte im Western Blot ein schwaches Signal von assemblierten Kapsiden, die im Agarosegel schneller migrierten als die WT-Kontrollen. Zusätzlich war noch ein Signal von Coreproteinen zu sehen, die sich im elektrischen Feld langsamer bewegten als die des WT. Durch die Substitution schien sich das Assemblierungsverhalten der Coreproteine derart verändert zu haben, dass es auch zu größeren und evtl. kompakteren Strukturen gekommen war, die das Netzwerk des Agarosegels langsamer bzw. schneller durchwanderten. In den Kapsiden der Mutante R98H konnte keine HBV-DNA nachgewiesen werden (Southern Blot) (4.2.7.2, Abb. 22), dafür aber verpackte pgRNA (RT-PCR) (4.2.7.3, Abb. 23). Das deutet darauf hin, dass die reverse Transkription der pgRNA blockiert sein musste. Erwartungsgemäß konnten nach CsCl-Fraktionierung des Kulturüberstandes keine umhüllten, unreifen Kapside detektiert werden, die von den HuH7-Zellen sezerniert worden waren (4.2.7.4, Abb. 24 c). Die Ergebnisse der Untersuchungen deuten darauf hin, dass an dieser Position die Struktur wichtiger war als die Ladung der Seitenkette der Substituenten, da das ebenfalls positiv geladene Histidin nicht in der Lage war, den $\mathrm{K}+/ \mathrm{V}+$ Phänotyp zu reproduzieren. Weiterhin weist 
dies auf eine Beteiligung dieser Position an der Kapsidassemblierung hin, die durch grobe Veränderung der Seitenkettenstruktur beeinträchtigt werden kann.

Keine der getesteten Mutanten der Positionen, die nach Alanin-Substitution den WT Phänotyp zeigten, war umhüllungsdefizient (K+/V-). Entweder reproduzierten sie den WT Phänotyp $(\mathrm{K}+/ \mathrm{V}+)$ oder blockierten frühe Morphogenese-Schritte wie die Kapsidbildung oder die reverse Transkription (K-/V-). Durch die frühe Störung kann eine Beteiligung an der Umhüllung selbst nicht untersucht und damit nicht ausgeschlossen werden. Jedoch haben diese untersuchten Positionen eher strukturelle als funktionelle Aufgaben innerhalb der Kapside, wie die Ergebnisse aufzeigen.

\subsubsection{Einschränkungen bei der Interpretation der Ergebnisse}

Während dieser Arbeit wurde stets der Phänotyp einer einzelnen Punktmutation analysiert. Dabei zeigten sich je nach Substitution unterschiedliche Auswirkungen auf die Kapsidstabilität sowie die Umhüllungskompetenz. Man muss jedoch davon ausgehen, dass durch den Austausch der Seitenketten nicht nur andere Strukturen, sondern darüber hinaus differente Eigenschaften in das Coreprotein eingebracht worden sind, die auch benachbarte Positionen beeinflussen können. Und nicht nur direkt benachbarte AS-Reste könnten durch Punktmutationen betroffen sein, auch eine Wirkung auf weiter entfernt gelegene Positionen muss berücksichtigt werden. So konnte gezeigt werden, dass die Punktmutation I97L, die einen aberranten Sekretions-Phänotyp aufwies, durch die strukturell entfernt gelegene Mutation P130T funktionell komplementiert werden konnte (YUAN \& SHIH, 2000). Es ist also schwierig, die Mutanten ausschließlich isoliert zu betrachten. Es muss immer eine Mitbeteiligung anderer, nicht identifizierter AS-Reste an solch komplexen Vorgängen wie der Umhüllung berücksichtigt werden. Aus diesem Grund kann auch nicht ausschließlich davon ausgegangen werden, dass die Interaktion zwischen dem Kapsid und den Hüllproteinen durch nur jeweils eine AS vermittelt wird; dafür spricht auch die Anzahl der umhüllungsdefizienten Mutanten und deren Verteilung auf der Kapsidoberfläche. Auch die putative Bindungsregion des LHBs (Matrix-Domäne) umfasst eine Sequenz von 22 AS (BRUSS, 1997). Weiterhin könnten sicherlich auch Positionen wie F122 aktiv an der Umhüllung beteiligt sein, was aber aufgrund der Destabilisierung des Kapsids 
oder der Behinderung der reversen Transkription nicht genauer bestimmt werden konnte. Desweiteren sollte bedacht werden, dass die Ergebnisse nur die gesamte Umhüllungskompetenz widerspiegeln und nicht direkte Beweise für den Kontakt zwischen der getesteten AS und dem Hüllprotein liefern. Es wäre gut möglich, dass z.B. Position I126 essentiell für die Generierung des Reifungssignals ist, nicht aber für die Kontaktaufnahme während der Umhüllung. Neben dem Reifungssignal muss auch ein mögliches intrinsisches Membran-targeting Signal der Coreproteine berücksichtigt werden (LingAPPA et al., 2005), das durch die Mutationen gestört wird, wodurch es zu einer Blockierung des Membran-gerichteten Transports und der anschließenden Kapsidassemblierung an der Membran kommen könnte. Neben dem Austausch von ASEigenschaften könnte dies ein weiterer Grund für Assemblierungsdefizienz der sechs Mutanten sein, bei denen im Western Blot keine Signale von Kapsiden detektiert werden konnten (4.2.7.1).

Auch zelluläre Faktoren müssen berücksichtigt werden, wie zum Beispiel Chaperone, die eine Bindung begünstigen. Die Matrix-Domäne und die oberflächenexponierten ASReste S17, L95, K96 und I126 könnten Bindungsstellen für zelluläre Faktoren sein, die eine indirekte Interaktion zwischen dem Kapsid und dem Hüllprotein ermöglichen oder die eine Interaktion mit dem ,budding-Apparat' der Wirtszelle vermitteln. Für eine direkte Interaktion würde jedoch sprechen, dass die Punktmutation I97L im Coreprotein, die eine Umhüllung von unreifen Kapsiden ermöglicht, durch eine weitere Punktmutation (A119F) in der Matrix-Domäne des LHBs funktionell komplementiert wurde, wodurch es wieder zur Sekretion von WT Virionen kam (LE PogAm \& SHIH, 2002). Interessanterweise befindet sich die Seitenkette der Position 197 im Inneren des Spikes, weshalb man spekulieren könnte, dass die Mutation zu Leucin eine Strukturänderung, ähnlich einem Reifungssignal, bewirkte. Dies zeigt, dass eine Mutation mehr als nur eine Änderung der Eigenschaften einzelner AS-Reste nach sich zieht.

Neben der Annahme, dass das Kapsid zu Beginn des Umhüllungsprozesses eine direkte Bindung mit den N-terminalen Schleifen der transmembranen LHBs eingeht, um näher an die Membran rekrutiert zu werden, müssen auch andere Möglichkeiten der Kontaktaufnahme mit der Membran in Betracht gezogen werden. Im DHBV-Modell konnte bei einer Subpopulation von intrazellulären Nukleokapsiden eine intrinsische 
Membranbindungs-Affinität nachgewiesen werden (MABIT \& SCHALLER, 2000). Diese Nukleokapside repräsentierten dabei wahrscheinlich die Partikel, die für gewöhnlich umhüllt und sezerniert werden. Denn im Gegensatz zu den zytosolisch gelegenen, wiesen diese Membran-assoziierten Kapside das reife virale DNA-Genom auf und zeigten keine Hyperphosphorylierung. Daraus kann geschlossen werden, dass die reifen Kapside als erstes mit nicht-viralen Membrankomponenten in Kontakt treten (Phospholipide oder zellulären Membranproteine) und erst nachfolgend die Interaktion mit den Hüllproteinen erfolgt. Eine Störung dieser Membranbindungs-Affinität durch die Substitutionen könnte ebenfalls zu einem Verlust der Umhüllungsfähigkeit führen.

Es ist auch schwierig, die ermittelten Phänotypen einzelner Substitutionen mit der natürlichen Variabilität des entsprechenden AS-Restes (NCBI-Proteindatenbank) zu vergleichen: Zum Beispiel zeigten sich die Core-Mutanten K96R und R127H sowie F122V und R127G in der EPR als umhüllungsinkompetente bzw. letale Substitutionen (4.2.3.1), jedoch sind alle als natürlich vorkommende Mutationen in der Datenbank vermerkt. Eine Möglichkeit der Erklärung dazu wäre eine weitere komplementierende Mutation im Coreprotein, wie sie in ähnlicher Weise schon beschrieben wurde (YUAN \& SHIH, 2000). Ein weiterer Erklärungsansatz könnte in der Sequenz des dazugehörigen LHBs oder SHBs des analysierten Virus zu finden sein. Dort könnte eine komplementierende AS-Substitution vorhanden sein, wie mit Hilfe einer artifiziell geschaffenen Mutation in der Matrix-Domäne schon gezeigt wurde (LE POGAM \& SHIH, 2002). Auch eine Transkomplementation durch ein ebenfalls vorhandenes WT-Genom sollte berücksichtigt werden. Weiterhin ist in dieser Datenbank nicht vermerkt, ob die analysierten Gene funktionelle Proteine exprimieren konnten oder ob es sich um Gene von nicht replikationsfähigen HBV handelte.

\subsubsection{Core-Mutanten an Position I126 besitzen keine transdominant negative Wirkung auf die Umhüllungseffizienz}

Bis auf zwei Ausnahmen zeigten alle Core-Mutanten der Position I126 in den Versuchen dieser Arbeit eine ausgeprägte Umhüllungsinkompetenz (vgl. 4.2.3.1 und 5.1.1). Ein bekannter Effekt bei mutagenisierten Proteinen mit funktionellem oder strukturellem Charakter ist eine transdominant negative Wirkung auf das koexprimierte 
WT Protein. So zeigten umhüllungsdefiziente Mutanten des HBV LHBs einen transdominant negativen Phänotyp bei Kotransfektion mit WT-Hüllproteinen (BRUSS, 1997). Zurückzuführen war dies auf Homo- und Heterodimer-Bildung über Disulfidbrücken mit LHBs, MHBs und SHBs. Da auch der Nukleokapsidassemblierung eine Dimerbildung vorausgeht und das Kapsid wahrscheinlich nicht nur als Homosondern auch als Heteromultimer vorliegen kann, ist es denkbar, dass bei den I126Mutanten ein ähnliches Phänomen zu beachten sein könnte.

Nach Koexpression mit dem WT Coreprotein zeigte in den EPR-Experimenten keine der 14 Mutanten an Position I126 einen transdominant negativen Effekt auf den Umhüllungsprozess, und sie generierten mit der Kontrolle vergleichbare Signale (4.2.5, Abb. 19). Nur I126P und I126T generierten schwächere Signale, das Verhältnis von intrazellulären Kapsiden zu sekretierten Virionen blieb dem WT und den Kontrollen gegenüber aber nahezu unverändert. Die Kotransfektion des WT Coreproteins, wie auch die der umhüllungskompetenten Mutante I126M erbrachte ein etwa doppelt so starkes Signal von sezernierten Virionen im Vergleich zu der alleinigen Transfektion des WT HBV-Genoms, was auf die doppelte Menge an verfügbaren, umhüllungskompetenten Nukleokapsiden zurückzuführen sein müsste. Ob die umhüllten Kapside ausschließlich aus Homodimeren der Core-Mutanten oder WT Coreproteine bestehen, oder ob Heterodimer als Bausteine bei der Assemblierung verwendet wurden, konnte leider nicht bestimmt werden. Wenn zusätzlich ein transdominant negativer Effekt der CoreMutanten auf die Assemblierungsfähigkeit des WT Coreproteins berücksichtigt wird, ist zu bemerken, dass I126P und I126T zwar keine vollständige Blockierung induzieren, wohl aber eine sehr starke Reduktion.

Bei der genaueren Untersuchung, ab welchem Expressionsverhältnis von WT Coreprotein zu Core-Mutante I126A keine Umhüllung mehr möglich war und damit ein transdominant negativer Effekt vorlag, zeigte sich eine sichtbare Abnahme der Umhüllungseffizienz bei den Expressionsverhältnissen des WT Coreproteins zur CoreMutante I126A von 50:50 bis 10:90 (4.2.6, Abb. 20). Da weiterhin unklar war, ob sich Hetero- oder nur Homodimere bilden, und ob sich analog dazu Kapside nur aus Homooder auch aus Heterodimeren assemblieren können, bestanden zwei Möglichkeiten der Erklärung. Man hätte annehmen können, dass sowohl das WT Coreprotein, als auch die Core-Mutante I126A jeweils nur Homodimere ausbilden. In diesem Fall sollte es zu 
einem etwa konstanten Signal von zytosolischen Nukleokapsiden kommen, während das Signal von sezernierten Virionen in etwa proportional zur Menge des exprimierten WT Proteins abnehmen sollte. Es zeigte sich jedoch eine mehr als 50 \%-ige Abnahme des Virionen-Signals der 50 \% (WT): 50 \% (I126A) Expression gegenüber dem Signal des WT Coreproteins alleine (100\%). Die Signalintensitäten von Partikeln aus dem Medium der weiteren vier Kotransfektionen nahm zwar erwartungsgemäß ab, jedoch waren auch sie stets schwächer als der erwartete prozentuale Anteil. Aus diesem Grund scheint eine zweite Erklärung naheliegender, bei der davon ausgegangen wird, dass sich neben Homo- auch Heterodimere bilden können. Für diese Annahme spricht auch, dass Mutationen an der Position I126, mit Ausnahme von I126P, keine Destabilisierung des Kapsides verursachten. Diese Position scheint also für die Dimer- oder Kapsidbildung nicht essentiell zu sein. Die Umhüllungseffizienz hängt demnach nicht nur von dem prozentualen Anteil der Mutante, sondern auch von der Verteilung von I126A auf der Oberfläche des Kapsids ab. Statistisch ist eine gleichmäßige Verteilung bei einem Expressionsverhältnis von 50:50 sicherlich möglich. Eine zufällige Anordnung scheint jedoch wahrscheinlicher, so dass nicht an jeder Symmetrie-Achse die gleiche Anzahl an WT-Coreproteinen und Core-Mutanten vorhanden ist. So könnte es zu einer großen Anzahl an unterschiedlichen Verteilungsmustern bei der Kapsidassemblierung und somit bei der Umhüllungskompetenz kommen, wenn sowohl Homodimere des WT Coreproteins und der I126A-Mutante, als auch Heterodimere als Baustein dienen. Und von diesen Möglichkeiten ist durch die Verteilung von I126A sicherlich nur ein geringer Anteil umhüllungskompetent. Selbst bei einem ausschließlich aus Heterodimeren aufgebauten Kapsid und der Annahme, dass um jede Pore oder 6-fachSymmetrieachse die gleiche Anzahl an WT Proteinen und I126A-Mutanten vorhanden ist, ergeben sich drei Möglichkeiten, die wahrscheinlich unterschiedliche Verpackungskompetenzen besitzen: Während eine alternierende Anordnung von WT Coreproteinen und Core-Mutanten um eine Pore ausreichend für den Umhüllungsprozess sein könnte, wäre es vorstellbar, dass eine 2 (WT):1 (I126A): 1 (WT):2 (I126A) oder $3(\mathrm{WT}): 3$ (I126A) Formation den Umhüllungsprozess blockieren würde. Die große Anzahl an möglichen Kapsidzusammensetzungen ist wahrscheinlich die Erklärung dafür, warum die Signalintensität bei der 50 \%-igen I126A Expression weniger als 50\% der WT Coreprotein Expression betrug. 
Da bislang die Interaktion zwischen LHBs und Kapsidoberfläche nicht im Detail bekannt ist, kann letztendlich nur spekuliert werden, welche Oberflächenverteilung der Core-Mutante I126A eine Umhüllung zulässt und welche nicht. Die Ergebnisse zeigen, dass I126A keinen transdominant negativen Effekt in Form einer vollständigen Blockade der Umhüllung auf das WT Coreprotein besitzt. Dies wird dadurch offensichtlich, dass selbst bei einem Expressionsverhältnis von 10:90 (WT:I126A) noch ein sehr schwaches Signal von sezernierten Virionen nachweisbar war (4.2.6, Abb. 20). Sehr deutlich wird jedoch, dass es sukzessive zu einer starken Reduktion der Umhüllungsfähigkeit kommt, was auf die geringer werdende Konzentration an WT Coreproteinen zurückzuführen ist. Für einen effizienten Umhüllungsprozess bzw. effiziente Protein-Protein-Interaktionen mit den Hüllproteinen reichen wenige umhüllungskompetente WT Coreproteine auf der Oberfläche des Kapsids nicht aus.

\subsection{Etablierung eines HuH7-Zellkultursystems zur funktionellen Transkomplementierung einer Punktmutation im Coregen durch das env-Gen}

Im ersten Teil der Arbeit wurden zehn AS-Positionen des Coreproteins durch Substitution mit verschiedenen anderen AS-Resten auf ihre Umhüllungskompetenz hin analysiert. Allen Mutanten war eine explizite Oberflächen-Exposition auf dem HBVNukleokapsid gemein, so dass sie als Interaktionspartner für die Hüllproteine während des Umhüllungsprozesses in Frage kamen und den Kontakt etablieren könnten. Von sechs dieser zehn Positionen war zuvor bekannt, dass sie nach Substitution mit Alanin die Assemblierung reifer Nukleokapside gestatteten, die Umhüllung jedoch blockierten $(\mathrm{K}+/ \mathrm{V}-)$. Dies deutet auf die Relevanz dieser Positionen während der VirusMorphogenese hin. Nach weiteren Substitutionen kristallisierte sich bei vier dieser sechs Positionen heraus, dass die Mehrheit ihrer Mutationen ebenfalls den K+/VPhänotyp besaßen: S17, L95, K96 und I126. Insbesondere bei Position I126 zeigten elf der 13 getesteten Substitutionen dieses Verhalten, was eine wichtige Rolle bei dem Umhüllungsprozess vermuten lässt. Da die Mutante WT-Level an zytosolischen 
Nukleokapsiden bildete und keine nachweisbaren Virionen (K+/V-), wurde I126A schließlich als Core-Mutante für einen Komplementierungsansatz ausgewählt.

Das primäre Ziel war die Etablierung eines HuH7-Zellkultursystem, in dem zunächst konstitutiv exprimierte WT Core- und P-Proteine ein verpackungskompetentes aber replikationsdefizientes HBV-Genom, das nur die Hüllproteine exprimieren kann, in trans komplementieren können. Mit diesem System sollte es möglich sein, ein in der Matrix-Domäne zufallsmutiertes LHBs zu selektionieren, das die ausgewählte CoreMutante I126A in trans funktionell komplementiert.

Bei der Durchführung von Transduktionsexperimenten muss beachtet werden, dass der Vorgang der Integration des Provirus nicht sequenzspezifisch, sondern zufällig ist. Daher ist es möglich, dass der Provirus auch in Bereichen integriert, an denen keine effiziente Transkription stattfindet. Aus diesem Grund wurde erwartet, dass die ProteinExpression nach der Transduktionen von Zellklon zu Zellklon stark variiert. Bei der Generierung der Zelllinien, die das WT Coreprotein bzw. die Core-Mutante I126A konstitutiv exprimieren sollten, zeigte sich, dass die Signalintensitäten der ZK im Western Blot im Vergleich zu denen der Kontrollen gleich stark, zum Teil sogar stärker waren (4.3.2, Abb. 26). Da bei der Transduktion der Coreprotein-tragenden MuLVRetroviren nicht mit einer bestimmten MOI transduziert, sondern die maximale Virusmenge eingesetzt wurde, ist es möglich, dass mehrere Kopien der jeweiligen Gene in die Zellen eingebracht worden waren. In der EPR, zum funktionellen Nachweis der exprimierten Core-Proteine (WT bzw. I126A), zeigten sich jedoch bei allen getesteten ZK gegenüber den WT-Kontrollen abgeschwächte Signale sowohl von zytosolischen Kapsiden, als auch von sezernierten Virionen (4.3.2, Abb. 27 a und b). Dies könnte an einer eventuell schlechteren Funktionalität der konstitutiv in den Zellen exprimierten Coreproteine liegen, vielleicht auch an einer verstärkten spontanen Assemblierungsrate, ohne dass dabei virale HBV-RNA verpackt wird. Möglicherweise spielt auch eine Rolle, dass die Coreproteine in cis für die Kapsidassemblierung vorhanden waren: Diese wurden bei den Kontrollen von der gleichen RNA translatiert, die später auch verpackt wurde, wodurch es zu einem Lokalisationsvorteil kam und der Verpackungsvorgang effizienter verlaufen konnte (BIRNBAUM \& NASSAL, 1990). 
Durch eine zweite Transduktion wurde in die Coreprotein-exprimierenden Zellen zusätzlich das Gen der HBV Polymerase eingebracht (4.3.3). Jeweils zwei der drei ZK zeigten in der EPR die erwarteten Signale von Kapsiden und Virionen (nur WT Coreprotein), die nur wenig schwächer waren als die der WT-Kontrollen (4.3.3, Abb. 28 a und b). In Abbildung 28 a) ist deutlich zu erkennen, dass der WT Coreprotein- und Polymerase-exprimierende ZK 6 weder Signale von Kapsiden, noch von Virionen generieren konnte. Dieser war nach Transduktion resistent gegen Zeocin und Geneticin, musste aber einen Defekt bei der Expression oder Funktionalität der Polymerase besitzen, da die Synthese und Funktion des Coreproteins in den vorherigen Tests ausreichend nachgewiesen wurde; vollständig kann jedoch ein Verlust oder eine Inhibierung der Coreprotein-Synthese nicht ausgeschlossen werden. Ein deutlich reduziertes Signal von zytosolischen Nukleokapsiden generierte der ZK 3, der konstitutiv die Core-Mutante I126A und die Polymerase exprimieren sollte (4.3.3, Abb. 28 b). Scheinbar war auch hier, wie schon bei ZK 6, eine Inhibierung der Polymeraseaktivität oder -expression vorhanden. Möglicherweise ist die Expression oder Funktionalität der Polymerase durch ein solches Transduktionssystem nicht immer gesichert. Weiterhin wäre denkbar, dass die ZK, die starke Signale generieren konnten, mehrfach transduziert worden waren, während die ZK mit schwachem Signal nur ein retrovirales Genom inseriert haben, und dieses eventuell an einer Position im Wirtszellgenom integrierte, die weniger häufig transkribiert wird. Das scheint möglich, da bei der Herstellung der Zelllinien nicht auf eine bestimmte MOI bei der Transduktion geachtet wurde. Die EPR-Analysen zeigten außerdem, dass bei keinem der drei ZK, die Kapside mit der Core-Mutante I126A assemblierten, ein Signal von Virionen aus dem Medium registriert werden konnte. Damit wurde ersichtlich, dass die Mutante erwartungsgemäß auch in diesem Versuchsansatz nicht umhüllungskompetent war.

Die Zugabe des Hüllprotein-exprimierenden HBV-Genoms im Zellkultursystem sollte ebenfalls mittels Transduktion erfolgen, um eine Kontrolle über die Menge der in die Zellen eingeführten DNA zu bekommen, was bei einer Transfektion nicht möglich wäre. Durch die Wahl einer geeignet geringen MOI sollten sowohl Doppel- oder Mehrfach-Transduktionen, als auch nachfolgend inter- und intramolekulare Rekombinationen verhindert werden. Erfolgreiche Transduktionen von HepG2- bzw. HuH7-Zellen mit HBV-Genomen wurde schon mittels Baculoviren (DELANEY \& IsOM, 
1998; LIEDER, 2002) oder replikationsinkompetenter Adenoviren (REN \& NASSAL, 2001) gezeigt. Zum ersten Mal wurde nun ein MuLV-Retrovirus Transduktionssystem, wie es von Knödel und Kollegen (KNÖDEL et al., 1999) beschrieben wurde, für die Einbringung des viralen Genoms verwendet. Das die Hüllproteine exprimierende HBVGenom konnte erfolgreich durch die konstitutiv exprimierten Coreproteine (WT bzw. I126A) und die Polymerase in trans komplementiert werden, was durch Transfektion und EPR-Analyse nachgewiesen wurde. In Vorversuchen stellte sich heraus, dass die Herstellung von Retroviren mit kleinen Insertionen wie dem Gen des Coreproteins (706 bp) sehr viel effizienter vonstatten ging, als die Herstellung von Retroviren mit großen Insertionen wie dem HBV-Genom (4344 bp). Dieses Phänomen hängt mit der allgemeinen RNA-Verpackungskapazität des retroviralen Kapsids, sowie mit der veränderten Struktur des gesamten retroviralen Genoms zusammen, die bei einer zu großen Insertion beeinträchtigt wird. Auch dass das HBV-Prägenom stabile Sekundärstrukturen ausbildet, könnte bei der Generierung des retroviralen Genoms störenden Einfluss gehabt haben (D. Lindemann, persönl. Mitteilung). Die unter dem Fluoreszenzmikroskop betrachteten parallel transduzierten HuH7-Zellen zeigten dementsprechend deutliche Unterschiede bezüglich der Transduktionseffizienz zwischen den Retroviren, die das Gen des Coreproteins und denen, die das HBVGenom enthielten. Deshalb mussten für die Herstellung der retroviralen Vektoren mit dem HBV-Genom größere Kulturvolumina bzw. Kulturschalen verwendet werden. Da zunächst nur die allgemeine Fähigkeit der ZK untersucht wurde, das transduzierte Hüllprotein-exprimierende Genom zu transkomplementieren, musste noch nicht auf eine bestimmte MOI geachtet werden, sondern es wurde mit der dreifachen Menge an Retrovirus-haltigem Überstand inkubiert. Unter dem Fluoreszenzmikroskop waren starke Signale bei der Transduktions- und der Transfektionskontrolle zu sehen, während bei den HuH7-Zellen, die mit den HBV-Genom tragenden Retrovirus transduziert worden waren, im Verhältnis zu den Kontrollproben deutlich weniger Zellen eGFP exprimierten. Man sah also, dass trotz der großen Menge an verwendetem Retrovirushaltigem Kulturüberstand die Transduktionseffizienz nicht sehr hoch war. Trotzdem zeigten sich in der Nachweis-PCR für das virale Genom deutliche Signale sowohl bei der Transfektion, als auch bei der Transduktion des ZK 4 mit dem Hüllproteinexprimierenden HBV-Genom. Das ließ darauf schließen, dass die Trans- 
komplementation mit den Core- und P-Proteinen erfolgreich war und reife Virionen sezerniert worden waren. Bei dem ZK 2 konnten wie erwartet reife zytosolisch gelegene Nukleokapside nachgewiesen werden, deren Umhüllung blockiert war. Damit konnte zum ersten Mal mit Hilfe eines MuLV-Retrovirus-Transduktionssystem ein replikationsnegatives, aber umhüllungskompetentes HBV-Genom funktionell in trans mit in der Zellkultur konstitutiv exprimierten Core- und P-Proteinen komplementiert werden. Dies stellt eine Basis für die Komplementations-Experimente mit dem zufallsmutierten LHBs dar. Die Einführung von zufälligen Substitutionen in die MatrixDomäne des LHBs und die Komplementierungs-Experimente der Core-Mutante I126A wurden während dieser Arbeit jedoch nicht mehr durchgeführt.

Es wurde in dieser Arbeit gezeigt, dass mit Hilfe des etablierten Transduktionssystems ein Hüllprotein-exprimierendes HBV Genom in trans durch in HuH7-Zellen konstitutiv exprimiertes Core- und P-Protein funktionell komplementiert werden konnte. In kommenden Experimenten sollte nun mutagenisiertes LHBs statt WT LHBs eingesetzt werden. Durch in der Matrix-Domäne zufallsmutierte LHBs könnte es möglich sein, die umhüllungsdefiziente Core-Mutante I126A in trans $\mathrm{zu}$ komplementieren. Diese Annahme wird unterstützt durch den Nachweis, dass die natürlich vorkommende CoreMutante I97L, die eine Umhüllung von zum Teil unreifen Kapsisden zuließ, durch eine artifizielle Punktmutation innerhalb der Matrix-Domäne (A119F) funktionell komplementiert wurde, so dass das Sekretionsverhalten anschließend wieder dem WT Phänotyp entsprach (LE PoGAM \& SHIH, 2002). Bei der Auswahl der zu substituierenden AS innerhalb des LHBs konzentrierten sich Le Pogam \& Shih auf hydrophobe Reste, die mit hoher Wahrscheinlichkeit für einen Kontakt mit dem ebenfalls hydrophoben Leucin in Frage kamen. Da bei dem in dieser Arbeit verwendeten Transduktionsystem Zufallssubstitutionen vorgenommen werden sollen und damit theoretisch alle AS eingesetzt werden könnten, wird die Chance, einen funktionell komplementierenden Austausch zu identifizieren, wesentlich gesteigert. 


\section{ZUSAMMENFASSUNG}

Während der Morphogenese des HBV gehen die transmembranen Hüllproteine eine direkte Interaktion mit zytosolischen Nukleokapsiden ein. Um hierbei die Beteiligung einzelner Aminosäuren des Coreproteins zu bestimmen, wurden sechs oberflächenexponierte Positionen (S17, L95, K96, F122, I126 und R127) bzw. vier Positionen (S21, D22, N90 und R98), bei denen eine Alanin-Substitution die Umhüllung blockierte bzw. nicht beeinflusste, mit verschiedenen AS-Resten substituiert.

Die generierten Mutanten wurden in Hinblick auf die Kapsidbildung, Genomreifung und Umhüllungskompetenz phänotypisiert. Die Positionen S17, L95, K96 und I126 spielten eine essentielle Rolle während des Umhüllungsprozesses: 24 von 28 Mutanten erlaubten die Assemblierung von reifen Nukleokapsiden, blockierten aber deren Umhüllung (K+/V-). Die drei Positionen S21, N90 und R98 tolerierten hingegen unterschiedliche AS-Reste weitgehend ohne Verlust an Assemblierungsfähigkeit $(\mathrm{K}+/ \mathrm{V}+)$. Mutationen der Positionen R127 und D22 zeigten unterschiedliche Phänotypen. Die Mutanten der Position F122 blockierten zumeist die Kapsidformation (K-/V-), was auf eine strukturelle Bedeutung hindeutet. Sechs Mutanten, die keine DNA-Genom-haltigen Kapside bilden konnten, formten Kapside, die pgRNA enthielten, was auf eine blockierte reverse Transkription schließen lässt. Dies deutet auf eine komplexe Beteiligung der Kapsidschale bei der reversen Transkription hin.

Aufbauend auf die Ergebnisse des ersten Teils wurde ein HuH7-Zellkultursystem etabliert, bei dem in den Zellen konstitutiv die virale Polymerase und das WT Coreprotein bzw. die I126A Mutante des Coreproteins exprimiert wurde. Ein mittels Transduktion von rekombinanten MuLV-Retroviren in die Zellen eingebrachtes verpackungskompetentes aber replikationsdefizientes HBV-Genom stellte die Hüllproteine zur Verfügung. Die erfolgreiche Transkomplementierung, d.h. Sekretion von virusähnlichen Partikeln, konnte durch PCR nachgewiesen werden. Mit diesem System sollte der Nachweis einer direkten L-Protein-Kapsid Interaktion möglich sein, indem nach einer L-Mutante gesucht wird, die den Umhüllungsblock der I126A CoreMutante aufhebt. 


\section{LITERATURVERZEICHNIS}

Acs, G., Sells, M.A., Purcell, R.H., Price, P., Engle, R., Shapiro, M. und Popper, H. (1987). Hepatitis B virus produced by transfected HepG2 cells causes hepatitis in chimpanzees. Proc. Natl. Acad. Sci. U.S.A. 84: 4641-4644

Aden, D.P., Fogel, A., Plotkin, S., Damjanov, I. und Knowless, B.B. (1979). Controlled synthesis of HBsAg in a differentiated liver carcinoma-derived cell line. Nature 282: 615-618

Bang, G., Kim, K.-H., Guarnieri, M., Zoulim, F., Kawai, S., Li, J., Wands, J. und Tong, S. (2005). Effect of mutating the two cysteines required for HBe antigenicity on hepatitis B virus DNA replication and virion secretion. Virology 332: 216-224

Bartenschlager, R. und Schaller, H. (1988). The amino-terminal domain of the hepadnaviral P-gene encodes the terminal protein (genome-linked protein) believed to prime reverse transcription. EMBO J. 7: 4185-4192

Bartenschlager, R. und Schaller, H. (1992). Hepadnaviral assembly is initiated by polymerase binding to the encapsidation signal in the viral RNA genome. EMBO J. 11: 3413-3420

Bartenschlager, R., Junker-Niepmann, M. und Schaller, H. (1990). The P gene product of hepatitis $B$ virus is required as a structural component for genomic RNA encapsidation. J. Virol. 64: 5342-5352

Beasley, R.P., Hwang, L.Y., Lin, C.C. und Chien, C.S. (1981). Hepatocellular carcinoma and hepatitis B virus. A prospective study of 22707 men in Taiwan. Lancet 2: 1129-1133

Beasley, R.P. (1988). Hepatitis B virus: the major etiology of hepatocellular carcinoma. Cancer 61: 1942-1956

Birnbaum, F. und Nassal, M. (1990). Hepatitis B virus nucleocapsid assembly: primary structure requirements in the core protein. J. Virol. 64: 3319-3330

Birnboim, C. und Doly, P. (1979). A rapid alkaline extraction procedure for screening recombinant plasmid DNA. Nucl. Acids Res. 7: 1513-1515

Blum, H.E., Zhang, Z.S., Galun, E., Weizsäcker, F., Garner, B., Liang, T.J. und Wands, J.R. (1992). Hepatitis B virus $X$ protein is not central to the viral life cycle in vitro. J. Virol. 66: 1223-1227

Blumberg, B.S., Alter, H.J. und Visnich, S. (1965). A "new“ antigen in leukemia sera. JAMA 191, 541

Bock, C.T., Schranz, P., Schröder, C.H. und Zentgraf, H. (1994). Hepatitis B virus genome is organized into nucleosomes in the nucleus of the infected cell. Virus Genes. 8: 215-229 
Bosch, V., Bartenschlager, R., Radziwill, G. und Schaller, H. (1988). The duck hepatitis B virus $P$-gene codes for protein strongly associated with the 5 end of the viral DNA minus strand. Virology 166: 475-485

Böttcher, B., Wynne, S.A. und Crowther, R.A. (1997). Determination of the fold of the core protein of hepatitis B virus by electron cryomicroscopy. Nature 386: 88-91

Breiner K.M., Urban S. und Schaller, H. (1998). Carboxypeptidase D (gp180), a Golgi resistant protein, functions in the attachment and entry of avian hepatitis B viruses. J. Virol. 72: 8098-8104

Bringas, R. (1997). Folding and assembly of hepatitis B virus core protein: A new model proposal. J. Struct. Biol. 118: 189-196

Bruss, V. und Gerlich, W.H. (1988). Formation of transmembranous hepatitis B e-antigen by cotranslational in vitro processing of the viral precore protein. Virology 163: 268-275

Bruss, V. und Ganem, D. (1991a). The role of envelope proteins in hepatitis B virus assembly. Proc. Natl. Acad. Sci. U.S.A. 88: 1059-1063

Bruss, V. und Ganem, D. (1991b). Mutational analysis of hepatitis B surface antigen particle assembly and secretion. J. Virol. 65: 3813-3820

Bruss, V., Lu, X.Y., Thomssen, R. und Gerlich, W.H. (1994). Post-translational alterations in transmembrane topology of the hepatitis B virus envelope protein. EMBO J. 13: 2273-2279

Bruss, V. und Vieluf, K. (1995). Functions of the internal pre-S domain of the large surface protein in hepatitis B virus particle morphogenesis. J. Virol. 69: 6652-6657

Bruss, V., Gerhardt, E., Vieluf, K. und Wunderlich, G. (1996a). Functions of the large hepatitis B virus surface protein in viral particle morphogenesis. Intervirology 39: 23-31

Bruss, V., Hagelstein, J., Gerhardt, E. und Galle, P.R. (1996b). Myristylation of the large surface protein is required for hepatitis B virus in vitro infectivity. Virology 218: 396-399

Bruss, V. (1997). A short linear sequence in the pre-S domain of the large hepatitis B virus envelope protein required for virion formation. J. Virol. 71: 9350-9357

Ceres, P. und Zlotnick, A. (2002). Weak protein-protein interactions are sufficient to drive assembly of hepatitis B virus capsids. Biochemistry 41: 11525-11531

Chen, H., Kew, M., Hornbuckle, W., Tennant, B., Cote, P., Gerin, J., Purcell, R. und Miller, R. (1992). The precore gene of the woodchuck hepatitis virus genome is not essential for viral replication in the natural host. J. Virol. 66: 5682-5684

Chen, H.S., Kaneko, S., Girones, R., Anderson, R.W., Hornbuckle, W.E., Tennant, B.C., Cote, P.J., Purcell, R.H. und Miller, R.H. (1993). The woodchuck hepatitis virus $X$ gene is important for establishment of virus infection in woodchucks. J. Virol. 67: 1218-1226

Chisari, F.V. und Ferrari, C. (1995). Hepatitis B virus immunopathogenesis. Annu. Rev. Immunol. 13: 29-60 
Choi, Y., Gyoo Park, S., Yoo, J.H. und Jung, G. (2005). Calcium ions affect the hepatitis B virus core assembly. Virology 332: 454-463

Cohen, B.J. und Richmond, J.E. (1982). Electron microscopy of hepatitis B core antigen synthesized in E. coli. Nature 296: 677-678

Colgrove, R., Simon, G. und Ganem, D. (1989). Transcriptional activation of homologous and heterologous genes by the hepatitis $B$ virus $X$ gene product in cells permissive for viral replication. J. Virol. 67: 4019-4026

Conway, J.F., Cheng, N., Zlotnik, A., Wingfield, P.T., Stahl, S.J. und Steven, A.C. (1997) Visualization of a 4-helix bundle in the hepatitis B virus capsid by cryo-electron microscopy. Nature 386: 91-94

Crowther, R.A., Kiselev, N.A., Böttcher, B., Berriman, J.A., Borisova, G.P., Ose, V. und Pumpens P. (1994). Three-dimensional structure of hepatitis B virus core particles determined by electron cryomicroscopy. Cell 77: 943-950

Dane, D.S., Cameron, C.H. und Briggs, M. (1970). Virus-like particles in serum of patients with Australia-antigen-associated hepatitis. Lancet 1: 695-698

Daub, H., Blencke, S., Habenberger, P., Kurtenbach, A., Dennenmoser, J., Wissing, J., Ullrich, A. und Cotten, M. (2002). Identification of SRPK1 and SRPK2 as the major cellular protein kinases phosphorylating hepatitis B virus core protein. J. Virol. 76: 8124-8137

Delaney, W.E. und Isom, H.C. (1998): Hepatitis B virus replication in human HepG2 cells mediated by hepatitis B virus recombinant Baculovirus. Hepatology 28: 1134-1146

Eble B.E., Lingappa V.R. und Ganem, D. (1986). Hepatitis B surface antigen: an unusual secreted protein initially synthesized as a transmembrane polypeptide. Mol. Cell. Biol. 6: 1454-1463

Eble B.E., MacRae, D.R., Lingappa V.R. und Ganem, D. (1987). Multiple topogenic sequences determin the transmembrane orientation of hepatitis $B$ surface antigen. Mol.Cell. Biol 7: 2591-3601

Eble B.E., Lingappa V.R. und Ganem, D. (1990). The N-terminal (preS2) domain of hepatitis $B$ virus surface glycoprotein is translocated across membranes by downstream signal sequences. J. Virol. 64: 1414-1419

Eckhardt, S.G, Milich, D.R. und McLachlan, A. (1991). Hepatitis B virus core antigen has two nuclear localization sequences in the arginine-rich carboxyl terminus. J. Virol. 65: 575-582

Enders, G.H., Ganem, D. und Varmus, H.E. (1987). 5'-terminal sequences influence the segregation of ground squirrel hepatitis virus RNAs into polyribosomes and viral core particles. J. Virol. 61: 35-41

Eng, F.J., Novikova, E.G., Kuroki, K., Ganem, D. und Fricker, L.D. (1998). gp180, $a$ protein that binds duck hepatits B virus particles, has metallocarboxypeptidase D like enzymatic activity. J. Biol. Chem. 273: 8382-8388 
Evans, A.A., und London, W.T. (1998). Epidemiology of hepatitis B. in: Viral hepatitis. Hrsg.: Zuckerman, A.J. und Thomas, H.C.; Harcourt Brace \& Co., Ltd., London, United Kingdom, 107-114

Farauqi, A.F., Roychoudhury, S., Greenberg, R., Israel, J. und Shih, C. (1991). Replicationdefective missense mutations within the terminal protein and spacer/intron regions of the polymerase gene of human hepatitis B virus. Virology 183: 764-768.

Fernholz, D., Stemler, M., Brunetto, M., Bonino, F. und Will, H. (1991). Replicating and virion secreting hepatitis B mutant virus unable to produce preS2 protein. J. Hepatol. 13 Suppl. 4: $102-104$

Freed, E.O. (2002). Viral late domains. J. Virol. 76: 4679-4687

Funk, A., Mhamdi, M., Lin, L., Will, H. und Sirma, H. (2004). Itinerary of hepatitis B viruses: delineation of restriction points critical for infectious entry. J. Virol. 78: 8289-8300

Gallina, A., Bonelli, G., Zentilin, I., Rindi, G., Muttini, M. und Milanesi, G. (1989). A recombinant hepatitis $B$ core antigen polypeptide with the protamine-like domain deleted selfassembles into capsid particles but fails to bind nucleic acids. J. Virol. 63: 4645-4652

Ganem, D. (1996). Hepadnaviridae and their replication. in: Fields Virology. Third Edition. Hrsg.: Fields, B.N., Knipe, D.M. und Howley, P.M.; Lippincott-Raven Publishers, Philadelphia, 2703-2737

Ganem, D. und Prince, A.M. (2004). Hepatitis B virus infection--natural history and clinical consequences. N. Engl. J. Med. 350: 1118-1129

Ganem, D. und Varmus, H.E. (1987). The molecular biology of the hepatitis B viruses. Ann. Rev. Biochem. 56: 761-766

Gavilanes, F., Gonzalez-Ros, J.M. und Peterson, D.L. (1982). Structure of hepatitis B surface antigen. Characterization of the lipid components and their association with the viral proteins. J. Biol. Chem. 257: 7770-7777

Gazina, E.V., Fielding, J.E., Lin, B. und Anderson, D.A. (2000). Core protein phosphorylation modulates pregenomic RNA encapsidation to different extents in human and duck hepatitis B viruses. J. Virol. 74: 4721-4728

Gerelsaikhan, T., Tavis, J.E. und Bruss, V. (1996). Hepatitis B virus nucleocapsid envelopment does not occur without genomic DNA synthesis. J. Virol. 70: 4269-4274

Gerlich, W.H. und Robinson, W.S. (1980). Hepatitis B virus contains protein attached to the 5' terminus of its complete DNA strand. Cell 21: 801-809

Glebe, D., Aliakbari, M., Krass, P., Knoop, E.V., Valerius, K.P. und Gerlich, W.H. (2003). Pre-S1 dependent infection of Tupaia hepatocyte cultures with human hepatitis B virus. J. Virol. 77: 9511-9521

Graham, F.L., Smiley, J., Russell, W.C. und Nairn, R. (1977). Characteristics of a human cell line transformed by DNA from human adenovirus type 5. J. Gen. Virol. 36: 59-72 
Gripon, P., Diot, C., Theze, N., Fourel, I., Loreal, O., Brechot, C. und GuguenGuillouzo, C. (1988). Hepatitis B virus infection of adult human hepatocytes cultured in the presence of dimethyl sulfoxide. J. Virol. 62: 4136-4143

Gripon, P., Le Seyec, J., Rumin, S. und Guguen-Guillouzo, C. (1995). Myristylation of the hepatitis B virus large surface protein is essential for viral infectivity. Virology 213: 292-299

Gripon, P., Rumin, S., Urban, S., Le Seyec, J., Glaise, D., Cannie, I., Guyomard, C., Lucas, J., Trepo, C. und Guguen-Guillouzo, C. (2002). Infection of a human hepatoma cell line by hepatitis B virus. Proc. Natl. Acad. Sci. U.S.A. 99: 15655-15660

Gripon, P., Cannie, I. und Urban, S. (2005). Efficient inhibition of hepatitis B virus infection by acylated peptides derived from the large viral surface protein. J. Virol. 79: 1613-1622

Gust, I.D., Burrell, C.J., Coulepis, A.G., Robinson, W.S. und Zuckerman, A.J. (1986). Taxonomic classification of human hepatitis B virus. Intervirology 25: 14-29

Hanahan, D. (1983). Studies of transformation of Escherichia coli with plasmids. J. Mol. Biol. 166: $557-580$

Hatton, T., Zhou, S. und Standring, D.N. (1992). RNA- and DNA-binding activities in hepatitis $B$ virus capsid protein: a model for their roles in viral replication. J. Virol. 66: 5232-5241

Heermann, K.H., Goldmann, U., Schwartz, W. Seyffarth, T., Baumgarten, H. und Gerlich, W.H. (1984). Large surface proteins of hepatitis B virus containing the pre-S sequence. J. Virol. 52: 396-402

Heermann, K.H., Kruse, F., Seifer, M. und Gerlich W.H. (1987). Immunogenicity of the gene $S$ and pre-S domains in hepatitis B virions and HBsAg filaments. Intervirology 28: 14-25

Henkler, F., Lopes, A.R., Jones, M. und Koshy, R. (1998). Erk-independent partial activation of $A P-1$ sites by the hepatitis B virus HBx protein. J. Gen. Virol. 79: 2737-2742

Hirsch, R.C., Lavine, J.E., Chang, L.J., Varmus, H.E. und Ganem, D. (1990). Polymerase gene products of hepatitis $B$ viruses are required for genomic RNA packaging as well as for reverse transcription. Nature 344: 552-555

Hollinger, F.B. (1991). Hepatitis B virus. In: Viral Hepatitis. Second Edition. Hrsg: Hollinger, F.B., Robinson, W.S., Purcell, H., Gerin, J.L. und Ticeburst, J. S.; Raven Press, New York, 73-122

Hruska, J.F., Clayton, D.A., Rubenstein, J.L. und Robinson, W.S. (1977). Structure of hepatitis B Dane particle DNA before and after the Dane particle DNA polymerase reaction. J Virol 21: 666-672

Hu, J. und Seeger, C. (1996). Hsp90 is required for the activity of a hepatitis B virus reverse transcriptase. Proc. Natl. Acad. Sci. U.S.A. 93: 1060-1064

Hu, J., Toft, D.O. und C. Seeger, C. (1997). Hepadnavirus assembly and reverse transcription require a multi-component chaperone complex which is incorporated into nucleocapsids. EMBO J. 16: 59-68 
Huang, M.J. und Summers, J. (1991). Infection initiated by the RNA pregenome of a DNA virus. J. Virol. 65: 5435-5439

Huovila, A.P., Eder, A.M. und Fuller, S.D. (1992). Hepatitis B surface antigen assembles in a post-ER, pre-Golgi compartment. J. Cell Biol. 118: 1305-1320

Jeoung, J.K., Yoon, G.S. und Ryu, W.S. (2000). Evidence that the 5'-end cap structure is essential for encapsidation of hepatitis B virus pregenomic RNA. J. Virol. 74: 5502-5508

Junker-Niepmann, M., Bartenschlager, R. und Schaller, H. (1990). A short cis-acting sequence is required for hepatitis $B$ virus pregenome encapsidation and sufficient for packaging of foreign RNA. EMBO J. 9: 3389-3396

Kann, M., Thomssen, R., Köchel, H.G. und Gerlich, W.H. (1993). Characterization of the endogenous protein kinase activity of the hepatitis B virus. Arch. Virol. Suppl. 8: 53-62

Kann, M. und Gerlich, W.H. (1994). Effect of core protein phosphorylation by protein kinase $C$ on encapsidation of RNA within core particles of hepatitis B virus. J. Virol. 68: 7993-8000

Kann, M., Bischof, A. und Gerlich, W.H. (1997). In vitro model fort he nuclear transport of the hepadnavirus genome. J. Virol. 71: 1310-1316

Kann, M., Sodeik, B., Vlachou, A., Gerlich, W.H. und Helenius, A. (1999). Phosphorylation-dependent binding of hepatitis $B$ virus core particles to the nuclear pore complex. J. Cell. Biol. 145: 45-55

Kaplan, P.M., Greenman, R.L., Gerin, J.L., Purcell, R.H. und Robinson, W.S. (1973). DNA polymerase associated with human hepatitis B antigen. J. Virol. 12: 995-1005

Kekule, A.S., Lauer, U., Weiss, L., Luber, B. und Hofschneider, P.H. (1993). Hepatitis B virus transactivator HBx uses a tumour promotor signalling pathway. Nature 361: 742-745

Kelly, J.J., Munholland, J.M. und Wildeman, A.G. (1989). Comeasurement of simian virus 40 early and late promoter activity in HeLa and 293 cells in the presence of T antigen. J. Virol. 63: 383-391

Kluge, B., Schläger, M., Pairan, A. und Bruss, V. (2005). Determination of the minimal distance between the matrix and transmembrane domains of the large hepatitis $B$ virus envelope protein. J. Virol. 79: 7918-7921

Knödel, M., Kuss, A.W., Lindemann, D., Berberich, I. und Schimpl, A. (1999). Reversal of Blimp-1-mediated apoptosis by A1, a member of the Bcl-2 family. Eur. J. Immunol. 29: 2988-2998

Köck, J. und Schlicht, H.J. (1993). Analysis of the earliest steps of hepadnavirus replication: genome repair after infectious entry into hepatocytes does not depend on viral polymerase activity. J. Virol. 67: 4867-4874

Köck, J., Nassal, M., MacNelly, S., Baumert, T.F., Blum, H.E. und von Weizsäcker, F. (2001). Efficient infection of primary tupaia hepatocytes with purified human and woolly monkey hepatitis B virus. J. Virol. 75: 5084-5089 
Koschel, M., Thomssen, R. und Bruss, V. (1999). Extensive mutagenesis of the hepatitis $B$ virus core gene and mapping of mutations that allow capsid formation. J. Virol. 73: 2153-2160

Koschel, M., Oed, D., Gerelsaikhan, T., Thomssen, R. und Bruss, V. (2000). Hepatitis B virus core gene mutations which block nucleocapsid envelopment. J. Virol. 74: 1-7

Kozak, M. (1986). Point mutations define a sequence flanking the AUG initiator codon that modulates translation by eukaryotic ribosomes. Cell 44: 283-392

Kratz, P.A., Böttcher, B. und Nassal, M. (1999). Native display of complete foreign protein domains on the surface of hepatitis B virus capsids. Proc. Natl. Acad. Sci. U.S.A. 96: 1915-1920

Kumar, R. und Agrawal, B. (2004). Novel treatment options for hepatitis B virus infection. Curr. Opin. Investig. Drugs 5: 171-178

Lambert, C. und Prange, R. (2003). Chaperone action in the posttranslational topological reorientation of the hepatitis $B$ virus large envelope protein: Implications for translocational regulation. Proc. Natl. Acad. Sci. U.S.A. 100: 5199-5204

Landers, T.A., Greenberg, H.B. und Robinson, W.S. (1977). Structure of hepatitis B Dane particle DNA and nature of the endogenous DNA polymerase reaction. J. Virol. 23: 368-376

Lanford, R.E. und Notvall, L. (1990). Expression of hepatitis B virus core and precore antigens in insect cells and characterization of a core-associated kinase activity. Virology 176: 222-233

Lanford, R.E., Chavez, D., Brasky, K.M., Burns III., R.B. und Rico-Hesse, R. (1998). Isolation of a hepadnavirus from the woolly monkey, a New World primate. Proc. Natl. Acad. Sci. U.S.A. 95: 5757-5761

Le Pogam, S., Yuan, T.T., Sahu, G.K., Chatterjee, S. und Shih, C. (2000). Low-level secretion of human hepatitis $B$ virus virions by two independent, naturally occurring mutations (P5T and L60V) in the capsid protein. J. Virol. 74: 9099-9105

Le Pogam, S. und Shih, C. (2002). Influence of a putative intermolecular interaction between core and the pre-S1 domain of the large envelope protein on hepatitis B virus secretion. $\mathrm{J}$. Virol. 76: 6510-6517

Le Pogam, S., Chua, P.K., Newman, M. und Shih, C. (2005). Exposure of RNA templates and encapsidation of spliced viral RNA are influenced by the arginine-rich domain of hepatitis $B$ virus core antigen (HBcAg 165-173). J. Virol. 79: 1871-1887

Le Seyec, J., Chouteau, P., Cannie, I., Guguen-Guillouzo, C. und Gripon, P. (1998). Role of the pre-S2 domain of the large envelope protein in hepatitis B virus assembly and infectivity. $\mathrm{J}$. Virol. 72: 5573-5578

Le Seyec, J., Chouteau, P., Cannie, I., Guguen-Guillouzo, C. und Gripon, P. (1999). Infection process of the hepatitis $B$ virus depends on the presence of a defined sequence in the pre-S1 domain. J. Virol. 73: 2052-2057 
Lenhoff, R.J. und Summers, J. (1994). Coordinate regulation of replication and virus assembly by the large envelope protein of an avian hepadnavirus. J. Virol. 68: 4565-4571

Lenhoff, R.J., Luscombe, C.A. und Summers, J. (1998). Competition in vivo between a cytopathic variant and a wild-type duck hepatitis B virus. Virology 251: 85-95

Leupin, O., Bontron, S., Schaeffer, C. und Strubin, M. (2005). Hepatitis B virus $X$ protein stimulates viral genome replication via a DDB1-dependent pathway distinct from that leading to sell death. J. Virol. 79: 4238-4245

Liao, W. und Ou, J.H. (1995). Phosphorylation and nuclear localisation of the hepatitis B virus core protein: significance of serine in the three repeated SRRRR motifs. J. Virol. 69: 1025-1029

Liaw, Y.F., Leung, N.W., Chang, T.T., Guan, R., Tai, D.I., Ng, K.Y., Chien, R.N., Dent, J., Roman, L., Edmundson, S. und Lai, C.L. (2000). Effects of extended lamivudine therapy in Asian patients with chronic hepatitis B. Gastroenterology 119: 172-180

Liébecq, C. (1978). Biochemical nomenclature and related documents. International Union for Biochemistry. London: The Biochemical Society

Lieder, D. (2002). Untersuchung der Reifung des Hepatitis B Virus Nukleokapsids. Dissertation, Göttingen

Lingappa, J.R., Newman, M.A., Klein, K.C. und Dooher, J.E. (2005). Comparing capsid assembly of primate lentiviruses and hepatitis B virus using cell-free systems. Virology 333: 114-123

Löffler-Mary, H., Werr, M. und Prange, R. (1997). Sequence-specific repression of cotranslational translocation of the hepatitis $B$ virus envelope proteins coincides with binding of heat shock protein Hsc70. Virology 235: 144-152

Löffler-Mary, H., Dumortier, J., Klentsch-Zimmer, C. und Prange, R. (2000). Hepatitis B virus assembly is sensitive to changes in the cytosolic $S$ loop of the envelope proteins. Virology 270: 358-367

Mabit, H. und Schaller, H. (2000). Intracellular hepadnavirus nucleocapsids are selected for secretion by envelope-protein independent membrane binding. J. Virol. 74: 11472-11478

Mabit, H., Breiner, K.M., Knaust, A., Zachmann-Brand, B. und Schaller, H. (2001). Signals for bidirectional nucleocytoplasmic transport in the duck hepatitis B virus capsid protein. J. Virol. 75: 1968-1977

Machida, A., Kishimoto, S., Ohnuma, H., Baba, K., Ito, Y., Miyamoto, H., Funatsu, G., Oda, K., Usuda, S., Togami, S., Nakamura, T., Miyakawa, Y. und Mayumi, M. (1984). A polypeptide containing 55 amino acid residues coded by the pre-S region of hepatitis $B$ virus deoxyribonucleotide acid bears the receptor of polymerized human as well as chimpanzee albumins. Gastroenterology 86: 910-918

Macrae, D.R., Bruss, V. und Ganem, D. (1991). Myristylation of a duck hepatitis B virus envelope protein is essential for infectivity but not for virus assembly. Virology 181: 359-363. 
Marion, P.L., Oshiro, L.S., Regnery, D.C., Scullard, G.H. und Robinson, W.S. (1980). A virus in Beechey ground squirrels that is related to hepatitis $B$ virus of humans. Proc. Natl. Acad. Sci. U.S.A. 77: 2941-2945

Mason, W.S., Seal, G. und Summers, J. (1980). Virus of Peking ducks with structural and biological relatedness to human hepatitis B virus. J. Virol. 36: 829-836

McAleer W.J., Bunyak, E.B., Maigetter, R.Z., Wampler, D.E., Miller, W.J. und Hilleman, M.R. (1984). Human hepatitis B vaccine from recombinant yeast. Nature 307: 178-180

Melegari, M., Scaglioni, P.P. und Wands, J.R. (1998). Hepatitis B virus mutants associated with 3TC and famciclovir administration are replication defective. Hepatology 27: 628-633

Messageot, F., Salhi, S., Eon, P. und Rossignol, J.M. (2003). Proteolytic processing of the hepatitis B virus e antigen precursor. J. Biol. Chem. 278: 891-895

Milich, D., Jones, J., Hughes, J., Price, J., Raney, A. und McLachlan, A. (1990). Is a function of the secreted hepatitis $B$ e antigen to induce immunological tolerance in utero? Proc. Natl. Acad. Sci. U.S.A. 87: 6599-6603

Milich, D. (1999). Do $T$ cells "see" the hepatitis B core and e antigens differently? Gastroenterology 116: 765-768

Milich, D. und Liang, T. (2003). Exploring the biological basis of hepatitis $B$ e antigen in hepatitis B virus infection. Hepatology 38: 1075-1086

Modrow, S. und Falke, D. (1998). Molekulare Virologie. 1. korrigierter Nachdruck; Hrsg.: Modrow, S. und Falke, D.; Spektrum Akademischer Verlag Heidelberg

Moriyama, T., Guilhot, S., Klopchin, K., Moss, B., Pinkert, C.A., Palmiter, R.D., Brinster, R.L., Kanagawa, O. und Chisari, F.V. (1990). Immunobiology and pathogenesis of hepatocellular injury in hepatitis B virus transgenic mice. Science 248: 361-364

Nakabayashi, H., Taketa, K., Miyano, K., Yamane, T. und Sato, J. (1982). Growth of human hepatoma cell lines with differentiated functions in chemically defined medium. Cancer Res. 42: 3858-3863

Nassal, M., Junker-Niepmann, M. und Schaller, H. (1990). Translational inactivation of RNA function: discrimination against a subset of genomic transcripts during HBV nucleopcapsid assembly. Cell 63: 1357-1363

Nassal., M. (1992a). The arginine rich domain of the hepatitis B virus core protein is required for pregenome encapsidation and productive viral positive-strand DNA synthesis but not for virus assembly. J. Virol. 66: 4107-4116

Nassal, M. (1992b). Conserved cysteines of the hepatitis B virus core protein are not required for assembly of replication-competent core particles nor for their envelopment. Virology 190: 499-505

Nassal, M. und Rieger, A. (1993). An intramolecular disulfide brifge between Cys-7 and Cys61 determines the structure of the secretory core gene product (HBeAg) of hepatitis B virus. J. Virol. 67: 4307-4315 
Nassal, M. (1999). Hepatitis B virus replication: novel roles for virus-host interactions. Intervirology 42: 100-116.

Newbold, J.E., Xin, H., Tencza, M., Sherman, G., Dean, J., Bowden, S. und Locarnini, S. (1995). The covalently closed duplex form of the hepadnavirus genome exists in situ as a heterogeneous population of viral minichromosomes. J. Virol. 69: 3350-3357

Ou, J., Laub, O. und Rutter, W. (1986). Hepatitis B virus gene function: the precore region targets the core antigen to cellular membranes and causes the secretion of the e antigen. Proc. Natl. Acad. Sci. U.S.A. 83: 1578-1582

Panté, N. und Kann, M. (2002). Nuclear pore complex is able to transport macromolecules with diameters of $39 \mathrm{~nm}$. Mol. Biol. Cell 13: 425-434

Park, S.G. und Jung, G. (2001). Human hepatitis B virus polymerase interacts with the molecular chaperonin Hsp60. J. Virol. 75: 6962-6968

Park, S.G., Lee, S. M. und Jung, G. (2003). Antisense oligodeoxynucleotides targeted against molecular chaperonin Hsp60 block human hepatitis B virus replication. J. Biol. Chem. 41: 39851-39857

Parkin, D.M., Pisani, P. und Ferlay, J. (1999). Estimates of the worldwide incidence of 25 major cancers in 1990. Int. J. Cancer 80: 827-841

Patzer, E.J., Nakamura, G.R., Simonsen, C.C., Levinson, A.D. und Brands, R. (1986). Intracellular assembly and packaging of hepatitis B surface antigen particles occur in the endoplasmic reticulum. J. Virol. 58: 884-892

Perlman, D. und Hu, J. (2003). Duck hepatitis B virus secretion requires a doublestranded DNA genome. J. Virol. 77: 2287-2294

Persing, D.H., Varmus, H.E. und Ganem, D. (1987). The pre-S1 protein of hepatitis B virus is acylated at its amino terminus with myristic acid. J.Virol. 61: 1672-1677

Peterson, D.L. (1981). Isolation and characterization of the major protein and glycoprotein of hepatitis B surface antigen. J. Biol. Chem. 256: 6975-6983

Petit, M.A. und Pillot, J. (1985). HBc and HBe antigenicity and DNA binding affinity of major core protein P22 in hepatitis B virus core particles isolated from the cytoplasm of human liver cells. J. Virol. 53: 543-551

Pietschmann, T., Heinkelein, M., Heldmann, M., Zentgraf, H., Rethwilm, A. und Lindemann, D. (1999). Foamy virus capsids require the cognate envelope protein for particle export. J. Virol. 73: 2613-2621

Pollack, J.R. und Ganem, D. (1993) An RNA stem-loop structure directs hepatitis B virus genomic RNA encapsidation. J. Virol. 67: 3254-3263

Pollack, J.R. und Ganem, D. (1994). Site-specific RNA binding by a hepatitis B virus reverse transcriptase initiates two distinct reactions: RNA packaging and DNA synthesis. J. Virol. 68: 5579-5587 
Ponsel, D. (2003). Kartierung von umhüllungsrelevanten Aminosäureresten auf dem Hepatitis$B$-Virus-Kapsid. Dissertation, Göttingen

Ponsel, D. und Bruss, V. (2003). Mapping of amino acid side chains on the surface of hepatitis $B$ virus capsids required for envelopment and virion formation. J. Virol. 77: 416-422

Pourcel, C., Louise, A., Gervais, M., Chenciner, N., Dubois, M.F. und Tiollais, P. (1982). Transcription of the hepatitis B surface antigen gene in mouse cells transformed with cloned viral DNA. J. Virol. 42: 100-105

Prange, R. und Streeck, R.E. (1995). Novel transmembrane topology of the hepatitis B virus envelope proteins. EMBO J. 14: 247-256

Prange, R., Werr, M. und Löffler-Mary, H. (1999). Chaperones involved in hepatitis B virus morphogenesis. Biol. Chem. 380: 305-314

Previsani, N. und Lavanchy, D. (2002). Hepatitis B. World Health Organization. Department of communicable Diseases Surveillance and Response. 1-76;

www.who.int/csr/disease/hepatitis/en/HepatitisB_whocdscsrlyo2002_2.pdf

Prince, A.M. (1968). An antigen detected in the blood during the incubation period of serum hepatitis. Proc. Natl. Acad. Sci. U.S.A. 60: 814-821

Pugh, J.C., Zweidler, A. und Summers, J. (1989). Characterization of the major duck hepatitis B virus core particle protein. J. Virol. 63: 1371-1376

Rall, L.B., Standring, D.N. und Laub, O. (1983). Transcription of hepatitis B virus by RNA polymerase II. Mol. Cell. Biol. 3: 1766-1773

Ren, S. und Nassal, M. (2001). Hepatitis B virus (HBV) virion and covalently closed circular DNA formation in primary Tupaia hepatocytes and human hepatoma cell lines upon HBV genome transduction with replication-defective adenovirus vectors. J. Virol. 75: 1104-1116

Ribeiro, R.M., Lo, A. und Perelson, A.S. (2002). Dynamics of hepatitis B virus infection. Microbes. Infect. 4: 829-835

Robinson, W.S., Clayton, D.A. und Greenman, R.L. (1974). DNA of a human hepatitis $B$ virus candidate. J. Virol. 14: 384-391

Rossner, M.T. (1992). Hepatitis B virus X-gene product: a promiscuous transcriptional activator. J. Med. Virol. 36: 101-117

Saiki, R.K., Scharf, S., Faloona, F., Mullis, K.B., Horn, G.T., Erlich, H.A. und Arnheim, N. (1985). Enzymatic amplification of $\beta$ globin genomic sequences and restriction site analysis for diagnostic of sickle cell anemia. Science 230: 1350-1354

Salfeld, J., Pfaff, E., Noah, M. und Schaller, H. (1989). Antigenic determinants and functional domains in core antigen and e antigen from hepatitis B virus. J. Virol. 63: 798-808

Sällberg, M., Ruden, U., Magnius, L.O., Harthus, H.P., Noah, M. und Wahren, B. (1991). Characterisation of a linear binding site for a monoclonal antibody to hepatitis B core antigen. J. Med. Virol. 33: 248-252 
Sanger, F., Nicklen, S. und Coulson, A.R. (1977). DNA sequencing with chain-terminating inhibitors. Proc. Natl. Acad. Sci. U.S.A. 74: 5463-5467

Satoh, O., Imai, H., Yoneyama, T., Miyamura, T., Utsumi, H., Inoue, K. und Umeda, M. (2000). Membrane structure of the hepatitis B virus surface antigen particle. J. Biochem. (Tokyo) 127: 543-550

Sattler, F. und Robinson, W.F. (1979). Hepatitis B viral DNA molecules have cohesive ends. J. Virol. 32: 226-232

Schaller, H. und Fischer, M. (1991). Transcriptional control of hepadnavirus gene expression. Curr. Top. Microbiol. Immunol. 168: 21-39

Schlicht, H.J. und Schaller, H. (1989). Analysis of hepatitis B virus gene functions in tissue culture and in vivo. Curr. Top. Microbiol. Immunol. 144: 253-263

Seeger, C., Ganem, D. und Varmus, H.E. (1986). Biochemical and genetic evidence for the hepatitis B virus replication strategy. Science 232: 477-484

Seeger, C. und Hu, J. (1997). Why are hepadnaviruses DNA and not RNA viruses. Trends in Microbiology 11: 447-450

Seeger, C. und Mason, W.S. (2000). Hepatitis B virus biology. Microbiol. Mol. Biol. Rev. 64: 51-68

Seifer, M., Zhou, S. und Standring, D.N. (1993). A micromolar pool of antigenically distinct precursors is required to initiate cooperative assembly of hepatitis B virus capsids in Xenopus oocytes. J. Virol. 67: 249-257

Shaul, Y., Rutter, W.J. und Laub, O. (1985). A human hepatitis B virus enhancer element. EMBO J. 4: 427-430

Sheu, S.Y. und Lo, S.J. (1992). Preferential ribosomal scanning is involved in the differential synthesis of the hepatitis B viral surface antigens from subgenomic transcripts. Virology 188: 353-357

Soneoka, Y., Cannon, P.M., Ramsdale, E.E., Griffiths, J.C., Romano, G., Kingsman, S.M. und Kingsman, A.J. (1995). A transient three-plasmid expression system for the production of high titer retroviral vectors. Nucl. Acids Res. 23: 628-633

Sonveaux, N., Thines, D. und Ruysschaert, J.M. (1995). Characterization of the HBsAg particle lipid membrane. Res. Virol. 146: 43-51

Sprengel, R., Kaleta, E.F. und Will, H. (1988). Isolation and characterization of a hepatitis $B$ virus endemic in herons. J. Virol. 62: 3832-3839

Staprans, S., Loeb, D.D. und Ganem, D. (1991). Mutations affecting hepadnavirus plusstrand DNA synthesis dissociate primer cleavage from translocation and reveal the origin of linear viral DNA. J. Virol. 65: 1255-1262 
Stibbe, W. und Gerlich, W.H. (1982). Variable protein composition of hepatitis B surface antigen from different donors. Virology 123: 436-442

Stirk, H.J., Thornton, J.M. und Howard, C.R. (1992). A topological model for hepatitis B surface antigen. Intervirology 33: 148-158

Southern, E.M. (1975). Detection of specific sequences among DNA fragments separated by gel electrophoreses. J. Mol. Biol. 98: 503-517

Summers, J., O’Connell, A. und Millman, I. (1975). Genome of hepatitis B virus: restriction enzyme cleavage and structure of DNA extracted from Dane particles. Proc. Natl. Acad. Sci. U.S.A. 72: 4597-4601

Summers, J. und Mason, W.S. (1982). Replication of the genome of a hepatitis B-like virus by reverse transcription of an RNA intermediate. Cell 29: 403-415

Summers, J., Smith, P.M. und Horwich, A.L. (1990). Hepadnavirus envelope proteins regulate covalently closed circular DNA amplification. J. Virol. 64: 2819-2824

Summers, J., Smolec, J.M. und Snyder, R. (1978). A virus similar to human hepatitis B virus associated with hepatitis and hepatoma in woodchucks. Proc. Natl. Acad. Sci. U.S.A. 75: 4533-4537

Szmuness, W., Stevens, C.E., Harley, E.J., Zang, E.A., Oleszko, W.R., William, D.C., Sadovsky, R., Morrison, J.M. und Kellner, A. (1980). Hepatitis B vaccine: demonstration of efficacy in a controlled clinical trial in a high-risk population in the United States. N. Engl. J. Med. 303: 833-841

Tavis, J.E., Perri, S. und Ganem, D. (1994). Hepadnavirus reverse transcription initiates within the stem-loop of the RNA packaging signal and embloys a novel strand transfer. J. Virol. 68: 3536-3543

Tiollais, P., Charnay, P. und Vyas, G.N. (1981). Biology of hepatitis B virus. Science 213: 406-411

Tong, S., Diot, C., Gripon, P., Li, J., Vitvitski, L., Trepo, C. und Guguen-Guillouzo, C. (1991). In vitro replication competence of a cloned hepatitis $B$ virus variant with a nonsense mutation in the distal pre-C region. Virology 181: 733-737

Tong, S., Li, J. und Wands, J.R. (1999): Carboxypeptidase D is an avian hepatitis B receptor. J. Virol. 73: 8696-8702

Treinin, M. und Laub, O. (1987). Identification of a promotor element located upstream from the hepatitis B virus X gene. Mol. Cell. Biol. 7: 545-548

Tuttleman, J. S., Pourcel, C. und Summers, J. (1986). Formation of the pool of covalently cloesed circular viral DNA in hepadnavirus-infected cells. Cell 47: 451-460

Urban, S., Breiner, K.M., Fehler, F., Klingmuller, U. und Schaller, H. (1998). Avian hepatitis $B$ virus infection is initiated by the interaction of a distinct pre-S subdomain with the cellular receptor gp180. J. Virol. 72: 8089-8097 
Urban, S. und Gripon, P. (2002). Inhibition of duck hepatitis $B$ virus infection by a myristoylated pre-S peptide of the large viral surface protein. J. Virol. 76: 1986-1990

Valenzuela, P., Gray, P., Quiroga, M., Zaldivar, J., Goodman, H.M. und Rutter, W.J. (1979). Nucleotide sequence of the gene coding for the major protein of hepatitis $B$ virus surface antigen. Nature 280: 815-819

Valenzuela, P., Quiroga, M., Zaldivar, J., Gray, P. und Ruttner, W. (1980). The nucleotide sequence of the hepatitis $B$ viral genome and the identification of the major viral genes. Animal Virus Genetics, Hrsg: Fields, B.N., Jaenisch, R. und Fox, C.F.; Academic Press, New York, $57-70$

von Schwedler, U.K., Stray, K.M., Garrus, J.E. und Sundquist, W.I. (2003). Functional surfaces of the human immunodeficiency virus type 1 capsid protein. J. Virol. 77: 5439-5450

Wasenauer, G., Köck, J. und Schlicht, H.J. (1993). Relevance of cysteine residues for biosynthesis and antigenicity of human hepatitis B virus e protein. J. Virol. 67: 1315-1321

Watts, N.R., Conway, J.F., Cheng, N., Stahl, S.J., Belnap, D.M., Steven, A.C. und Wingfield, P.T. (2002). The morphogenic linker peptide of HBV capsid protein forms a mobile array on the interior surface. EMBO J. 21: 876-884

Wei, Y., Tavis, J.E. und Ganem, D. (1996). Relationship between viral DNA synthesis and virion envelopment in hepatitis B virus. J. Virol. 70: 6455-6458

Weimer T., Salfeld, J. und Will, H. (1987). Expression og the hepatitis B virus core gene in vitro and in vivo. J. Virol 61: 3109-3113

WHO, Fact Sheet Hepatitis B. Fact Sheets, 2000. Nr. 204; http://www.who.int/mediacentre/ factsheets/fs204/en/index.html

Will, H., Reiser, W., Weimer, T., Pfaff, E., Büscher, M., Sprengel, R., Cattaneo, R. und Schaller, H. (1987). Replication strategy of human hepatitis B virus. J. Virol. 61: 904-911

Wunderlich, G. und Bruss, V. (1996). Characterization of early hepatitis B virus surface protein oligomers. Virology 141: 1191-1205

Wynne, S.A., Leslie, A.G.W., Butler, P.J.G. und Crowther, R.A. (1999a). Crystallization of hepatitis $B$ virus core protein shells: determination of cryoprotectant conditions and preliminary X-ray characterization. Acta Crystallogr. D 55: 557-560

Wynne, S.A., Crowther, R.A. und Leslie, A.G.W. (1999b). The crystal structure of the human hepatitis B virus capsid. Mol. Cell 3: 771-780

Yaginuma, K., Shirakata, Y., Kobayashi, M. und Koike, K. (1987). Hepatitis B virus (HBV) particles are produced in a cell culture system by transient expression of transfected HBV DNA. Proc. Natl. Acad. Sci. U.S.A. 84: 2678-2682

Yu, M. und Summers, J. (1994a). Multiple functions of capsid protein phosphorylation in duck hepatitis B virus replication. J. Virol. 68: 4341-4348 
Yu, M. und Summers, J. (1994b). Phosphorylation of the duck hepatitis virus capsid protein associated with conformational changes in the C terminus. J. Virol. 68: 2965-2969

Yuan, T.T., Sahu, G.K., Whitehead, W.W., Greenberg, R. und Shih, C. (1999a). The mechanism of an immature secretion phenotype of an highlyfrequent naturally occuring missense mutation at codon 97 of human hepatitis B virus core antigen. J. Virol. 73: 5731-5740

Yuan, T.T., Tai, P.C. und Shih, C. (1999b). Subtype-independent immature secretion and subtype-dependent deficiency of a highly frequent, naturally occuring mutation of human hepatitis B core antigen. J. Virol. 73: 10122-10128

Yuan, T.T. und Shih, C. (2000). A frequent, naturally occuring mutation (P130T) of human hepatitis $B$ virus core antigen is compensatory for immature secretion phenotype of another frequent variant (I97L). J. Virol. 74: 4929-4932

Yuh, C.H., Chang, Y.L. und Ting, L.P. (1992). Transcriptional regulation of precore and pregenomic RNA's of hepatitis B virus. J. Virol. 66: 4073-4084

Zheng, J., Schödel, F. und Peterson, D.L. (1992). The structure of hepadnaviral core antigens. Identification of free thiols and determination of the disulfide bonding pattern. J. Biol. Chem. 267: 9422-9428

Zhou, S. und Standring, D.N. (1991). Production of hepatitis B virus nucleocapsid like core particles in Xenopus oocytes. J. Virol. 66: 3086-3092

Zhou, S. und Standring, D.N. (1992). Hepatitis B virus capsids are assembled from core protein dimers. Proc. Natl. Acad. Sci. U.S.A. 89: 10046-10050

Zlotnick, A., Cheng, N., Conway, J.F., Booy, F.P., Steven, A.C., Stahl, S.J. und Wingfield, P.T. (1996). Dimorphism of hepatitis B virus capsids is strongly influenced by the C-terminus of the capsid protein. Biochemistry 35: 7412-7421

Zoulim, F. und Seeger, C. (1994). Reverse transcription in hepatitis B viruses is primed by a tyrosine residue of the polymerase. J. Virol. 68: 6-13

Zoulim, F., Saputelli, J. und Seeger, C. (1994). Woodchuck hepatitis virus X protein is required for viral infection in vivo. J. Virol. 68: 2026-2030 


\section{DANKSAGUNGEN}

Herrn Prof. Dr. G. Hunsmann und Herrn Prof. Dr. O. Götze danke ich für die Bereitstellung meines Arbeitsplatzes in der Abteilung Virologie am Hygiene-Institut in Göttingen.

Herrn Prof. Dr. W. Liebl danke ich für die Betreuung und Übernahme des Erstreferats, für die Übernahme des Korreferat bedanke ich mich bei Herrn Prof. Dr. D. Doenecke im Fachbereich Biologie der Georg-August-Universität Göttingen.

Mein besonderer Dank gilt Herrn HD Dr. Volker Bruß aus der Abteilung Virologie des Hygiene-Instituts für die Bereitstellung des interessanten Themas, die gewährte Unterstützung, sein Interesse an meiner Arbeit sowie für das stets gute Arbeitsklima.

Ich danke Prof. Dr. D. Doenecke für die Aufnahme und Unterstützung durch das Graduiertenkolleg 521.

Allen Kollegen und ehemaligen Mitstreitern, besonders Frau A. Koch und Herrn U. Goldmann danke ich für ein außergewöhnlich gutes Arbeitsklima und die stete Hilfsbereitschaft bei allen kleinen und großen Problemen.

Bei PD Dr. D. Lindemann bedanke ich mich für seine Hilfsbereitschaft und die Bereitstellung der Materialien für das Retrovirus-Transduktionssystem.

Für die Hilfe bei den Ag-ELISAs bedanke ich mich bei der Hepatitis-Diagnostik der Abteilung Virologie.

Großer Dank gilt meinen Eltern für die Unterstützung meiner Ziele, die stete Hilfsbereitschaft und für das Vertrauen, das sie in mich setzen.

Ganz besonders bedanke ich mich bei Lucia, die sehr intensiv alle Höhen und Tiefen mit mir durchlebt und mich jederzeit mit all ihren Kräften unterstützt hat. 


\section{LEBENSLAUF}

Name:

Geburtstag und -ort:

Familienstand:

Staatsangehörigkeit:
Alexander Pairan

13.06.1974 in Kassel

ledig

deutsch
1981-1985

1985-1994

1994-1995

1995-2001

Oktober 1997

Februar 2000

Mai 2000 bis

Mai 2001

August 2001 bis

April 2002

Mai 2002 bis

September 2005
Grundschule Fuldatal-Ihringshausen

Gymnasium Goetheschule, Kassel

Abschluss: allgemeine Hochschulreife

Zivildienst AWO/ Seniorenwohnheim Fasanenhof, Kassel

Studium der Biologie an der Universität Gh Kassel

mündliche Vordiplomprüfungen in den Fächern: Mikrobiologie/ Genetik, Zoologie, Botanik, Chemie und Physik

mündliche Diplomprüfungen in den Fächern: Mikrobiologie, Humanbiologie, Zoologie/Physiologie und Bodenkunde

Anfertigung der experimentellen Diplomarbeit in der Abteilung Mikrobiologie (FB 19 - Biologie/Chemie) bei Herrn Prof. Dr. Schmidt mit dem Thema „Charakterisierung eines EnterokokkenKollektivs auf ausgewählte Antibiotika-Resistenzen“

wissenschaftlicher Angestellter in der Abteilung Mikrobiologie (FB 19 - Biologie/Chemie), Universität Gh Kassel

Doktorarbeit am Zentrum für Hygiene und Humangenetik der Georg-August-Universität Göttingen in der Abteilung Virologie bei Herrn HD Dr. V. Bruß

Thema: „Charakterisierung von funktionellen Oberflächenstrukturen des Hepatitis-B-Virus Nukleokapsids“ 